SAND95-2000

Unlimited Release

UC-1260

OSTI

\title{
University Center of Excellence for Photovoltaics Research and Education: Annual Report
}

\author{
A. Rohatgi, G. Crotty, L. Cai, P. Sana, A. Doolittle, \\ M. Ropp, T. Krygowski, and S. Narasimha \\ Georgia Institute of Technology \\ School of Electrical and Computer Engineering \\ 777 Atlantic Drive \\ Atlanta, Georgia 30332-0250
}

Prepared by Sandia National Laboratories Albuquerque, New Mexico 87185

and Livermore, California 94550 for the United States Department of Energy

under Contract DE-AC04-94AL85000

Printed September 1995

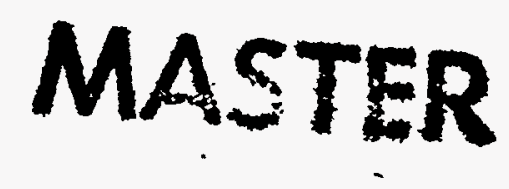


Issued by Sandia National Laboratories, operated for the United States Department of Energy by Sandia Corporation.

NOTICE: This report was prepared as an account of work sponsored by an agency of the United States Government. Neither the United States Government nor any agency thereof, nor any of their employees, nor any of their contractors, subcontractors, or their employees, makes any warranty, express or implied, or assumes any legal liability or responsibility for the accuracy, completeness, or usefulness of any information, apparatus, product, or process disclosed, or represents that its use would not infringe privately owned rights. Reference herein to any specific commercial product, process, or service by trade name, trademark, manufacturer, or otherwise, does not necessarily constitute or imply its endorsement, recommendation, or favoring by the United States Government, any agency thereof or any of their contractors or subcontractors. The views and opinions expressed herein do not necessarily state or reflect those of the United States Government, any agency thereof or any of their contractors.

Printed in the United States of America. This report has been reproduced directly from the best available copy.

Available to DOE and DOE contractors from

Office of Scientific and Technical Information

PO Box 62

Oak Ridge, TN 37831

Prices available from (615) 576-8401, FTS 626-8401

Available to the public from

National Technical Information Service

US Department of Commerce

5285 Port Royal Rd

Springfield, VA 22161

NTIS price codes

Printed copy: A06

Microfiche copy: A01 
Distribution

Category UC-1290

SAND95-2000

Unlimited Release

Printed September 1995

\title{
University Center of Excellence For Photovoltaics Research and Education Annual Report, July 1993-June 1994
}

A. Rohatgi, G. Crotty, L. Cai, P. Sana, A. Doolittle, M. Ropp, T. Krygowski, and S. Narasimha

Georgia Institute of Technology

School of Electrical and Computer Engineering

777 Atlantic Drive

Atlanta, Georgia 30332-0250

Sandia Contract AA-1638

\begin{abstract}
This is the second annual report since the University Center of Excellence for Photovoltaics Research and Education was established at Georgia Tech. The major focus of the center is crystalline silicon, and the mission of the Center is to improve the fundamental understanding of the science and technology of advanced photovoltaic devices and materials, to fabricate high-efficiency cells, and develop low-cost processes, to provide training and enrich the educational experience of students in this field, and to increase U.S. competitiveness by providing guidelines to industry and DOE to achieve cost-effective and high-efficiency photovoltaic devices. This report outlines the work of the Center from July 1993-June 1994.
\end{abstract}




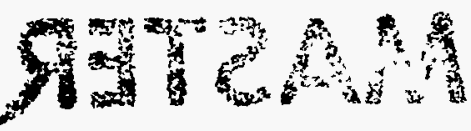




\section{TABLE OF CONTENTS}

CHAPTER 1 INTRODUCTION $\ldots \ldots \ldots \ldots \ldots \ldots \ldots \ldots \ldots \ldots \ldots \ldots \ldots$ 1-1

CHAPTER 2 HIGH EFFICIENCY MULTICRYSTALLINE SILICON

SOLAR CELLS $\ldots \ldots \ldots \ldots \ldots \ldots \ldots \ldots \ldots \ldots \ldots \ldots \ldots \ldots \ldots \ldots, 2-1$

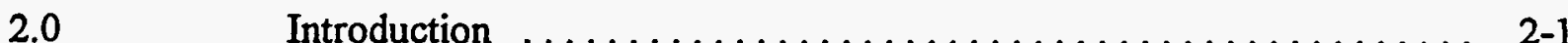

2.1 Fabrication of Multicrystalline Silicon Solar Cells Without Gettering and Passivation Techniques: Simple Base-line Process Sequence ....... 2-3

2.2 Understanding and Optimization of Phosphorus Gettering on Multicrystalline Silicon Solar Cells .................. 2-4

2.3 The Effect and Understanding of Partial Emitter Etch Back on the Performance of Multicrystalline Silicon Solar Cells ............ 2-7

2.4 Optimization and Fundamental Understanding of Multiple Effects of Al Treatment on Mc-Si Cells . . . . . . . . . . 2-10

2.4.1 Effect of Al Gettering Temperature on Cell Performance ........ 2-10

2.4.2 LBIC Response of Al-gettered Multicrystalline Silicon Solar Cells . . . . 2-18

2.5 The Understanding the Impact of Emitter Oxide Passivation on the Performance of Multicrystalline Silicon Solar Cells .......... 2-20

2.6 Bulk Defect Passivation by Forming Gas Anneal in Multicrystalline Silicon Cells ........................ $2-22$

2.7 Fabrication of Record High Efficiency Multicrystalline Silicon Solar Cells . . . . . . . . . . . . . . . . . . . . . . . . . . . . . 2-29

2.8 Detailed Characterizations and Analysis to Model the Performance of the Record High Efficiency Multicrystalline Silicon Solar Cell ........ 2-38

2.9 Guidelines for Achieving 20\% Efficiency Mc-Si Cells $\ldots \ldots \ldots \ldots$ 2-40

2.10 Surface Texturing of Mc-Si Wafer for Light Trapping . . . . . . . . 2-44 

Recombination Velocity at Plasma Enhanced Chemical Vapor Deposited $\mathrm{SiO}_{2}$-Si Interface

Experimental

4.1.3.1 Determination of bulk and surface passivation by PCD lifetime

PECVD-induced bulk and surface passivation in multicrystalline silicon solar cells 
Chapter 5 LOW-COST, HIGH-EFFICIENCY SILICON SOLAR CELLS BY RAPID THERMAL PROCESSING

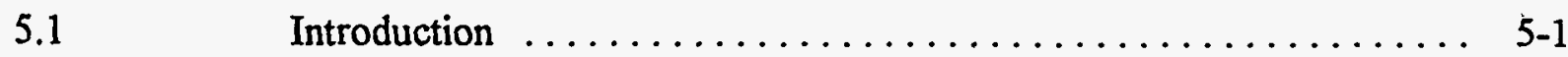

5.2 Comparison Between RTP and Conventional Furnace

Processing (CFP) .................... $5-1$

5.3 Progress of RTP/PECVD Silicon Solar Cells at Georgia Tech ..... 5-6

$5.4 \quad$ RTP Cooling Rate Effect on Silicon Solar Cells ............. $5-14$

5.4.1 Quenching Problem During RTP $\ldots \ldots \ldots \ldots \ldots \ldots \ldots \ldots \ldots \ldots \ldots$

5.4.2 Optimization of the RTP Cooling Rate and In-situ Anneal . . . . . . . 5-16

5.5 Characterization, Modeling, and Optimization of RTP Emitter

Etch-Back .............................. 5-23

5.6 Guidelines for Achieving Greater than 19\% Efficient Low-Cost

RTP/PECVD Cells ......................... 5-28

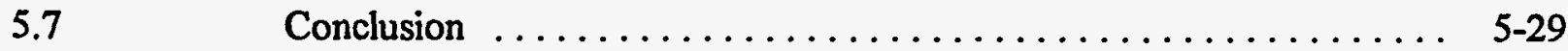

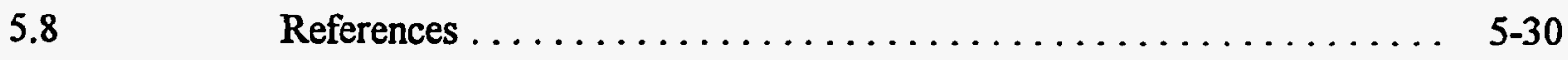

Chapter 6 UCEP EDUCATIONAL SUPPORT ACTIVITIES $\ldots \ldots \ldots \ldots$ 6-1 


\section{FIGURES}

Figure 2.1 Model costs and efficiencies versus 30-year levelized electricity costs for flat-plate photovoltaic systems.

Figure 2.2 Measured cell data and model calculations for the simple base-line cells. . . . . . . 2-5

Figure $2.3 \quad$ Simple base-line process sequence. $\ldots \ldots \ldots \ldots \ldots \ldots \ldots \ldots \ldots \ldots \ldots \ldots$

Figure 2.4 The effect of emitter étch back on the performance of multicrystalline silicon solar cells.

Figure 2.5 Process sequence to decouple the effect of Al diffusion. . . . . . . . . . . .

Figure 2.6 The effect of $\mathrm{Al}$ drive-in temperature on the cell performance. $\ldots \ldots \ldots \ldots \ldots \ldots 2-13$

Figure 2.7 The effect of $\mathrm{Al}$ drive-in temperature and Al BSF on the cell performance. . . . . . . 2-14

Figure 2.8 The effect of $\mathrm{Al}$ gettering temperature and Al BSF on bulk diffusion length. ...... 2-15

Figure 2.9 The effect of $\mathrm{Al}$ gettering temperature on $\mathrm{IQE}$ of solar cells. $\ldots \ldots \ldots \ldots \ldots \ldots$

Figure 2.10 LBIC map of the Al treated multicrystalline silicon wafers. . . . . . . .

Figure 2.11 The effect of emitter oxide passivation on the multicrystalline

silicon cell performance. ................................. 21

Figure 2.12 Process sequence for fabricating high efficiency multicrystalline silicon. . . . . . . . 2-23

Figure 2.13 The effect of FGA and forming gas/Al on the

performance of multicrystalline silicon solar cells.

Figure 2.14 The effect of nitrogen anneal on the performance

of forming gas annealed cells. $2-26$

Figure 2.15 The effect of different treatment on the diffusion length of EFG wafers.

Figure 2.16 The effect of FGA on the performance of solar cells made on different substrates ... 2-30

Figure 2.17 The effect of ribbon EFG Sheet and AP thin film silicon $\ldots \ldots \ldots \ldots \ldots \ldots \ldots \ldots$

Figure 2.18 Model of hydrogen passivation by forming gas anneal $\ldots \ldots \ldots \ldots \ldots \ldots \ldots \ldots 2$

Figure 2.19 The effect of lifetime on the performance of the cells modelled by PC-1D ....... 2-35 
Figure 2.20 Reflectance and internal quantum efficiency of the $17.8 \%$ efficient

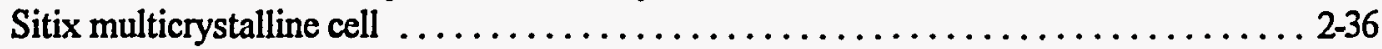

Figure 2.21 Cell efficiency distribution on the wafers produced $17.7 \%$ and $17.8 \%$ efficient cells . . . . . . . . . . . . . . . . . . . . . . . . . . . . . . . .

Figure 2.22 Comparison of the calculated and measured cell parameters and IQE for the

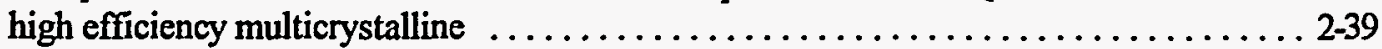

Figure 2.23 The effects of lifetime and surface texturing on multicrystalline cell performance ... 2-43

Figure 2.24 The reflectance of the best grooved multicrystalline silicon before and after

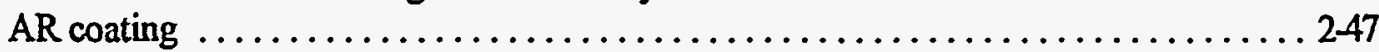

Figure 3.1 Four kinds of single crystal cells: (a) simple $\mathrm{n}^{+}-\mathrm{p}-\mathrm{p}^{+}$baseline cells (SBLC) with phosphorus emitter and Al back surface field (BSF),

(b) advanced baseline cell (ABLC) with deep phosphorus diffusion underneath the grid and point $\mathrm{Al}$ contacts on the pyramid texturing on front for light trapping and (d) IBLC cells with inverted pyramid texturing on front and localized diffusion and point contacts on the back 3-2

Figure 3.2 Process outline for simple base-line solar cell (SBLC) $\ldots \ldots \ldots \ldots \ldots \ldots \ldots \ldots \ldots$

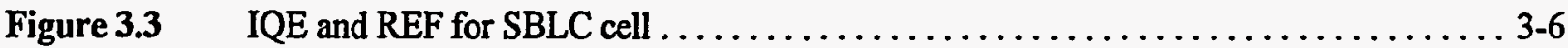

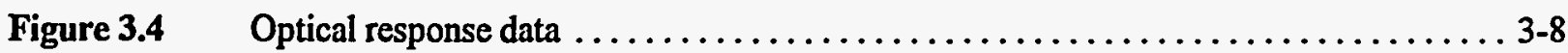

Figure $3.5 \quad$ Advanced IVP silicon solar process $\ldots \ldots \ldots \ldots \ldots \ldots \ldots \ldots \ldots \ldots \ldots \ldots \ldots$

Figure $3.6 \quad$ Internal quantum efficiency $\ldots \ldots \ldots \ldots \ldots \ldots \ldots \ldots \ldots \ldots \ldots \ldots \ldots \ldots \ldots$

Figure 3.7 Approach towards 25\% efficient inverted pyramid silicon solar cells $\ldots \ldots \ldots \ldots \ldots$ 3-12

Figure 4.1 Energy band diagram at $\mathrm{SiO}_{2}$-Si interface under non-equilibrium condition with definitions of electron energy and potentials. .............. 4-6

Figure 4.2 Calculated effective surface recombination velocity $\mathrm{S}_{\mathrm{eff}}$ at $\mathrm{SiO}_{2}$-Si interfaces as a function of the surface band bending based on the uniform distribution model of $D_{\mathfrak{n}}$ in the energy gap. 1: $\sigma_{\mathfrak{n}}=100 \sigma_{\mathrm{p}}=10^{-14} \mathrm{~cm}^{2} .2$ : $\sigma_{\mathrm{C}}=100 \mathrm{\sigma}_{\mathrm{N}}=10^{.14} \mathrm{~cm}^{2}$. Other parameters for both curves: $\mathrm{p}_{0}=10^{13} \mathrm{~cm}^{-3}, \Delta \mathrm{n}=5 \times 10^{14} \mathrm{~cm}^{-3}, \mathrm{D}_{\mathrm{it}}=10^{11} \mathrm{~cm}^{-2} \mathrm{eV}^{-1}$

Figure 4.3 High frequency and quasi-static CV curves of the MOS structure for $\mathrm{PECVD} \mathrm{SiO}_{2}-\mathrm{Si}$

Figure 4.4 $D_{i t}(E)$ distribution in the energy gap obtained from the HF-QS CV curves in Fig. $3(\mathbb{})$ and the assumed function of equation (12) (solid curve) 
Figure 4.5 Gate voltage dependence of effective surface recombination velocity

obtained by the PCD measurements ( $\square$ ) and theoretically fitted curve

Figure 4.6a $\quad S_{\text {eff }}$ as a function of surface band bending. Dashed curve:

theoretically fitted curve based on the capture cross section

model shown in equation (10).

Figure 4.6b Solid curve: theoretical curve based on the capture cross section model of equation (15). $\square$ : Experimental results plotted against the calculated band bending

Figure 4.7 Assumed $D_{i t}(E)$ distributions in the energy gap used for the calculation 4-19

Figure 4.8a Calculated $S_{\text {eff }}$ as a function of positive fixed oxide charge density under the injection of (a) $\Delta \mathrm{n}=10^{14} \mathrm{~cm}^{-3}$; and (b) $\Delta \mathrm{n}=10^{16} \mathrm{~cm}^{-3} \ldots \ldots \ldots \ldots 420$

Figure 4.8b Calculated $S_{\text {eff }}$ as a function of positive fixed oxide charge density under the injection of $\Delta \mathrm{n}=10^{16} \mathrm{~cm}^{-3}$

Figure 4.9a The calculated IQE for $\mathrm{n}^{+} \mathrm{pp}^{+}$solar cell with variation of substrate bulk lifetime $\mathrm{T}$ and for a fixed front side surface recombination velocity $\mathrm{S}$

Figure 4.9b The calculated IQE variation with front surface recombination velocity $S$ for a fixed bulk lifetime

Figure 4.10 Comparison of measured and calculated IQE to assess change in $S$ and $T_{b}$ due

PECVD coating

Figure 5.1 Single wafer fabrication time for RTP and conventional furnace processing ....... 5-4

Figure 5.2 Potential single wafer fabrication time for RTP with screen printed contacts $\ldots \ldots \ldots 5-5$

Figure 5.3 Programmed temperature cycle for RTP simultaneous diffusion and in-situ anneal

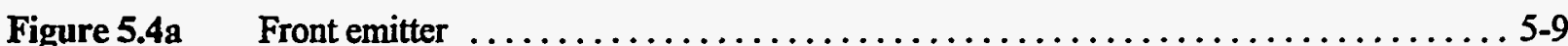

Figure 5.4b Back BSF carrier concentration profiles resulting from the RTP temperature cycle in figure 5-3.

Figure 5.5 I-V curve for the $16.9 \%$ efficient RTP/PECVD solar cell on $0.2 \Omega-\mathrm{cm}$ FZ silicon.

Measured at Sandia National Laboratories.

Figure 5.6 Comparison between the internal quantum efficiency of the $16.9 \%$ RTP/PECVD cell and the $18.8 \%$ conventional cell. Measured at Sandia National Laboratories. . . . . 5-10

Figure 5.7 I-V curve for the record high 17.1\% efficient RTP solar cell. Measured at SNL . . . . 5-11

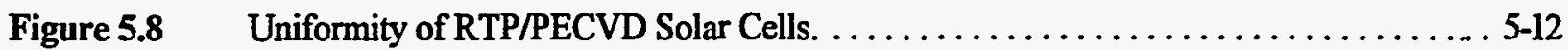


Figure 5.9 Progress of RTP-diffused silicon solar cells without any furnace treatment $\ldots \ldots \ldots \ldots$ 5-13

Figure 5.10 Effect of quenching during a conventional furnace process on $\mathrm{FZ}$ silicon $\ldots \ldots \ldots .5-15$

Figure 5.11 Temperature cycles of four different cooling rates between $880^{\circ} \mathrm{C}$ and $820^{\circ} \mathrm{C}$

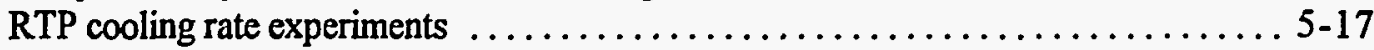

Figure 5.12 RTP cooling rate induced lifetime degradation of high resistivity FZ silicon $\ldots \ldots \ldots$ 5-18

Figure 5.13 Effect of RTP cooling rate $n 11$ W-ckm dendritic web silicon solar cells ........ 5-19

Figure 5.14 Diffusion length of the dendritic web cells as a function of RTP cooling rate ..... 5-19

Figure 5.15 Total $\mathrm{J}_{\mathrm{o}}$ as a function of RTP cooling rate for the dendritic web cells $\ldots \ldots \ldots \ldots$ 5-20

Figure 5.16 Effect of RTP cooling rate on $0.2 \mathrm{~W}-\mathrm{cm}$ FZ silicon solar cells $\ldots \ldots \ldots \ldots \ldots \ldots .21$

Figure 5.17 Total $\mathrm{J}_{\mathrm{o}}$ as a function of RTP cooling rate for the $\mathrm{FZ}$ cells $\ldots \ldots \ldots \ldots \ldots \ldots \ldots .22$

Figure 5.18 Improvement in short wavelength response due to emitter etch-back of slow-cooled cells ........................................ 5-24

Figure 5.19 Spreading resistance measurements of etched-back RTP emitters (diffused with the temperature cycle in figure $5-3$ ). . . . . . . . . . .

Figure 5.20 Determination of front surface recombination velocity (Sf) from measured $\mathrm{J}_{\mathrm{oe}} \ldots \ldots \ldots$. . . 26

Figure 5.21 Measured $\mathrm{J}_{\alpha}$ and calculated $\mathrm{Sf}$ for etched-back RTP emitters with

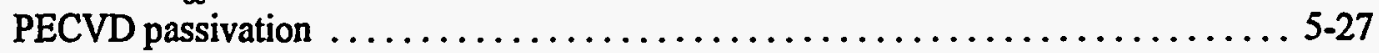

Figure 6.1 Outline for graduate level course in photovoltaic device and systems technology ............................... 6-2

Figure 6.2 Schematic diagram showing the current layout of the Educational Support Program (ESP) lab ........................... 6.3

Figure 6.3 Resistivity vs temperature for $\mathrm{POC13}$ diffusions carried out under different conditions of gas flow, deposition and drive times $\ldots \ldots \ldots \ldots \ldots \ldots \ldots .6 .4$

Figure 6.4 Oxidation furnace lifetime control chart from $P C D$ measurements $\ldots \ldots \ldots \ldots \ldots 6-4$

Figure 6.5 Representations of the four different cell structures fabricated as part of lab

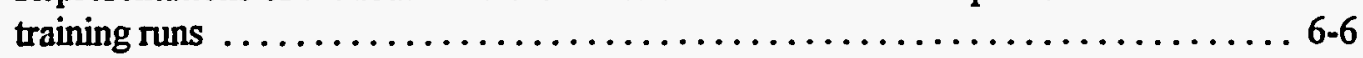




\section{TABLES}

Table 3.1 SBLC cells tested and verified by Sandia $\ldots \ldots \ldots \ldots \ldots \ldots \ldots \ldots \ldots$

Table 3.2 Run SN2 $2 \times 2$ ABLC Solar Cell Data $\ldots \ldots \ldots \ldots \ldots \ldots \ldots \ldots \ldots \ldots$

Table 2.1 The effect of phosphorus diffusion temperature on measured

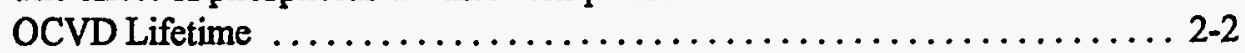

Table 2.2 Effect of aluminum treatment on multicrystalline silicon cell performance ... 2-17

Table 2.3 The multiple effects of Al gettering, the observed change in

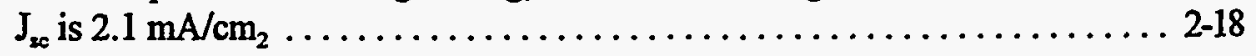

Table 2.4 High efficiency multicrystalline silicon solar cells fabricated at Georgia Tech .................................. 24

Table 2.5 Input parameters to PC-1D for model calculations $\ldots \ldots \ldots \ldots \ldots \ldots \ldots$ 2-41

Table 2.6 Modeling the effect of selected design parameters on performance

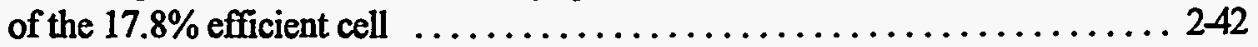

Table 4.1 The Effective Lifetime Measured Before and After the PECVD Coating .................................. 4-29

Table 4.2 The Lifetime in HF Measured Before and After the PECVD Coating ...... 4-29

Table 4.3 The Surface Lifetime Before and After the PECVD Coating Where (c) and (uc) Stand for Coated and Uncoated, Respectively ........ 4-35

Table 4.4 The Input Parameters Used in PCID Simulation of Cell's IQE . . . . . . . 4-35

Table 5.1 All cells measured at Sandia National Laboratories $\ldots \ldots \ldots \ldots \ldots \ldots \ldots$

Table 5.2 Simulated Performance of RTP/PECVD Solar Cells with Etched-Back Emitters .............................. 5-28

Table 6.1 Results form SBLC and ABLC training runs $\ldots \ldots \ldots \ldots \ldots \ldots \ldots \ldots$ 


\section{SUMMARY}

High efficiency and low cost are the keys to large scale applicability of photovoltaic systems. Current cost of PV modules is about $\$ 4 /$ watt, which needs to come down by a factor of 2 to be competitive for utility peak shaving, and a cost reduction of about a factor of 3-4 will be necessary for base load applications. No PV material or technology has yet met the cost and efficiency targets simultaneously to produce electricity at a rate of $6-10 \varangle / \mathrm{kWh}$, As research and development continue on various materials, it is becoming increasingly obvious that crystalline silicon will remain the most reliable and widely used PV material for many years to come. In 1994, out of the 25.6 MW of PV modules sold by companies in the U.S., 23.2 MW came from single and multicrystalline silicon. The remaining 2.4 MW was produced from thin film panels, primarily amorphous silicon.

In spite of the significant progress made in single crystalline and multicrystalline silicon solar cell efficiencies in the last decade, a large gap still remains between the cost of generating power from PV and fossil fuels, as well as between the current and theoretical efficiencies of solar cells made from silicons. This is why basic research toward low-cost, high-efficiency crystalline silicon cells is important for PV to become a cost-effective and environmentally clean source of electrical energy for the next generation.

The objective of single and multicrystalline silicon materials and device research at Georgia Tech is two-fold. One track pursues basic understanding of the efficiency limiting defects and mechanisms that affect material quality and device performance. The second track seeks to develop processes, cell designs, and methodologies that will enhance material quality, reduce cell processing time and cost, and lead to higher cell efficiencies.

We have made significant progress toward understanding the lifetime and efficiency limiting 
mechanisms in cast and sheet multicrystalline (mc-Si) materials. This understanding has enabled process optimization to achieve higher quality surface passivation, longer bulk carrier lifetimes, and higher efficiency cells on single crystal and multicrystalline silicon materials.

Aluminum and phosphorus gettering are important and highly compatible with multicrystalline silicon cell processing. A detailed investigation of quality enhancement techniques such as aluminum and phosphorus diffusion for defect and impurity gettering was conducted on several promising multicrystalline silicon materials. These defect passivation techniques were found to be quite beneficial in enhancing the performance of multicrystalline silicon cells. However, these effects were found to be material specific. It was found that for multicrystalline silicon from Sitix Corp., $930^{\circ} \mathrm{C}$ is the optimum temperature for phosphorus diffusion. In order to take advantage of intense phosphorus gettering without the harmful effects of an emitter dead layer, a deep phosphorus diffusion at $930^{\circ} \mathrm{C}$ was performed followed by a partial etch-back of the $\mathrm{n}^{+}$-region. It was found that this treatment is optimum for emitter formation in multicrystalline silicon cells, and results in high bulk lifetime without significant penalty from the heavy doping effects. The optimum aluminum treatment for Sitix multicrystalline silicon solar cells included $1.2 \mu \mathrm{m}$ thick Al deposition followed by $850^{\circ} \mathrm{C}, 35 \mathrm{~min}$ drive-in. This resulted in $1.4 \%$ increase in absolute cell efficiency primarily due to $\mathrm{Al}$ gettering-induced bulk lifetime enhancement. It was shown that the Al treatment forms a back surface field (BSF) and improves bulk lifetime but reduces back surface reflection because of the rough Al-Si alloyed back surface. Beneficial effects of $\mathrm{Al}$ on silicon solar cell performance were found to be material specific. Float-zoned (FZ) cells showed less than 1\% increase in cell performance, exclusively due to the Al back-surface field effect with little or no gettering and passivation. Heat- exchanged method (HEM) cast multicrystalline silicon cells showed about $1.6 \%$ increase in absolute cell efficiency primarily due to Al gettering-induced diffusion length enhancement. Finally, aluminum diffusion on the back side increased the edge-defined film-fed 
growth (EFG) cell efficiency by $1.7 \%$ (absolute) due to $\mathrm{Al}$ process-induced gettering.

During this study it was found that defect passivation by forming gas-anneal (FGA) is also highly material specific. In contrast to the EFG cells, the forming gas treatment had virtually no effect $(<5 \%)$ on the Sitix and HEM cast multicrystalline silicon cells. This is probably because higher quality cast mi-Si materials do not have enough of those defects that can benefit from hydrogen passivation. However, in materials like EFG and Astropower-Si thin film, which consist of a high concentration of active dislocations or grain boundaries, FGA showed a very significant effect on bulk diffusion length and cell performance.

After developing and optimizing gettering and passivation techniques, we integrated them into a process sequence that does not increase the cell fabrication cost by much. This process starts with intense phosphorus diffusion, followed by an etch-back. Then $1 \mu \mathrm{m}$ thick aluminum is evaporated, followed by a three-step drive-in: the first five minutes in oxygen at $850^{\circ} \mathrm{C}$ to grow a passivating oxide, next, thirty minutes in nitrogen at $850^{\circ} \mathrm{C}$ for aluminum gettering and BSF, and finally a two-hour forming gas anneal (FGA) at $400^{\circ} \mathrm{C}$. Then the grid pattern was defined by photolithography and, finally, the cells were capped with a two-layer antireflection (AR) coating. This advanced process sequence gave a record high efficiency for mc-Si of $17.8 \%$. It should be noted that through this study, impressive progress has been made in multicrystalline silicon cells with an efficiency approaching $18 \%$, which is less than $1 \%$ shy of $\mathrm{CZ}$ cells and about $1.5 \%$ shy of float zoned (FZ) cells, when fabricated without texturing.

After in-depth characterizations, cell model calculations were performed by ignoring the grain boundary effects, but using a measured effective excess lifetime in the cell. A good correlation was found between the measured and calculated cell parameters of the high- efficiency multicrystalline silicon cells. Model calculations were extended to outline an approach toward achieving greater than $20 \%$ efficient multicrystalline cells, which emphasizes the need for surface texturing, reduced back- 
surface recombination velocity, and reduced base resistivity without paying too much penalty for lifetime.

Significant progress was made during the past year on the development of plasma enhanced chemical vapor deposition (PECVD) of $\mathrm{SiO}_{x}$ and $\mathrm{SiN}_{x}$ films for surface and bulk defect passivation, in addition to AR coatings. We demonstrated that the (PECVD) $\mathrm{SiO}_{2} / \mathrm{SiN} \mathrm{AR}$ coating gives much greater improvement in cell parameters, when compared with thermally evaporated $\mathrm{MgF}_{2} / \mathrm{ZnS}$ coatings, for cells without thermal oxide passivation. For cells that have thin thermal oxide passivation, the improvements in efficiency are comparable for the two AR coatings. We have also demonstrated that thin $\mathrm{SiO}_{2}(-100 \AA)$ deposited on single crystal silicon by direct PECVD at $250^{\circ} \mathrm{C}$ on high resistivity wafers, and annealed using an optimized rapid thermal anneal (RTA) in forming gas at $350^{\circ} \mathrm{C}$, results in very low surface recombination velocity $(<2 \mathrm{~cm} / \mathrm{s})$. This low temperature process also resulted in very high effective carrier lifetimes $(>5 \mathrm{~ms})$ and low interface state density $\left(D_{\mathrm{j}}\right)$, in the range of $1-4 \times 10^{10} \mathrm{~cm}^{-2} \mathrm{eV}^{-1}$ near the midgap of silicon. The best $D_{\mathrm{it}}$ value achieved in this study was $1.1 \times 10^{10} \mathrm{~cm}^{-2} \mathrm{eV}^{-1}$. This is the lowest $\mathrm{D}_{\mathrm{it}}$ value reported to date for PECVD oxides.

It is shown for the first time that plasma-enhanced chemical vapor deposition (PECVD) passivation, which involves low-temperature PECVD of $\sim 100 \AA \mathrm{SiO}_{2}$ and $\sim 600 \AA$ SiN followed by photoassisted anneal, is very effective for both surface and bulk defect passivation in multicrystallineSi materials. It is found that PECVD coatings can increase the effective recombination lifetime by a factor of 2-10 depending upon the multicrystalline material. The bulk and surface passivation effects were quantified and decoupled by a combination of internal quantum efficiency measurements and computer modeling. The PECVD passivated OTC multicrystalline solar cells from Osaka Titanium Corp. (OTC) showed an increase in bulk lifetime from 10 to $20 \mu \mathrm{s}$, and a decrease in surface recombination velocity from $2 \times 10^{5}$ to $5 \times 10^{4} \mathrm{~cm} / \mathrm{s}$.

The effective surface recombination velocity $\left(S_{\text {eff }}\right)$ at the PECVD. SiQ $-S i$ interface was 
The effective surface recombination velocity $\left(\mathrm{S}_{\mathrm{eff}}\right)$ at the PECVD. SiO $-\mathrm{Si}$ interface was measured by PCD method in conjunction with the bias voltage via transparent ITO gates. A theoretical analysis based on the measured $\mathrm{D}_{\mathrm{i}}(\mathrm{E})$ distribution in the band gap was performed to obtain $S_{\text {eff }}$ as a function of the surface band bending, from which the electron and hole capture cross sections for the PECVD Si 2 -Si interface states were estimated to be $\sigma_{\mathrm{nD}}=4 \times 10^{-15} \mathrm{~cm}^{2}, \sigma_{\mathrm{pD}}=1 \times 10^{17} \mathrm{~cm}^{2}$, $\sigma_{\mathrm{nA}}=3 \times 10^{-17} \mathrm{~cm}^{2}$, and $\sigma_{\mathrm{pA}}=3 \times 10^{-16} \mathrm{~cm}^{2}$. Model calculations were extended further to investigate the relationship between $S_{e f f}, Q_{o x}, D_{i t}$, and injection level. It was found that $Q_{x}$ should be roughly 10 times larger than the midgap $D_{i t}$ value in order to reduce $S_{\text {eff }}$ below $10 \mathrm{~cm} / \mathrm{s}$ for $5 \Omega \mathrm{cm}(100)$ p-type Si. These results prove the effectiveness of $\mathrm{PECVD} \mathrm{SiO}_{2}$ for passivation of mi-Si surfaces and its application for devices like solar cells.

A combination of rapid thermal processing (RTP) and PECVD coatings was used to reduce cell fabrication cost and time. By developing an RTP temperature/time cycle consisting of an in-situ anneal for simultaneous front and back diffusion with suitable $\tau_{b}$ and $J_{o}$, silicon solar cell efficiencies of $\sim 17 \%$ and diffusion lengths $>200 \mu \mathrm{m}$ were achieved on FZ without any furnace treatment. Use of low temperature PECVD SiN/SiO ${ }_{2}$ coatings further speeds up the process in addition to providing bulk defect and surface passivation in conjunction with excellent antireflection properties. The RTP/PECVD process resulted in cell efficiencies of $16.4 \%$ on Czochralski silicon, $14.9 \%$ on dendritic web, and $14.8 \%$ on multicrystalline silicon. We are currently trying to incorporate screenprinted contact technology as an alternative to photolithography to reduce the cell fabrication time to less than two hours. The combination of RTP, PECVD, and screen-printing will make the process extremely rapid and industrially attractive.

Other major accomplishments include the establishment of close industry interaction, and development of state-of-the-art characterization and testing facilities. We have also developed powerful and user-friendly modelling capabilities to optimize any region of the cell, in addition to 
designing high efficiency solar cells and PV systems. We have established two separate solar cell fabrication laboratories that routinely produce cell efficiencies in the range of $18-21 \%$ on single crystal FZ silicon. The above research has resulted in about 50 technical papers and three patents (filed) in the last two years.

In the area of education and training, we have completed the establishment of the educational support program (ESP) lab and have started providing hands-on training to undergraduate and graduate students. We have also developed a three credit hour course on solar cells, which is taught once a year and covers PV materials and devices, efficiency limiting mechanisms, modelling, design and fabrication of silicon cells.

In summary we have made record high-efficiency silicon cells in a number of categories, developed and optimized RTP/PECVD technology for low-cost high-efficiency cells, established stateof-the-art characterization, modelling and silicon cell fabrication facilities, established the ESP lab, developed laboratory and classroom courses for training undergraduate and graduate students, and last but not least, establish a good working relationships with the PV industry and national laboratories. 


\section{EXECUTIVE SUMMARY}

In spite of progress made in the efficiencies of single-and multicrystalline silicon solar cells in the last decade, the cost of generating power from photovoltaics is still higher than from fossil fuels, and the actual and theoretical efficiencies of solar cells made from silicon continue to differ. For these reasons, basic research such as that carried out at Georgia Tech toward low-cost, high-efficiency crystalline silicon cells is important so that photovoltaics can become a cost-effective source of electricity that is also environmentally clean.

This annual report covers our work from July 1993 to June 1994, during which time record-high-efficiency solar cells were made, rapid thermal processing/plasma-enhanced chemical vapor deposition technology for low-cost, high-efficiency cells was optimized, stateof-the-art characterization, modelling, and silicon cell fabrication facilities were established, an educational support program laboratory was established, laboratory and classroom courses for training graduate and undergraduate students were developed, and a good working relationship was established with industry and the national labs.

More specifically, significant progress was made during this year toward understanding the lifetime- and efficiency-limiting mechanisms in cast and sheet multicrystalline materials, leading to an optimization of the process to achieve higher quality surface passivation, longer bulk carrier lifetimes, and higher efficiency cells on single- and multicrystalline silicon materials.

The report describes a detailed investigation of quality enhancement techniques, which were found to be beneficial in enhancing the performance of multicrystalline silicon cells, but were quite material specific. A review is given of how gettering and passivation techniques were optimized and integrated into a process sequence that does not greatly increase the cost of cell fabrication. Cell model calculations were made and extended to outline an approach toward achieving greater than $20 \%$ efficient multicrystalline cells that emphasizes the need for surface texturing, reduced back-surface recombination velocity, and reduced base resistivity without paying too much penalty for lifetime.

The progress made on developing plasma-enhanced chemical vapor deposition is described, and its passivation is for the first time shown to be effective for surface and bulk defect passivation in multicrystalline silicon materials.

Included is a report on how a combination of rapid thermal processing and plasmaenhanced chemical vapor deposition coatings was used to reduce the time and cost of cell fabrication. Other accomplishments outlined here are a close interaction with industry, development of state-of-the-art testing and characterization facilities, development of powerful, user-friendly modelling capabilities to optimize any region of the cell, and establishment of two solar cell fabrication laboratories capable of routinely producing cells with efficiencies of $18-21 \%$ on single-crystal FZ silicon. This research has resulted in two patents and about 50 technical papers in the last two years. 
\begin{tabular}{|} 
\\
\\
\\
\\
\\
\\
\\
\\
\end{tabular} 


\section{CHAPTER 1. INTRODUCTION}

This is the second annual report since the inauguration of the University Center of Excellence for Photovoltaics Research and Education (UCEP) at Georgia Tech. The major focus of the UCEP at Georgia Tech is crystalline silicon. The mission of the Center is to improve the fundamental understanding of the science and technology of advanced Photovoltaic devices and materials, to fabricate high-efficiency cells and develop low-cost processes, to provide training and enrich the educational experience of students in this field, and to increase U.S. competitiveness by providing guidelines to industry and DOE for achieving cost-effective and high efficiency PV devices.

These objectives are to be accomplished through a combination of research and education. In addition to teaching solar cell courses and providing practical training to students at Georgia Tech, a new Educational Support Program (ESP) laboratory has been built from scratch. This lab will support university-level educational PV programs in the nation through collaboration and technical assistance. The fabrication laboratory will provide a baseline capability to fabricate $18 \%-20 \%$ efficient silicon solar cells on single crystal float-zoned (FZ) wafers. The fabrication laboratory will fabricate silicon solar cells according to run sheets and materials submitted by other universities. The second major objective of this program is to conduct basic and applied research to advance the science and technology of silicon solar cells and materials. This work is expected to assist the PV industry in cost-effective development of silicon solar cells and give the USA a competitive edge in the field by setting the pace and trajectory of research and development. This program will produce welltrained graduate and undergraduate students to continue the much-needed development of costeffective and high-efficiency PV devices. Research thrusts involve development and optimization of cost-effective processes for use in the fabrication of solar cells, gettering and passivation of impurities and defects, modeling and design of high efficiency cells, and fabrication and testing of high- 
efficiency one-sun cells on monocrystalline and multicrystalline silicon substrates. Major research milestones at the end of the second year include (a) fabrication of high-efficiency cells on low-cost multicrystalline cells with a target efficiency of $17 \%$, (b) fabrication of single crystal silicon cells with target efficiency of $22 \%$, (c) development of high- efficiency, rapidly processed RTP/PECVD cells and (d) publication of three journal articles.

Photovoltaic education milestones were to establish the ESP lab to assist other university and industry PV programs in the USA, provide national focus for silicon PV research, establish a baseline process which will consistently produce $>18 \%$ efficiency cells on FZ silicon in the ESP lab, document run sheets, teach a course on solar cells, and provide hands-on training to graduate and undergraduate students in fabricating high efficiency silicon solar cells.

A number of faculty members from various academic units, including ECE, MSE, ME, ChE, Chemistry and Physics have contributed to the success of this program. In addition to the faculty members, a large number of talented research engineers have also made contributions to the PV program, and most of all 12 Ph.D. students and some undergraduate students and visiting scholars have also made significant contributions to the PV research at the Center.

The Center has established state-of-the-art facilities for PV materials and device characterization and has all the necessary tools to troubleshoot, test and analyze solar cells. Modelling and design are very important components of our PV program. To add depth to our research we have developed and assembled a library of 12 user-friendly computer models to design and analyze various regions of solar cells. For example, using these models we have designed and optimized AR coatings, surface texturing, SRV, grid patterns, bulk resistivity and lifetime, in addition to designing and fabricating high- efficiency cells.

The most difficult aspect of this program was to establish and operate a silicon solar cell fabrication facility. We now have two complete fabrication laboratories - one is exclusively for 
research and the other is for education, training and research. This program provides the opportunity for students and scientists to conduct theoretical and experimental research and a mechanism for technology transfer to the PV industry.

Significant progress was made last year in the area of research and education in photovoltaics. This report summarizes the technical accomplishments. Chapter 2 describes modeling, processing and characterization of cast multicrystalline silicon solar cells. Attempts were made to quantify and improve the fundamental understanding of the beneficial effects of oxide passivation, Al diffusion, and forming gas anneal, which resulted in the fabrication of a record high $17.8 \%$ efficient cell on Oseka Titenium Corporation (OTC) multicrystalline silicon, in addition to cell efficiencies in the range of $16-17 \%$ on a number of other multicrystalline silicon materials. Accomplishments on single crystal include fabrication of $20 \%$ efficient flat cells and $21 \%$ efficient textured monocrystalline cells. These results are described in Chapter 3. The development of a novel PECVD $\mathrm{SiN} / \mathrm{SiO}_{2} \mathrm{AR}$ coating that also provides good bulk and surface passivation is discussed in Chapter 4 . Chapter 5 describes the development of record high- efficiency, (17\%) rapidly processed RTP/PECVD cells. Finally, Chapter 6 describes our educational activities and accomplishments, which include construction and completion of the educational support program lab, hands-on training in the ESP lab, and course offerings on solar cells. 



\section{CHAPTER 2. HIGH-EFFICIENCY MULTICRYSTALLINE SUICON SOLAR CELLS}

\subsection{Introduction}

Low-cost and high-efficiency are the keys for large-scale applicability of photovoltaic systems. Unfortunately, the cost of solar cell modules is about a factor of 4 too high to be attractive for very large-scale utility applications in the USA. However, given the fact that in the 1970's this factor was about 100 , there is reason for optimism that photovoltaics will become a cost-effective source of electrical energy in the near future. Photovoltaic modules today cost about $\$ 4 /$ watt, which can produce electricity at a rate of about $25 \mathrm{c} / \mathrm{kWh}$. A factor of 2 in cost reduction will make PV attractive for peak-power load applications, and a reduction by a factor of 3 or 4 would make it extremely competitive with conventional energy sources for base load utility applications.

Figure 2.1 shows that a DOE goal of producing PV-generated electricity at $6 \mathrm{c} / \mathrm{kWh}$ can be realized by various combinations of module efficiency and cost. This is why research is being conducted today on various materials ranging from high-cost high-efficiency single crystal GaAs to low-cost low-efficiency materials like amorphous silicon thin films. No material or technology has yet achieved the cost and efficiency goals simultaneously. Large-grain multicrystalline silicon, which is the focus of this section, is a strong contender for cost-effective PV because of low material cost and potential for high-efficiency cells. Low-cost crystal growth techniques, such as casting, reduce the cost of multicrystalline silicon but at the same time introduce defects, impurities and grain boundaries, which can degrade cell performance. However, by implementing appropriate gettering and passivation techniques, and clever cell designs, it is possible to mitigate the impact of defects and impurities and reduce the gap between single and multicrystalline cell efficiency. This is why enhancement in multicrystalline silicon cell efficiency has become an area of very active investigation. 


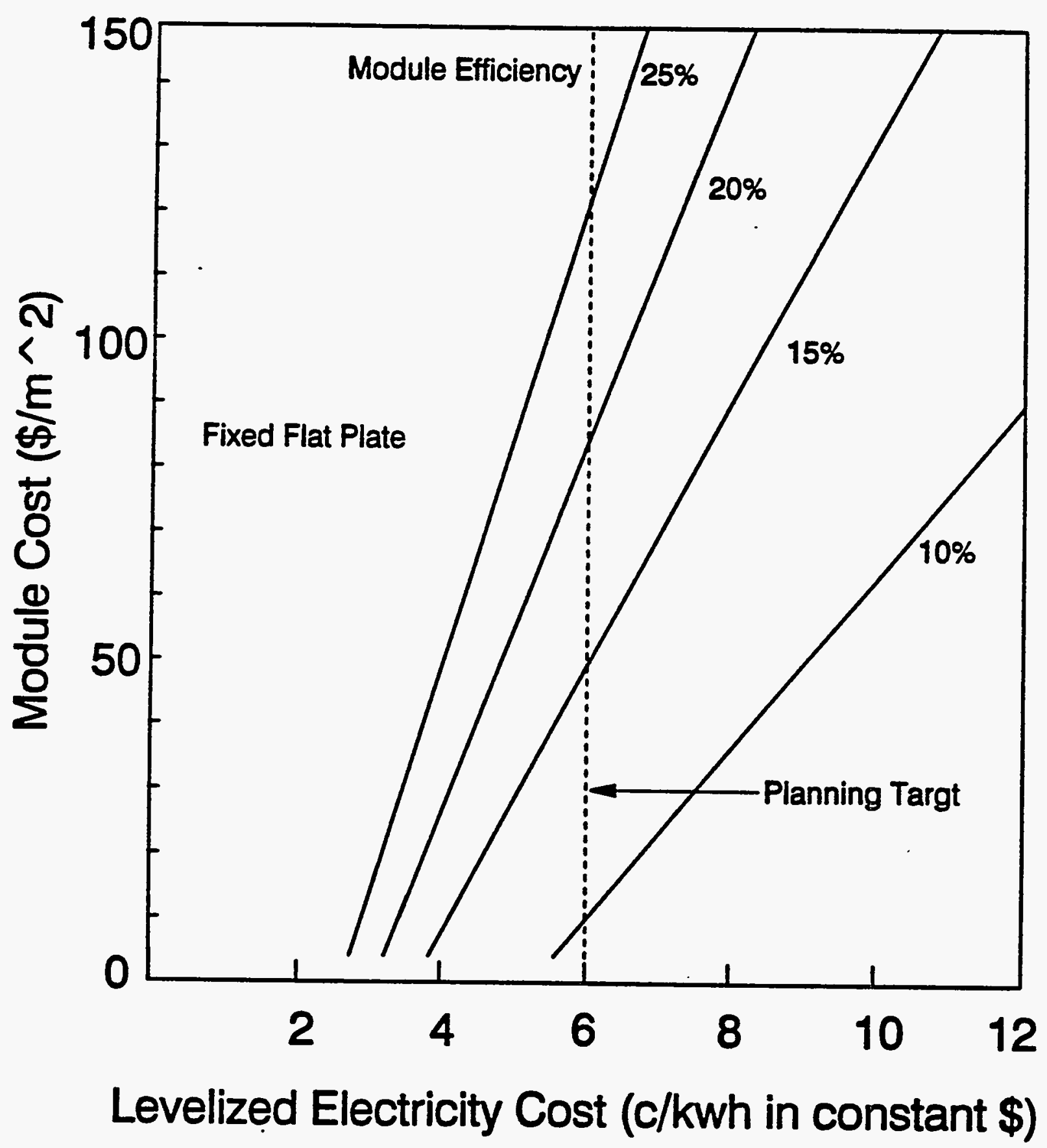

Figure 2.1. Module costs and efficiencies versus 30-year levelized electricity costs for flat-plate photovoltaic systems. 
The overall goal of this section is to design and fabricate a record-high-efficiency multicrystalline silicon cell through fundamental understanding of defects and quality enhancement techniques in multicrystalline silicon materials.

\subsection{Fabrication of Multicrystalline Silicon Solar Cells Without Gettering and Passivation Techniques; Simple Base-line Process Sequence}

At the beginning of the research, cast multicrystalline silicon material from Sitix (formerly OTC) was selected for cell fabrication. Figure 2.2 shows that when a simple process sequence (Figure 2.3) is used to fabricate $n^{+}-p$ solar cells, which involves unoptimized phosphorus gettering, no Al gettering, no oxide surface passivation, and no surface and bulk defect passivation by forming gas anneal (FGA), we were only able to achieve 14-15\% efficient cells. Diffusion length (L) obtained by internal quantum efficiency analysis was only $200 \mu \mathrm{m}$ (lifetime of $\sim 14 \mu \mathrm{s}$ ). Model calculations (Figure 2.2) were performed to show that this cell design with $\mathrm{L}$ of $200 \mu \mathrm{m}$ can only give a $14-15 \%$ efficient cells. However, if bulk lifetime increased to $25 \mu \mathrm{s}$, we can achieve $\sim 16.5 \%$ efficient cells. IQE response of these cells in Figure 2.2 also suggests that the performance of the cells can be improved if front and back surface recombination velocities can be reduced by incorporating front-surface oxide passivation and BSF, respectively. Therefore the next step was to change the design to $\mathrm{n}-\mathrm{p}-\mathrm{p}^{+}$structure and incorporate these gettering and passivation techniques that became an integral part of the cell process sequence, rather than using additional steps, so that cell performance could be increased without appreciably influencing the cell fabrication cost. 


\subsection{Understanding and Optimization of Phosphorus Gettering on Multicrystalline Silicon Solar Cells}

Phosphorus gettering is an integral part of cell fabrication because it also forms the $\mathrm{n}^{+}$emitter on p-silicon. In this investigation phosphorus gettering was performed for $25 \mathrm{~min}$, using $\mathrm{P}_{2} \mathrm{O}_{5}$ solid sources. The phosphorus diffusion temperature was varied in the range of $880-1030^{\circ} \mathrm{C}$ to find the optimum. Since phosphorus gettering is expected to improve bulk lifetime by extracting impurity or defects from the bulk by providing a sink due to the formation of misfit dislocations at surface, open circuit voltage decay lifetime on the phosphorus diffused $n^{+}-p$ samples was used as an indicator for gettering efficiency or process optimization. Table 2.1 clearly shows that there is an optimum phosphorus diffusion temperature $\left({ }^{\circ} 930^{\circ} \mathrm{C}\right)$ for this cast mc-Si material, which gives and optimizes OCVD lifetime of $\sim 9 \mu \mathrm{s}$.

Table 2.1. The effect of phosphorus diffusion temperature on measured OCVD OCVD lifetime

\begin{tabular}{|c|c|c||}
\hline $\begin{array}{c}\text { Phos. Diffusion Temperature } \\
\left({ }^{\circ} \mathrm{C}\right)\end{array}$ & $\begin{array}{c}\text { OCVD Lifetime } \\
(\mu \mathrm{sec})\end{array}$ & $\begin{array}{c}\text { Sheet } \\
\text { Resistance }(\Omega / \square)\end{array}$ \\
\hline 880 & $6.0( \pm 1.0)$ & 25 \\
\hline 930 & $9.0( \pm 1.0)$ & 16 \\
\hline 980 & $2.0( \pm 0.5)$ & 12 \\
\hline 1030 & $1.0( \pm 0.5)$ & 8 \\
\hline
\end{tabular}



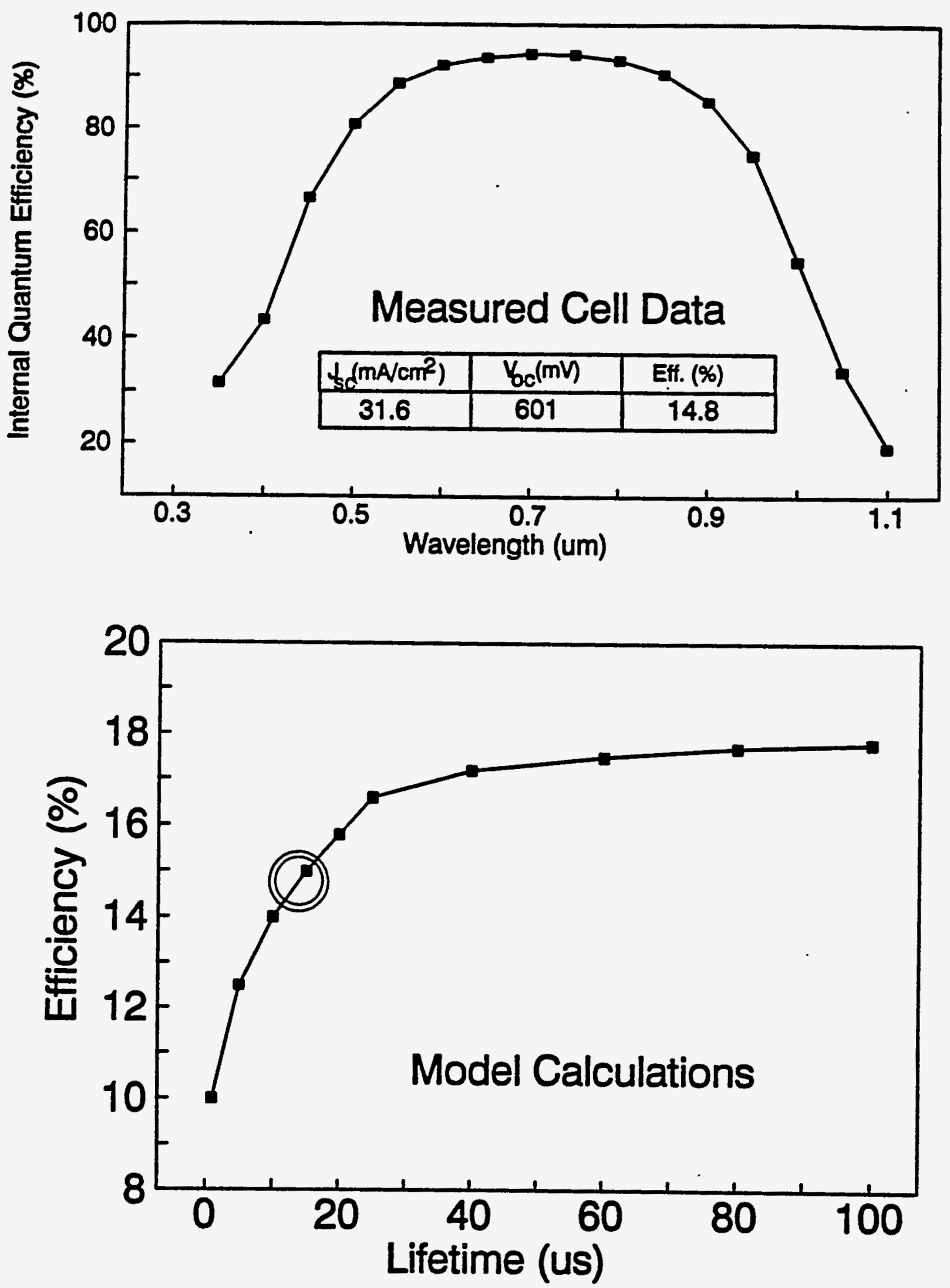

Figure 2.2. Measured cell data and model calculations for the simple base-line cells. 


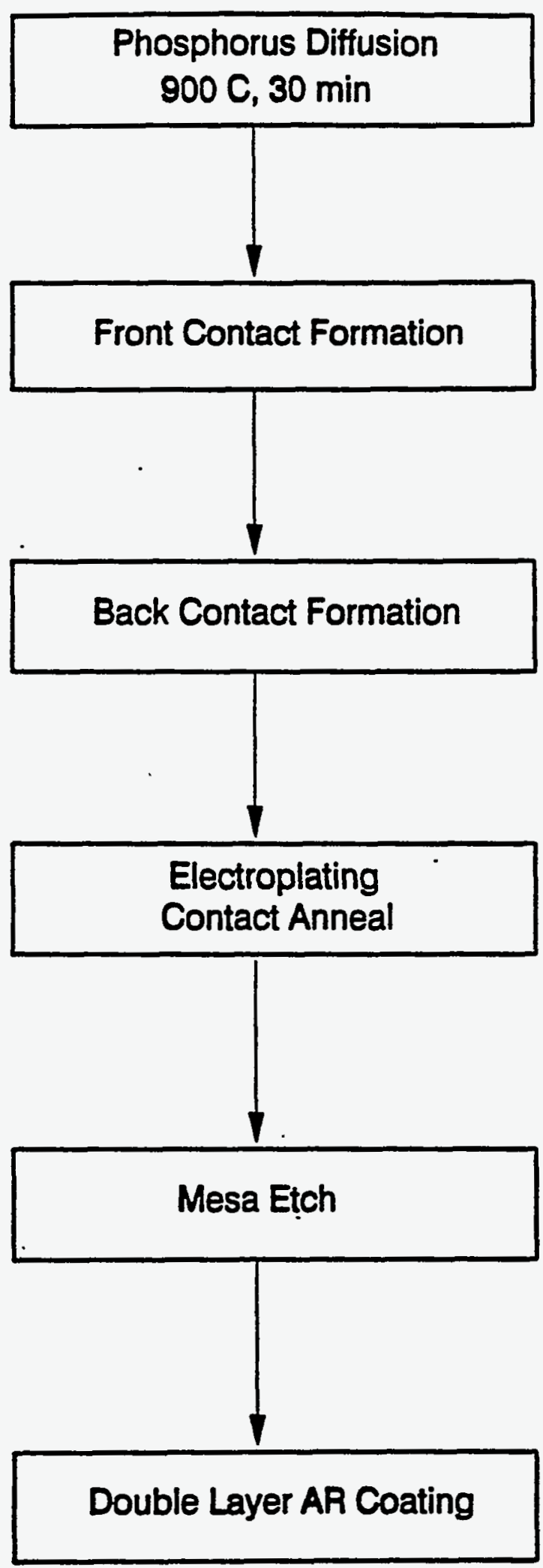

Figure 2.3. Simple base-line process sequence. 
Cost-effective gettering and passivation techniques passivate surface and bulk defects to improve the bulk lifetime and surface recombination velocities. When the diffusion time was varied from $15-45$ min at $930^{\circ} \mathrm{C}$ no appreciable change was observed in the bulk lifetime. Optimum gettering temperature is the result of competition between gettering of impurities and formation of processinduced defects. The latter is due to the fact that mc-Si has grown-in defects and impurities; at high temperatures these defects can migrate and form lifetime- limiting defect complexes, or some defects can get decorated with impurities. Generally, defective materials cannot stand high-temperature processing without lifetime degradation. This is why the phosphorus diffusion temperature was intentionally kept below $1000^{\circ} \mathrm{C}$ to prevent process-induced lifetime degradation [1], but was kept above $850^{\circ} \mathrm{C}$ for intense gettering (Table 2.1). It has been suggested [2] that the phosphorus gettering mechanism involves substitutional impurities in the bulk to become interstitial which then diffuse into the $\mathrm{n}^{+}$-region due to the sink provided by misfit dislocations in the $\mathrm{n}^{+}$-region. During phosphorus diffusion, a high phosphorus concentration is generated near the surface, which exceeds the solubility limit. Precipitates of SiP are formed and due to the molar volume expansion, the formation of SiP precipitate generates an excess of self interstitials, which are injected in to the bulk. Gettering sites could also be created by the dislocation network that is produced by the stress introduced by the atomic radius difference between phosphorus and silicon atoms. In addition, the $\mathrm{n}^{+}$doped region contains a large density of vacancies, which can trap interstitial metal atoms.

\subsection{The Effect and Understanding of Partial Emitter Etch Back on the Performance of Multicrystalline Silicon Solar Cells}

Spreading resistance data showed that the $930^{\circ} \mathrm{C} / 25$-min diffusion, which is optimum for phosphorus gettering of Sitix material, gave $16 \Omega / \square$ sheet resistance, with $-1 \mu \mathrm{m}$ thick, very heavily 
doped $\mathrm{n}^{+}$emitter. This gave lower cell performance because of the thicker dead layer and heavy doping effects, such as Auger recombination and bandgap narrowing. Therefore, an emitter etchback technique was attempted to partially remove the heavily doped $\mathrm{n}^{+}$-region, thus raising sheet resistance and thinning the emitter. Figure 2.4 shows a comparison of cells fabricated after two different emitter etch-back depths, resulting in a sheet resistance of 30 and $80 \Omega / \square$. The cells with high emitter sheet resistance of $80 \Omega / \square$ gave the highest $V_{\infty}, J_{s c}$ and cell efficiency while the $16 \Omega / \square$ cells, with no emitter etch back, gave the lowest cell efficiency. No attempts were made to increase the sheet resistance beyond the $80 \Omega / \square$ because the grid design used in this study was not suitable for greater than $100 \Omega / \square$ sheet resistance.

$V_{o c}$ of a solar cell is a strong function of $J_{0}\left(V_{\infty c}=k T / q \cdot \ln J_{x c} / J_{0}\right)$ while $J_{x c}$ depends strongly on the IQE. The above cells were also analyzed by the reverse saturation current $\left(\mathrm{J}_{01}\right)$ and internal quantum efficiency (IQE) measurements. $J_{01}$ consists of emitter and base components $\left(b_{b 1}=b_{b i c}+\right.$ $\mathrm{J}_{01 \mathrm{~b}}$ ). $\mathrm{J}_{01 \mathrm{~b}}$ should be independent of emitter etch-back; therefore, any measured difference in the $\mathrm{J}_{01}$ with emitter etch-back will reflect the change in the $\mathrm{J}_{01 \mathrm{e}}$ provided the $\mathrm{J}_{0 \mathrm{e} e}$ is an appreciable component of the $\mathrm{J}_{01}$. A comparison of the $\mathrm{J}_{01}$ of the oxide passivated cells, Figure 2.4, shows that an increase in the sheet resistance from 30 to $80 \Omega / \square$ had virtually no effect on the $J_{01}$, indicating that the $J_{00}$ plays a negligible role in dictating the $\mathrm{J}_{01}$ or $\mathrm{V}_{\mathrm{oc}}$ of these gettered and oxide passivated multicrystalline cells with effective bulk lifetimes of $25 \mu$ sec. Figure 2.4 shows that, unlike $\mathrm{J}_{01}$, the emitter etch-back from 30 to $80 \Omega / \square$ enhanced the quantum efficiency of the multicrystalline cells in the short wavelength range by reducing the heavy doping effects and absorption in the dead layer. This resulted in about $2.3 \mathrm{~mA} / \mathrm{cm}^{2}$ increase in $\mathrm{J}_{\mathrm{se}}$. 


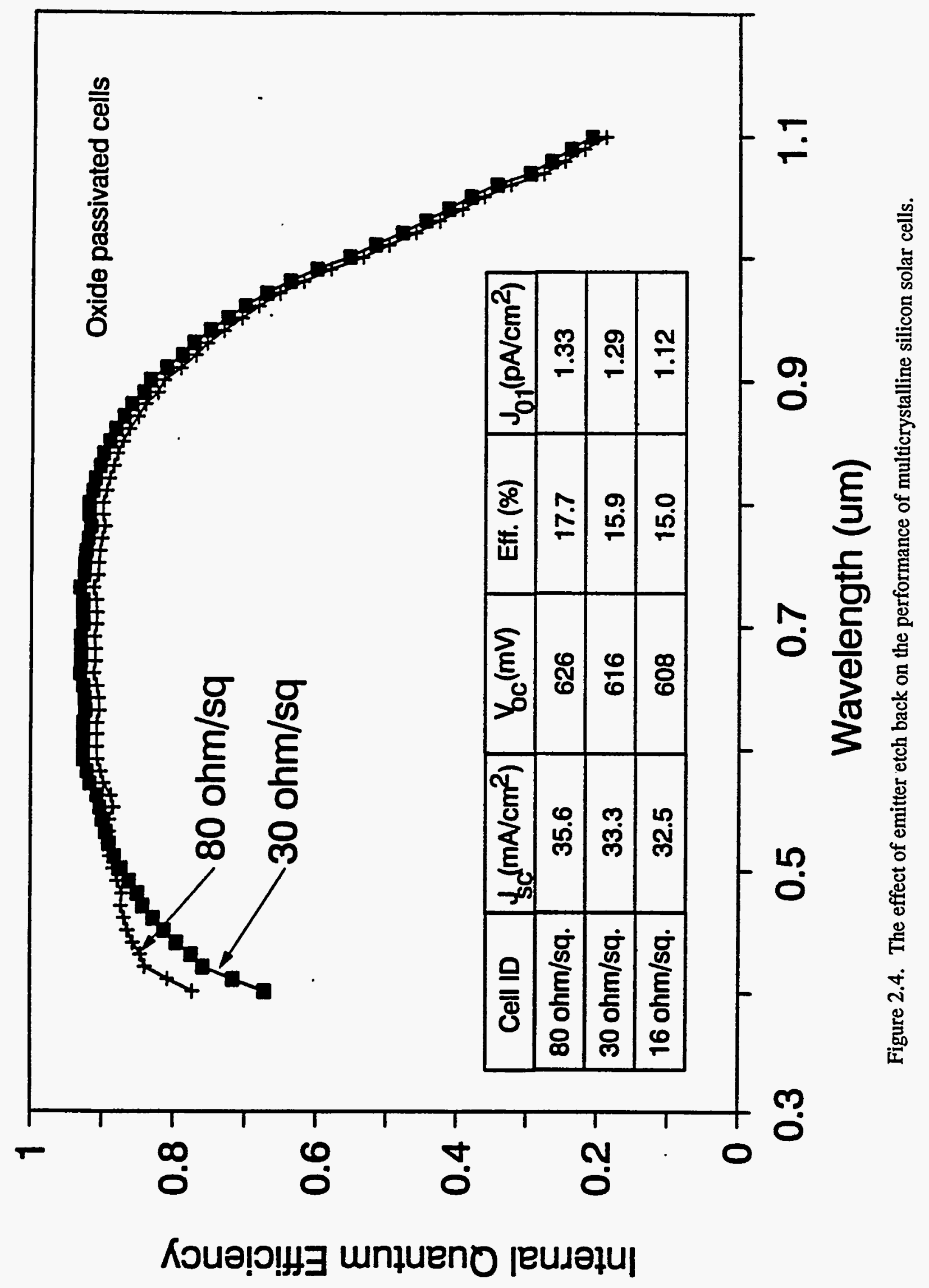


The observed increase in cell performance after the emitter etch back could result either from removal of the contaminated $\mathrm{n}^{+}$region, where gettered impurities end up, or from the reduction in heavy doping effects such as Auger recombination and bandgap narrowing. Therefore model calculations were performed to understand and quantify the effect of emitter etch back. Measured emitter profiles were fed into the device modeling program (PC-1D). Model calculations showed that the $2.5 \mathrm{~mA} / \mathrm{cm}^{2}$ increase out of the observed $3.0 \mathrm{~mA} / \mathrm{cm}^{2}$ increase in $\mathrm{J}_{\mathrm{sc}}$ came from the reduction in heavy doping effect. The remaining $0.5 \mathrm{~mA} / \mathrm{cm}^{2}$ can be attributed to better surface passivation due to reduced surface doping concentration. Thus, intense phosphorus gettering followed by an etch back is an ideal way to form an emitters in mc-Si cells because you retain the benefit of phosphorus gettering without the penalty of the heavy doping effects.

\subsection{Optimization and Fundamental Understanding of Multiple Effects of $\mathrm{Al}$ Treatment on MC-Si Cells}

\subsubsection{Effect of Al Gettering Temperature on Cell Performance}

In order to conduct a controlled investigation of $\mathrm{Al}$ gettering, cells were fabricated with onehalf of each wafer covered with $\mathrm{Al}$ on the back side (Al-diffused cells with $\mathrm{p}^{+}-\mathrm{BSF}$ ) while the other half was kept bare (Al-sintered cells with no BSF) during the Al drive-in (Figure 2.5). The drive-in temperature in this study was varied in the range of $800-925^{\circ} \mathrm{C}$ to find the optimum. Improvement in $\mathrm{V}_{\infty}$ contains the information about the gettering-enhanced bulk lifetime as well as the BSF effect. BSF tends to reduce the back surface recombination velocity (BSRV) at the $\mathrm{p}-\mathrm{p}^{+}$interface which manifests itself in the form of higher effective lifetime, $\mathrm{J}_{\kappa<}$, and $\mathrm{V}_{c}$; therefore, $\mathrm{Y}$ and cell 
efficiency were used as the indicator for process optimization. Figure 2.6 shows that for this Sitix multicrystalline silicon material, Al drive-in temperature in the range of $850-900^{\circ} \mathrm{C}$ gives the highest $\mathrm{V}_{\infty}$ and efficiency. An optimum Al gettering temperature is related to the competition between gettering and thermally-induced defect generation, as also seen in the case of phosphorus gettering. Figure 2.7 shows that at each temperature, Al-diffused solar cells showed better performance compared to those with no Al BSF. Below the $850^{\circ} \mathrm{C}$ drive-in, the $\mathrm{V}_{\propto}$ increased with increasing drive-in temperature because of two reasons: first the Al gettering efficiency increases with temperature, and second, the thickness and effectiveness of the BSF also increase with the temperature. The decrease in $\mathrm{V}_{\mathrm{o}}$ beyond $900^{\circ} \mathrm{C}$ is probably due to the fact that defective materials like multicrystalline silicon cannot stand very high temperature processing without lifetime degradation due to defect generation or defect complex formation. This hypothesis was confirmed by IQE and diffusion length $(\mathrm{L})$ measurements (Figures 2.8 and 2.9). Figure 2.8 clearly shows that low Al-drivein temperature does not improve $\mathrm{L}$, at intermediate temperatures $\left(850-900^{\circ} \mathrm{C}\right) \mathrm{L}$ increases rapidly due to gettering and BSF, but at high temperatures $\left(>900^{\circ} \mathrm{C}\right) \mathrm{L}$ decreases again due to processinduced defects. This fact is also reflected in the IQE of the cells with and without $\mathrm{Al}$ treatment at different drive-in temperatures. Table 2.2 shows a comparison of cell data for the Al-diffused and Al-sintered Sitix cast multicrystalline silicon. Cast multicrystalline cells showed an appreciable increase in the effective diffusion length from 195 to $261 \mu \mathrm{m}$ and a corresponding absolute cell efficiency improvement of $1.4 \%$ due to the Al process, Table 2.2. PC-1D device modeling was performed for the best cell (efficiency of $17.8 \%$ ) to understand the multiple effects of $\mathrm{Al}$ treatment. Model calculations showed ( Table 2.3) 


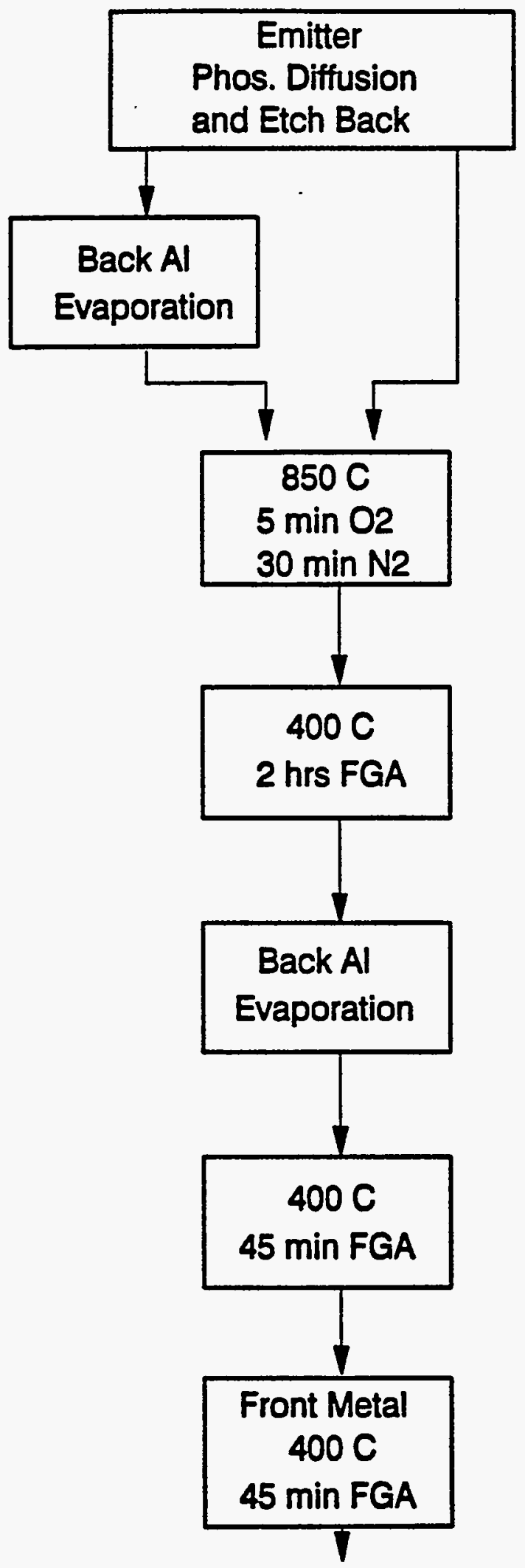

Figure 2.5. Process sequence to decouple the effect of $\mathrm{Al}$ diffusion. 


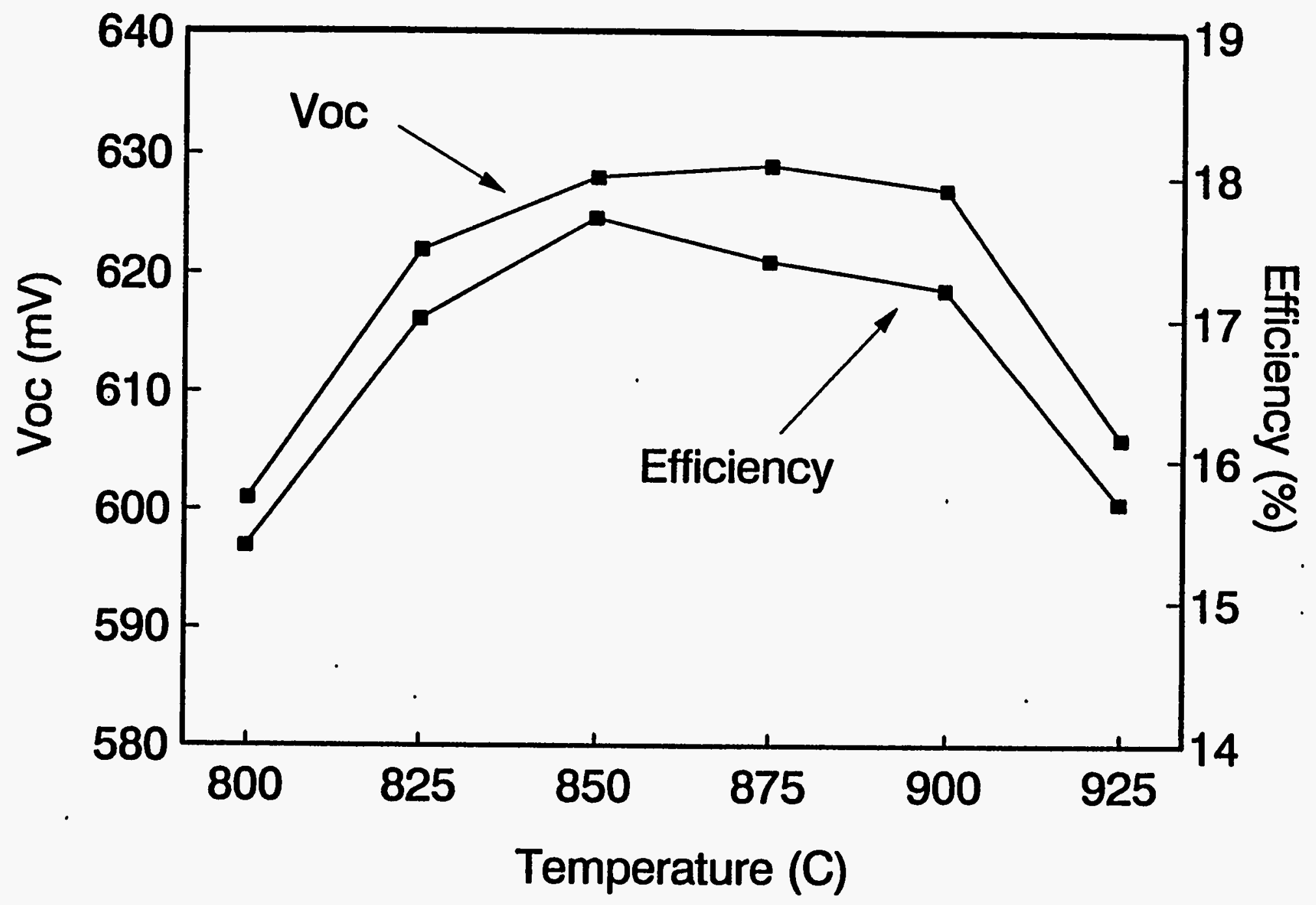

Figure 2.6. The effect of $\mathrm{Al}$ drive-in temperature on the cell performance. 


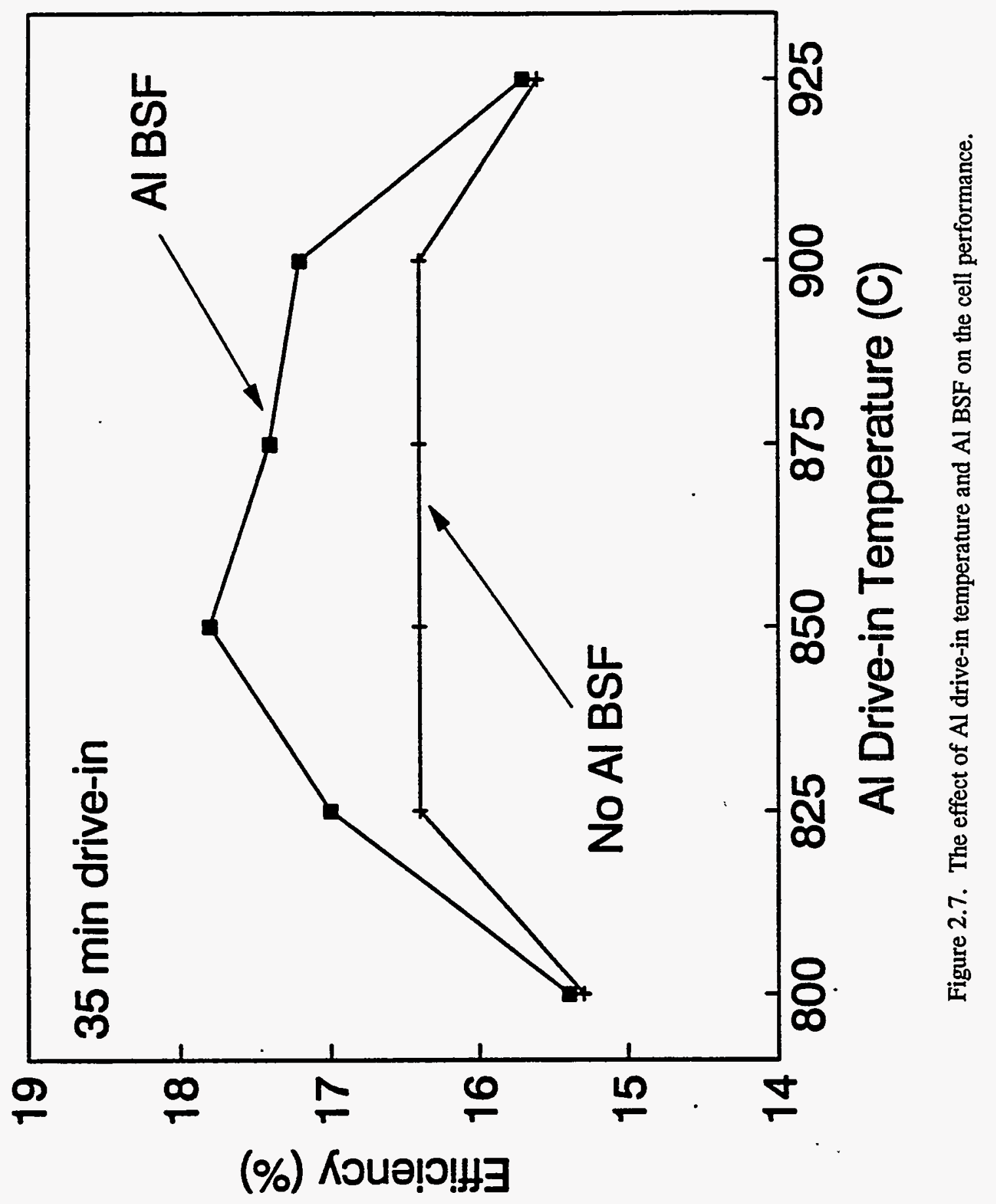




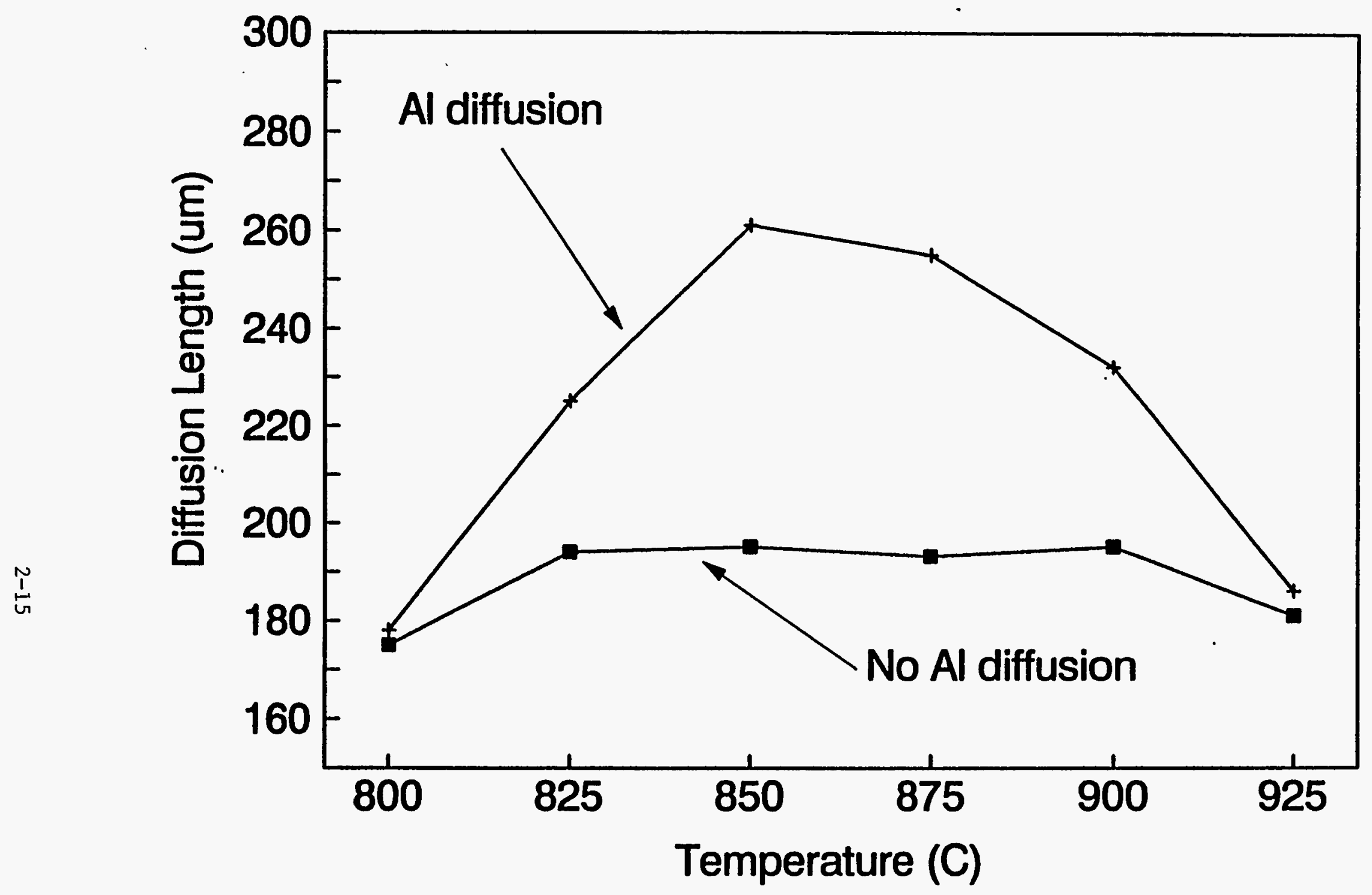

Figure 2.8. The effect of $\mathrm{Al}$ gettering temperature and Al BSF on bulk diffusion length. 

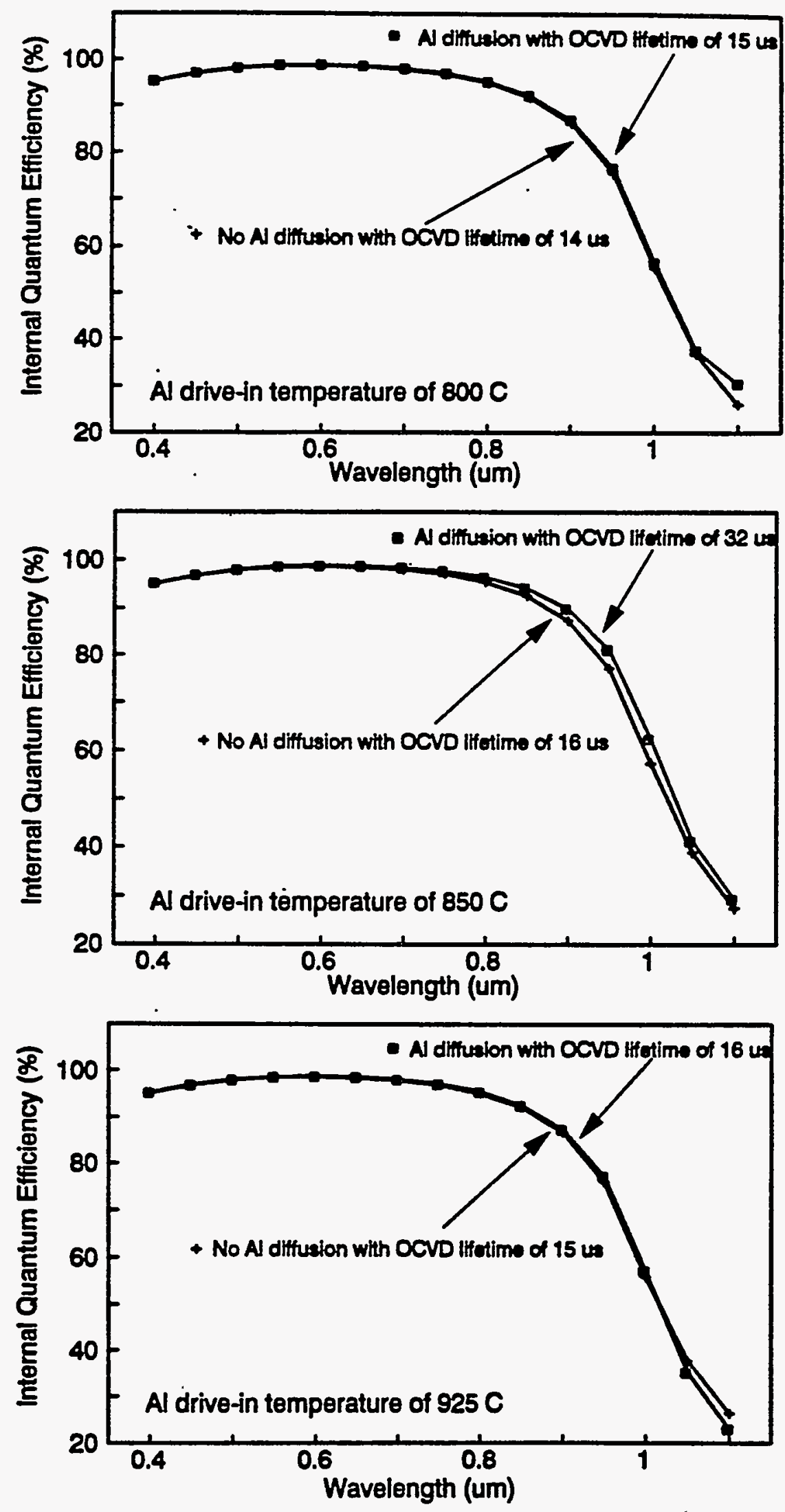

Figure 2.9. The effect of $\mathrm{Al}$ gettering temperature on IQE of solar cells. 
that in the $400 \mu \mathrm{m}$ thick Sitix polysilicon cells with $195 \mu \mathrm{m}$ diffusion length, Al BSF can only produce an efficiency improvement of $\sim 0.3 \%$. Detailed model calculations also showed that the observed $1.4 \%$ increase in cell efficiency in this case results from the multiple effects of $\mathrm{Al}$ treatment. In addition to the $\mathrm{BSF}$ and gettering effects, the $\mathrm{Al}$ treatment roughens the back surface, which reduces the back surface reflectance and introduces some light trapping. Detailed cell analysis showed a reduction in BSR (back surface reflectance) from $87 \%$ to $75 \%$ and path length enhancement by a factor of 1.4 due to back texturing in these cells. Model calculations in Table 2.3 revealed that $\mathrm{Al}$ treatment increased $\mathrm{J}_{\mathrm{k}}$ by $0.3 \mathrm{~mA} / \mathrm{cm}^{2}$ due to $\mathrm{BSF}$, decreased $\mathrm{I}_{\mathrm{c}}$ by $-0.1 \mathrm{~mA} / \mathrm{cm}^{2}$ due to reduced BSR, and increased $\mathrm{J}_{\mathfrak{c}}$ by $1.7 \mathrm{~mA} / \mathrm{cm}^{2}$ due to lifetime enhancement and light trapping, accounting for the observed increase of $2.1 \mathrm{~mA} / \mathrm{cm}^{2}$ in $\mathrm{J}_{\kappa \mathrm{c}}$ in these cells. Thus, even though there are multiple effects of $\mathrm{Al}$, the majority of the improvement results from the Al-gettering-induced increase in lifetime.

Table 2.2. Effect of aluminum treatment on multicrystalline silicon cell performance

\begin{tabular}{||c|c|c|c|c|c|c|c|c|}
\hline & \multicolumn{4}{|c|}{ Aluminum Diffused and Gettered } & \multicolumn{4}{c|}{ Aluminum Sintered with no Al Gettering } \\
\hline MCS & $v_{\infty}$ & $J_{\infty}$ & Efficiency & Diff. Length & $V_{\infty}$ & $J_{\infty}$ & Efficiency & Diff. Length \\
ID & $(\mathrm{mV})$ & $\left(\mathrm{mA} / \mathrm{cm}^{2}\right)$ & $(\%)$ & $(\mu \mathrm{m})$ & $(\mathrm{mV})$ & $\left(\mathrm{mA} / \mathrm{cm}^{2}\right)$ & $(\%)$ & $(\mu \mathrm{m})$ \\
\hline Sitix & 628 & 36.2 & 17.8 & 261 & 618 & 34.1 & 16.4 & 195 \\
\hline
\end{tabular}


Table 2.3. The multiple effects of $\mathrm{Al}$ gettering, the observed change in $\mathrm{J}_{\boldsymbol{~} \mathrm{c}}$ is $2.1 \mathrm{~mA} / \mathrm{cm}^{2}$

\begin{tabular}{|c|c|c|}
\hline & $\Delta \mathrm{J}_{c c}\left(\mathrm{~mA} / \mathrm{cm}^{2}\right)$ & $\Delta$ Efficiency $(\%)$ \\
\hline Lifetime & 1.0 & 0.7 \\
\hline BSF & 0.3 & 0.1 \\
\hline BSR & -0.05 & $<0.1$ \\
\hline Perfect Back Texture & 0.7 & 0.3 \\
\hline
\end{tabular}

\subsubsection{LBIC Response of Al-gettered Multicrystalline Silicon Solar Cells}

In order to support the above conclusion that $\mathrm{Al}$ treatment performs gettering, light beam induced current (LBIC) measurements were performed on Sitix cells, with and without the Al treatment, to investigate if bulk diffusion length enhancement results from Al-gettering inside the grains or at the grain boundary. Samples covered with $1-\mu \mathrm{m}$ thick $\mathrm{Al}$ on the back-side followed by $850^{\circ} \mathrm{C}$ drive-in were processed as a solar cells. They were divided into four groups: no Al gettering, 1-min, 35-min, and 120-min Al drive-in, respectively. LBIC measurements were performed in a region with the same microstructure on all four neighboring samples. The light beam spot size was $125 \mu \mathrm{m}$ for a LBIC-map, and $25 \mu \mathrm{m}$ spot size was for the scans over grain boundary to obtain a higher resolution. To generate carriers deeper in the bulk, a light beam with a wavelength of $975 \mathrm{~nm}$ was used. The LBIC maps for these four samples are shown in Figure 2.10. It is clearly seen that LBIC response is significantly enhanced by longer Al gettering time, with strong enhancement within the grains, but with not much change at grain boundaries. 


\section{ST}

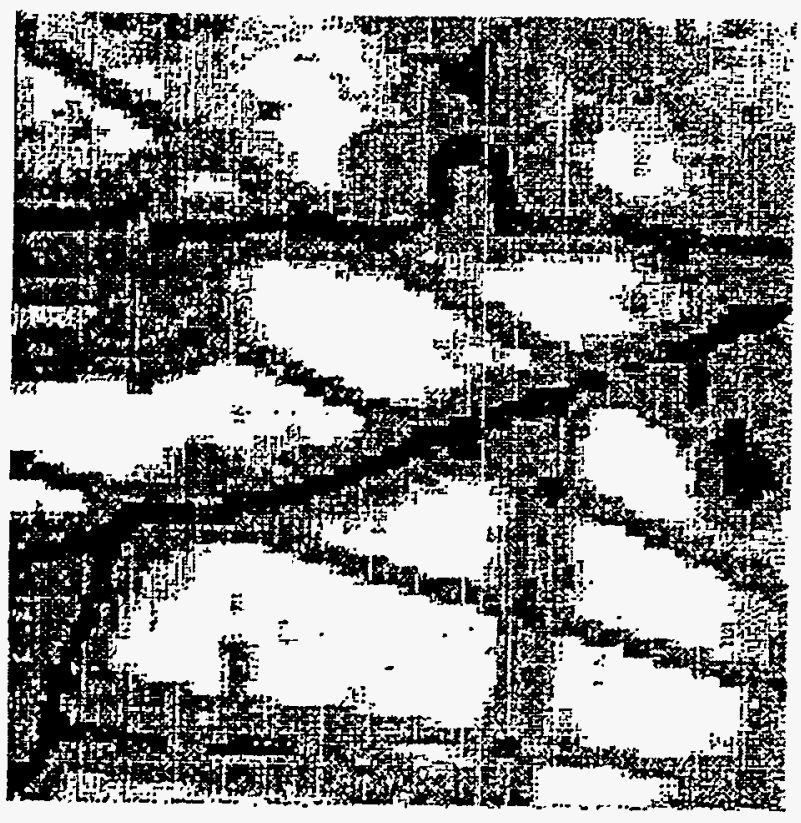

\section{MIN}

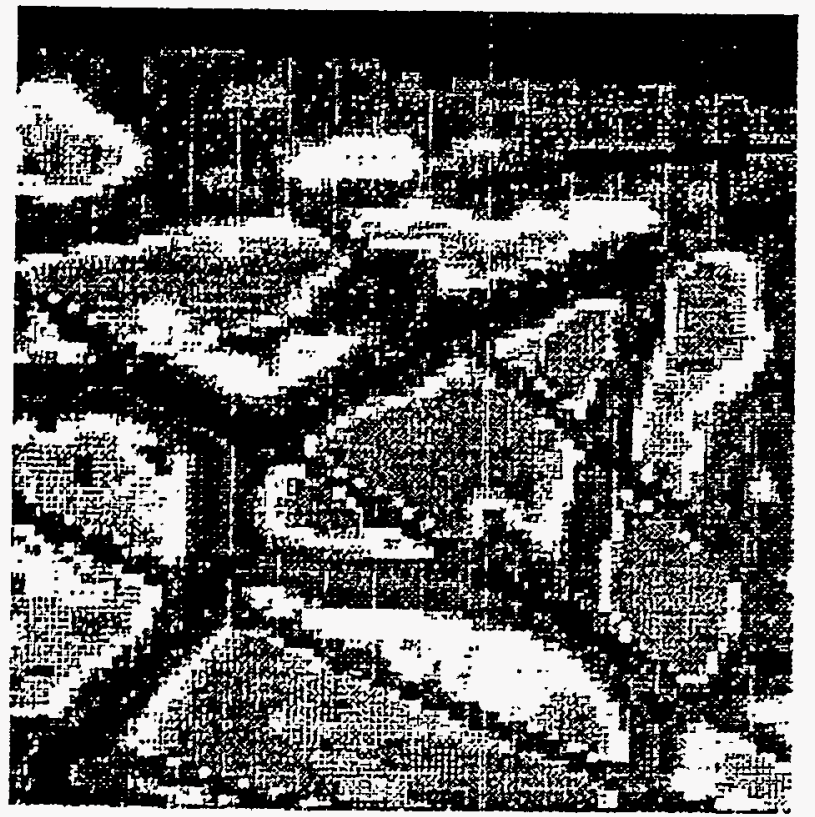

\section{$1 \mathrm{MIN}$}

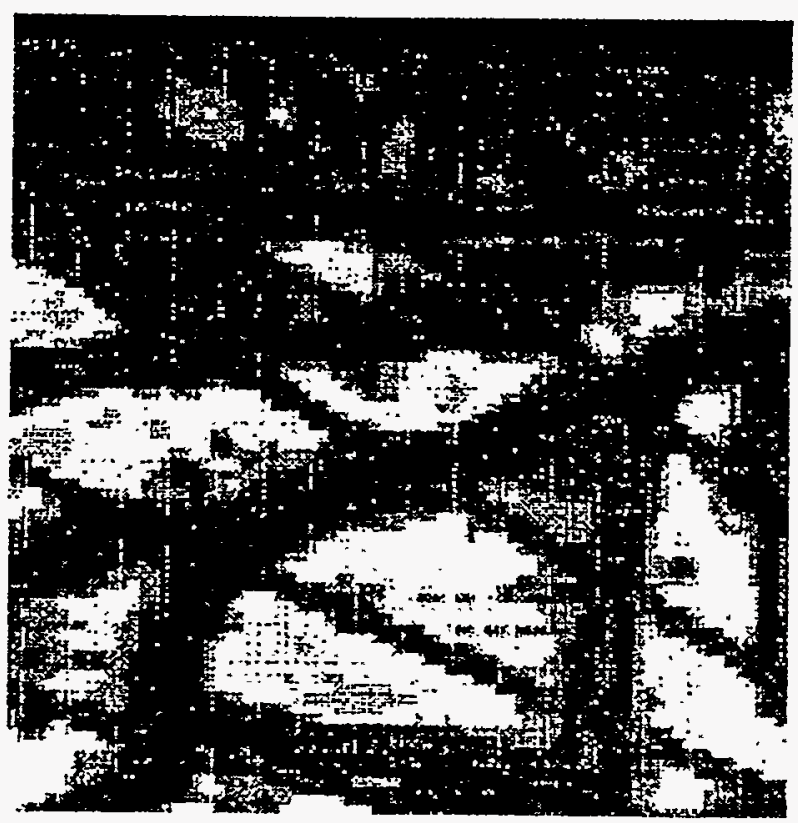

\section{$120 \mathrm{MIN}$}

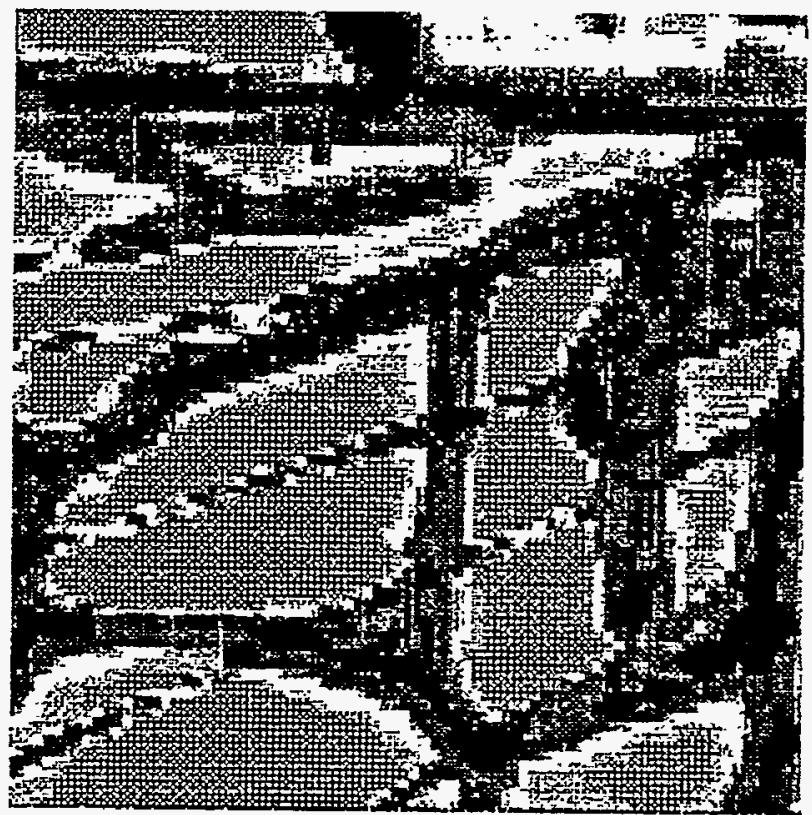

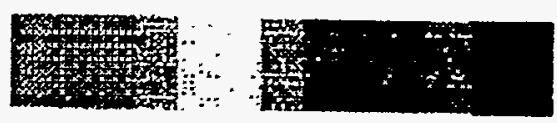

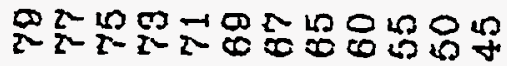

Figure 2.10. LBIC map of the Al-treated multicrystalline silicon wafers. 


\subsection{Understanding the Impact of Emitter Oxide Passivation on the Performance of Multicrystalline Silicon Solar Cells}

In addition to bulk lifetime, the front surface recombination velocity plays an important role in determining the $\mathrm{J}_{0}, \mathrm{~V}_{\infty}, \mathrm{J}_{\mathfrak{c}}$, and cell performance. Therefore an attempt was made to passivate the emitter surface during the $\mathrm{Al}$ drive-in. This simplifies the process and maintains the cost effectiveness of the process sequence. After Al evaporation on the back surface, wafers were inserted at $850^{\circ} \mathrm{C}$ in the oxygen ambient to first grow $\sim 100 \AA$ thick passivating oxide on top of the $\mathrm{n}^{+}$ emitter region on the front. After 5 minutes of oxide growth, the gas ambient was switched to nitrogen for an additional 30- minute $\mathrm{Al}$ drive-in. Similar to phosphorus gettering and emitter etchback, oxide passivation was found to be quite beneficial for the multicrystalline silicon cells. Figure 2.11 shows that oxide passivation resulted in about $1.0 \mathrm{~mA} / \mathrm{cm}^{2}$ improvement in the $\mathrm{J}_{\mathfrak{L}}$ and $1 \%$ increase in absolute efficiency of the Sitix multicrystalline cells. This increase in $\mathrm{J}_{2 c}$ is supported by the appreciable increase in the short wavelength response of the multicrystalline cells due to the oxide passivation (Figure 2.11). Dark I-V analysis in Figure 2.11 shows that the oxide passivation of these multicrystalline cells also reduced the $J_{01}$ by a factor of -2 . This combination of increased $I_{c}$ and reduced $\mathrm{J}_{01}$ should result in an increase of $18 \mathrm{mV}$ in $\mathrm{V}_{\propto \alpha}\left[\mathrm{V}_{\alpha c}=K T / q . \ln \left(\mathrm{J}_{\kappa \mathrm{c}} / \mathrm{J}_{0}+1\right)\right]$. This agrees fairly well with the observed increase of $16 \mathrm{mV}$ in $\mathrm{V}_{\mathrm{oc}}$. Thus oxide surface passivation can be quite beneficial in properly gettered high-lifetime multicrystalline cells. 


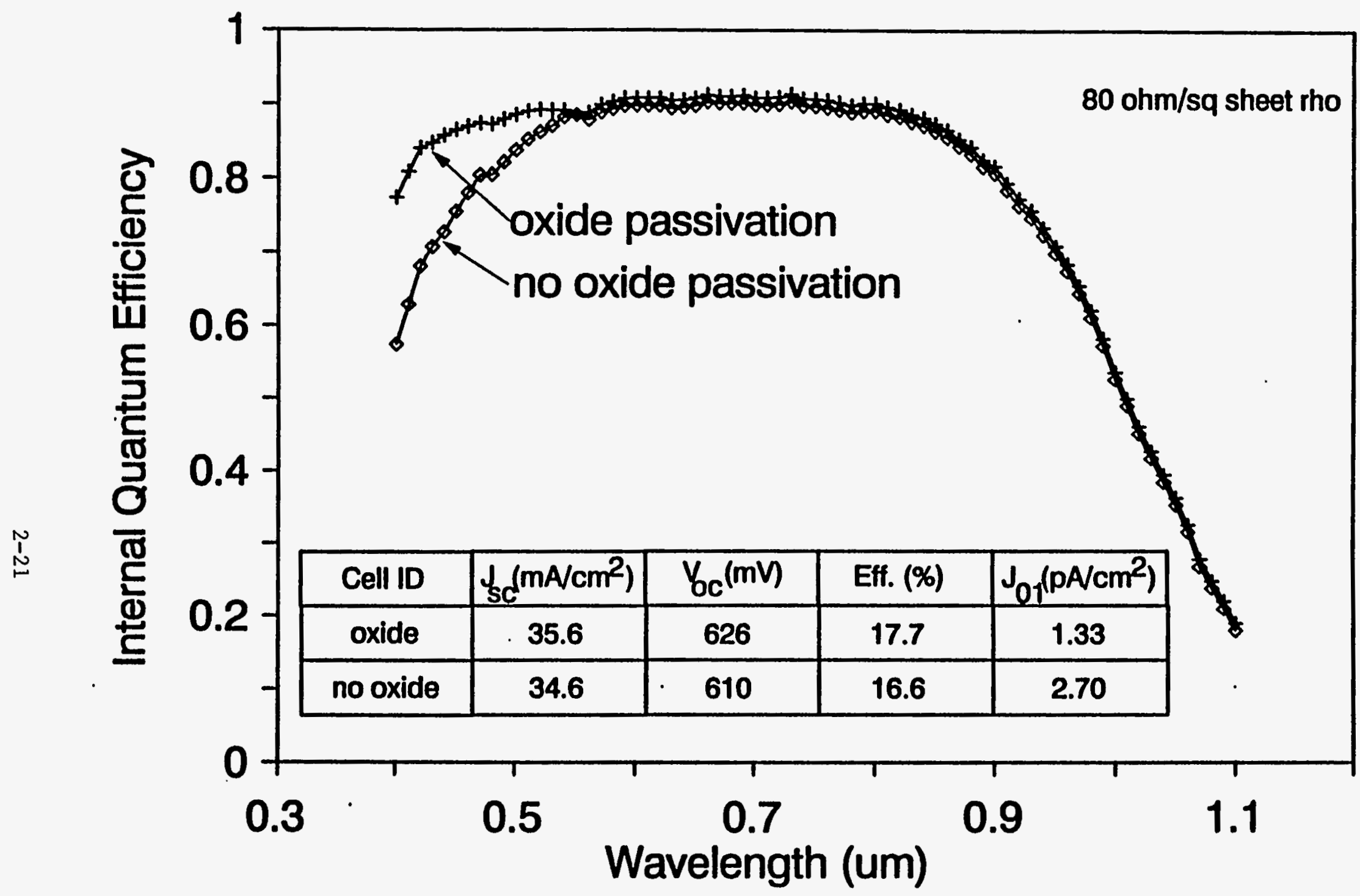

Figure 2.11. The effect of emitter oxide passivation on the multicrystalline silicon cell performance. 


\subsection{Bulk Defect Passivation by Forming Gas Anneal in Multicrystalline Silicon Cells}

Bulk defects, such as dislocations, grain boundaries etc., are an integral part of mc-Si. These defects are electrically active and provide sites for recombination of photogenerated carriers to reduce bulk lifetime and cell performance. Atomic hydrogen has been used successfully to passivate such defects. Forming gas, which contains $10 \%$ molecular hydrogen, can provide a source of atomic hydrogen if it can be dissociated. Therefore an attempt was made to use forming gas anneal (FGA) to passivate defects in this research. The process sequence in Figure 2.12 shows that we incorporated two forming gas treatments at $400^{\circ} \mathrm{C}$ in our cell fabrication, one directly after the $850^{\circ} \mathrm{C}$ Al drive-in step and the other after the Al back contact deposition. This was done intentionally to enhance the beneficial effect of FGA, phosphorus diffused region, $\mathrm{Al}$ metal, and $\mathrm{Al} / \mathrm{Si}$ alloy layers can assist in generating atomic hydrogen by interacting with the $10 \%$ molecular $\mathrm{H}_{2}$ in the forming gas. We selected EFG mc-Si, which is known to respond quite favorably to hydrogen passivation, to investigate the effect of FGA. In order to investigate and decouple the effects of $\mathrm{Al}$ gettering and FGA passivation in one experiment, we fabricated four kinds of cells. Figure 2.13 shows that incorporation of $\mathrm{Al}$ gettering treatment and first and second FGA for defect passivation resulted in an EFG cell efficiency of $\sim 13.8-14.1 \%$ [3], which is comparable to good EFG cells made by intentional hydrogen ion implantation [4]. If the $\mathrm{Al}$ diffusion is eliminated by fabricating $\mathrm{Al}$ sintered cells, then a significant drop in IQE and cell efficiency, from 13.8 to $12.4 \%$, is observed. This indicates that $\mathrm{Al}$ treatment-induced gettering alone improves the EFG cell efficiency by $\sim 1.5 \%$. Figure 2.13 shows that if the $\mathrm{Al}$ or alloyed $\mathrm{Al}$ layer interaction with forming gas is turned off by replacing the second FGA by nitrogen anneal in the case of sintered cells, then the IQE drops further and the EFG cell efficiency decreases from 12.4 to $11.2 \%$. 


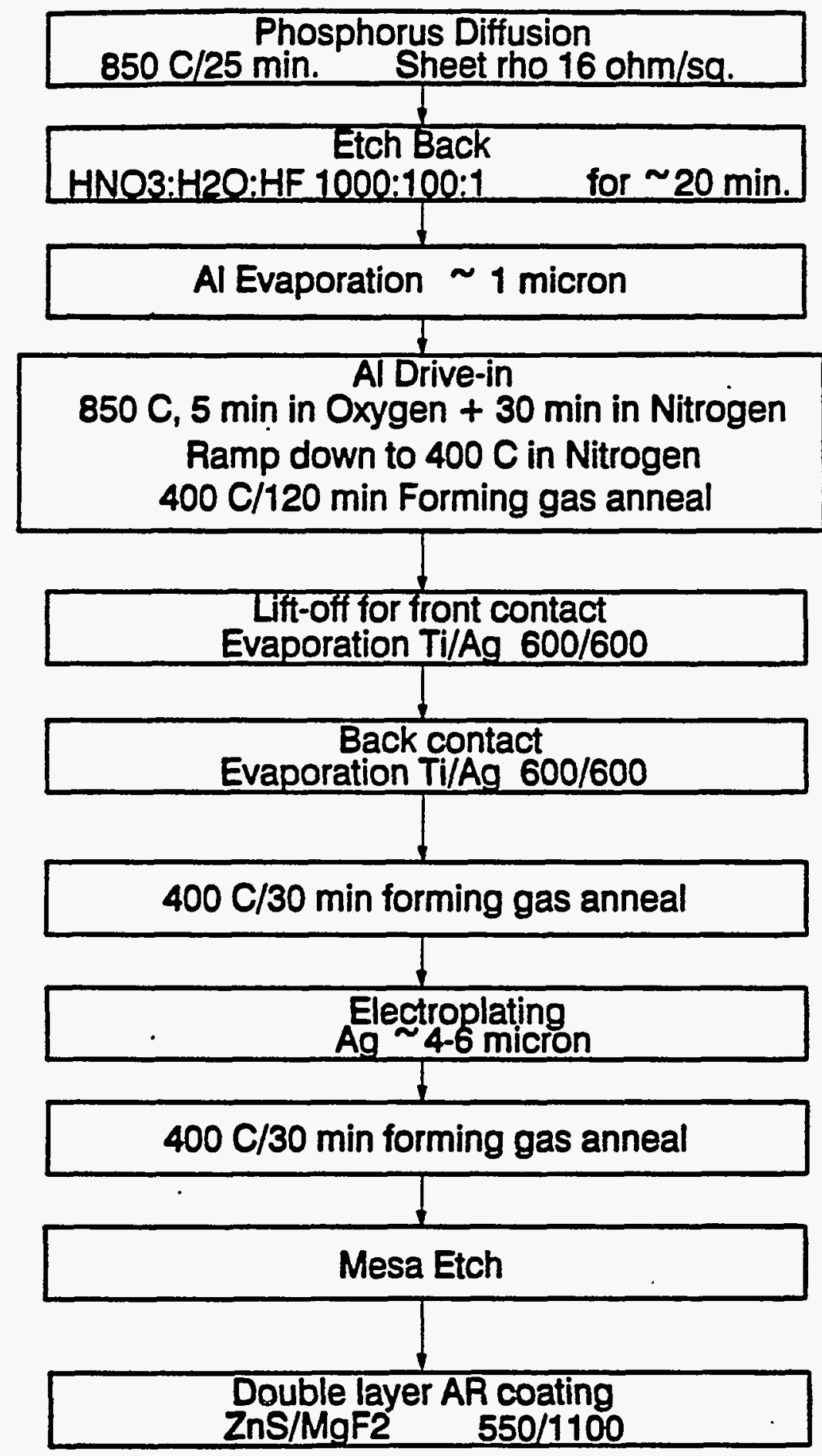

Figure 2.12. Process sequence for fabricating high-efficiency multicrystalline silicon solar cells. 


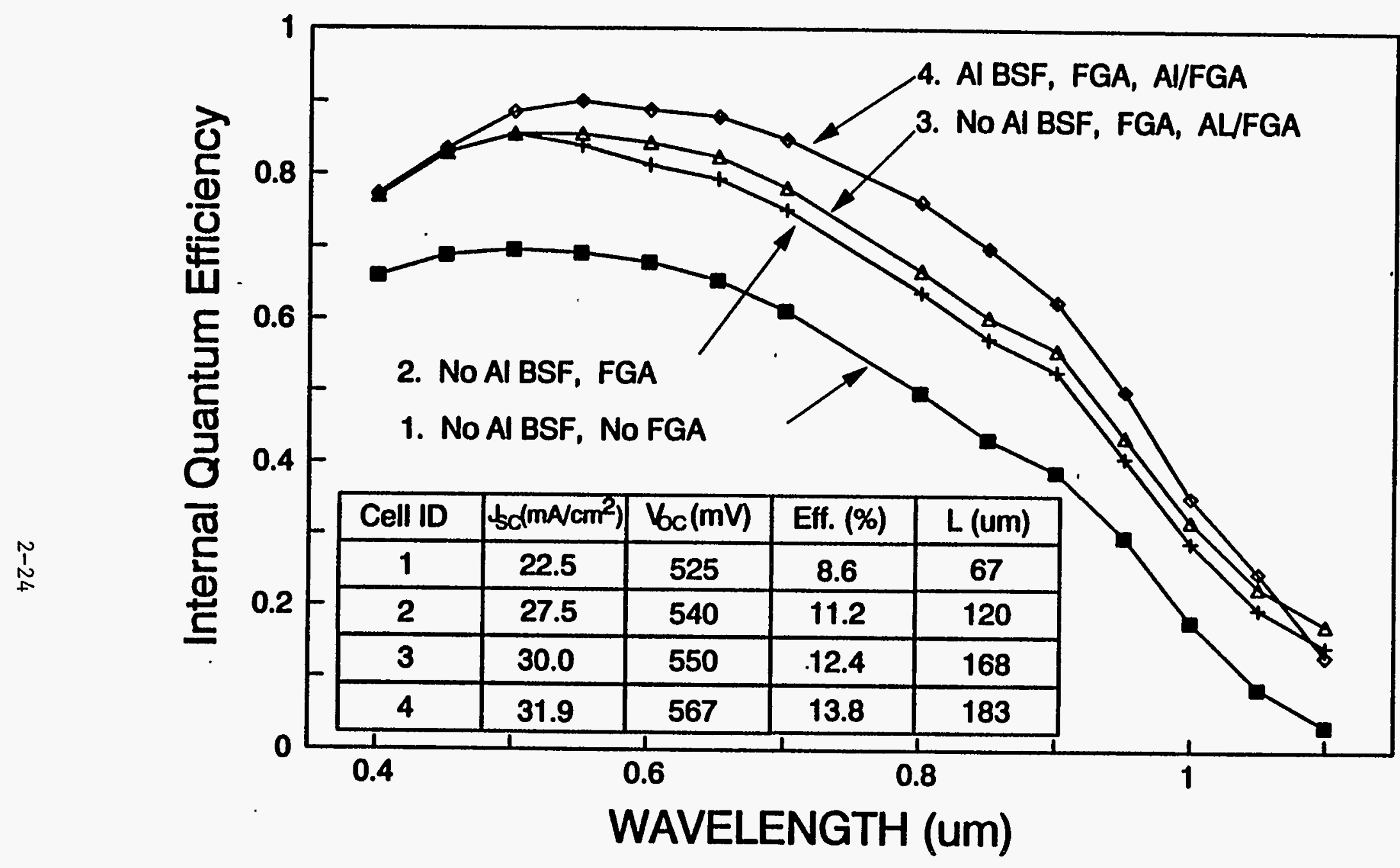

Figure 2.13. The effect of FGA and forming gas/Al on the performance of multictrystalline silicon solar cells. 
This suggests that $\mathrm{Al}$ or $\mathrm{Al}$ doped $\mathrm{p}^{+}$region/FGA interaction leads to some hydrogenation and defect passivation in the EFG material. Finally if both the $400^{\circ} \mathrm{C}$ forming gas anneals are replaced by nitrogen anneals, then the EFG cell efficiency drops significantly to $8.6 \%$, which indicates that the first FGA alone does significant defect passivation in the EFG material. Thus EFG material not only benefits from $\mathrm{Al}$ gettering but also from FGA-induced defect passivation.

In order to prove that the FGA-induced improvement is related to hydrogenation, after the $400^{\circ} \mathrm{C} / 2 \mathrm{hr} \mathrm{FGA}$, the temperature was raised to $600^{\circ} \mathrm{C}$ and the ambient gas was switched to nitrogen to drive out the incorporated hydrogen. Indeed it was found that the cell efficiency decreased from $14 \%$ to $10 \%$, shown in figure 2.14 , suggesting that hydrogen passivation is the most likely mechanism for the FGA effect.

In an attempt to further investigate the interaction of molecular hydrogen in forming gas with surface defects, $\mathrm{n}^{+}$and $\mathrm{p}^{+}$regions, a systematic study was conducted using EFG silicon without the cell fabrication. It was found that FGA alone increases the diffusion length of EFG silicon from 61 to $95 \mu \mathrm{m}, \mathrm{Al}$ diffusion alone increases it to $153 \mu \mathrm{m}$, and phosphorus diffusion alone increases the EFG diffusion length from $61 \mu \mathrm{m}$ to $173 \mu \mathrm{m}$ (Figure 2.15). However FGA after the phosphorus or Al diffusion results in much greater enhancement in diffusion length $(>300 \mu \mathrm{m})$, suggesting that FGA is not only beneficial by itself but in the presence of $\mathrm{Al}$ metal, $\mathrm{n}^{+}$, and $\mathrm{p}^{+}$regions, it becomes even more effective. This could be because surface defects, such as dislocations and grain boundaries, can dissociate molecular hydrogen into atomic hydrogen and provide paths for hydrogen diffusion into the bulk. This could explain why FGA by itself is so effective in defective mc-Si. Phosphorus and Al diffusions tend to create more surface defects, stress, and vacancies, which can increase the solubility of hydrogen and facilitate the formation of rapidly diffusing hydrogen-vacancy pairs near the surface [5]. This could explain why the FGA effect is magnified in the presence of $\mathrm{n}^{+}$ or $\mathrm{p}^{+}$regions. The exact mechanism behind the FGA-induced passivation is not yet fully understood. 


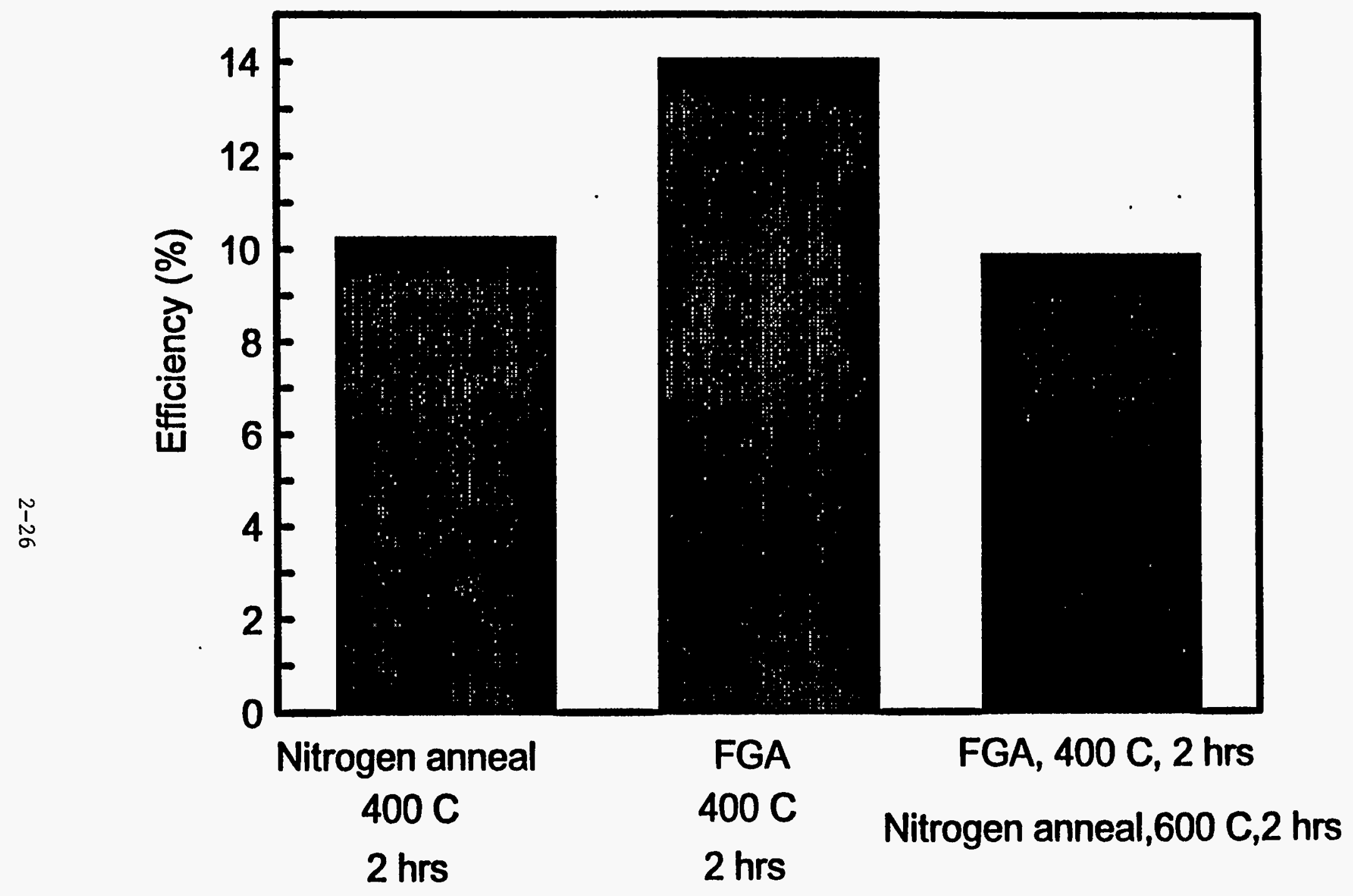

Figure 2.14. The effect of nitrogen anneal on the performance of forming gas annealed cells. 


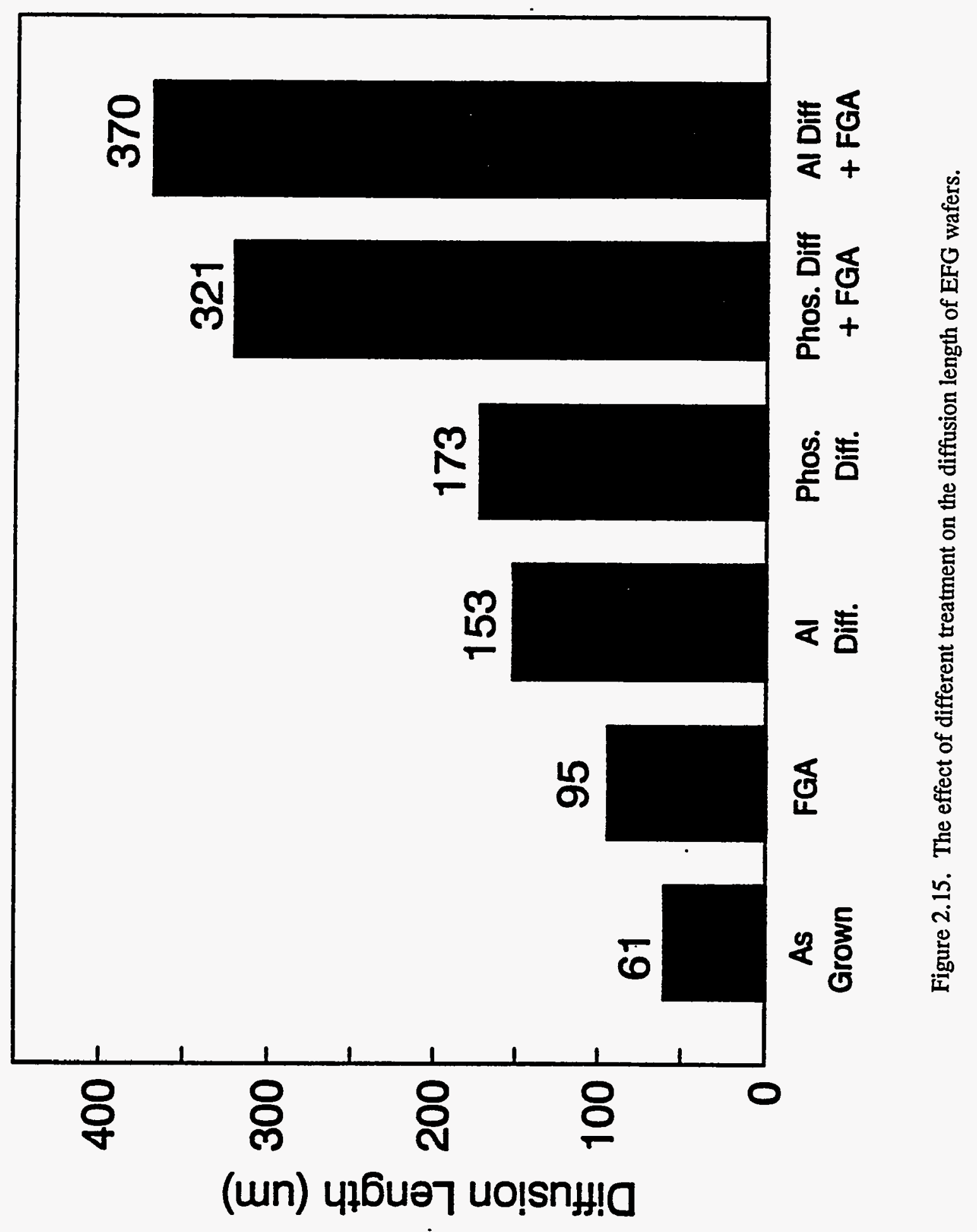


Figure 2.16 shows that defect passivation by FGA is highly material specific. In contrast to EFG cells, the forming gas treatment had virtually no effect $(<5 \%)$ on the Sitix and HEM cast multicrystalline silicon cells. This is probably because higher quality cast multicrystalline silicon materials do not have defects that can benefit from hydrogen passivation. However, in materials like EFG and AP-Si thin film, which consist of a high concentration of active dislocations or grain boundaries, FGA has a very significant effect on bulk diffusion length and cell performance, as seen in figure 2.17.

We have been trying to develop a physical model for hydrogen dissociation and diffusion. Based on the literature, $\mathrm{H}_{2}$ solubility in silicon at $400^{\circ} \mathrm{C}$ is very small, on the order of $10^{-16}, \mathrm{~cm}-3$. According to the literature, if $\mathrm{H}_{2}$ diffuses in silicon via an interstitial plus trapping mechanism, then it should not get beyond 1 or $2 \mu \mathrm{m}$ at $400^{\circ} \mathrm{C}$. However in mc-Si cells we see a substantial increase in long wavelength response. We think the FGA effect can be explained by the following model (Figure 2.18). First, both phosphorus and $\mathrm{Al}$ diffusion lead to stress and surface damage. Phosphorus diffusion introduces misfit dislocations, and Al treatment results in stress-induced voids and surface damage. It has been shown [6] that such surface damage can increase the solubility of molecular hydrogen by orders of magnitude.

Phosphorus and $\mathrm{Al}$ treatments also introduce near-surface defects like vacancies, interstitials and dislocations, which can dissociate molecular hydrogen [7] resulting in a huge source of atomic hydrogen. Mc-Si materials not only have vacancies to begin with but the $\mathrm{Al}$ and phosphorus diffusions also generate vacancies near the surface, and this enhances the possibility of formation of $\mathrm{H}-\mathrm{V}$ pairs that can diffuse in silicon more rapidly than interstitial hydrogen. This explains why we see FGA defect passivation so deep in the bulk. At this point this explanation is just a hypothesis, and more work needs to be done in this area to prove or disaprove it. 


\subsection{Fabrication of Record High-Efficiency Multicrystalline Silicon Solar Cells}

After developing, optimizing, and improving the fundamental understanding of the above gettering and passivation techniques, we designed and fabricated high-efficiency mc-Si cells by integrating these techniques in a process sequence. Attempts were made to fabricate $1 \mathrm{~cm} \times 1 \mathrm{~cm}$ highefficiency multicrystalline solar cells using the optimized phosphorus and aluminum gettering conditions, oxide passivation, $\mathrm{FGA}$, and an evaporated double layer $\mathrm{ZnS} / \mathrm{MgF}_{2}$ antireflection coating. Sitix silicon was selected for this task, since it was one of the best mc-Si available at that time. Figure 2.19 shows the model calculations for a $400 \mu \mathrm{m}$ thick $\mathrm{n}^{+}-\mathrm{p}-\mathrm{p}^{+}$silicon cell, with a junction depth of $\sim 0.5 \mu \mathrm{m}$, a BSF thickness of $\sim 1.5 \mu \mathrm{m}$, and a two layer AR coating. Notice that in order to achieve high- efficiency ( $>17 \%$ ) cells, a bulk lifetime of more than $20 \mu$ s is required. Bulk lifetime in the as-grown Sitix material is only 6-10 $\mu \mathrm{s}$. Thus, gettering and passivation techniques will have to play a significant role to achieve the high-efficiency record. First $30-40 \mu \mathrm{m}$ silicon was removed from each side by a chemical etch in order to remove the saw damage from the as-received multicrystalline wafers. After the chemical polishing, the substrate thickness was reduced to about $400 \mu \mathrm{m}$. The emitter region was formed by $930^{\circ} \mathrm{C} / 25 \mathrm{~min}$ phosphorus diffusion followed by an etch-back to $80 \Omega / \square$. Then $850^{\circ} \mathrm{C}$ oxide passivation and $\mathrm{Al}$ drive-in were performed. As shown in the previous sections, these treatments not only constitute the best phosphorus and Al gettering conditions but also give desired $\mathrm{n}^{+}$and $\dot{\mathrm{p}}$ regions with 0.5 and $1.5 \mu \mathrm{m}$ thickness, respectively. The front grid contact was formed by evaporation of Titanium/Silver $(600 \AA / 600 \AA)$ and the lift-off technique. The back contact was formed by evaporating $500 \AA \mathrm{Ti} / 500 \AA \mathrm{Ag}$ on the top of the Al BSF region. Contacts were annealed in a forming gas ambient for 30 minutes at $400^{\circ} \mathrm{C}$. About $5 \mu \mathrm{m}$ thick silver was plated on the front grid pattern to reduce the series resistance. Finally, a $550 \AA \mathrm{ZnS} / 1100 \AA \mathrm{MgF}_{2}$ double layer AR coating was deposited by thermal evaporation on the 


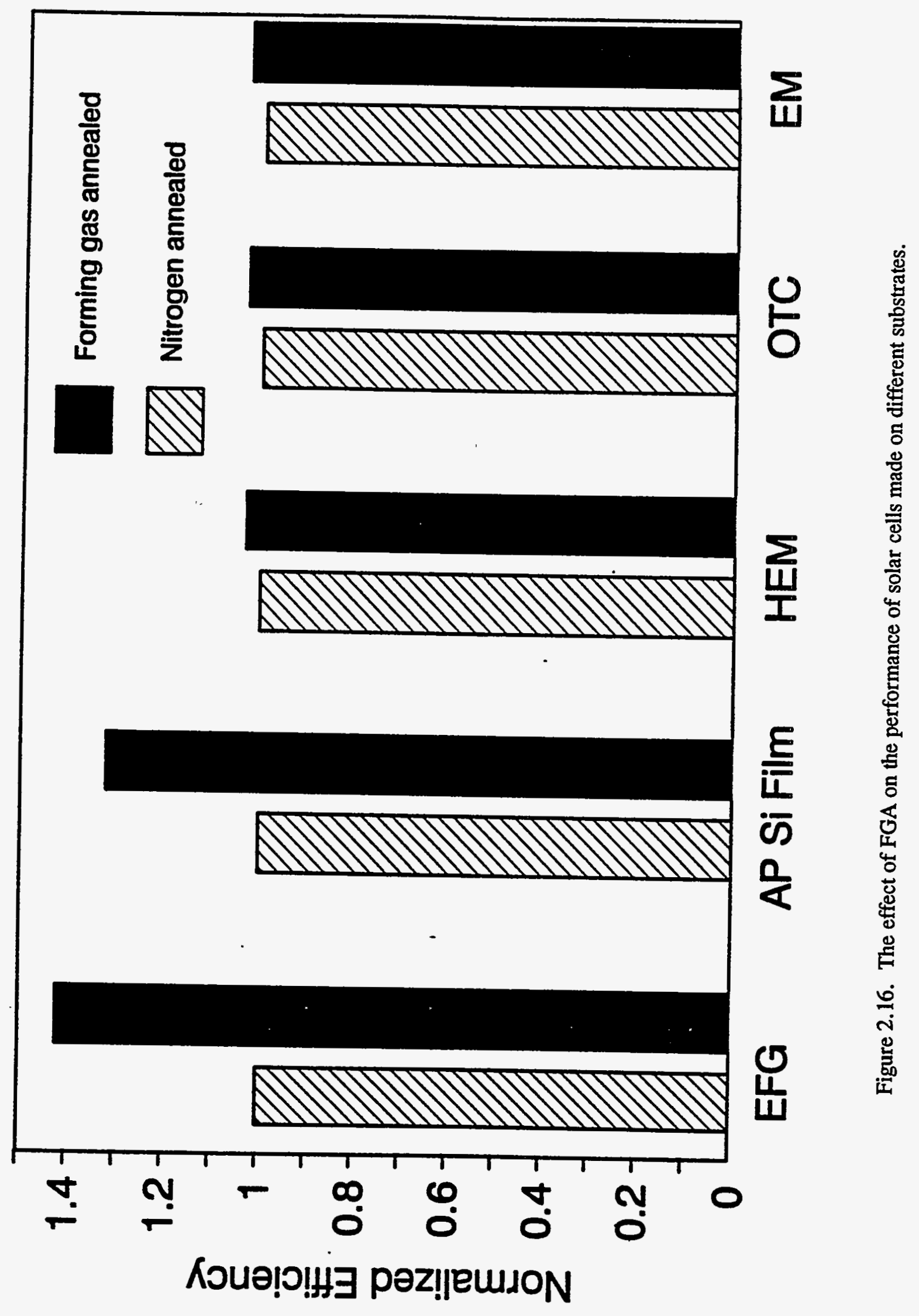



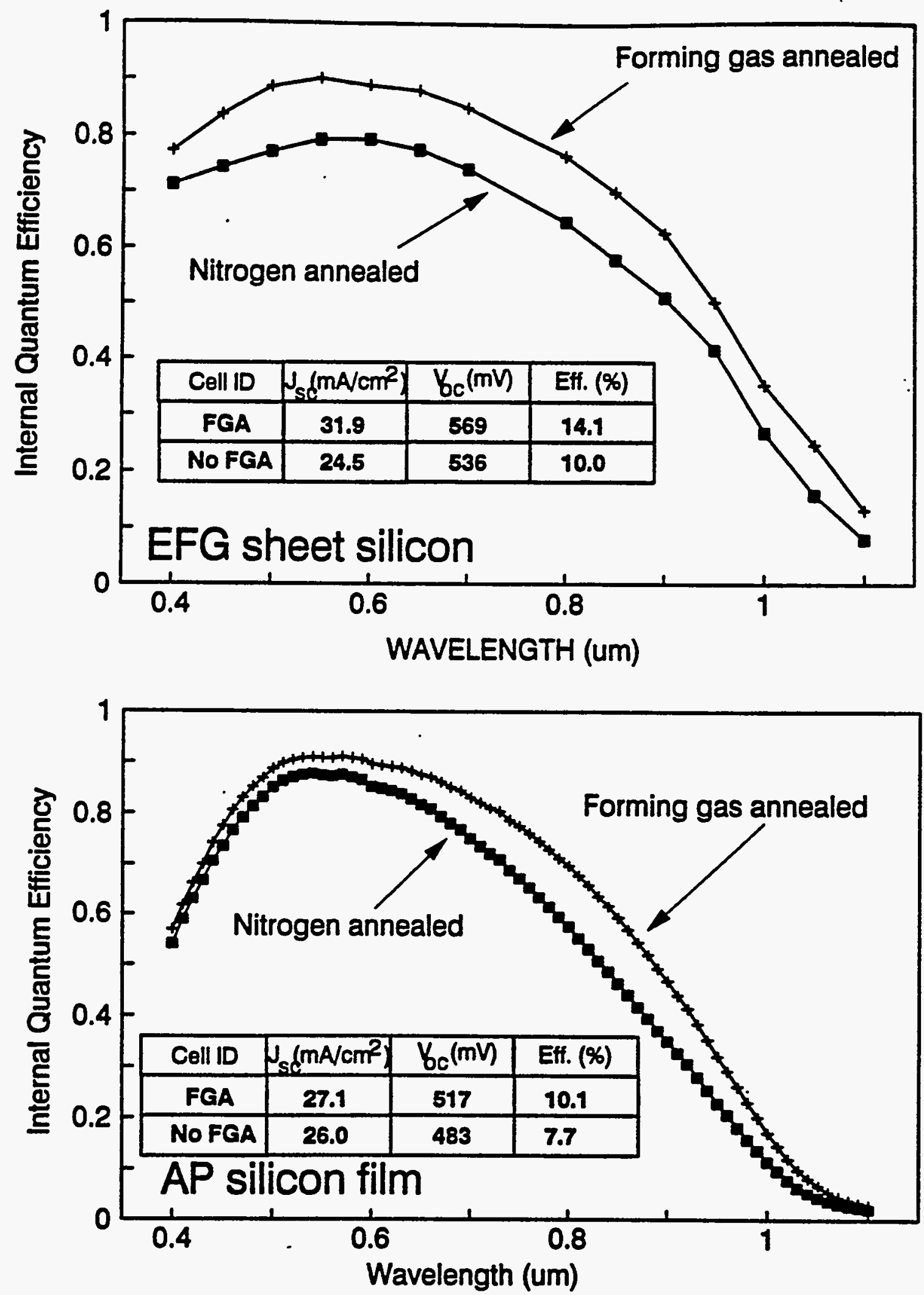

Figure 2.17. The effect of FGA on EFG Sheet ribbon and AP thin film silicon. 


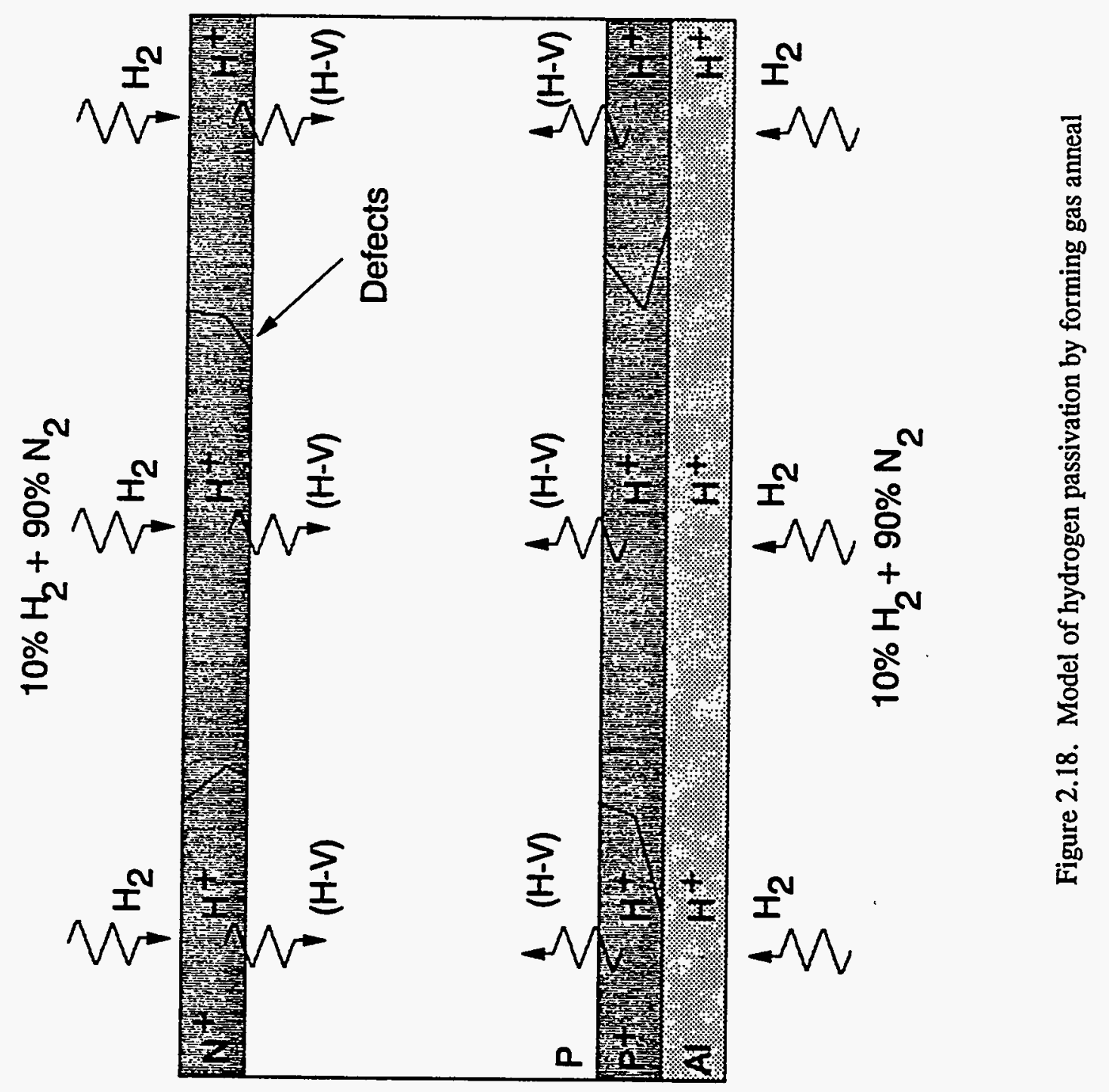


thermal evaporation on the cells. Figure 2.20 shows that the optimized process sequence indeed resulted in a record high efficiency of $17.8 \%$ for a mc-Si cell (tested and verified by Sandia) with $V_{\infty}$ of $628 \mathrm{mV}$ and $\mathrm{J}_{\mathrm{kc}}$ of $36.2 \mathrm{~mA} / \mathrm{cm}^{2}$. Dark I-V analysis gave a reverse saturation current density of $1.33 \times 10^{-12} \mathrm{~A} / \mathrm{cm}^{2}$ and a series resistance of $0.45 \Omega-\mathrm{cm}^{2}$. Open circuit voltage decay (OCVD) lifetime measurements gave an effective carrier lifetime of $32 \mu \mathrm{s}$ measured at $\mathrm{V}_{\infty}$, which is quite respectable for such low resistivity $(0.8 \Omega-\mathrm{cm})$ multicrystalline silicon. As shown in section 2.1 , without the optimized gettering conditions, passivation, and cell design, we were able to achieve only $14.8 \%$ efficient cells on this material. Figure 2.20 also shows the reflectance and internal quantum efficiency of the $17.8 \%$ efficient cell. Table 2.4 shows all the mcs cells we have fabricated so far with efficiencies greater than $17 \%$. It should also be recognized that an optimum process sequence for multicrystalline silicon may be material specific because of the large variation in the material quality, grain size, and impurity and defect content of multicrystalline materials.

It should be noted that the efficiency distribution (Figure 2.21 ) was in the range of $16.8 \%$ $17.8 \%$ (tested and verified at Sandia). This difference in cell efficiency is partly due to nonuniform defect distribution in the Sitix mc-Si material. Figure 2.21 also shows the efficiency distribution on the wafer that produced a $\mathbf{1 7 . 7 \%}$ efficient cell (all tested at NREL). 
Table 2.4. High-efficiency multicrystalline silicon solar cells fabricated at Georgia Tech

\begin{tabular}{|c|c|c|c|c|c|c|}
\hline Cell ID & Substrate & $\mathrm{J}_{\mathrm{se}}\left(\mathrm{mA} / \mathrm{cm}^{2}\right)$ & $V_{o c}(m v)$ & $\mathrm{FF}$ & Efficiency (\%) & Measured at \\
\hline OPS-21 & OTC & 36.2 & 628 & 0.785 & 17.8 & Sandia \\
\hline GIT125-23 & OTC & 35.6 & 626 & 0.792 & 17.7 & NREL \\
\hline OPS-31 & OTC & 36.0 & 626 & 0.783 & 17.6 & Georgia Tech \\
\hline OPS-13 & OTC & 35.7 & 626 & 0.783 & 17.5 & Sandia \\
\hline GITCS205 & OTC & 35.7 & 612 & 0.800 & 17.5 & NREL \\
\hline GITCS106 & HEM & 36.2 & 614 & 0.782 & 17.4 & NREL \\
\hline NPS1-24 & OTC & 34.5 & 629 & 0.801 & 17.4 & Sandia \\
\hline OPS-12 & OTC & 35.6 & 625 & 0.782 & 17.4 & Georgia Tech \\
\hline OPS-11 & OTC & 35.6 & 625 & 0.781 & 17.4 & Georgia Tech \\
\hline GITCS110 & HEM & 35.9 & 613 & 0.791 & 17.4 & NREL \\
\hline GITCS207 & OTC & 35.0 & 615 & 0.805 & 17.3 & NREL \\
\hline GITCS108 & HEM & 34.7 & 618 & 0.802 & 17.3 & NREL \\
\hline GITCS109 & HEM & 35.9 & 616 & 0.782 & 17.3 & Georgia Tech \\
\hline GITCS101 & HEM & 35.7 & 613 & 0.790 & 17.3 & Georgia Tech \\
\hline GITCS203 & OTC & 34.9 & 615 & 0.803 & 17.2 & Georgia Tech \\
\hline GITCS111 & HEM & 35.8 & 615 & 0.781 & 17.2 & Georgia Tech \\
\hline NPS2-12 & OTC & 34.8 & 627 & 0.790 & 17.2 & Sandia \\
\hline OPS-22 & OTC & 35.4 & 621 & 0.781 & 17.2 & Georgia Tech \\
\hline GT125-43 & OTC & 34.8 & 627 & 0.790 & 17.2 & Sandia \\
\hline GITCS111 & HEM & 35.8 & 615 & 0.781 & 17.2 & NREL \\
\hline GITCS210 & OTC & 35.1 & 614 & 0.798 & 17.2 & NREL \\
\hline GITCS214 & OTC & 35.2 & 614 & 0.798 & 17.2 & NREL \\
\hline GIT225 & HEM & 34.3 & 626 & 0.790 & 17.0 & Sandia \\
\hline NPS2-24 & OTC & 34.7 & 622 & 0.786 & 17.0 & Sandia \\
\hline GITCS206 & OTC & 33.5 & 612 & 0.783 & 17.0 & Georgia Tech \\
\hline GITCS208 & OTC & 34.8 & 611 & 0.796 & 17.0 & Georgia Tech \\
\hline STPS3-32 & OTC & 34.9 & 622 & 0.782 & 17.0 & Sandia \\
\hline OPS-32 & OTC & 35.4 & 622 & 0.771 & 17.0 & Georgia Tech \\
\hline
\end{tabular}




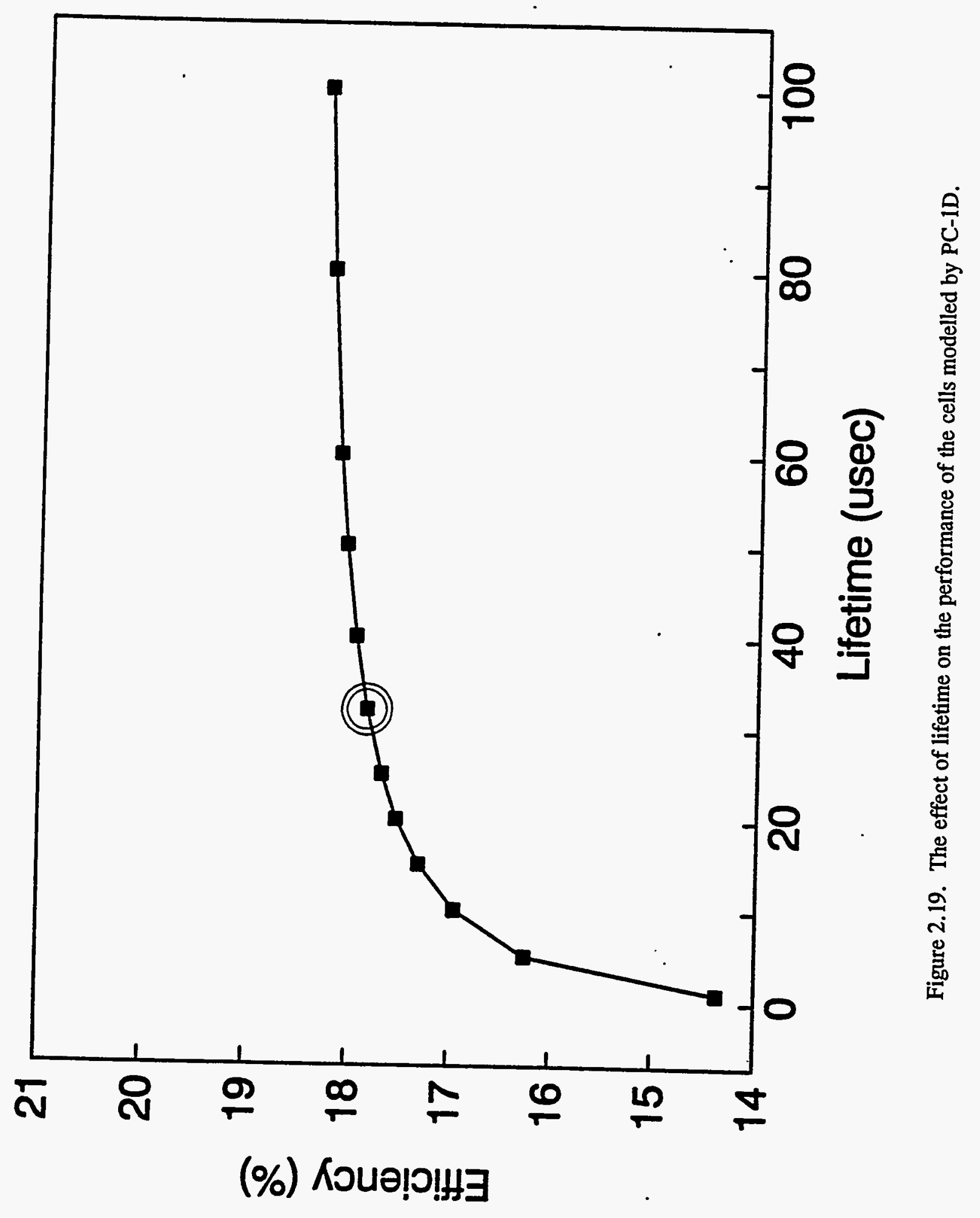




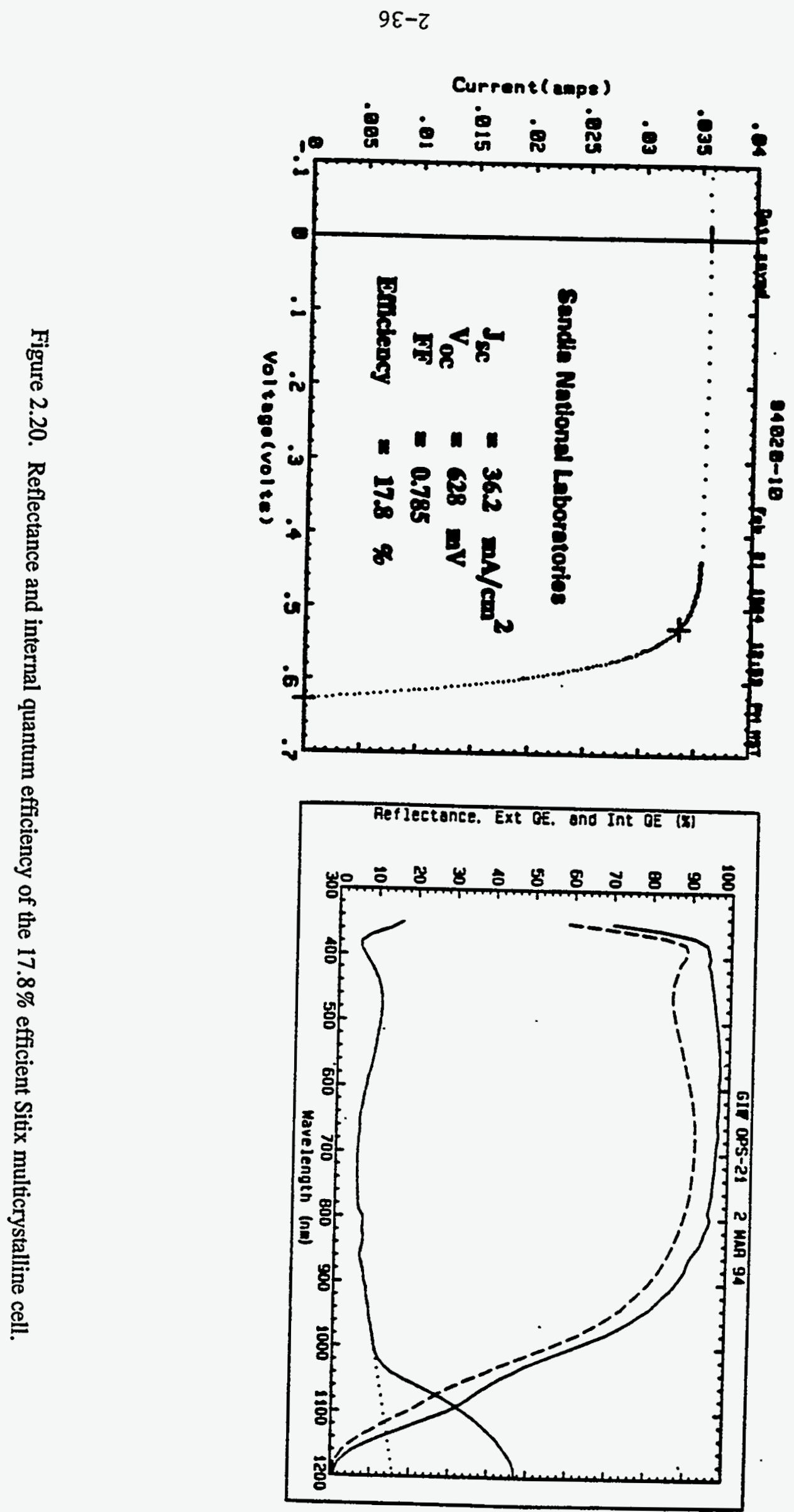



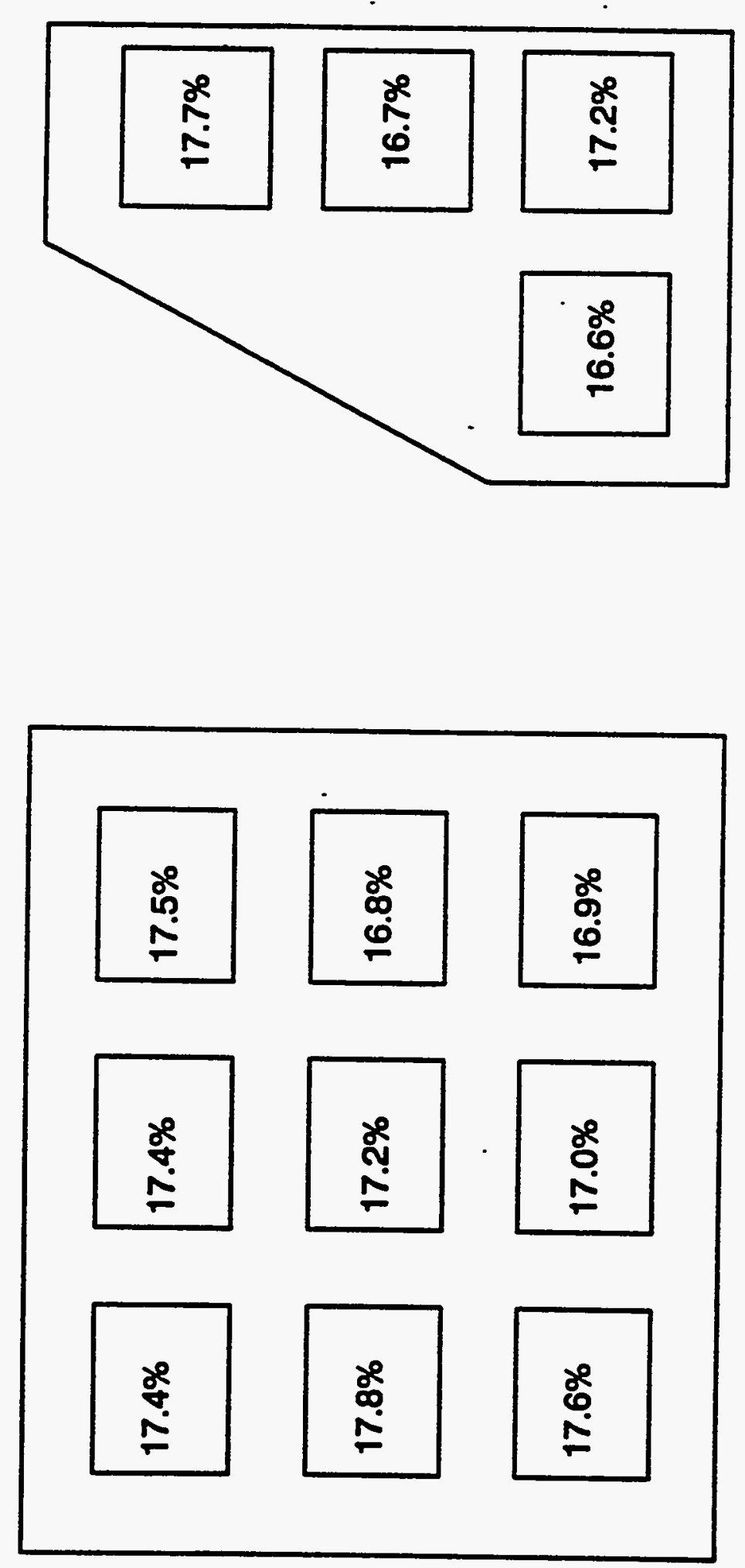

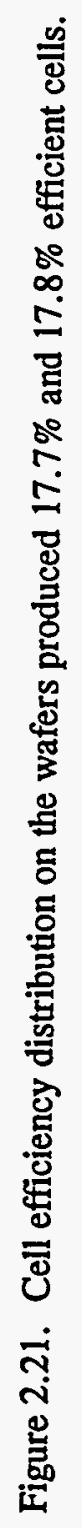




\subsection{Detailed Characterizations and Analysis to Model the Performance of the Record High Efficiency Multicrystalline Silicon Solar Cell}

Solar cell modeling and characterization were performed to match the performance of the best cells obtained in this study and to provide guidelines for achieving greater than $20 \%$ efficient cells. Solar cell efficiency calculations were performed using the PC-1D model [8] in a mode that allows external input files for the doping profile and front surface reflectance. PC-1D is a software package for personal computers that uses finite-element, drift-diffusion analysis to solve the fully-coupled, two-carrier, semiconductor transport equations in one dimension [9]. Grain boundary defects and effects were ignored. Instead the measured bulk diffusion length was used as the input to assess whether grain boundary or intragrain defects dominate the cell performance. A good match between the measured and calculated cell parameters and IQE would suggest that intragrain defects dominate it. A significant mismatch would indicate the importance/dominance of grain boundary defects on the cells. Model calculations were performed to match the performance of the $17.8 \%$ efficient cell using the PC-1D program with the input parameters shown in Table 2.5. Figure 2.22 shows that the model calculations are in reasonably good agreement with the experimentally measured cell parameters, in spite of ignoring the grain boundary defects and effects. Figure 2.22 shows a very good match between the measured and calculated IQE for the $17.8 \%$ efficient cell. A measured OCVD effective bulk lifetime of $32 \mu \mathrm{s}$ was used in the model calculation. This indicates that in properly-gettered, large-grain multicrystalline cells, intragrain defects are probably more important than the grain boundary defects in dictating the cell performance. 


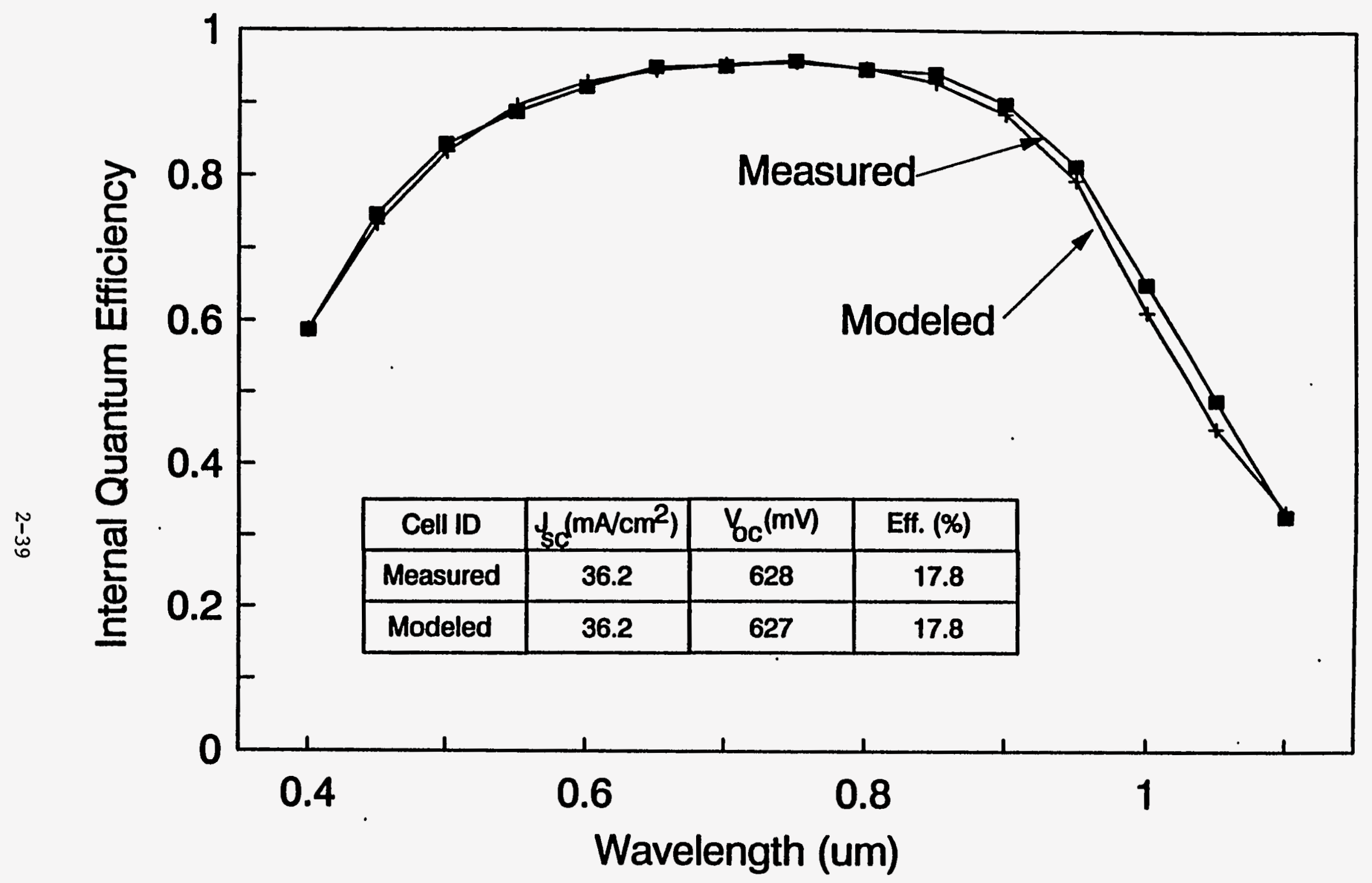

Figure 2.22. Comparison of the calculated and measured cell parameters and IQE for the high efficiency multicrystalline silicon cell. 


\subsection{Guidelines for Achieving 20\% Efficient MC-Si Cells}

After matching the measured cell parameters of the $17.8 \%$ efficient multicrystalline cell, attempts were made to change the cell design and material properties, such as $\mathrm{R}_{\text {zeries, }}$ cell thickness, front and back SRV, BSF thickness, lifetime, and surface texturing, to provide guidelines for achieving even higher efficiencies. Table 2.6 shows quantitatively the effect of changing some of the design parameters on the performance of the cell. Table 2.6 shows that a change in FSRV has very little effect on the cell efficiency for this cell structure. An increase in the carrier lifetime from 32 to $100 \mu \mathrm{sec}$ increases the absolute efficiency by $0.5 \%$ (case $\mathrm{d}$ ) for this cell design with $\sim 1.5 \mu \mathrm{m}$ deep unpassivated BSF. Therefore additional gettering will not do much for this cell unless the BSF or BSRV are improved. Figure 2.23 shows that initial gettering was very important for this cell, because the efficiency increases rapidly with lifetime ( $\tau$ ) up to a lifetime value of about $40 \mu \mathrm{s}$. Beyond $\tau=40 \mu \mathrm{s}$, relative improvement in cell efficiency becomes very small. Model calculations show that even with the increase in the bulk lifetime value up to $1 \mathrm{~ms}$, an efficiency of only $18.5 \%$ can be realized with this cell structure. Since $\mathrm{J}_{01}$ is dominated by base or $\mathrm{I}_{6 b}$ in this cell, reduced FSRV from 6000 to $50 \mathrm{~cm} / \mathrm{sec}$ also has very little effect on the performance of this cell (case b). However a significant gain in the performance, from $17.8 \%$ to $18.5 \%$, can be realized by reducing the BSRV alone from $10^{6}$ to $500 \mathrm{~cm} / \mathrm{sec}$ by growing a passivating oxide on the back surface (case $\mathrm{g}$ ). Similarly surface texturing alone (case f), using slats or grooves with a pitch of $100 \mu \mathrm{m}$ and slat angle of $60^{\circ}$, can also raise the efficiency of this cell to $18.5 \%$ (Figure 2.23). Such surface texturing can be achieved by a dicing machine [10], [11] or laser grooving [12]. A combination of reduced BSRV and front surface texturing can produce $19.1 \%$ efficient cells (case h). Finally a combination of texturing, reduced BSRV, and increase in lifetime up to $100 \mu$ s can raise the efficiency of the cell to $20.2 \%$ (case i). It should be noted that there could be some inaccuracy in the absolute values of 
Table 2.5. Input parameters to PC-1D for model calculations

- Cell area of $1 \mathrm{~cm}^{2}$.

- Cell thickness of $400 \mu \mathrm{m}$.

- p-type base with resistivity of $0.8 \Omega-\mathrm{cm}$.

- External doping file, $16 \Omega / \square$ Erfc doping etched to $80 \Omega / \square$ sheet resistance, junction depth of $\sim 0.5 \mu \mathrm{m}$.

- Erfc doping profile with surface concentration of $5 \times 10^{18} \mathrm{~cm}^{-2}$ for ${ }^{-1.5}$ $\mu \mathrm{m}$ thick Al BSF

- Measured bulk lifetime of $32 \mu$ s.

- FSRV of $6000 \mathrm{~cm} / \mathrm{s}$.

- BSRV of $10^{6} \mathrm{~cm} / \mathrm{s}$ at metal-silicon contact.

- Measured $\mathrm{J}_{02}$ of $4.37 \times 10^{-7} \mathrm{~A} / \mathrm{cm}^{2}$ and ideality factor of 2.8 .

- Measured series resistance of $0.45 \Omega-\mathrm{cm}^{2}$.

- External input file for the measured front surface reflectance.

- $\quad 75 \%$ efficient back surface reflectance.

- $81 \%$ front internal reflectance.

- Flat front and textured back surface.

- Spectrum AM1.5 Global. 
Table 2.6. Modeling the effect of selected design parameters on performance of the $17.8 \%$ efficient cell

\begin{tabular}{|c|c|c|c|c|}
\hline Changed Parameters & $\begin{array}{c}\mathrm{J}_{\mathfrak{x c}} \\
\left(\mathrm{MA} / \mathrm{cm}^{2}\right) \\
\end{array}$ & $\begin{array}{l}\mathrm{V}_{\infty} \\
(\mathrm{mV}) \\
\end{array}$ & FF & $\begin{array}{r}\text { Efficiency } \\
(\%) \\
\end{array}$ \\
\hline a: Cell thickness $=250 \mu \mathrm{m}$ & 36.9 & 636 & 0.785 & 18.4 \\
\hline b: FSRV $=50 \mathrm{~cm} / \mathrm{sec}$ & 36.5 & 629 & 0.785 & 18.0 \\
\hline c: $R_{\text {series }}=0.1 \Omega-\mathrm{cm}^{2}$ & 36.2 & 627 & 0.809 & 18.4 \\
\hline d: Lifetime $(\tau)=100 \mu \mathrm{s}$ & 36.7 & 634 & 0.785 & 18.3 \\
\hline e: BSF thickness $=10 \mu \mathrm{m}$ & 36.7 & 631 & 0.788 & 18.2 \\
\hline f: Front surface texturing & 38.2 & 618 & 0.784 & 18.5 \\
\hline $\mathrm{g}: \mathrm{BSRV}=500 \mathrm{~cm} / \mathrm{sec}$ & 37.2 & 634 & 0.785 & 18.5 \\
\hline $\begin{array}{l}\text { h: Front surface texturing and Reduced } \\
\qquad \text { BSRV }(f+g)\end{array}$ & 39.0 & 624 & 0.785 & 19.1 \\
\hline $\begin{array}{l}\text { i: Lifetime of } 100 \mu \mathrm{sec}, \text { Front surface } \\
\text { texturing, and Reduced BSRV }(\mathrm{d}+\mathrm{f}+\mathrm{g})\end{array}$ & 40.0 & 644 & 0.784 & 20.2 \\
\hline
\end{tabular}




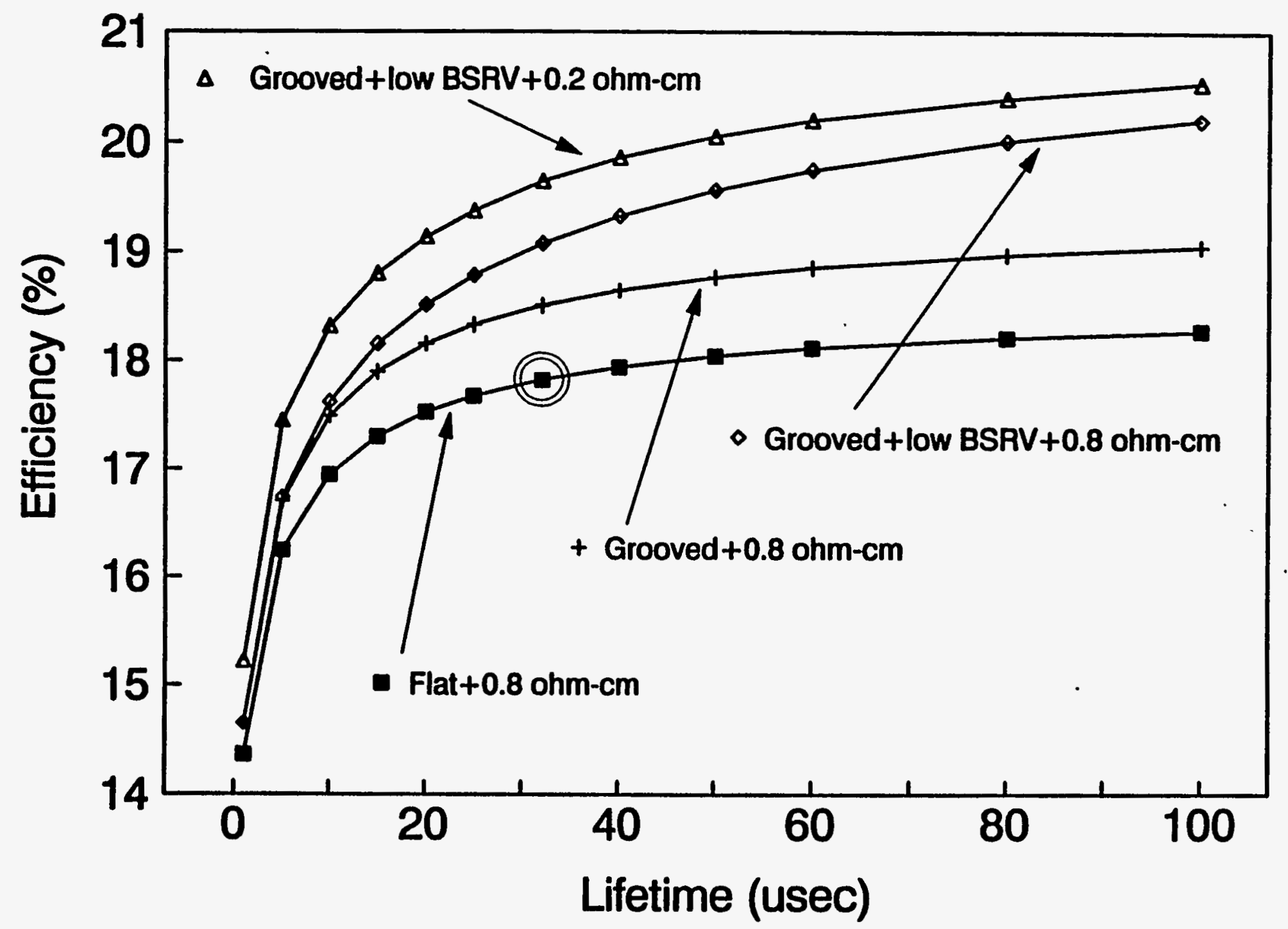

Figure 2.23. The effects of lifetime and surface texturing on multicrystalline cell performance. 
the calculated cell parameters due to assumptions; nevertheless, these model calculations provide useful guidelines for achieving $20 \%$ efficient multicrystalline silicon cells

\subsection{Surface Texturing of MC-Si Wafer for Light Trapping}

We have shown [13] that multicrystalline silicon solar cells with efficiencies close to $18 \%$ can be achieved on cast material by a combination of improvement in casting technology and in cell fabrication process. For highly efficient crystalline silicon solar cell devices some form of surface texturization has to be implemented in order to enhance the optical path length within the material and to reduce the reflection losses. Different light trapping schemes have been developed for monocrystalline silicon solar cells using a combination of photolithography and anisotropic alkaline etching relies on the regular crystallographic structure of the crystalline silicon to improve single crystalline cell performance. Regular inverted pyramids [14], random texturing and V-grooves are some examples of successful texturing schemes for single crystalline silicon. Pyramidal or grooved microstructures are composed of facets of $<111\rangle$ crystallographic planes. In multicrystalline silicon, the above the methods are rather ineffective due to the irregular distribution of crystal orientations. The overall spectral reflectance for a multicrystalline substrate after anisotropic alkaline etching is not as good because the substrates has grains with different crystal orientations. Due to the lack of a cost- effective texturing process, commercial multicrystalline silicon wafers are often lightly textured by chemical etching prior to cell processing and antireflection coating. Therefore, there is a strong need for an orientation-independent, cost-effective and efficient texturing method that can be implemented in an industrial environment.

Several approaches for texturing multicrystalline silicon wafers have been considered but none are suitable for commercial production at this time because of perceived development and/or 
processing costs. Laser-beam texturing [15] is costly and requires a high-energy laser and long exposure time. Reactive ion etching has been used to texture multicrystalline silicon wafers with an oxide mask. Results have been promising, producing $20 \%$ more short-circuit current. This etching process is suitable for large-scale production, however the mask is formed photolithographically and requires additional processing steps. For the purpose of reducing the surface reflectance and introducing light trapping in multicrystalline silicon solar cells, several investigators have recently begun to use a dicing machine for mechanical grooving of the multicrystalline silicon substrate. This technique offers maximum flexibility for changing groove depth, shape and pitch. It provides very good antireflection and light trapping properties and is independent of the structural quality of the starting material.

We have made some attempts to mechanically groove mc-Si by a dicing saw. The average integrating sphere measurements on an uncoated wafer with $200 \mu \mathrm{m}$ depth grooves and $100 \mu \mathrm{m}$ spacing gave a reflectance of $3.8 \%$ (from 400 to $1100 \mathrm{~nm}$ ), which represents the lowest reflectance reported to date on uncoated multicrystalline silicon. The minimum reflectance for this sample was $3.3 \%$ at $770 \mathrm{~nm}$. After, using a double layer $\mathrm{ZnS} / \mathrm{MgF}_{2}$ antireflection coating, the average reflectance went down to $1.5 \%$, with a minimum of $0.87 \%$ at $540 \mathrm{~nm}$ (Figure 2-24). Because of the very low reflectance of an uncoated grooved wafer, a double-layer AR coating does not show a significant improvement. Instead we found that a single-layer $\mathrm{AR}$ coating $\left(\mathrm{SiO}_{2}\right.$ or $\left.\mathrm{SiN}\right)$ results in almost the same reflectance as a double-layer coating on these grooved samples. Because of the high surface recombination velocity of the grooved surface, a single-layer $\mathrm{SiO}_{2}$ or $\mathrm{SiN} \mathrm{AR}$ coating may be more advantageous due to better surface passivation characteristics (which is crucial in grooved cells).

In conclusion, a new mechanical texturing scheme with a conventional blade followed by a chemical etching resulted in the record-low average reflectance of $3.8 \%$ on bare-grooved- 
multicrystalline silicon. Such low reflectance allows the use of a thick $\mathrm{SiO}_{2}$ single-layer $\mathrm{AR}$ coating, which can be more beneficial for grooved multicrystalline cells because of its lower surface recombination velocity. 


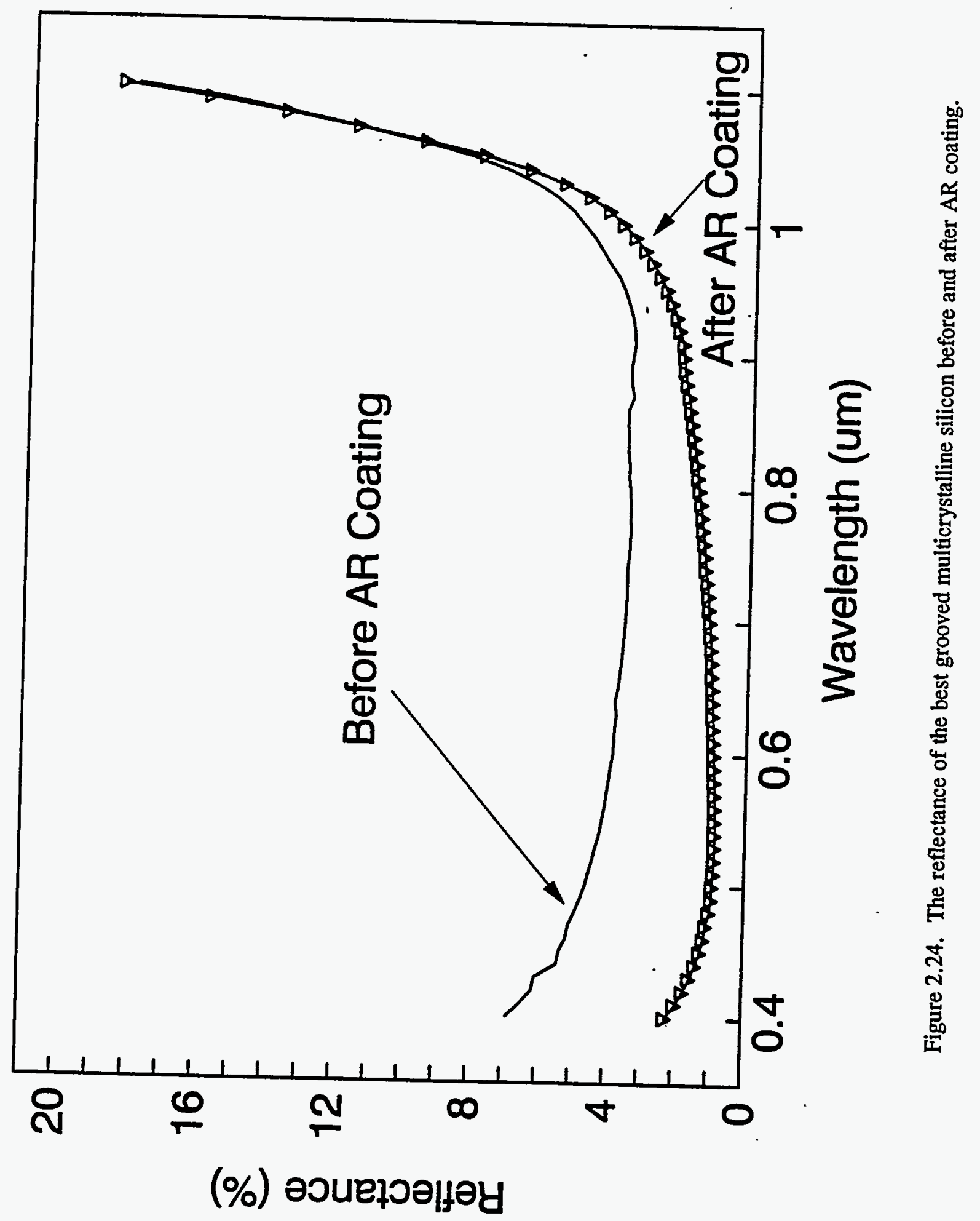




\subsection{Endnotes}

1. S. Martinuzzi, H. El Ghitani, D. Sarti, and P. Torchio, "Influence of phosphorus external gettering on recombination activity and passivation of defects in polycrystalline silicon," in Proceedings of the 20th IEEE Photovoltaics Specialists Conference, (1988), pp. 1575-1678.

2. W. Schroter and R. Kuhnapfel, "Model describing phosphorus diffusion gettering of transition elements in silicon," Applied Physics Letters, vol. 56, (1990):, pp. 2207-2209

3. P. Sana, A. Rohatgi, J. P. Kalejs, and R. O. Bell, " Gettering and hydrogen passivation of edge-defined film-fed grown multicrystalline silicon solar cells by Al diffusion and forming gas anneal", Applied Physics Letters, vol. 1, no. 64, pp. 97-99, 1994.

4. P. Sana, A. Rohatgi, J. P. Kalejs, and R. O. Bell, "The effect of aluminum treatment and forming gas anneal on EFG silicon solar cells", in Proceeding of 23rd IEEE Photovoltaic Specialist Conf., pp 111-116, 1993.

5. B. L. Sopori, X. Deng, A. Rohatgi, P. Sana, S. Estreicher, and M. Robertson, "Hydrogen in silicon: current understanding of diffusion and passivation mechanisms", to be published in the proceedings of $1 \mathrm{st}$ World Conference on Photovoltaic Energy Conversion, Hawaii, December 1994.

6. S. K. Estreicher, "Hydrogen Diffusion And Passivation Mechanisms," in Proceedings of the 3rd NREL Workshop on "The Role of Point Defects and Defect complexes in Silicon Device Processing", pp. 99-106, 1993.

7. C. Kisielowski-Kemmerich, and W. Beyer, "Hydrogen desorption from crystalline silicon and its modification due to the presence of dislocations," Journal of Applied Physics, 55 (2), pp. 552-558, 1989.

8. P.A. Basore, D.T. Rover, and A.W. Smith, "PC-1D Version 2: Enhanced Numerical Solar Cell Modeling", in Preceedings of the 20th IEEE Photovoltaic Specialists Conf, pp. 389-396, 1988.

9. P.A. Basore, "PC-1D Installation Manual and User's Guide Version 3 ", Sandia National Laboratories, Albuquerque, NM, 1991.

10. K. Okamoto, N. Shibuya, T. Nammori, T. Nunoi, and T. Tsuji, "Reduction of surface reflection in polycrystalline silicon solar cell", Technical Digest of Second "Sunshine" Workshop on Solar Cells, pp. 82-85, 1990.

11. G. Willeke, H. Nussbaumer, H. Bender, and E. Bucher, "A simple and effective light trapping technique for polycrystalline silicon solar cells", Solar Energy Materials and Solar Cells, Vol. 26, No. 4, pp. 345-356, 1992. 
12. S. Narayanan, J. Zolper, F. Yun, S. R. Wenham, A. B. Sproul, C. M. Chong, and M. A. Green, " $18 \%$ Efficient polycrystalline silicon solar cells ", in Proceedings of the 21st IEEE Photovoltaic Specialists Conf., pp. 678-680, 1990.

13. P. Sana, J. Salami, and A. Rohatgi, "Fabrication and Analysis of High-Efficiency Polycrystalline Silicon Solar Cells," in IEEE Transactions on Electron Devices, Vol. 40, No. 8, pp. 1461-1468, 1993.

14. A. Wang, J. Zhao, and M. A. Green, "24\% efficient silicon solar cells," Applied Physics Letters, vol. 57, pp. 602-604, 1990.

15. J. C. Zopler, S. Narayanan, S. R. Wenham, and M. A. Green, "16.7\% efficient, laser textured, buried contact polycrystalline silicon solar cell," Applied Physics Lefters, vol. 55, pp. 2363-2365, 1989. 
$\mid$ 


\section{CHAPTER 3. HIGH-EFFICIENCY CELLS ON SINGLE-CRYSTAL SILICON}

Chapter 2 described the research and development of high efficiency cells with multicrystalline silicon. This chapter discusses the progress on single crystal silicon. Figure 3.1 shows that four kinds of single-crystal cells are being fabricated in our labs. These cells include (a) simple $\mathrm{n}^{+}-\mathrm{p}-\mathrm{p}^{+}$baseline cell (SBLC) with phosphorus-diffused emitter and Al back surface field (BSF), (b) advanced baseline cell (ABLC) with deep phosphorus diffusion underneath the grid and point $\mathrm{Al}$ contacts on the back, (c) textured baseline cells (TBLC) with random pyramid texturing on front for light trapping and (d) IBLC cells with inverted pyramid texturing on front and localized diffusion and point contacts on the back. SBLC cells involve two masks while IBLC is a very complicated six-mask process.

Figure 3.2 shows a schematic diagram of the SBLC process, which starts with phosphorus diffusion on the front, followed by Al BSF. During the Al drive-in, a five-minute oxidation is performed to grow $100 \AA$ thick passivating oxide on top of the emitter. The front grid pattern is formed by photolithography and a lift-off technique. The back contact is formed by evaporation of $\mathrm{Ti} / \mathrm{Ag}$, and the front grid contact is finished by $4-6 \mu \mathrm{m}$ thick silver plating on top of evaporated thin $\mathrm{Ti} / \mathrm{Ag}$ contact. Finally a double-layer $\mathrm{ZnS} / \mathrm{MgF}_{2}$ antireflection coating is thermally evaporated on the front-side.

Table 3.1 shows the SBLC cells with efficiencies in the range of $18.5-19.5 \%$ on $0.2 \mathrm{ohm}-\mathrm{cm}$ FZ silicon. Figure 3.3 shows the internal quantum efficiency of one of the best SBLC cell tested and verified at Sandia National Laboratories. This cell had an efficiency of $19.4 \%$ with excellent short wavelength response. However, the long wavelength response drops sharply, partly because of the use of $0.2 \mathrm{ohm}-\mathrm{cm}$ silicon with diffusion length of only 250 microns. 


\section{Simple Base Line Cell (SBLC)}

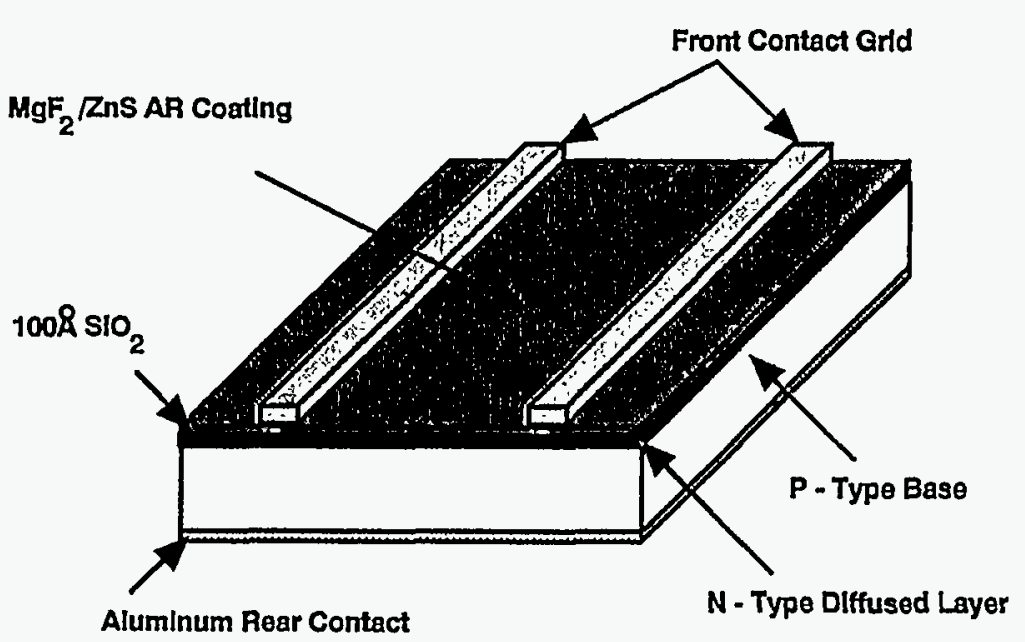

\section{Advanced Base Line Cell (ABLC)}
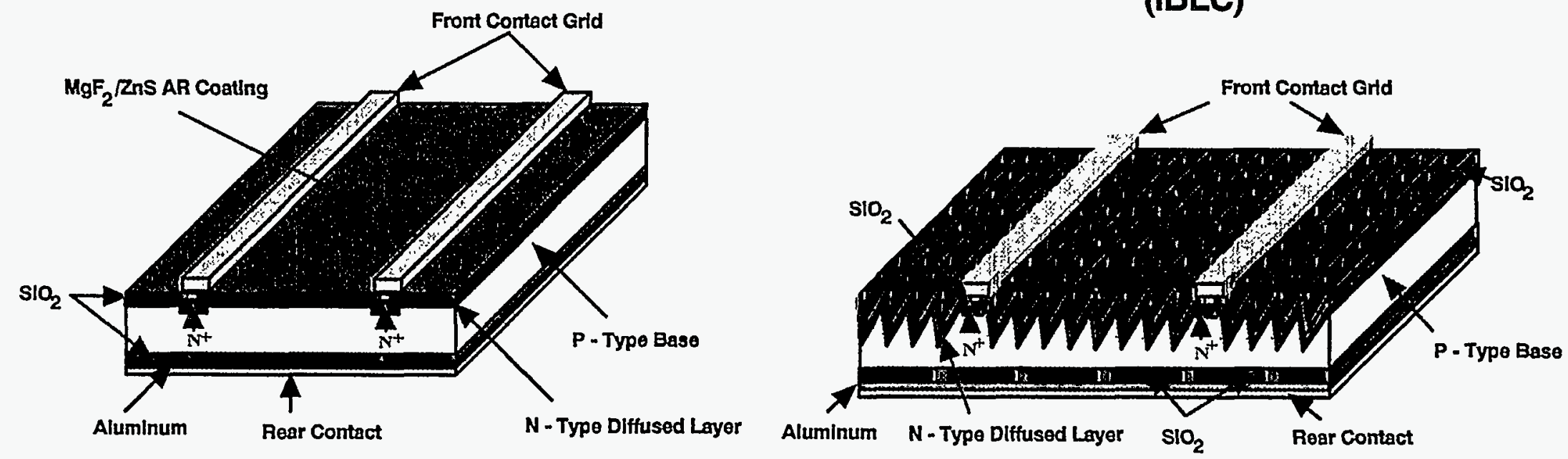

Figure 3.1. Four kinds if single-crystal cells: (a) simple $\mathrm{n}^{+}-\mathrm{p}-\mathrm{p}^{+}$baseline cells (SBLC) with phosphorus diffused emitter and Al back surface field (BSF), (b) advanced baseline cell (ABLC) with deep phosphorus diffusion underneath the grid and point Al contacts on the back, (c) textured baseline cells (TBLC) with random pyramid texturing on front for light trapping and (d) IBLC cells with inverted pyramid texturing on front and localized diffusion and point contacts on the back. 


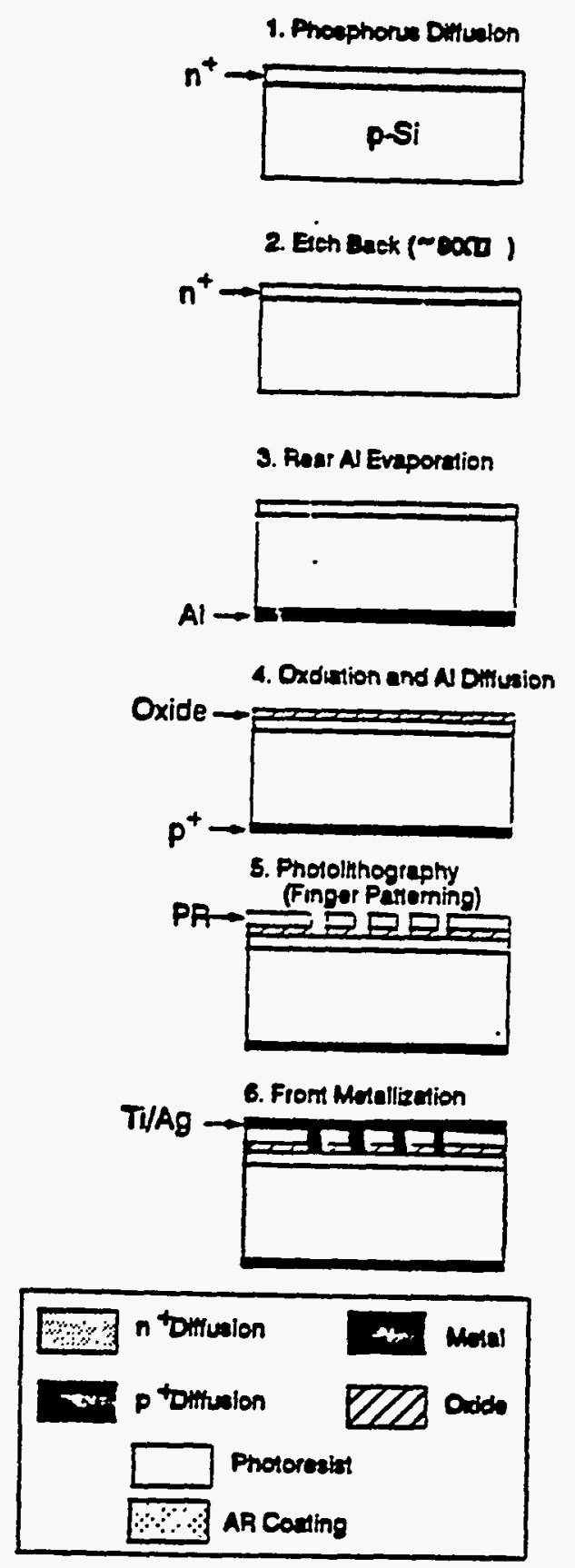

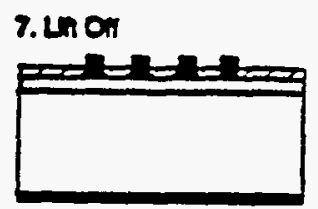

4. Seek unationation

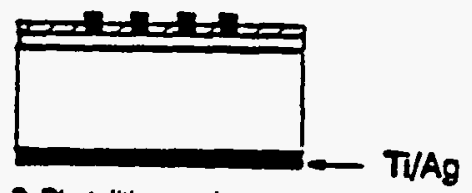

0. Protolinhooraphy

(What Eich)

REDEDER- PR

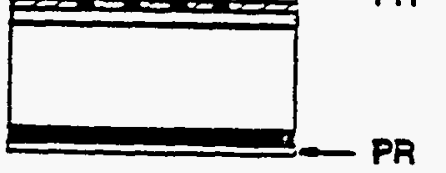

10. Mone Etch

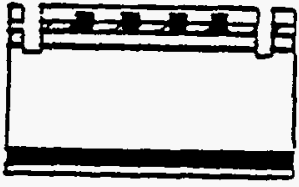

11. Photorcelex Romoval
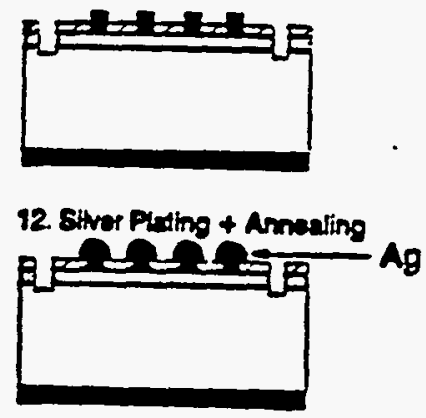

13. AR Costing

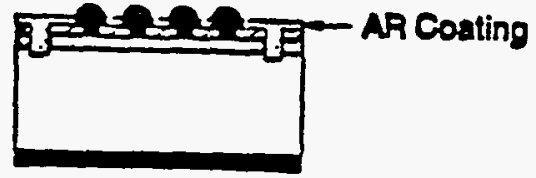

Figure 3.2. Process outline for simple base line solar cell (SBLC). 
Table 3.2 shows cell data of a few advanced baseline cells with double phosphorus diffusion. Because of deep grid diffusions, the field diffusion sheet resistance was raised to $120 \mathrm{ohm}$-sq as opposed to $80 \mathrm{ohms}-\mathrm{sq}$ in the case of SBLC cells. This reduced the heavy doping effects, resulting in higher $\mathrm{V}_{\infty}$, on the order of $690 \mathrm{mV}$ as opposed to $660 \mathrm{mV}$ for the SBLC cells. ABLC cell efficiencies of about $20 \%$ were achieved. Another advantage of the ABLC process is reflected in the IQE curves shown in Figure 3.4, which, due to reduced contact recombination and heavy doping effects, not only gave higher short wavelength response compared to the SBLC cells, but also resulted in better long wavelength response. This may be the result of a gettering-induced lifetime increase due to the intense phosphorus grid diffusion.

We have also fabricated textured TBLC and IBLC cells, in addition to the flat SBLC and ABLC cells. Figure 3.5 shows that the IBLC cell involves six masks. A second mask is used for Al or boron localized BSF. A third mask is used to perform deep phosphorus diffusion underneath the grid lines. A fourth mask is for field diffusion and cell isolation. After $100-\AA$ - thick front thermal oxide passivation, a fifth mask is used to make small-area point contacts to localized rear diffusion. The sixth and final mask is used to define front grid lines. The IBLC cells may be ideal to test the capability of a fabrication lab, but because of their complexity and the many mask steps required to make them, they may not be able to meet the criteria for cost-effective solar cells. An IBLC run takes roughly three weeks in our lab and is also quite vulnerable to failures because of the six mask process, and for that reason not too much emphasis was placed on the IBLC runs this year. Instead, more effort was directed toward developing simplified, rapid and low-cost processes. 
Table 3.1. SBLC Cells tested and verified by Sandia.

\begin{tabular}{|c|c|c|c|c|}
\hline Cell ID & $v_{\infty}(m V)$ & $J_{\infty}(\mathrm{mA} / \mathrm{cm} 2)$ & CFF & EFFY \\
\hline \multicolumn{5}{|c|}{ RUN TGM (NEW 1XI) } \\
\hline 2 & 664.8 & 35.7 & .817 & 19.4 \\
\hline 3 & 664.8 & 35.7 & .812 & 19.3 \\
\hline 6 & 664.8 & 35.8 & .814 & 19.4 \\
\hline 7 & 664.1 & 35.6 & .808 & 19.1 \\
\hline 10 & 663.4 & 35.7 & .788 & 18.6 \\
\hline 11 & 664.8 & 35.5 & .819 & 19.3 \\
\hline 12 & 663.2 & 35.3 & .814 & 19.1 \\
\hline 14 & 663.7 & 35.2 & .819 & 19.2 \\
\hline \multicolumn{5}{|c|}{ RUN JT3 (OLD IX1) } \\
\hline 4 & 666.8 & 35.2 & .797 & 18.7 \\
\hline 14 & 664.9 & 35.2 & .804 & 18.8 \\
\hline 15 & 658.4 & 34.8 & .797 & 18.3 \\
\hline 16 & 663.0 & 35.3 & .787 & 18.4 \\
\hline \multicolumn{5}{|c|}{ RUN TGM (2X2'S) } \\
\hline 1 & 658.6 & 34.3 & .820 & 18.5 \\
\hline 2 & 659.4 & 34.6 & .819 & 18.7 \\
\hline 3 & 658.8 & 34.4 & .818 & 18.6 \\
\hline 4 & 658.6 & 34.2 & .817 & 18.4 \\
\hline
\end{tabular}




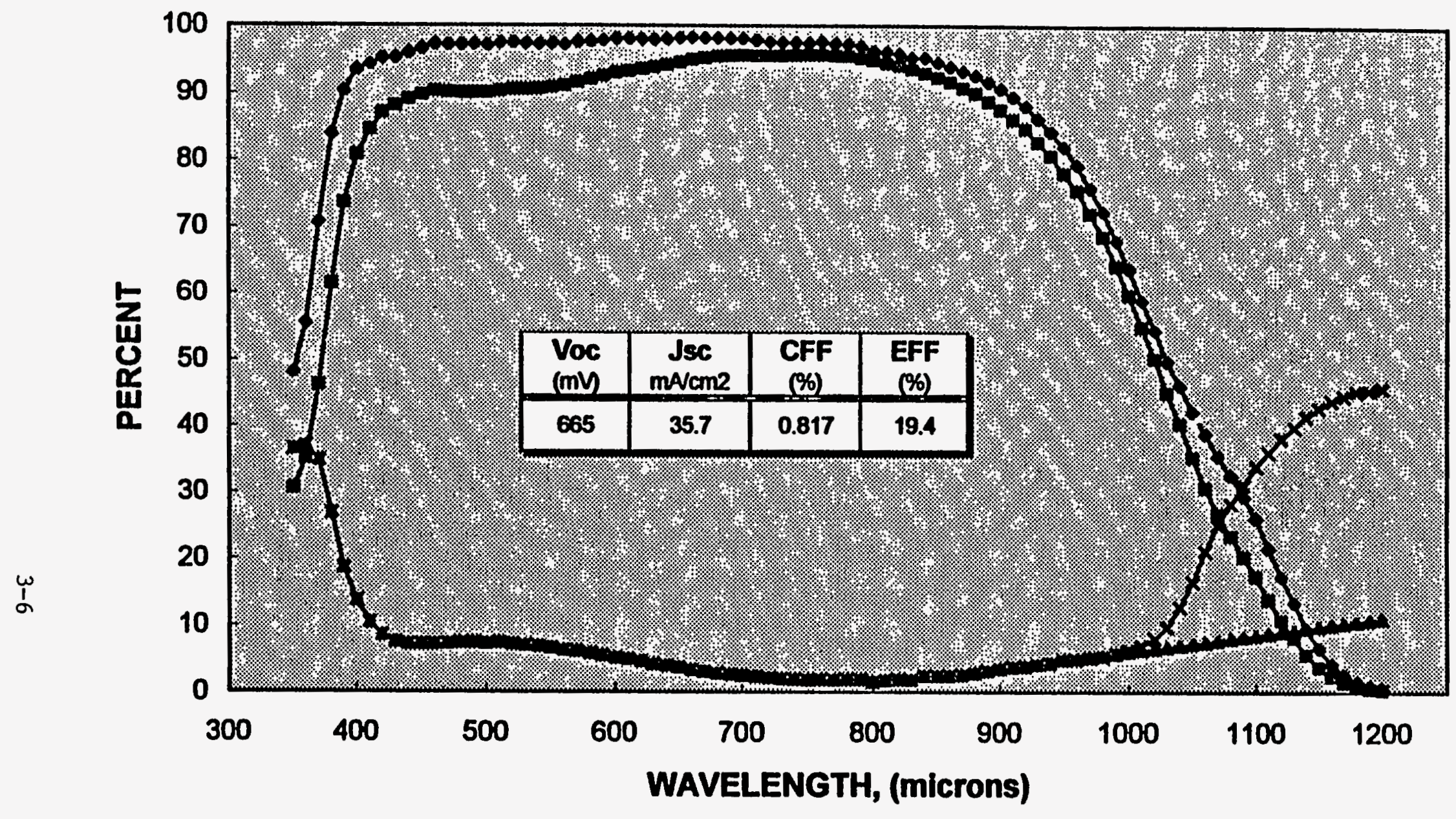

$\rightarrow(\mathrm{nm})$ IQE $\rightarrow-\mathrm{EQE} \rightarrow-\mathrm{FRF} \rightarrow-\mathrm{TRF}$

Figure 3.3. IQE and REF for SBLC cell. 
Figure 3.6 shows the IQE response of a $\sim 21 \%$ efficient IBLC cell made on a $0.2 \mathrm{ohm}-\mathrm{cm}$ FZ Si-. For comparison we have plotted the IQE response of the $23.5 \%$ efficient UNSW cell. Figure 3.6 shows that the short wavelength response of both the cells is quite comparable, but the long wavelength response of our cell is lower. This is largely because we used $0.2 \mathrm{ohm}-\mathrm{cm}$ silicon with bulk lifetime of $30 \mu \mathrm{s}$ while UNSW used $2 \mathrm{ohm}-\mathrm{cm}$ silicon with a lifetime of $2 \mathrm{~ms}$.

Table 3.2. Run SN2 $2 \times 2$ ABLC Solar Cell Data

\begin{tabular}{|c|c|c|c|c|}
\hline Cell & $V_{o c}(m V)$ & $J_{s c}\left(\mathrm{~mA} / \mathrm{cm}^{2}\right)$ & CFF & EFFY \\
\hline \multicolumn{5}{|c|}{ WAFER 1} \\
\hline $1-1$ & 681.2 & 36.8 & .811 & 20.3 \\
\hline $1-2$ & 677.8 & 37.0 & .809 & 20.3 \\
\hline $1-3$ & 676.7 & 36.8 & .809 & 20.2 \\
\hline $1-4$ & 675.7 & 36.7 & .811 & 20.2 \\
\hline \multicolumn{5}{|c|}{ WAFER 2} \\
\hline $2-1$ & 667.1 & 36.7 & .806 & 19.8 \\
\hline $2-2$ & 666.5 & 36.7 & .814 & 19.9 \\
\hline 2.3 & 665.5 & 36.3 & .794 & 19.2 \\
\hline $2-4$ & 666.4 & 36.2 & .784 & 18.9 \\
\hline
\end{tabular}




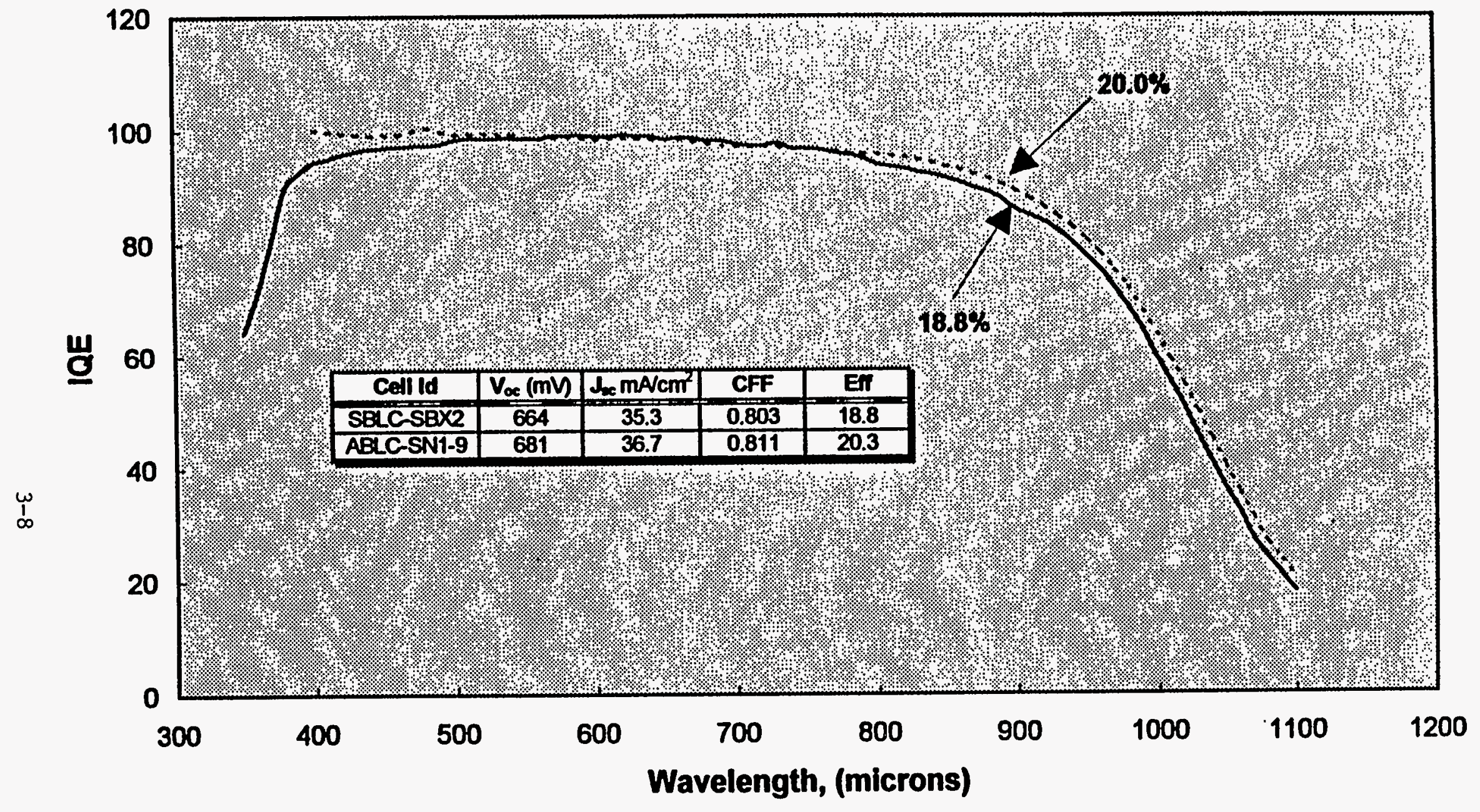

Figure 3.4. Optical response data. 
1. Texture

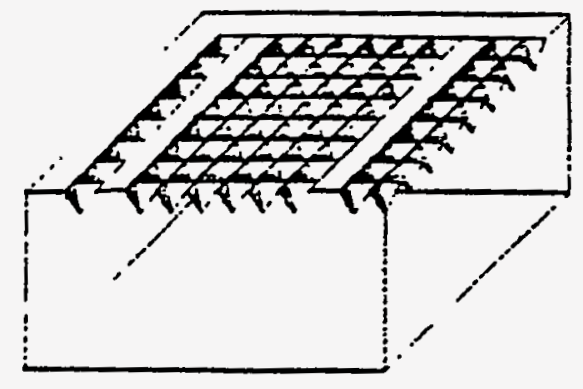

2. Bor-LBSF Diffusion

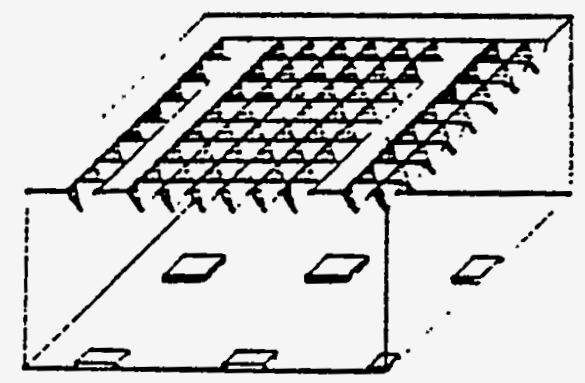

3. $\mathrm{n}^{++}$-Diffusion
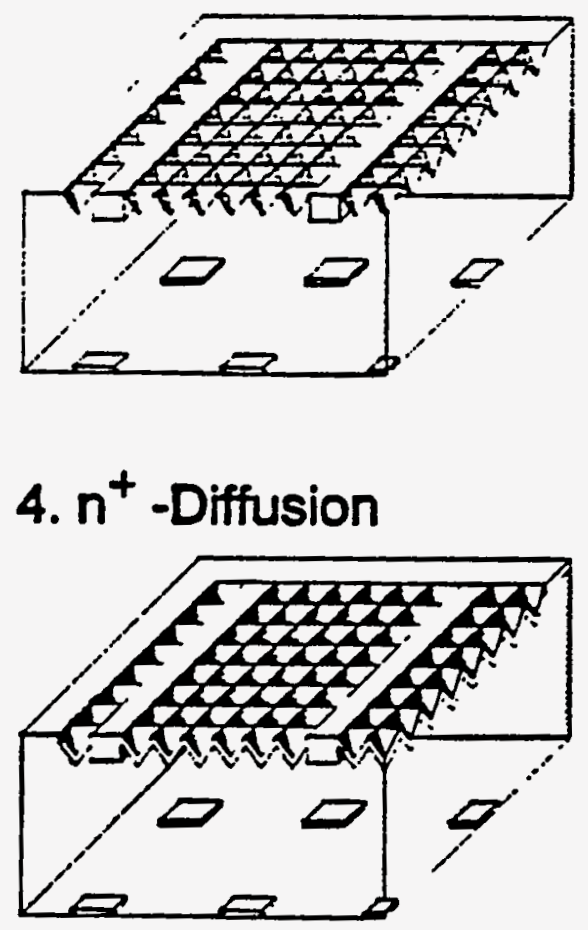

5. Oxide passivation

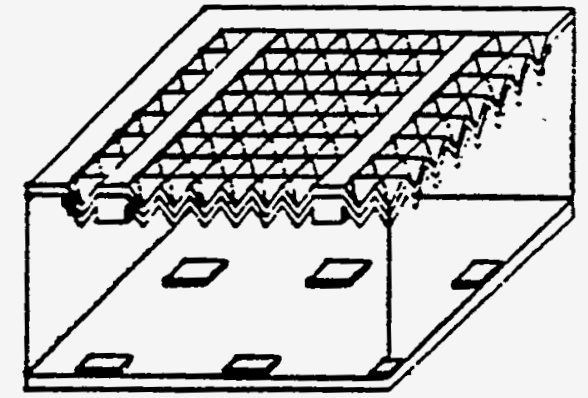

6. Metallization (rear side)

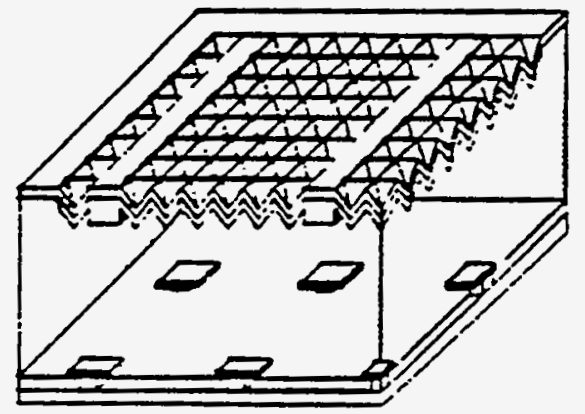

7. Metallization (front side)

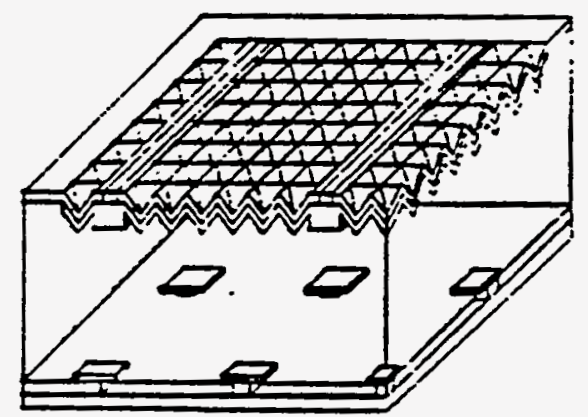

8. Electroplating, Annealing

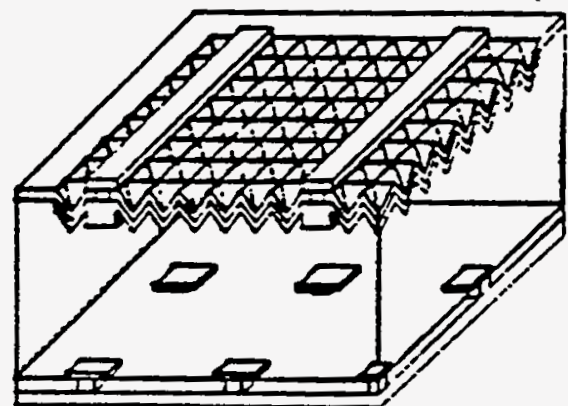

Figure 3.5. Advanced IVP silicon solar cell process. 
Model calculations in Figure 3.7 show that it is possible to achieve 25\% efficient IBLC cells. However, if surface recombination velocities are on the order of a few hundred, $\mathrm{cm} / \mathrm{S}$ then $0.2 \mathrm{ohm}$ $\mathrm{cm}$ silicon needs to have a lifetime of $1 \mathrm{~ms}$, which does not exist, or 2-10 ohm-cm silicon should have a lifetime of several ms, which is possible but hard to maintain during the prolonged cell processing. The lower part of the Figure 3.7 shows that in order to achieve $\geq 25 \%$ IBLC cell efficiency, using $2 \mathrm{ohm}-\mathrm{cm}$ with $2 \mathrm{~ms}$ lifetime, SRV values of less than $50 \mathrm{~cm} / \mathrm{s}$ will be required. This not only requires point contacts, but very good front and back surface passivation.

In summary, in the area of single-silicon solar cells, we have fabricated $19 \%$ efficient SBLC cells, $20 \%$ efficient ABLC cells and $\sim 21 \%$ efficient IBLC cells. 


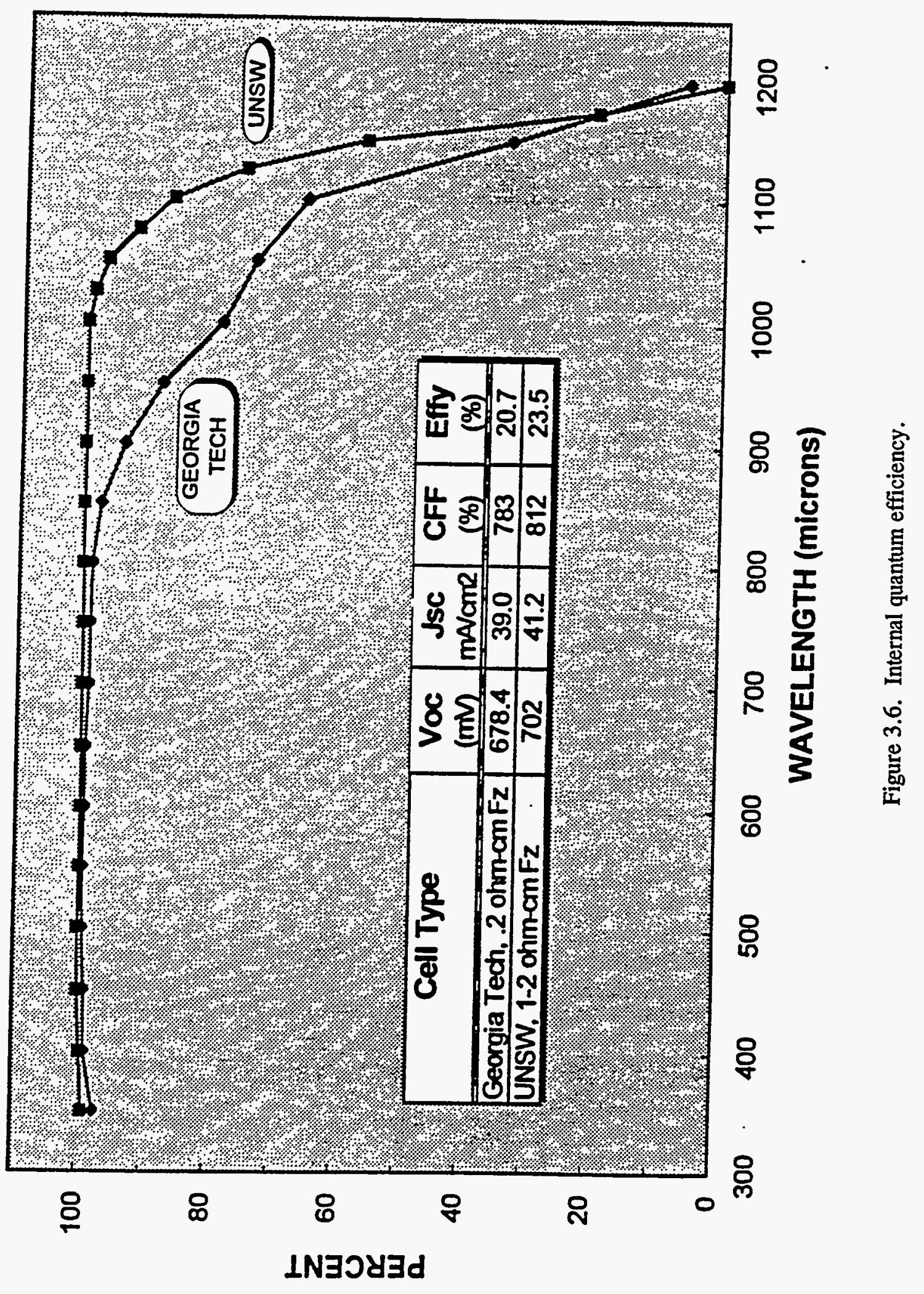



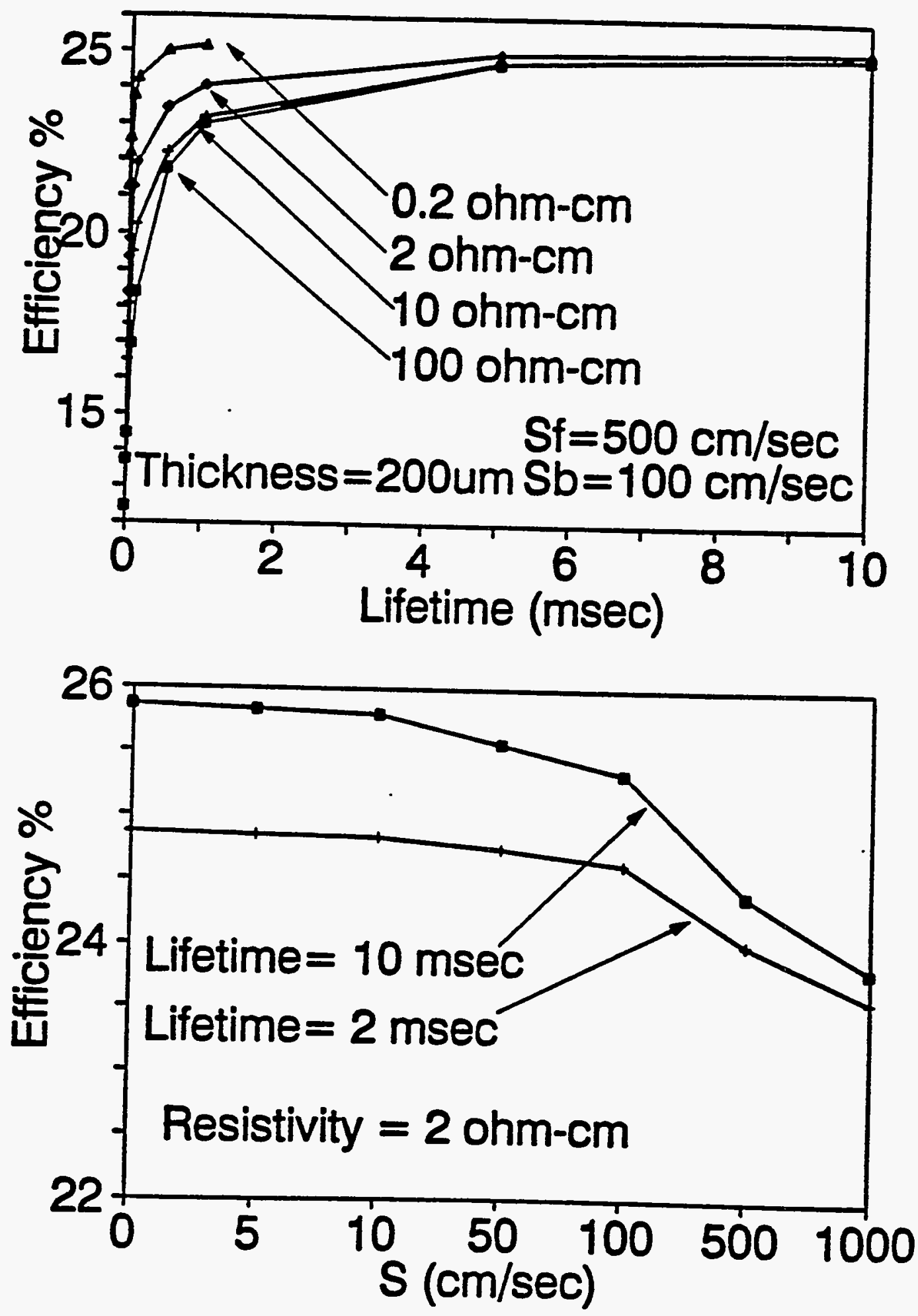

Figure 3.7. Approach toward $25 \%$ efficient inverted pyramid silicon solar cells. 


\section{CHAPTER 4. SURFACE/BULK DEFECT PASSIVATION BY PLASMA ENHANCED CHEMICAL VAPOR DEPOSITED}

\subsection{Modeling And Characterization of Interface State Parameters And Surface Recombination Velocity At Plasma Enhanced Chemical Vapor Deposited $\mathrm{SiO}_{2}$-Si Interface.}

\subsubsection{Introduction}

Low surface recombination velocity and high effective recombination lifetime both are critical for high-efficiency Si solar cells. Thin thermal oxides grown at high temperatures $\left(850-1050^{\circ} \mathrm{C}\right)$ are generally used for surface passivation. [1] However, low-temperatures deposited oxide is more desirable because of the possibility of high-temperature induced degradation of bulk lifetime, increased flexibility in cell processing and reduced cell cost.

We have developed and reported a low-temperature process to passivate a Si surface by plasmaenhanced chemical vapor deposition (PECVD) of $\mathrm{SiO}_{2}$ at $250^{\circ} \mathrm{C}$ followed by forming gas anneal at $350^{\circ} \mathrm{C}$ in a tungsten halogen lamp furnace. This process gives low effective surface recombination velocity $\left(\mathrm{S}_{\mathrm{eff}}\right)$ of less than $2 \mathrm{~cm} / \mathrm{sec}$ at intrinsic $\mathrm{FZ}-\mathrm{Si} / \mathrm{PECVD}-\mathrm{SiO}_{2}$ interface. [2] It should be noted that this process is compatible with a double-layer anti-reflection coating process using $\mathrm{PECVD} \mathrm{SiO}_{2}$ and $\mathrm{SiN}$. [3] Therefore PECVD oxide passivation is considered promising for improving the efficiency and cost effectiveness of $\mathrm{Si}$ solar cells.

The low $\mathrm{S}_{\text {eff }}$ of $\mathrm{PECVD} \mathrm{SiO}_{2}$ passivated $\mathrm{Si}$ surface is attributed to a combination of moderately low density of interface states at midgap $\left(D_{\mathrm{it}}=(1-10) \times 10^{10} \mathrm{~cm}^{-2} \mathrm{eV}^{-1}\right)$ and high positive oxide-fixed charge density $\left.\left[Q_{o x}=(1-10) \times 10^{11} \mathrm{~cm}^{-2}\right]\right)$. [2] The higher $Q_{o x}$ results in increased downward band bending $\left(\psi_{\mathrm{s}}\right)$ at the surface. The larger $\psi_{\mathbf{s}}$ lowers surface hole concentration for recombination and consequently reduces the 
$S_{\text {eff }}$ Therefore even if the $D_{i t}$ is moderately high, it is possible to get low $S_{\text {eff }}$ with higher $Q_{o x}$. A preliminary study shows that $D_{i t}$ and $Q_{o x}$ increase with increasing PECVD oxide deposition rate. [4] However, $Q_{o x}$ increases at a higher rate than $D_{i t}$ These results suggest the possibility of optimizing the PECVD process to get low $\mathrm{S}_{\text {eff }}$ with high throughput. In order to optimize the PECVD passivation process for Si cells, a knowledge of the interface properties of $\mathrm{PECVD} \mathrm{SiO}_{2}-\mathrm{Si}$ interface and model calculation of $\mathrm{S}_{\mathrm{eff}}$ as a function of $D_{i t} Q_{o x}$ and other interfaced parameters are essential.

Numerous studies have been conducted on the properties of the thermal $\mathrm{SiO}_{2}-\mathrm{Si}$ interface, along with realistic modeling of the recombination at the interface using experimentally obtained parameters. [5-8] The modelling studies on the thermal $\mathrm{Si}_{-} \mathrm{SiO}_{2}$ interface have shown that besides the interface state density, the capture cross-section model for electrons and holes can significantly affect the calculated value of $\mathrm{S}_{\mathrm{eff}}$. However, the fundamental properties of $\mathrm{PECVD} \mathrm{SiO}_{2}-\mathrm{Si}$ interface states including the capture cross sections have not yet been investigated.

Recently, several authors reported on the capture cross sections for electron and holes at the thermal $\mathrm{SiO}_{2}$-Si interface using small bias DLTS method. [8-10] Although this method gives energy dependence of capture cross sections for majority carriers, capture cross sections for minority carriers cannot be obtained. When temperature is varied in the DLTS measurements, the interface state charge density changes with temperature because of the shift in the Fermi level, which in turn causes significant flat band voltage shift in CV measurement especially when $D_{i t}$ is high. Therefore the bias setting for the DLTS measurement should be temperature dependent, which makes the measurement complicated. In this paper we have employed a simple method for measuring $\mathrm{S}_{\mathrm{eff}}$ as a function of gate bias voltage in order to obtain the information on

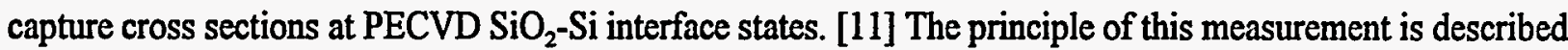
in Section 4.3.2.

In this work, we first performed capacitance voltage (CV) measurements on the metal oxide semiconductor (MOS) structure and photoconductive voltage decay (PCD) measurements as a function of 
gate bias voltage to investigate the properties of $\mathrm{PECVD} \mathrm{SiO}_{2}-\mathrm{Si}$ interface states. Then we used a combination of these measurements and the model calculations to obtain the information about the defect parameters $\left(D_{i t}, \sigma_{n}, \sigma_{p}\right)$ at the interface. Finally, model calculations were extended to obtain the correlation between $D_{i t}, Q_{o x}$ and $S_{o f f}$, utilizing the experimentally determined parameters at this interface.

\subsubsection{Experimental}

Boron-doped p-type (100) 5-inch diameter CZ-Si wafers with resistivity of about $5 \Omega$-cm was used in this study. Two samples (a quarter of the wafer) cut from the same wafer were used for PCD and MOS measurements. After cleaning the wafers, $1000 \AA$ PECVD oxide was deposited at $250^{\circ} \mathrm{C}$ on the front surface for the MOS sample. Detailed PECVD deposition conditions have been reported elsewhere. [2] After evaporation of $\mathrm{Al}$ on both front and back surfaces, the MOS samples were annealed at $350^{\circ} \mathrm{C}$ in forming gas for $20 \mathrm{~min}$ in a tungsten halogen lamp furnace. The lamp annealing in forming gas with $\mathrm{Al}$ present was found to be extremely effective in passivating the $\mathrm{PECVD} \mathrm{SiO}_{2}-\mathrm{Si}$ interface. [4] The same procedure on the back surface gave good ohmic contact. After defining 1-mm-diameter MOS capacitors on the front, the $D_{i t}$ distribution in the band gap was determined by the combination of standard high frequency (HF) and quasistatic (QS) CV measurements. [5] The fixed oxide charge $Q_{o x}$ was determined by the HF-CV measurement.

In order to measure gate bias dependence of $\mathrm{S}_{\text {eff }} \mathrm{PECVD} \mathrm{SiO}_{2}$ was deposited on both sides of another sample. The same deposition conditions were used. After the forming gas anneal, $\sim 1000 \AA$ Indium tin oxide (ITO) was sputtered on both surfaces of $S_{\text {eff }}$ measured samples to form transparent conducting gate electrodes for applying bias. The measurement system and the sample configuration are similar to that illustrated in Yablonavich, Swanson, and Eades. $S_{\text {eff }}$ was measured by the PCD method as a function of gate bias voltage and injected carrier density. The details of the PCD measurements are described in Parag and Rohatgi. ${ }^{12}$ 


\subsubsection{Theory and Modeling}

\subsubsection{Calculations of $\mathrm{S}_{\mathrm{en}}$ at the $\mathrm{PECVD} \mathrm{SiO}_{2}$-Si Interface}

The effective surface recombination velocity $\left(S_{\text {eff }}\right)$ defined at the edge of the surface depletion region can be calculated by standard Shockley-Read-Hall (SRH) theory. [13,14] For a continuum of non-interacting interface states, $S_{\text {eff }}$ is obtained by the following integration over the band gap: [7,8 and 15]

$$
\begin{aligned}
& S_{e f f}=\frac{V_{t h}\left(n_{s} p_{s}-n_{i}^{2}\right)}{\Delta n} \times \\
& {\left[\int_{E_{V}}^{E_{c}} \frac{D_{i t A}(E)}{\frac{\left(n_{s}+n_{1}\right)}{\sigma_{p A}(E)}+\frac{\left(p_{s}+p_{1}\right)}{\sigma_{n A}(E)}} d E+\int_{E_{V}}^{E_{c}} \frac{D_{i t D}(E)}{\frac{\left(n_{s}+n_{1}\right)}{\sigma_{p D}(E)}+\frac{\left(p_{s}+p_{1}\right)}{\sigma_{n D}(E)}} d E\right]}
\end{aligned}
$$

where

(1)

$$
n_{1}=n_{i} e^{\frac{E-E_{i}}{k T}}, \quad p_{1}=n_{i} e^{\frac{E_{l}-E}{k T}}
$$

Here $n_{i}$ is the intrinsic carrier concentration, $E$ the interface trap energy level, $E_{i}$ represents the intrinic Fermi level, $E_{c}$ is the bottom of the conduction band, $E_{v}$ is the top of the valence band, $v_{t h}$ is the carrier thermal velocity, $k$ is the Boltzman constant, $T$ is the absolute temperature, $\Delta \mathrm{n}$ is the injected carrier concentration, $D_{i t}$ is the interface state density, and $\sigma_{n}, \sigma_{p}$ are the capture cross sections for electrons and holes, respectively. Subscripts $A$ and $D$ denote acceptor and donor type interface states, respectively. 
The concentrations of electrons and holes at the interface can be written as

$$
n_{s}=n_{i} e^{\beta\left(\psi_{s}-\phi_{n}\right)}, \quad p_{s}=n_{i} e^{\beta\left(\phi_{p}-\psi_{s}\right)}
$$

where $\beta=q / k T, \psi_{s}$ is the surface band bending, $\phi_{n}, \phi_{p}$ are the quasi-Fermi potential for electrons and holes, respectively.

From the above equations, it can be seen that $S_{e f f}$ is strongly dependent on the surface band bending $\Psi_{\mathrm{n}}$, which can be calculated from the overall charge neutrality condition for the system,

$$
Q_{s i}+Q_{i t}+Q_{o x}+Q_{8}=0
$$

Here, $Q_{\mathrm{xi}}$ is the charge density induced in the silicon, $Q_{\mathrm{it}}$ is the interface state charge density, $Q_{\mathrm{ox}}$ is the oxide fixed charge density and $Q_{B}$ is the charge density induced in the gate electrode. A numerical procedure for calculating $\Psi_{s}$ under the approximation of flat quasi Fermi-levels through the whole semiconductor region was proposed by Girisch et al. And was adopted by Aberle et al. to calculate the recombination velocity at the thermal $\mathrm{SiO}_{2}-\mathrm{Si}$ interface. $[8-15]$

We started from the flat quasi-Fermi level approach to numerically solve the band bending problem

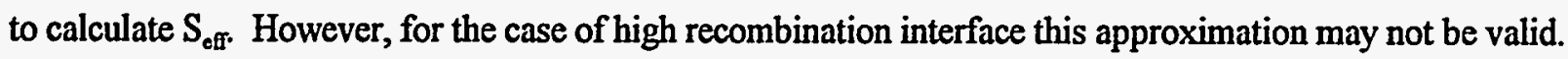
Therefore, we modified the flat quasi-Fermi level approach by using the different minority quasi-Fermi level $\phi_{n}$ in the depletion region at the interface compared to that in the bulk $\phi_{n B}$ (Figure 4.1). 


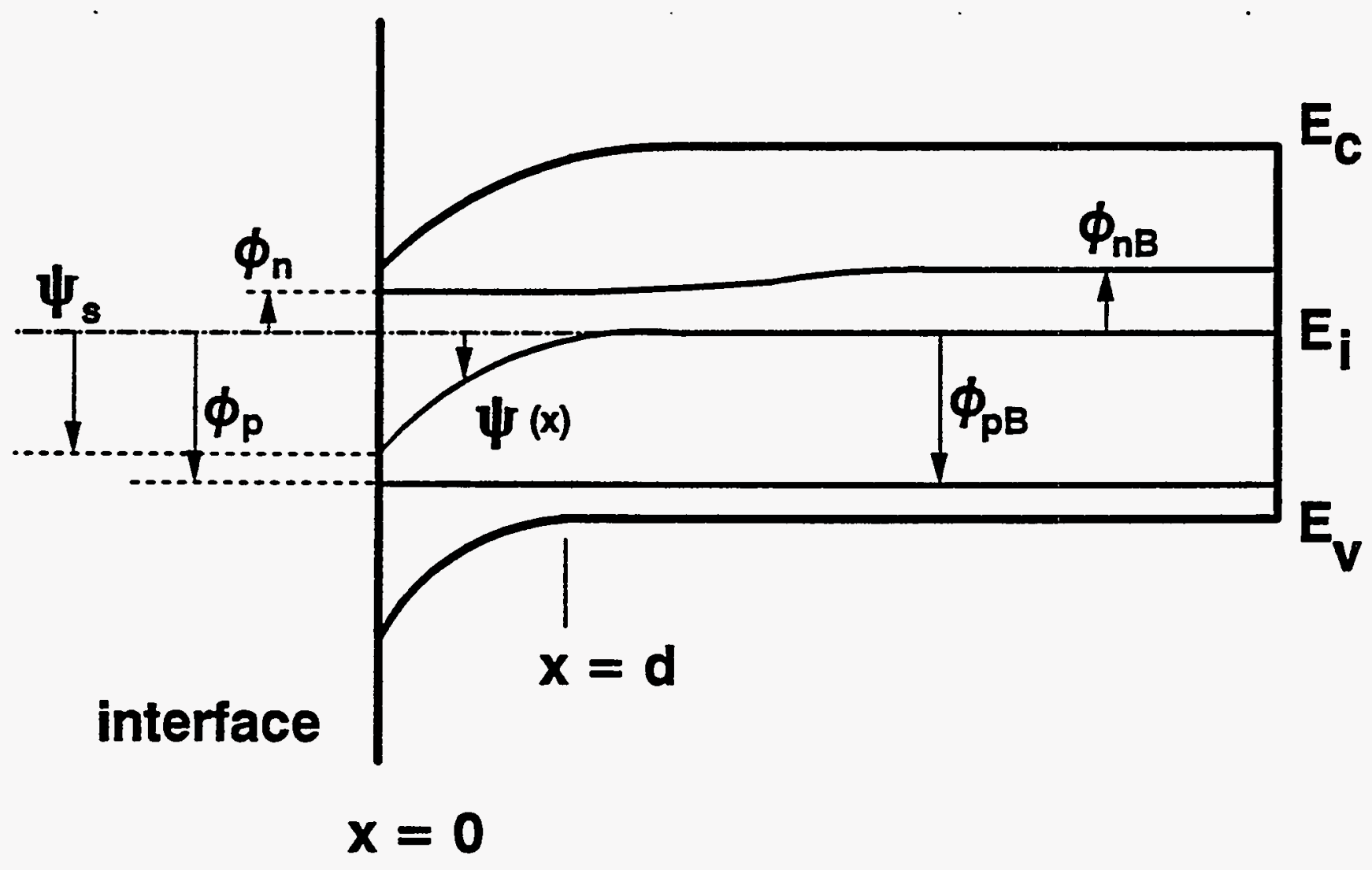

Figure 4-1. Energy band diagram at $\mathrm{SiO}_{2}-\mathrm{Si}$ interface under non-equilibrium condition with definitions of electron energy and potentials. 
These quantities can be calculated using the current continuity equations neglecting the recombination in the depletion region: [16]

$$
J_{n}(x)=J_{r}(0)
$$

$\mathrm{J}_{\mathrm{n}}(\mathrm{x})$ is the minority carrier current density in the depletion region which for p-type case is given by

$$
J_{n}(x)=-q \mu_{n} n(x) \nabla \Phi_{n}(x)
$$

and $\mathrm{J}_{\mathrm{r}}$ is the interface recombination current density which is obtained from the flat quasi-Fermi level approach according to

$$
J_{r}(0)=q \Delta n(d) S_{e f f}
$$

where $\mu_{n}$ is the minority electron mobility and $d$ is the width of the depletion region. Assuming flat minority quasi-Fermi level in the depletion region, we calculated $\phi_{n}$ at the surface from equation (8) shown below and then used this value for more accurate calculation of $\psi_{\mathrm{s}}$ and $S_{\mathrm{eff}}$ (a detailed derivation of equation (8) is shown in the Appendix).

$$
e^{-\beta \phi_{n s}}-e^{-\beta \phi_{n}}= \pm \frac{\Delta n S_{e f f}}{D}\left[\frac{\epsilon_{s}}{2 q \beta n_{i}^{3}}\right]^{\frac{1}{2}}\left[e^{-\beta \psi_{s}}-1\right] \times
$$

$$
\left[\frac{\beta \psi_{s}\left(p_{0}-n_{0}\right)}{n_{i}}+e^{\beta\left[\phi_{p}-\psi_{z}\right]}-e^{\beta \phi_{p}}+e^{\beta\left[\psi_{z}-\phi_{n}\right]}-e^{-\beta \phi_{R}}\right]^{-\frac{1}{2}}
$$

where the plus sign represents downward band bending the minus sign is for upward band bending, $D_{n}$ is the minority carrier electron diffusion coefficient, $\varepsilon_{s}$ is the dielectric constant of $\mathrm{Si}, \mathrm{n}_{\mathrm{o}}$ is the equilibrium electron concentration and $\mathrm{p}_{\mathrm{o}}$ is the equilibrium hole concentration. In the derivation, $\phi_{\mathrm{p}}=\phi_{\mathrm{pB}}$ is assumed. 


\subsubsection{Effects of $\Psi_{s}$ and Interface State Parameters on $S_{\text {en }}$}

For a realistic calculation of $S_{e f f}$, the interface state parameters $\left(D_{i t}, \sigma_{n}, \sigma_{p}\right)$ as well as $Q_{o x}$ should be known. $D_{i t}$ can be obtained by the standard HF-QS CV analysis, but reliable values of $\sigma_{n}, \sigma_{p}$ and the type of the interface states (acceptor or donor) are difficult to obtain as described earlier. However, if $S_{\text {eff }}$ can be measured as a function of $\Psi_{z}$, useful information can be obtained about the cross sections. By differentiating Eg. (1) with respect to $\Psi_{s}$, the band bending $\Psi_{s, \max }$ at which $S_{\text {eff }}$ is maximum can be obtained from $d S_{\text {eff }} / d \Psi_{s}$ $=0$, which gives

$$
\Psi_{s, \max }=\left(\frac{k T}{2 q}\right) \ln \left[\frac{\sigma_{p}(E)\left(p_{0}+\Delta n\right)}{\sigma_{n}(E)\left(n_{0}+\Delta n\right)}\right]
$$

for either acceptor or donor type states. Under high-level injection condition Eg. (9) reduces to $\Psi_{x, \max }=0.03$ $\log \left(\sigma_{\mathrm{p}} / \sigma_{\mathrm{n}}\right)$ in volts.

Figure 4.2 shows the results of the theoretical calculation of $S_{e f}$ as a function of $\psi_{s}$ based on the uniform $\mathrm{D}_{\mathrm{it}}$ distribution model with two different cross-section models under a high-injection condition. The first model (case 1 in Figure 4.2) assumes that the electron capture cross section is 100 times larger than that of the holes, irrespective of the nature of $D_{\text {it. }}$

$$
\sigma_{n A}=\sigma_{n D}=\sigma_{n}, \quad \sigma_{p A}=\sigma_{p D}=\sigma_{p} \quad \text { and } \quad \sigma_{n}>\sigma_{p}(10)
$$

which was used in the recent model calculation. [8] The second model (case 2 in Figure 2) assumes that the capture cross section for the charged states $\left(\sigma_{\mathrm{c}}\right)$ is 100 times larger than the neutral ones $\left(\sigma_{\mathrm{N}}\right)$ : 


$$
\sigma_{n D}=\sigma_{p A}=\sigma_{C}, \quad \sigma_{n A}=\sigma_{p D}=\sigma_{N} \quad \text { and } \quad \sigma_{C}>\sigma_{N}^{(11)}
$$

which is considered physically more realistic. [15] In Figure 4.2, cross sections are assumed to be independent of energy for both models, and $D_{i t A}=D_{i t D}$ is assumed. A model calculation showed that for case

1 , there is one $S_{\text {eff } \max }$ at $\Psi_{s, \max }=-0.06 \mathrm{~V}$, but for the case 2 we get two $S_{\text {eff } \max }$ peaks at $\psi_{s, \max }=-0.06$ and 0.06 $\mathrm{V}$, corresponding to the contribution from the donor and the acceptor type states, respectively. Thus the calculations show that not only the information on the cross section ratios for electron and holes can be obtained from the measured $\psi_{\mathrm{s} \text {, max }}$ values but the predominance of donor or acceptor type interface states can also be deduced.

\subsubsection{Results and Discussion}

Figure 4.3 shows high and low frequency CV measurements on a PECVD MOS sample. The voltage ramping rate was $0.1 \mathrm{~V} / \mathrm{s}$ for both $\mathrm{HF}$ and QS-CV measurements. The standard analysis gave an oxide charge density of about $5 \times 10^{11} \mathrm{~cm}^{-2}$ and a $U$ shape distribution of $D_{i t}(E)$ shown in Figure 4.4. [4-5] The experimental data, shown with the filled square, gave a good fit to an empirical function:

$$
\begin{aligned}
D_{i t}(E) & =D_{i t A}(E)+D_{i t D}(E) \\
& =6.5 \times 10^{15} \times|E-0.57|^{8}+D_{i t} \quad\left(\mathrm{~cm}^{-2} e V^{-1}\right)
\end{aligned}
$$

where $D_{i t}$ is the mid gap value of $D_{i t}(E)$ and is equal to $1.17 \times 10^{11} \mathrm{~cm}^{-2} \mathrm{eV}^{-1}$ in this case. This function is indicated by the solid curve in Figure 4.4 and will be used for the later calculation. 


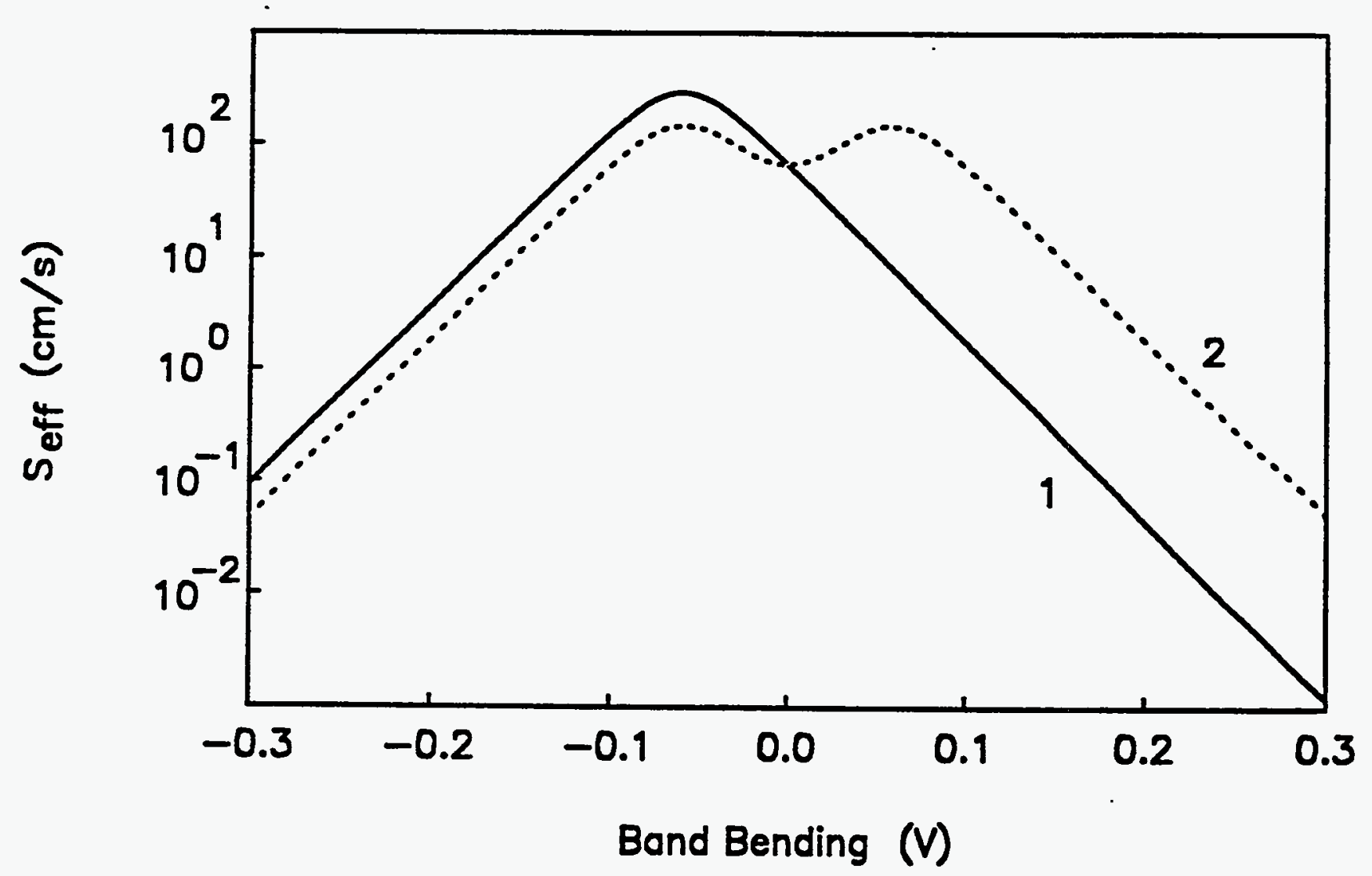

Figure 4.2. Calculated effective surface recombination velocity $\mathrm{S}_{\text {ex }}$ at $\mathrm{SiO}_{2}-\mathrm{Si}$ interfaces as a function of the surface band bending based on the uniform distribution model of $D_{i t}$ in the energy gap. 1: $\sigma_{\mathrm{n}}=100 \sigma_{\mathrm{p}}=10^{-14} \mathrm{~cm}^{2} . \quad 2: \sigma_{\mathrm{c}}=100 \sigma_{\mathrm{N}}=10^{-14}$ $\mathrm{cm}^{2}$. Other parameters for both curves: $\mathrm{p}_{\mathrm{o}}=10^{-13} \mathrm{~cm}^{-3}, \Delta \mathrm{n}=5 \times 10^{14} \mathrm{~cm}^{-3}, \mathrm{D}_{\mathrm{it}}=$ $10^{11} \mathrm{~cm}^{-2} \mathrm{eV}^{-1}$. 


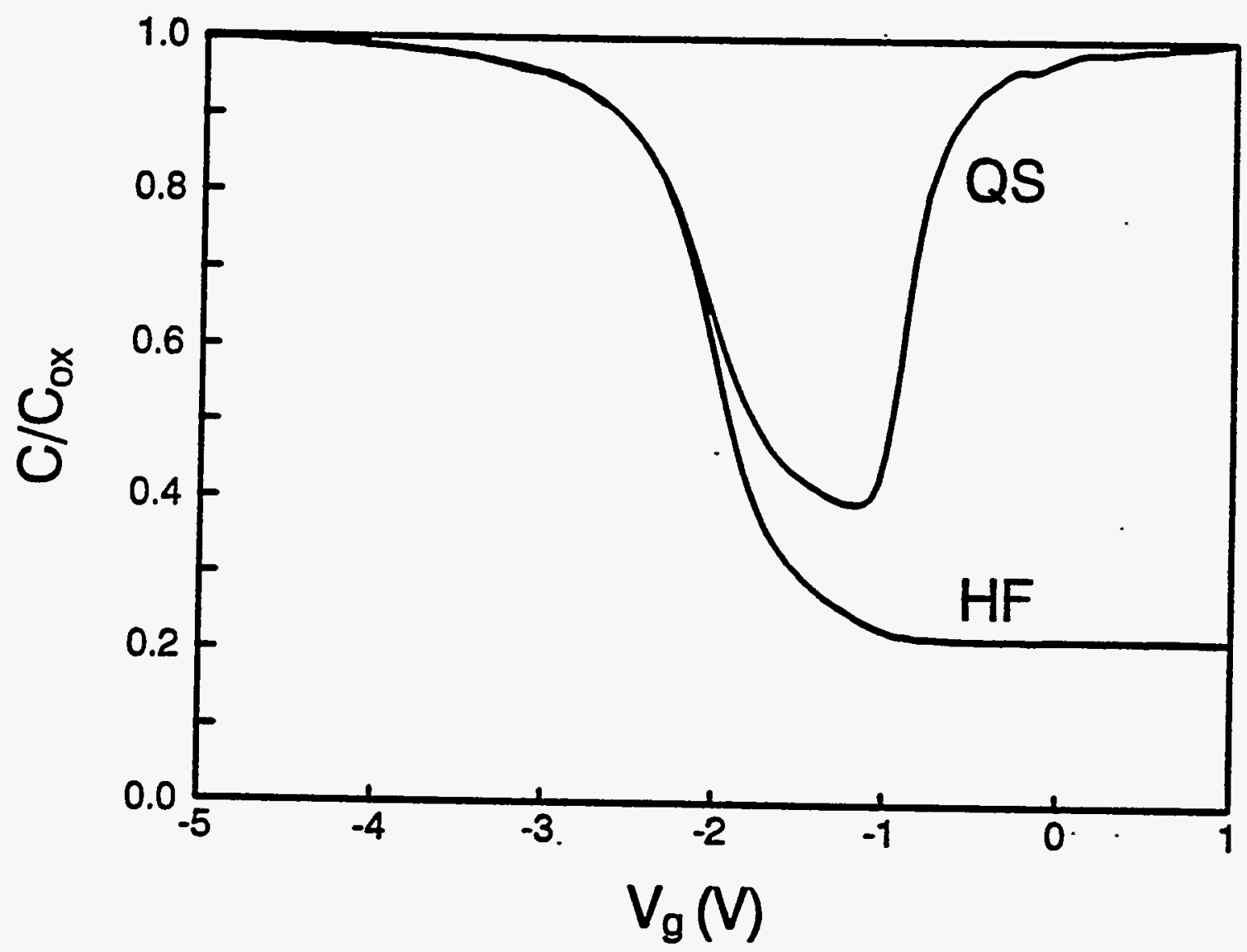

Figure 4.3. High frequency and quasi-static CV curves of the MOS structure for PECVD $\mathrm{SiO}_{2}-\mathrm{Si}$. 


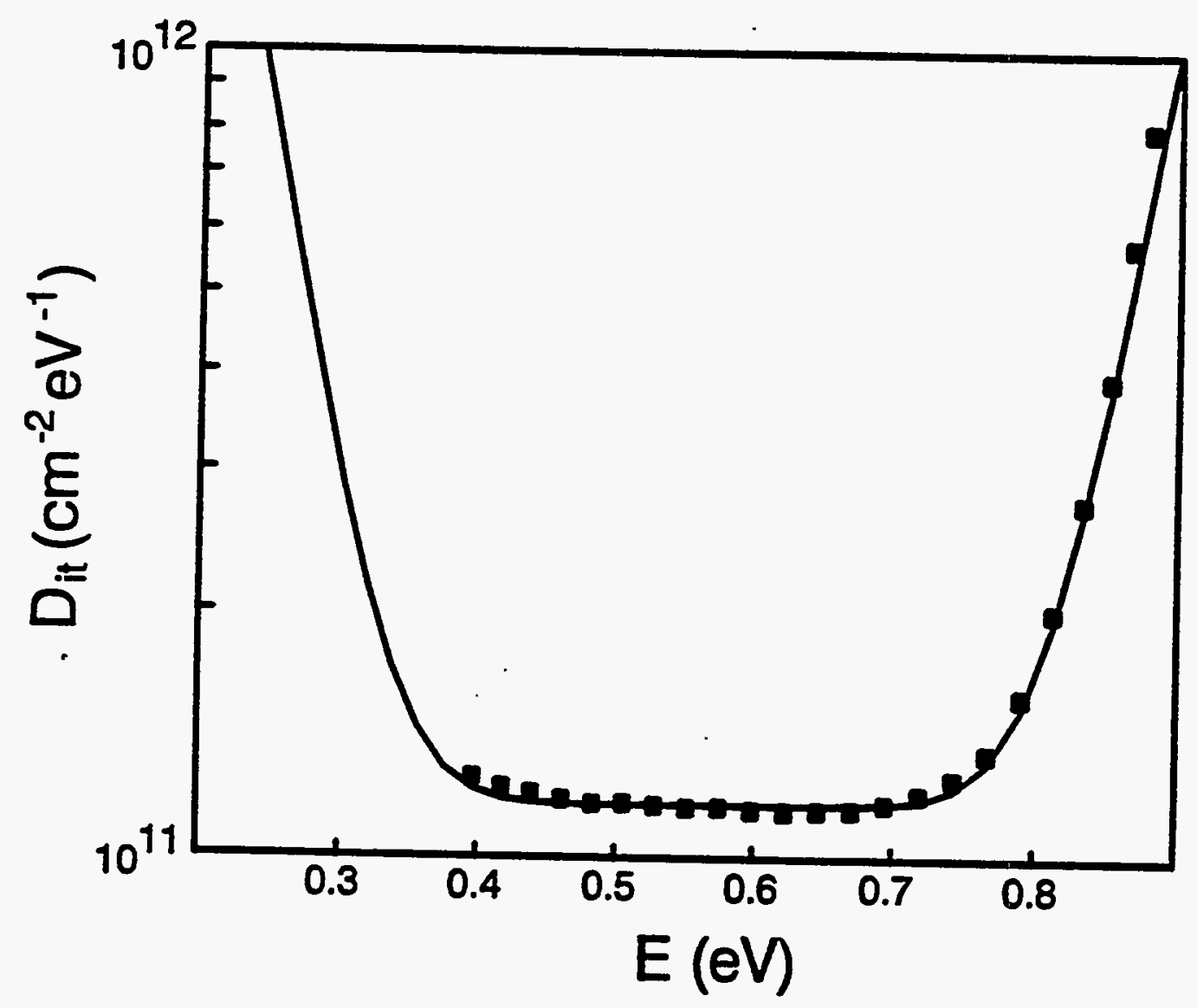

Figure 4.4. $\quad D_{i t}(E)$ distribution in the energy gap obtained from the HF-QS CV curves in Figure $4.3(\square)$ and the assumed function of equation (12) (solid curve). 
From the PCD measurements of the sample, we obtained the effective lifetime $\tau_{\mathrm{ex}}$ The relation between $S_{e f f}, \tau_{e f f}$ and the bulk lifetime $\tau_{b}$ is given by the following equations. [17]

$$
\begin{aligned}
& \frac{1}{\tau_{\text {eff }}}=\frac{1}{\tau_{b}}+D_{n} \frac{\Delta^{2}}{W^{2}} \\
& \Delta \tan \left(\frac{\Delta}{2}\right)=\frac{S_{\text {eff }} W}{D_{n}}
\end{aligned}
$$

where $W$ is the wafer thickness. From the measurements of the thickness dependence of $\tau_{\text {eff }}$ we obtained $\tau_{b}$ $=430 \mu \mathrm{sec}$ at the injection level of $\Delta \mathrm{n}=10^{16} \mathrm{~cm}^{-3}$. The measured $\tau_{\text {eff }}$ as a function of gate bias voltage $V_{g}$ was converted to $S_{e f f}$ using the equations (13) and (14), and then $S_{e f}$ was plotted against $V_{B}$ in Figure 4.5. $S_{e f f}$ appears to have one maximum at about $\mathrm{V}_{\mathrm{g}}=-5 \mathrm{~V}$ and decreases with increasing or decreasing $\mathrm{V}_{\mathrm{g}}$ in accordance with the change of $\psi_{\mathbf{s}}$.

Because it is difficult to obtain $\Psi_{\mathrm{s}}$ from experiments under the illuminated condition, we tried to simulate the results in Figure 4.5 theoretically using the distribution of $\mathrm{D}_{\mathrm{it}}(\mathrm{E})$ in Figure 4.4. Adjustable parameters were the ratio of $\mathrm{D}_{\mathrm{itA}} / \mathrm{D}_{\mathrm{itD}}$ and capture cross section. The work function difference between $\mathrm{Si}$ and ITO was neglected in accordance with a recent report, which suggests very little difference in work functions for these materials. [18] Notice that the peak position of $S_{\text {eff }}$ can be adjusted by changing the ratio of $\sigma_{n}$ and $\sigma_{p}$. The best theoretical fit to the $S_{e f f}$ data in Figure 4.5 was obtained by assuming $D_{i t A}=D_{i t D}$ and energy independent cross section values of

$$
\begin{array}{ll}
\sigma_{n D}=4 \times 10^{-15} \mathrm{~cm}^{2}, & \sigma_{p D}=1 \times 10^{-17} \mathrm{~cm}^{2}, \\
\sigma_{n A}=3 \times 10^{-17} \mathrm{~cm}^{2}, & \sigma_{p A}=3 \times 10^{-16} \mathrm{~cm}^{2} .
\end{array}
$$

These results suggest that the capture cross sections are dependent on the charged state of the interface defects. Yablonovitch et al. reported two cross section ratios $\sigma_{n} / \sigma_{p}$ for the interface states of thermally grown 
$\mathrm{SiO}_{2}$, which suggests a remarkable similarity between the interface properties of thermally grown and PECVD deposited $\mathrm{SiO}_{2}-\mathrm{Si}$ interfaces. [11] As we mentioned in Section 4.3, the plot of $\mathrm{S}_{\text {eff }}$ as a function of $\psi_{s}$ can provide more information about the interface states. Therefore, $S_{\text {eff }}$ is re-plotted as a function of $\psi_{s}$ in Figures $4.6 \mathrm{a}$ and $4.6 \mathrm{~b}$ for the two different cross-section models, by obtaining $\psi_{\mathrm{s}}$ from $\mathrm{V}_{\mathrm{g}}$ using equation (4). In Figure 4.6a, the theoretical curve using the first capture cross section model (equation (10) is shown with the dashed line. Although the first cross section model gives good fit at the dominant maximum of $S_{\text {eff }}$ the shoulder at about $0.03 \mathrm{~V}$ could not be fitted by this model. The better fit is obtained by the second model described by Eg. (15) as shown in Figure 4.6b. However, there still exists a discrepancy between the theoretical curve and data points at $\psi_{\mathrm{s}}$ larger than $0.08 \mathrm{~V}$. This can be improved by using the energydependent cross-section model; however, the experimental error also increases with decreasing $\mathrm{S}_{\text {eff }}$ Therefore, at this point, the capture cross section values in Eg. (15) are considered to be sufficiently accurate to perform further calculations.

Utilizing the cross-section model given in $\mathrm{Eg}$. (15), the dependence of $\mathrm{S}_{\mathrm{eff}}$ on $\mathrm{Q}_{\mathrm{ox}}$ was calculated for several values of $D_{i t}$ for a boron-doped substrate with $N_{A}=2 \times 10^{15} \mathrm{~cm}^{-3}$. Figure 4.7 shows the assumed $D_{\mathrm{it}}(E)$ distribution where mid-gap $D_{\mathrm{it}}$ was varied in the range of $10^{10}-10^{12} \mathrm{~cm}^{-2},\left(10^{10}, 5 \times 10^{10}, 10^{11}, 5 \mathrm{x}\right.$ $10^{11}$ and $\left.10^{12}\right)$, which is experimentally achievable for PECVD oxides. The calculated results are shown in figures 4.8a and 4.8b for an injected carrier density of $\Delta n=10^{14} \mathrm{~cm}^{-3}$ (close to flat plate one-sun solar cell operating condition) and $\Delta \mathrm{n}=10^{16} \mathrm{~cm}^{-3}$ (concentrator cell operating condition), respectively.

From Figures $4.8 \mathrm{a}$ and $4.8 \mathrm{~b}$, we can estimate the required density of $\mathrm{Q}_{\mathrm{ox}}$ to reduce $\mathrm{S}_{\text {eff }}$ for $P E C V D$ $\mathrm{SiO}_{2}$-Si interface. Under a high-injection condition, see Figure 4.8b, we need a higher $\mathrm{Q}_{\mathrm{ax}}$ to reduce $\mathrm{S}_{\mathrm{eff}}$ compared to the low-injection case, seen in Figure 4.8a, because the high-injected carrier density neutralizes the charges at the interface and lowers the $\psi_{s}$. This requires higher $Q_{o x}$ to obtain the same $\Psi_{s}$. It is important to recognize that the band bending due to this mechanism will begin to decrease if the injection level becomes very high. We have limited experimental data that shows the $S_{\text {eff }}$ value increases from 2 to $30 \mathrm{~cm} / \mathrm{s}$ when the 
injection level increases from $5 \times 10^{14}$ to $1 \times 10^{16} \mathrm{~cm}^{-3}$. For high $D_{\mathrm{it}}$ values, the $S_{\mathrm{efr}}-Q_{\mathrm{ox}}$ curves in Figures $4.8 \mathrm{a}$ and $4.8 \mathrm{~b}$ show a hump or a rise in $S_{\mathrm{efr}}$ with increasing $Q_{\mathrm{ox}}$ before $S_{\mathrm{eff}}$ decreases monotonically. This is the result of the two kinds of cross sections, Eg. (15), where the acceptor type interface states contribute to the hump. Calculations in Figures 4.8a and 4.8b indicate that $Q_{o x}$ should be more than 10 times the value of $D_{i t}$ at the mid gap in order to reduce $S_{\text {eff }}$ below $10 \mathrm{~cm} / \mathrm{s}$. This $Q_{a x}$ to $D_{\text {it }}$ ratio is approximately 10 times higher than our previous calculation ${ }^{2}$ based on uniform distribution of $D_{i t}$ in the band gap and the cross section model of Eg. (10). In the present model, increasing $D_{i t}(E)$ toward the band edges (Figure 4.7) and the presence of acceptor type states contribute to the need for higher $Q_{o x}$.

Careful PECVD deposition of $\mathrm{SiO}_{2}$ can produce 10 times larger $Q_{\mathrm{ax}}$ values than the $\mathrm{D}_{\text {it }}$ at the midgap values. Our recent results of a low $D_{i t}=1.1 \times 10^{10} \mathrm{~cm}^{-2} \mathrm{eV}^{-1}$ with $\mathrm{Q}_{\mathrm{ox}}=3.4 \times 10^{11} \mathrm{~cm}^{-2}$ for carefully prepared $\mathrm{PECVD} \mathrm{SiO}_{2}-\mathrm{Si}^{4}$, proves the potential of $\mathrm{PECVD} \mathrm{SiO}_{2}$ passivation of $\mathrm{Si}$ surfaces and also suggests the importance of optimization of PECVD process. The situation becomes more difficult when $\mathrm{D}_{\mathrm{it}}$ is greater than $10^{11} \mathrm{~cm}^{-2} \mathrm{eV}^{-1}$. Further study on the properties on $\mathrm{PECVD} \mathrm{SiO}_{2}-\mathrm{Si}$ interface (especially grown at different conditions and with different substrate doping density) will be helpful and necessary for optimizing the $\mathrm{PECVD} \mathrm{SiO}_{2}$ passivation process for solar cells. 


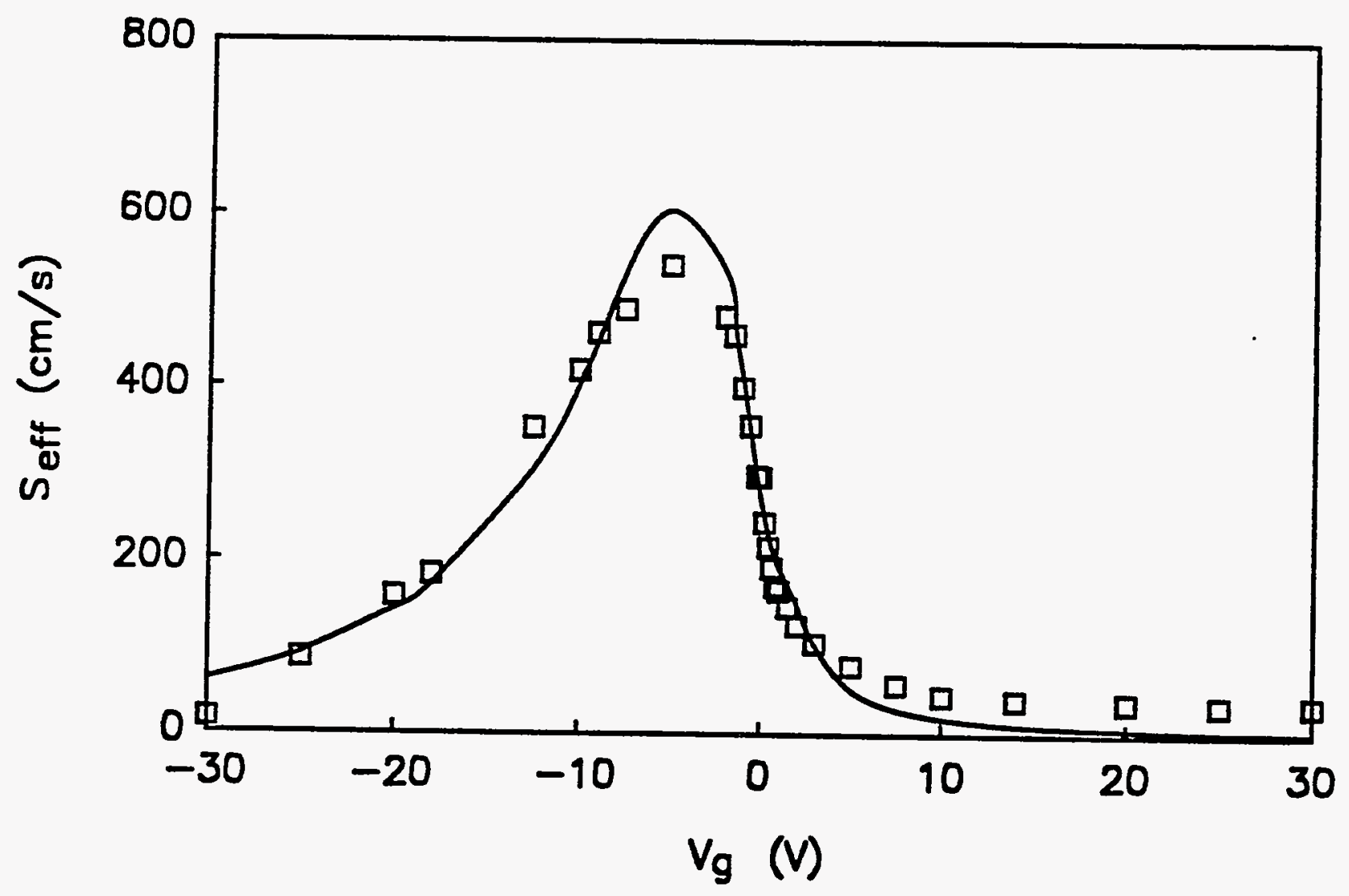

Figure 4.5. Gate voltage dependence of effective surface recombination velocity obtained by the PCD measurements ( $\square$ ) and theoretically fitted curve. 


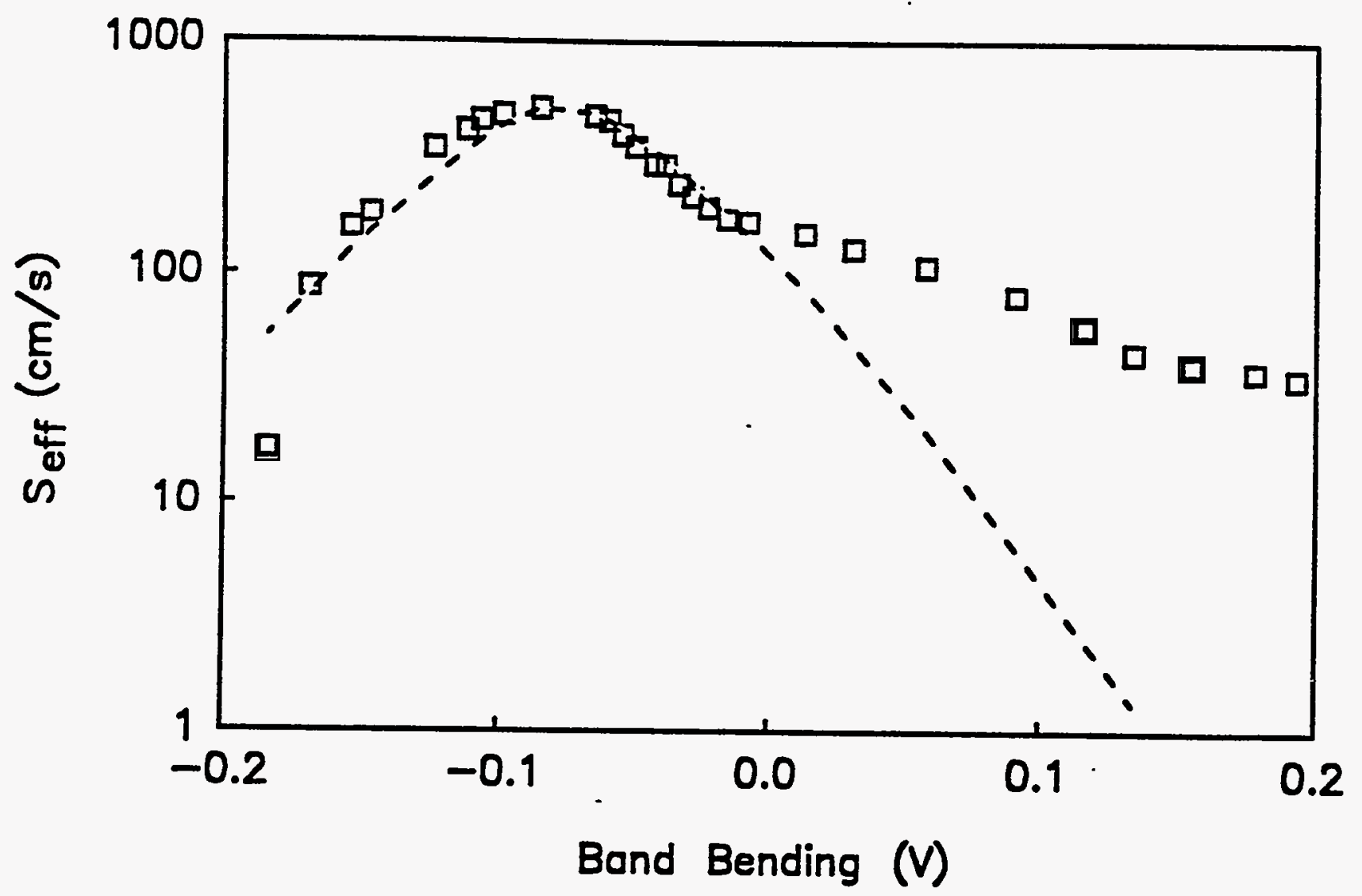

Figure 4.6a. $S_{\text {eff }}$ as a function of surface band bending. Dashed curve: theoretically fitted curve based on the capture cross section model shown in equation (10). 


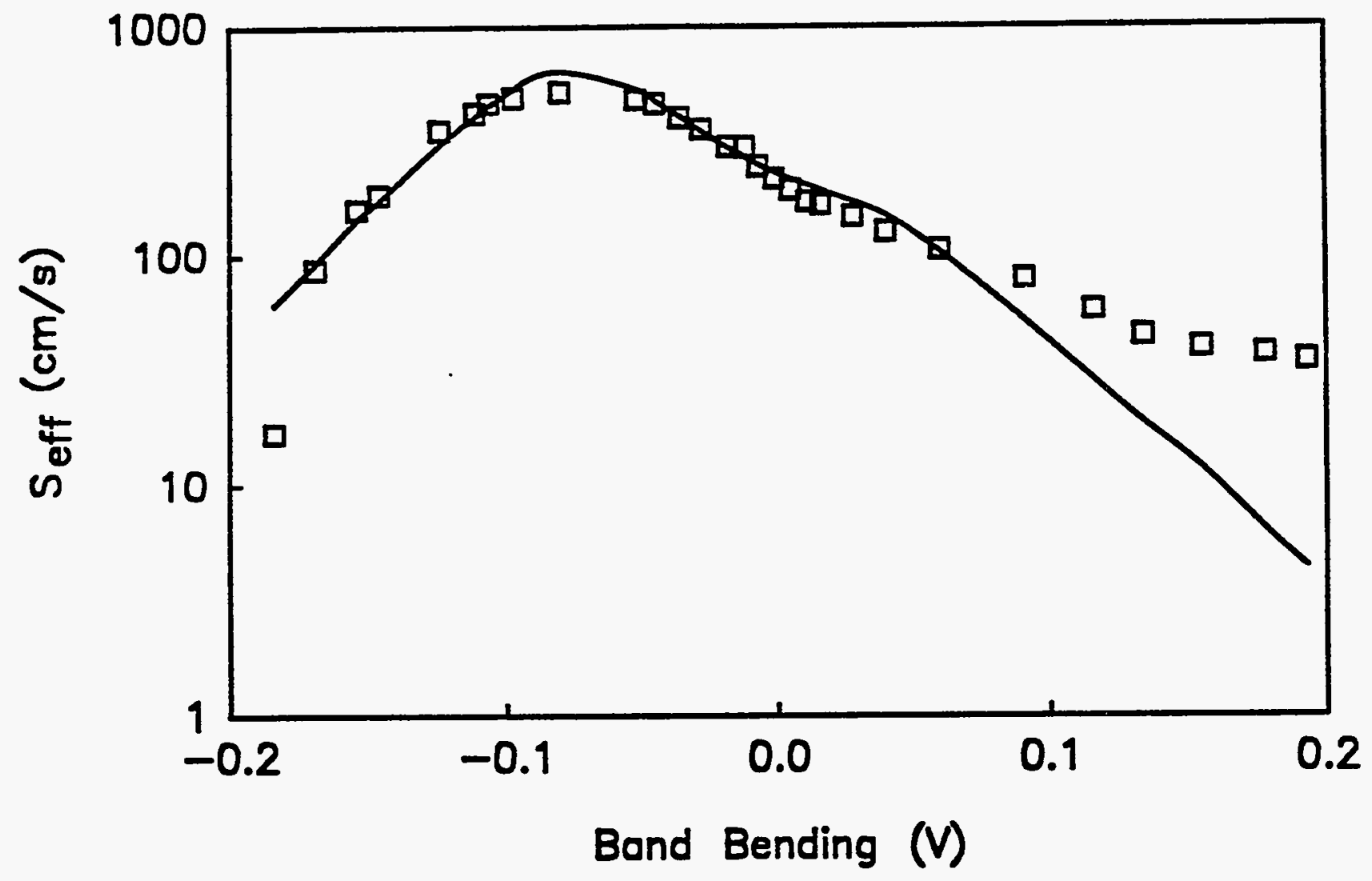

Figure 4.6b. Solid curve: theoretical curve based on the capture cross section model of equation (15). 마 Experimental results plotted against the calculated band bending. 


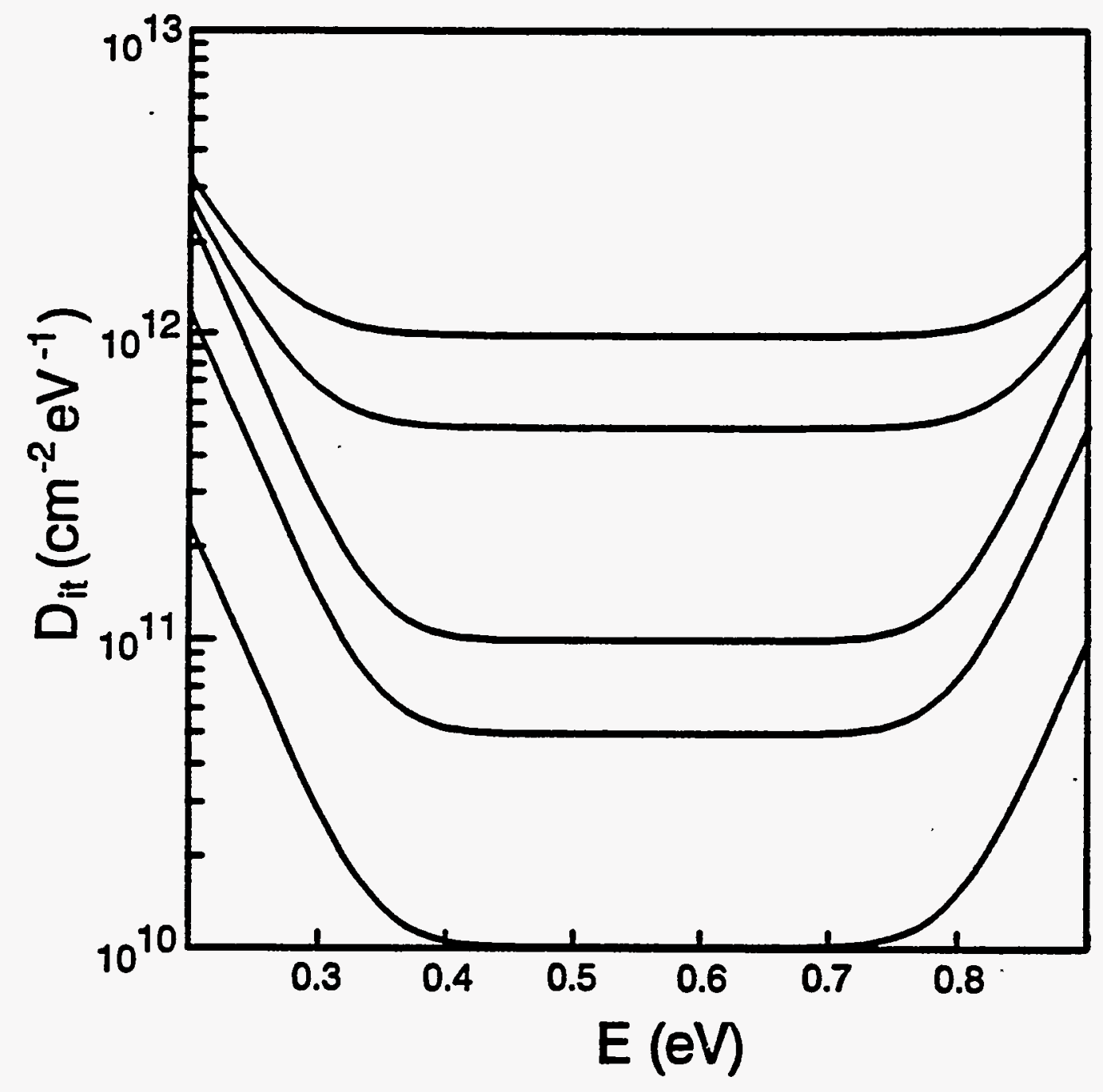

Figure 4.7. Assumed $D^{\text {it }}(E)$ distributions in the energy gap used for the calculation. 


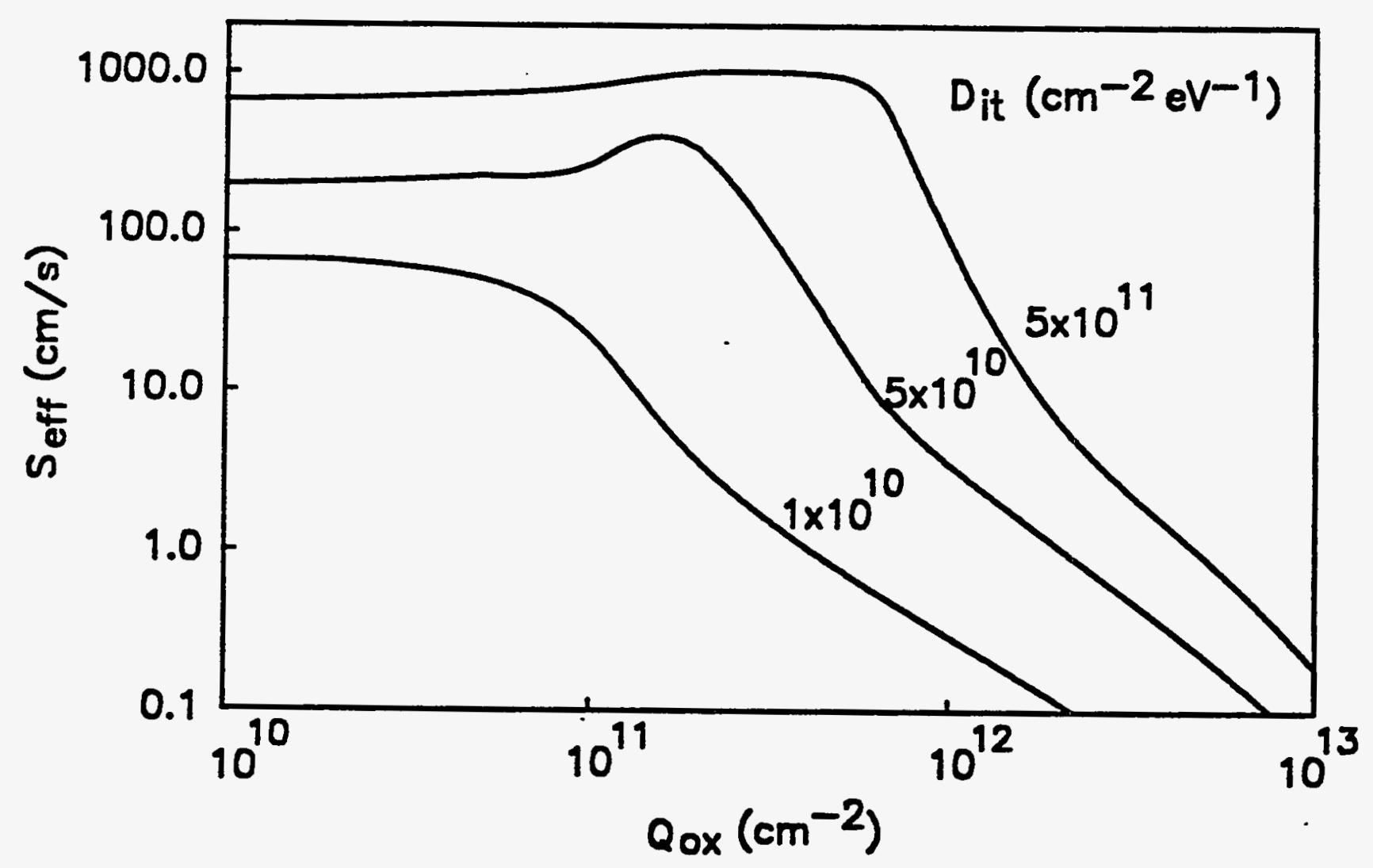

Figure 4.8a. Calculated $S_{\mathrm{efr}}$ as a function of positive fixed. oxide charge density under the injection of $\Delta \mathrm{n}=10^{14} \mathrm{~cm}^{3}$. 


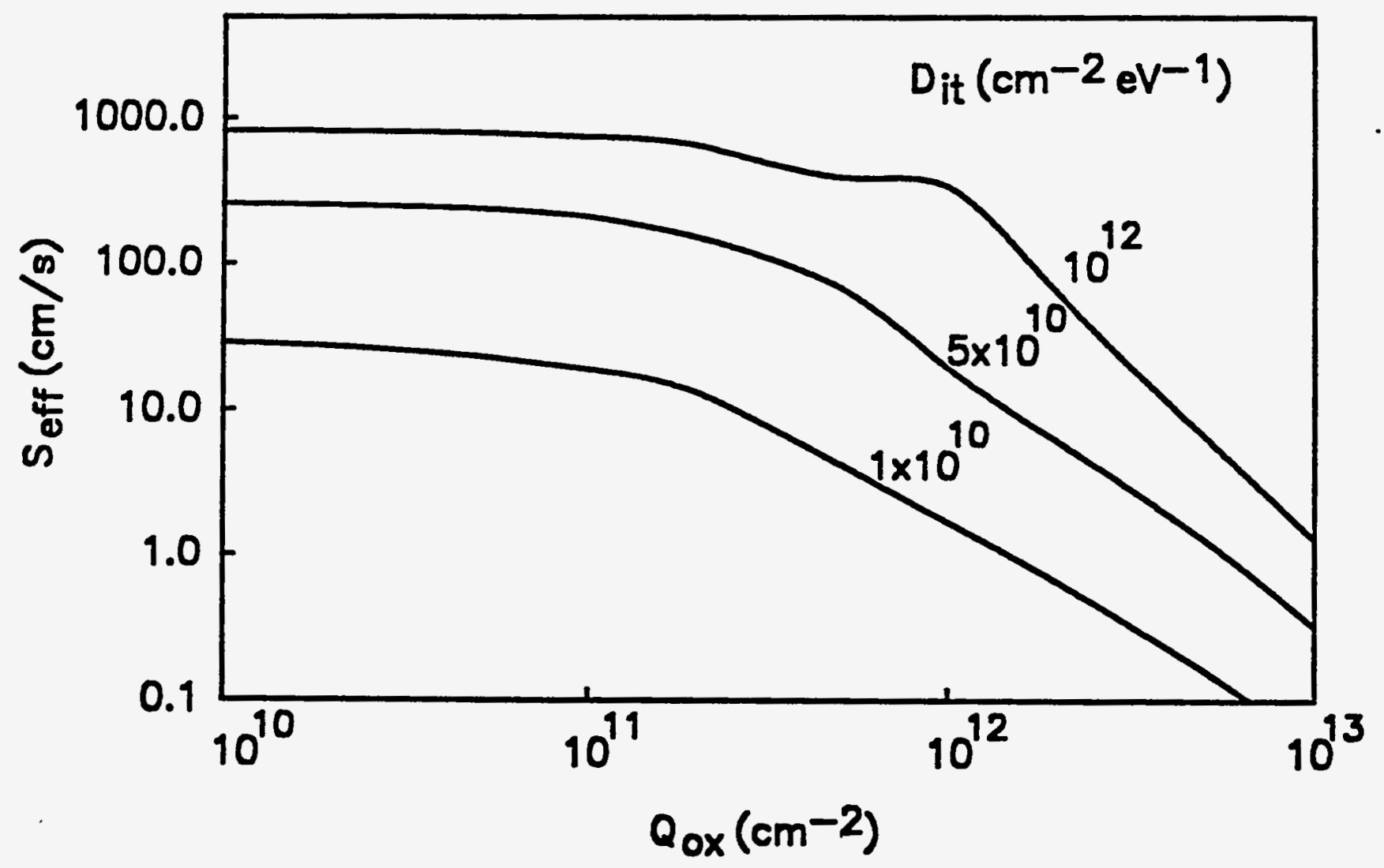

Figure 4.8b. Calculated $S_{\text {efr }}$ as a function of positive fixed oxide charge density under the injection of $\Delta n=10^{16} \mathrm{~cm}^{-3}$. 


\subsubsection{Conclusion}

The effective surface recombination velocity $\left(\mathrm{S}_{\mathrm{eff}}\right)$ at the $\mathrm{PECVD} \mathrm{SiO}_{2}-\mathrm{Si}$ interface was measured by a PCD method in conjunction with the gate bias voltage via transparent ITO gates. A theoretical analysis based on the measured $D_{i t}(E)$ distribution in the band gap was performed to obtain $S_{\text {eff }}$ as a function of the surface band bending, from which the electron and hole capture cross sections for the PECVD $\mathrm{Si}_{2} \mathrm{Si}_{\text {interface }}$ states were estimated to be $\sigma_{\mathrm{nD}}=4 \times 10^{15} \mathrm{~cm}^{2}, \sigma_{\mathrm{pD}}=1 \times 10^{-17} \mathrm{~cm}^{2}, \sigma_{\mathrm{nA}}=3 \times 10^{-17} \mathrm{~cm}^{2}$ and $\sigma_{\mathrm{pA}}=3 \times 10^{-16}$ $\mathrm{cm}^{2}$. Model calculations were extended further to investigate the relationship between $S_{\text {eff }}, Q_{o x}, D_{i t}$, and injection level. It was found that $Q_{a x}$ should be roughly 10 times larger than the mid gap $D_{i t}$ value to in order to reduce $\mathrm{S}_{\mathrm{eff}}$ below $10 \mathrm{~cm} / \mathrm{s}$ for $5 \Omega$-cm $(100) \mathrm{p}$-type $\mathrm{Si}$. These results prove the effectiveness of PECVD $\mathrm{SiO}_{2}$ for passivation of $\mathrm{Si}$ surfaces and its application for devices like solar cells. 


\subsection{Surface And Bulk Defect Passivation In Multicrystalline-Si Materials By

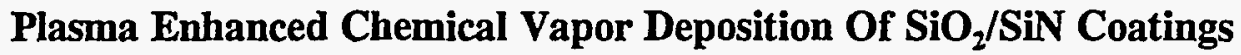

\subsubsection{Introduction}

Previous studies have shown that the application of single-layer PECVD-SiN thin film can be helpful in improving efficiency of mc-Si solar cells. [19 to 24] It not only acts as an antireflection coating layer with a suitable refraction index of -2.0 , but can also improve the performance of photovoltaic devices. This is because the PECVD process ambient contains a large amount of atomic hydrogen, some of which can be incorporated in the PECVD film and the substrate. In addition, PECVD is a low-temperature process (about $300^{\circ} \mathrm{C}$ ) with high throughput, good uniformity, better thickness control ( $<5 \%)$ and excellent reproducibility, compared to other CVD processes (LPCVD or APCVD) and physical evaporation. All these advantages make PECVD SiN film very attractive for silicon solar cells.

The beneficial effects of single-layer PECVD SiN on $\mathrm{J}_{\infty}, \mathrm{V}_{\infty}$, and cell efficiency (Eff) on mcSi cells have been reported. [22 to 24] Recently, Kishore etal. have reported a $28 \%$ improvement in $\mathrm{J}_{\mathrm{sc}}$ and a $13 \mathrm{mV}$ increase in $\mathrm{V}_{\mathrm{cc}}$ due to single-layer PECVD SiN. [23] Even though it has been shown that PECVD SiN improves the Si solar cell performance, it is still not clear whether this improvement results from surface passivation, bulk defect passivation; or a combination of both. No attempt has been made in the past to decouple and quantify the surface and bulk passivation effects. Moreover, the defect passivation effect of the PECVD deposition on different promising photovoltaic mc-Si materials has not been investigated. Recently we showed that the deposition of thin $\mathrm{PECVD} \mathrm{SiO}_{2}$ on single-crystal silicon followed by a photo-assisted anneal results in very high effective minority carrier lifetime, very low surface recombination velocity, and very low interface state density. [25,26] We also showed that the deposition of PECVD SiN film on top of a thin $\mathrm{PECVD} \mathrm{SiO}_{2}$ not only improves 
the degree of surface passivation but also the stability of the passivation. We have shown elsewhere

that a combination of PECVD grown $600 \AA \mathrm{SiN}$ on Si with an refractive index of 2.3 and $950 \AA \mathrm{SiO}_{2}$ on top of that SiN can act as a very efficient double-layer antireflection coating. [27] In our previous studies, single-crystal Si was used and no attempt was made to decouple bulk and surface passivation effects. [ 25 to 27 ] In this article, the surface and bulk passivation effects are quantified due to the double-layer PECVD coating on different multicrystalline Si materials, including EFG sheet silicon, Osaka regular cast (Osaka), Solarex, and Wacker cast multicrystalline silicon materials. The bulk defect passivation was monitored by minority carrier lifetime measured by a photo-conductivity decay (PCD) technique. Some solar cells were fabricated with PECVD coatings and the bulk and surface passivation effects on solar cells were quantified by a combination of quantum efficiency measurements and modeling.

\subsubsection{Experimental}

Low-temperature PECVD is used for the defect passivation of various multi-crsytalline Si materials. The process sequence involves PECVD deposition of $600 \AA$ SiN on top of PECVD grown $100 \AA \mathrm{SiO}_{2}$ on various substrates, followed in a photo-assisted anneal by a tungsten halogen lamp heated system in forming gas ambient. The PECVD SiN and $\mathrm{SiO}_{2}$ films were prepared in a PlasmaTherm Inc reactor (series 700) operated at $13.6 \mathrm{MHz} . \mathrm{SiH}_{4}, \mathrm{NH}_{3}, \mathrm{~N}_{2}$ gases were used for $\mathrm{SiN}$ deposition, and $\mathrm{SiH}_{4}$ and $\mathrm{N}_{2} \mathrm{O}$ gases were involved in $\mathrm{SiO}_{2}$ deposition. The saline concentration was $2 \%$. The ratio of $\mathrm{SiH}_{4} / \mathrm{NH}_{3}$ was controlled to obtain $\mathrm{SiN}$ films with refractive index of 2.3. Substrate temperature was $250^{\circ} \mathrm{C}$ and the if power was $20 \mathrm{~W}$ for $\mathrm{SiO}_{2}$, and $295 \mathrm{C}$ and $30 \mathrm{~W}$ for the $\mathrm{SiN}$ deposition, respectively. After the PECVD depositions, a photo-assisted anneal was performed at $350^{\circ} \mathrm{C}$ for $20 \mathrm{~min}$, in forming gas ambient. Four kinds of wafers were studied, including EFG, Osaka cast (Osaka), Solarex, and Wafer cast Si, with a thickness of $390 \mu \mathrm{m}, 270 \mu \mathrm{m}, 305 \mu \mathrm{m}, 330 \mu \mathrm{m}$, 
respectively. The as-grown wafer cleaning process, prior to PECVD film deposition, is described in detail in Chen etal.25. Each sample was tested by PCD lifetime measurements before and after the passivation. The bulk and surface passivation effects were decoupled and quantified by PCD lifetime measurements in air and HF solution, and also by modeling and IQE measurements before and after the passivation on solar cells fabricated on cast silicon from Osaka Titanium Corporation.

\subsubsection{Results and Discussion}

\subsubsection{Determination of bulk and surface passivation by PCD lifetime measurements}

PCD measurement in air gives an effective lifetime by

$$
\frac{1}{\tau_{\text {eff }}}=-\frac{1}{N} \frac{d N}{d t}
$$

where $\mathrm{N}$ is the injected carrier concentration and $t$ is the decay time. The $\tau_{\text {eff }}$ includes both bulk and surface recombination of photogenerated carriers. [28] Table 4.1 shows the effective minority carrier lifetime ( $\tau_{\text {eff }}$ ) for the four kinds of as-grown samples determined by PCD measurements in the air. The uc and $c$ terms in the brackets of Table 4.2 represent samples not coated and coated, respectively, with the $\mathrm{PECVD} \mathrm{SiO}_{2} / \mathrm{SiN}$ double layer coating. It is clear from the data that a substantial improvement in $\tau_{\text {eff }}$ was observed in all four materials after the PECVD depositions followed by photo-assisted anneal. The $\tau_{\text {ef }}$ improved by a factor of 2.5 to 9.5 due to the PECVD passivation, depending upon the material. It is important to recognize that $\tau_{\text {eff }}$ includes both surface and bulk passivation effects. 
Table 4.1. The effective lifetime (Ms) measured before and after the PECVD coating

\begin{tabular}{||l|l|l|l|l||}
\hline & EFG & Osaka & Solarex & Wacker \\
\hline$\tau_{\text {eff }}(\mathrm{uc})$ & 1.4 & 2.2 & 5.9 & 2.1 \\
\hline$\tau_{\text {ef }}(\mathrm{c})$ & 4.3 & 21.0 & 23.1 & 5.6 \\
\hline$\tau_{\text {eff }}(\mathrm{c}) / \tau_{\text {eff }}(\mathrm{uc})$ & 3.1 & 9.5 & 3.9 & 2.6 \\
\hline
\end{tabular}

Table 4.2. The lifetime (Ms) in HF measured before and after the PECVD coating

\begin{tabular}{||l|l|l|l|l||}
\hline & EFG & Osaka & Solarex & Wacker \\
\hline$\tau_{\mathrm{HF}}(\mathrm{uc})$ & 3.6 & 22.3 & 41.4 & 4.1 \\
\hline$\tau_{\mathrm{HF}}(\mathrm{c})$ & 5.4 & 38.6 & 58.7 & 5.3 \\
\hline$\tau_{\mathrm{HF}}(\mathrm{uc}) / \tau_{\mathrm{HF}}(\mathrm{c})$ & 1.5 & 1.7 & 1.4 & 1.3 \\
\hline
\end{tabular}

In order to decouple the bulk and surface passivation effects, each sample was also measured in concentrated HF solution before and after the PECVD passivation. HF solution is known to provide a near-perfect surface passivation for silicon, via H-Si bond formation. [28] Therefore, the PCD lifetime measured in HF $\left(\tau_{\mathrm{HF}}\right)$ reveals true bulk recombination, and the change in $\tau_{\mathrm{HF}}$ before and after the PECVD passivation should represent bulk defect passivation. Table 4.2 shows the improvement in $\tau_{\mathrm{HF}}$ due to the PECVD passivation of all four materials. It can be seen that these four materials show significant bulk defect passivation after the PECVD deposition of $\mathrm{SiN} / \mathrm{SiO}_{2}$. The $\tau_{\mathrm{HF}}$ increases by $30 \%$ to $70 \%$ after the passivation depending upon the multicrystalline material. It should be noted that the passivation efficiency is material specific, but seems to be independent of the initial bulk lifetime value. 
As indicated above, $\tau_{\mathrm{HF}}$ can be used as a good measure of true bulk lifetime; therefore, $\tau_{\text {eff }}$ can be approximately expressed as: [28]

$$
\frac{1}{\tau_{\text {eff }}}=\frac{1}{\tau_{b}}+\frac{2 S}{L}=\frac{1}{\tau_{H F}}+\frac{1}{\tau_{s}}
$$

where $\mathrm{L}$ is wafer thickness, $S$ is surface recombination velocity, and $\tau_{s}$ is the surface lifetime. Thus $\tau_{\text {s }}$ can now be determined by measuring $\tau_{\text {eff }}$ and $\tau_{\mathrm{HF}}$. The surface lifetime after the PECVD passivation, shown in Table 4.3 increases by a factor of 5.5 to 23 , depending upon the material.

Table 4.3. The surface lifetime before and after the PECVD coating where (c) And (uc) stand for coated and uncoated, respectively.

\begin{tabular}{||l|l|l|l|l||}
\hline & EFG & Osaka & Solarex & Wacker \\
\hline$\tau_{s}(\mathrm{uc})$ & 2.3 & 2.4 & 6.9 & 4.3 \\
\hline$\tau_{\mathrm{s}}(\mathrm{c})$ & 21.1 & 46.1 & 38.1 & 98.9 \\
\hline$\tau_{s}(\mathrm{c}) / \tau_{s}(\mathrm{uc})$ & 9.2 & 18.8 & 5.5 & 22.9 \\
\hline
\end{tabular}

By knowing the sample thickness and $\tau_{s}$, the $S$ value can be determined from Eq. (2). For example, Osaka cast with a thickness of $270 \mu \mathrm{m}$ and the $\tau_{\mathrm{a}}$ of $46.1 \mu \mathrm{s}$ after the PECVD passivation, then S value was found to be $292 \mathrm{~cm} / \mathrm{sec}$. Using $\mathrm{Eq}(2)$, the relationship between $\tau_{\mathrm{eff}}, \tau_{\mathrm{HF}}$, and $\tau_{\mathrm{g}}$ can be expressed as:

$$
\frac{\tau_{e f f}(c)}{\tau_{e f f}(u c)}=\frac{\tau_{s}(c) \frac{\tau_{H F}(c)}{\tau_{H F}(u c)}+\tau_{H F}(c) \frac{\tau_{s}(c)}{\tau_{s}(u c)}}{\tau_{H F}(c)+\tau_{s}(c)}
$$


The first and second terms in the numerator on the right side of Eq.(3) are related to the improvements in $\tau_{\mathrm{HF}}$ and $\tau_{s}$, and represent the partial contribution to the improvement in $\tau_{\text {eff }}$ from bulk and surface passivation, respectively.

Thus, the above results show that the $\mathrm{PECVD} \mathrm{SiO}_{2} / \mathrm{SiN}$ coating provides significant bulk and surface defect passivation, but the degree of passivation is material specific. For example, Osaka cast silicon showed the highest degree of bulk passivation, and Wacker material showed maximum improvement in surface passivation. This is not surprising because these materials are made by different manufacturers and contain a large variation in bulk and surface defects. No attempt was made to correlate the degree of passivation with defect variation at the microscopic scale in the materials. Therefore, the exact passivation mechanism is not fully understood at this time. However, atomic hydrogen, generated during PECVD SiN deposition and the use of forming gas in photoassisted anneal are expected to play a significant role in the defect passivation. This was supported by the large amount of hydrogen detected by FTIR measurements in the PECVD SiN film. [29]

\subsubsection{PECVD-induced bulk and surface defect passivation in multicrystalline silicon solar cells}

Simple $\mathrm{n}^{+}-\mathrm{p}-\mathrm{p}^{+}$solar cells were fabricated by phosphorus diffusion on the front and $\mathrm{Al}$ diffusion on the back of the cells. The internal quantum efficiency (IQE) measurements were performed to decouple bulk and surface passivation effects in the cells. The IQE of a solar cell is a strong function of surface recombination velocity(s) and bulk lifetime $(\tau)$. [30] The short wavelength response is primarily influenced by surface passivation, while the long wavelength response is primarily affected by bulk defect passivation. Therefore, the experimentally measured IQE of a solar cell before and after the PECVD passivation, in conjunction with IQE modeling, can provide useful information about the degree of both surface and bulk passivation. A one-dimensional 
simulation program, PC1D, was used to calculate and fit the measured IQE as a function of wavelength with varying front surface recombination velocity(s) and bulk lifetime ( $\tau)$. [31] The important input parameters for the $\mathrm{n}^{+} \mathrm{p}-\mathrm{p}^{+}$cell structure used in the PC1D simulation are listed in Table 4.4 Grain boundary and defect passivation effects are represented by effective bulk lifetime.

Table 4.4. The Input Parameters Used In PC1D Simulation Of Cell's IQE

$\begin{array}{ll}\text { Material } & \mathrm{p}-\mathrm{Si} \\ \text { Substrate resistivity } & 0.8 \Omega-\mathrm{cm} \\ \text { Substrate thickness } & 300 \mu \mathrm{m} \\ \text { Emitter surface doping concentration } & 1 \times 10^{19} \mathrm{~cm}^{-3} \\ \text { Emitter junction depth } & 1 \mu \mathrm{m} \\ \text { Emitter doping profile } & \text { external } \\ \text { Front surface recombination velocity } & \text { variable } \\ \text { Bulk lifetime } & \text { variable } \\ \text { Rear surface recombination velocity } & 10^{6} \mathrm{~cm} / \mathrm{s} \\ \text { Rear surface doping } & \mathrm{p}-\mathrm{type} \\ \text { Rear surface doping concentration } & 5 \times 10^{18} \mathrm{~cm}^{-3} \\ \text { Rear junction depth } & 1 \mu \mathrm{m} \\ \text { Rear doping profile } & \text { Erfc } \\ \text { Rear surface reflection } & 70 \% \\ \text { Auger coefficient for hole } & 9.9 \times 10^{-32} \mathrm{~cm}^{6} \mathrm{~s}^{-1} \\ \text { Auger coefficient for electron } & 2.8 \times 10^{-31} \mathrm{~cm}^{6} \mathrm{~s}^{-1} \\ \text { Temperature } & 25{ }^{\circ} \mathrm{C}\end{array}$

The calculated variation in IQE for $\mathrm{s}=10^{4} \mathrm{~cm} / \mathrm{s}$ and $\tau$ in the range of $5-25 \mu \mathrm{s}$ is shown in Figure 4.9a. Similarly variation in IQE for a fixed $\tau=25 \mu \mathrm{s}$ and $\mathrm{s}$ in the range of $10^{3}-10^{6} \mathrm{~cm} / \mathrm{s}$ is shown in Figure $4.9 \mathrm{~b}$. It is clear that, for this cell design with fixed back surface conditions, short wavelength IQE $(\lambda<800 \mathrm{~nm})$ is a strong function of front surface recombination velocity, s, but s has no effect on the IQE in long wavelength region $(\lambda>850 \mathrm{~nm})$, Figure $4.9 \mathrm{~b}$ In contrast to the effect of s, bulk lifetime $\tau$ has strong influence on IQE in the long wavelength region $\lambda>800 \mathrm{~nm}$, but has no effect on the short wavelength $\operatorname{IQE}(\lambda<700 \mathrm{~nm})$, Figure $4.9 \mathrm{a}$. Thus, the change in IQE 
can be modeled by selecting $s$ and $\tau$ to fit short and long wavelength IQE, respectively. Thus the PECVD coating induced changes in $s$ and $\tau$ can be estimated from modeling the measured IQE data.

Figure 4.10 shows the measured and calculated IQE data for the same cell before and after the PECVD coating. The s and $\tau$ values were adjusted in the PC1D simulation to obtain the best fit to the experimental data. Before the PECVD passivation, $\mathrm{s}=2 \times 10^{5} \mathrm{~cm} / \mathrm{s}$ and $\tau=10 \mu \mathrm{s}$ gave a very good match between the measured and modelled IQE data. However, after the PECVD coating, $s$ $=5 \times 10^{4} \mathrm{~cm} / \mathrm{s}$ and $\tau=20 \mu \mathrm{s}$ gave the best fit to the measured IQE data, Figure $4.10 \mathrm{It}$ should be noted that in the wavelength range of $400-475 \mathrm{~nm}$, the calculated IQE is higher than the measured IQE. We have shown elsewhere that the slight absorption in short wavelength is due to high index of PECVD SiN, which is not accounted for in the PC1D modeling. [27] The higher refractive index of $\operatorname{SiN}(2.3$, instead of 2.0$)$ is used for the better double layer antireflection coating. [27] The decrease in $\mathrm{s}$ from $2 \times 10^{5}$ to $5 \times 10^{4} \mathrm{~cm} / \mathrm{s}$ and increase in $\tau$ from 10 to $20 \mu \mathrm{s}$ indicate that the PECVD coating not only passivates the surface but also gives rise to significant bulk defect passivation. This is consistent with the passivation results on as-grown samples in the Tables $4.1,4.2$ and 4.3 It is interesting to note that the bulk and surface passivation effect of the PECVD remained noticeable in the cells even though cells have undergone phosphorus and $\mathrm{Al}$ gettering. This suggests that PECVD passivation is complementary to the getting treatment. 


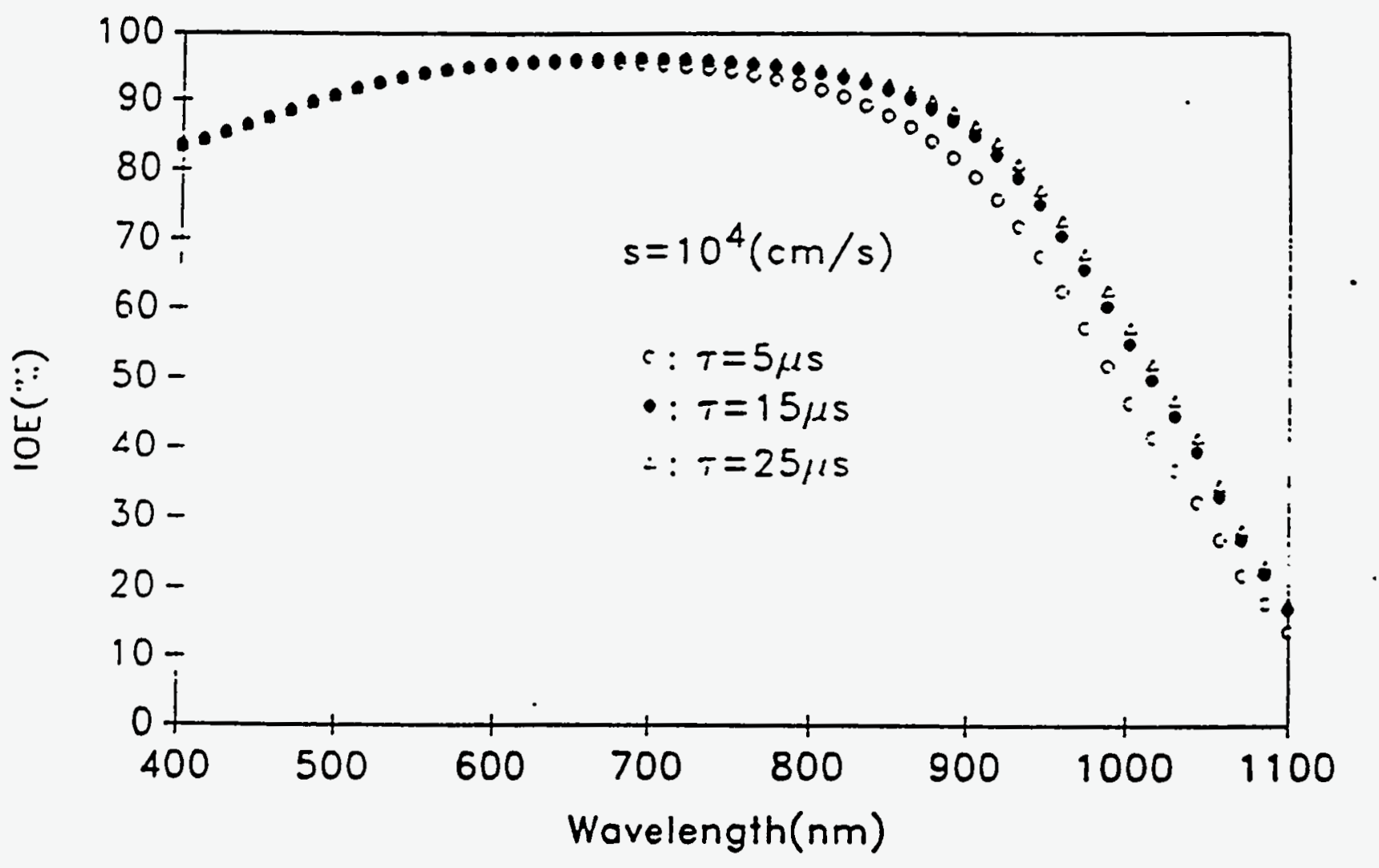

Figure 4.9a. The calculated IQE for $\mathbf{n}^{+} \mathrm{pp}^{+}$solar cell with variation of substrate bulk lifetime $T$ and for a fixed front side surface recombination velocity $S$. 


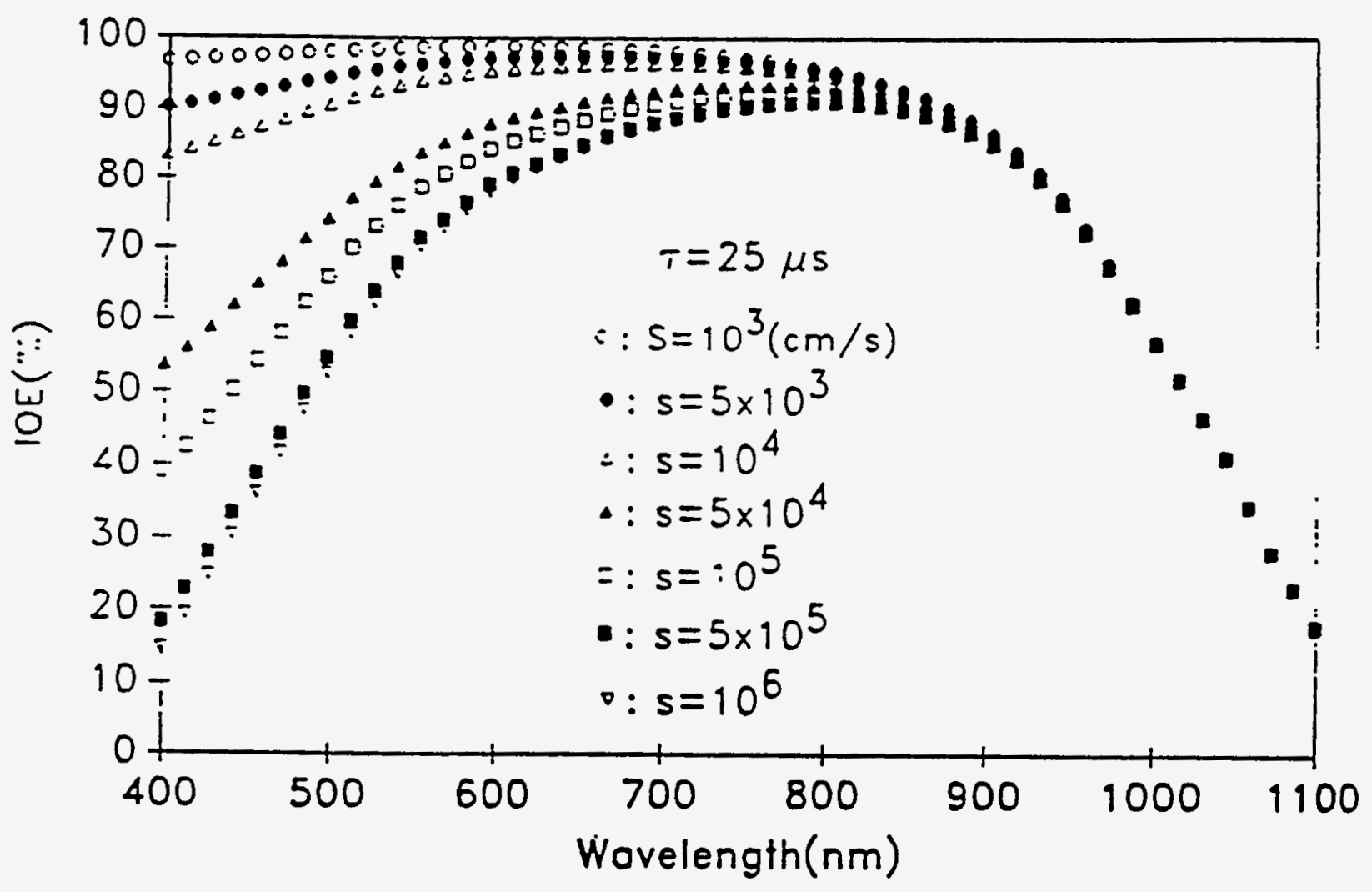

Figure 4.9b The calculated IQE variation with front surface recombination velocity $S$ for a fixed bulk lifetime. 


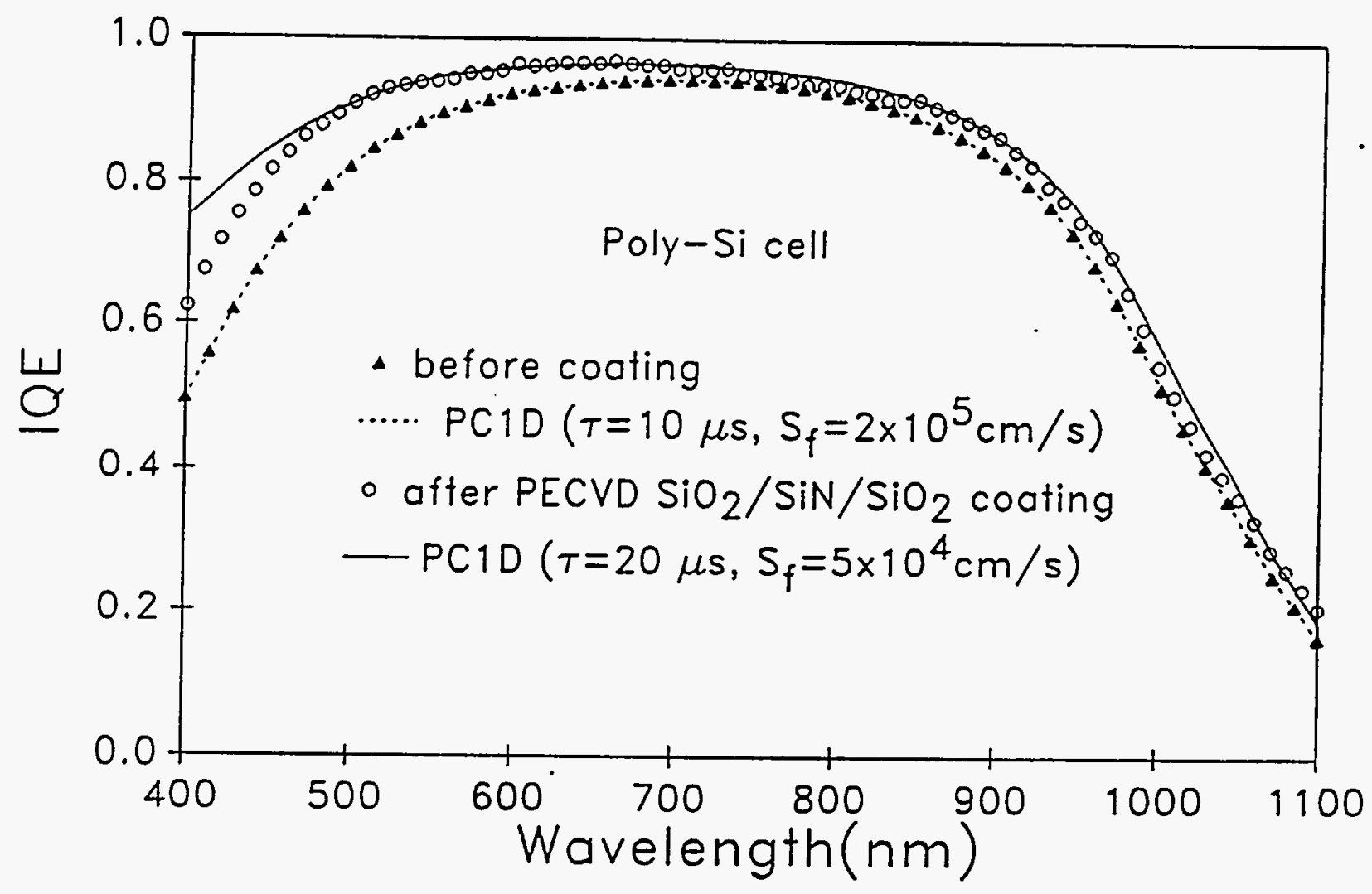

Figure 4.10 Comparison of measured and calculated IQE to asses change in $S$ and $T_{b}$ due to PECVD coating. 


\subsubsection{Conclusions}

A novel PECVD passivation technique has been used for bulk and surface passivation of multicrystalline Si materials. This technique consists of low-temperature $\left(250^{\circ} \mathrm{C}\right) \mathrm{PECVD}$ deposition of $\operatorname{SiN}(600 \AA) / \operatorname{SiO}(100 \AA)$ double layer coating followed by photo-assisted anneal at $350^{\circ} \mathrm{C}$ in forming gas ambient. The surface and bulk defect passivation effects of the PECVD passivation were decoupled and quantified for the first time by the PCD lifetime measurements in air and HF solution, as well as by cell fabrication, followed by matching the measured and calculated IQE. It is shown that the PECVD coating is very effective for both surface and bulk defect passivation of promising photovoltaic mc-Si materials. However, the passivation efficiency is found to be material specific. In the as-grown materials, the bulk lifetime improved by $30 \%$ to $70 \%$ and the surface passivation improved by a factor of 5.5 to 23 due to the PECVD coating. Solar cells made on Osaka-cast multicrystalline Si showed a decrease in surface recombination velocity by a factor of 4 and increase in bulk lifetime by a factor of 2 . This compares with an increase in bulk lifetime by a factor of 1.7 and $\tau_{\mathrm{s}}$ by a factor of 18.8 for PECVD coated as-grown sample. The significant difference in the surface passivation of the cell and the as-grown wafer suggests that the PECVD is less effective in passivating the heavily diffused front surface of the cells compared to the lightly diffused as-grown wafer surface. 


\subsection{References}

4.1 High_Efficiency Silicon Solar Cells, ed. M.A. Green (editor) Trans Tech Publications, Switzerland, (1987): 100.

4.2 Z. Chen, S.K. Pan, K. Yasutake and A. Rohatgi, "Plasma Enhanced Chemical Vapor Deposited Oxide for Low Surface Recombination Velocity and High Effective Lifetime in Silicon," Journal of Applied Physics vol. 74, no. 4, August 1993: 2856-2859.

4.3 Z. Chen, P. Sana, J. Salami and A. Rohatgi, "A Novel and Effective PECVD $\mathrm{SiO}_{2} / \mathrm{SiN}$ Antireflection Coating for Si Solar Cells," IEEE Transactions on Electron Devices, vol. 40, no. 6, June 1993: 1161-1165.

4.4 Z. Chen, K. Yasutake, A. Doolittle, and A. Rohatgi, "Record Low $\mathrm{SiO}_{2} / \mathrm{Si}$ Interface State Density for Low temperature Oxides Prepared by Direct Plasma-Enhanced Chemical Vapor Deposition," Applied Physics Letters, vol. 63, no. 15, October 1993:1-3.

4.5 E.H. Nicollian and J.R. Brews, MOS (Metal Oxide Semiconductor) Physics and Technology, (New York: John Wiley, 1982)

4.6 T. Saitoh and H. Hasegawa, "Computer Analysis of Surface Recombination Velocity for High Efficiency Single Crystalline Solar Cells," Technical Digest of the International PVSEC-5, Kyoto Japan, (1990): 579-582.

4.7 W.D. Eades and R.M. Swanson, "Calculation of Surface Generation and Recombination Velocities at the $\mathrm{Si}_{-} \mathrm{SiO}_{2}$ Interface," Journal of Applied Physics, vol. 58, 1985: 4267-76.

4.8 A.G. Aberle, S. Glunz and W. Warta, "Impact of Illumination Level and Oxide Parameters on Shockley-Read-Hall Recombination at the $\mathrm{Si}_{-} \mathrm{SiO}_{2}$ Interface," Journal of Applied Physics, vol. 71, no. 9, 1992: 4422-31.

4.9 W.D. Eades and R.M. Swanson, "Determination of the Capture Cross Section and Degeneracy Factor of $\mathrm{Si}_{-} \mathrm{SiO}_{2}$ Interface States," Applied Physics Letters, vol. 44, no. 10, 1984: 988-990.

4.10 T. Katsube, K. Kakimoto and T. Ikoma, "Temperature and Energy Dependence of Capture Cross Sections at Surface States in Si Metal-Oxide-Semiconductor Diodes Measured by Deep

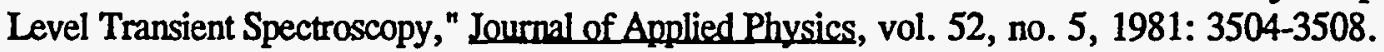

4.11 E. Yablonovitch, R.M. Swanson, W.D. Eades and B.R. Weinberger, "Electron-Hole Recombination at the Si-Si0//2 Interface," Applied Physics Letter, vol. 48, 1986: 245-247.

4.12 S.K. Pang and A. Rohatgi, "Record High Recombination Lifetime in Oxidized Magnetic Czochralski Silicon", Applied Physics Letters, vol. 59, 1991: 195-197.

4.13 W. Shockley and W.T. Read, "Statistics of the Recombination of Holes and Electrons," Physics Review, vol. 87, (1952): 835-842. 
4.14 R.N. Hall, "Electron-Hole Recombination in Germanium", Pbysics Review vol. 87, (1952): 387.

4.15 R.B.M. Girisch, R.P. Mertens and R.F. DeKeersmaecker, "Determination of $\mathrm{Si}_{-} \mathrm{SiO}_{2}$ Interface Recombination Parameters Using a Gate-Controlled Point-Junction Diode Under Illumination," IEEE Transactions on Electron Devices, vol. 35, no. 2, (1988): 203-222.

4.16 D.P. Joshi and D.P. Bhatt, "Theory of Grain Boundary Recombination and Carrier Transport in Polycrystalline Silicon Under Optical Illumination," IEEE Transactions on Electron Devices, vol. 37, no. 1, (1990): 237-249.

4.17 S.K. Pang and A. Rohatgi, "A New Methodology for Separating Shockley-Read-Hall Lifetime and Auger Recombination Coefficients from Photoconductivity Decay Technique", Journal of Applied Physics, vol. 74, no. 9, (Nov. 1993): 5554-5560.

4.18 N. Balasubramanian and A. Subrahmanyam, "Studies on Evaporated Indium Tin Oxide (ITO)/Silicon Junctions and an Estimation of ITO Work Function", Journal of the Electrochemical Society, vol. 138, no 1, (1991): 322-324.

4.19 P.P Michiels, L.A. Verhoef, J.C. Stroom, W.C. Sinke, R.J.C. van Zolingen, C.M.M. Denisse and M. Hendriks, "Hydrogen Passivation of Polycrystalline Silicon Solar Cells by Plasma Deposition of Silicon Nitride" in Proceedings of the 21st IEEE Photovoltaics Specialists Conf., (1990): 638-643.

4.20 M. Lemiti, J. Gervais, and S. Martinuzzi, "Hyfrogentation Of Multicrystalline Silicon From A Backside Silicon Nitride Layer" in Proceedings of the 22nd IEEE Photovoltaics Specialists Conf, (1991): 1002-1005.

4.21 J.C. Muller, B. Hartit, E. Hussian, J.P. Schunck, P.Siffert and D. Sarti, "Improvement Of Silicon Nitride Solar Cells After Thermal Processing Gettering Or Passivation?" in Proceedings of 22nd IEEE Photovoltaics Specialists Conf, (1991): 883-886.

4.22 S.R. Wenham, M.R. Willison, S. Narayanan, M.A. Green, "Efficiency Improvement In Screen Printed Polycrystalline Silicon Solar Cells By Plasma Treatments" in Proceedings of the 18th IEEE Photovoltaics Specialists Conf, (1985): 1008-1013.

4.23 Ram Kisshore, S.N.Singh, B.K. Das, "Growth Of Silicon Nitride Films On Single Crystalline And Multicrystalline Silicon Solar Cells Using PECVD Technique," 6th_International Photovoltaic Science and Engineering Conf, (1992): 249-253.

4.24 S. Narayanan, S. Ronein, J. Wohlgemuth, "Silicon Nitride AR Coatings For Low Cost Silicon Solar Cells, "6th International Photovoltaic Science and Engineering Conf, (1992): 133-136.

4.25 Z. Chen, S.K. Pang, K. Yasutake, and A. Rohatgi, "Plasma Enhanced Chemical Vapor Deposited Oxide For Low Surface Recombination Velocity And High Effective Lifetime in Silicon", Journal of Applied Physics, vol. 74, (1993): 2856. 
4.26 Z. Chen, K. Yasutake, A. Doolittle, and A. Rohatgi, "Record Low $\mathrm{SiO}_{2} / \mathrm{Si}$ Interface State Density For Low Temperature Oxides Prepared By Direct Plasma-Enhanced Chemical Vapor Deposition", Applied Physics Letters, vol. 63, (1993): 2117-2119.

4.27 Z. Chen, P. Sana, J. Salami, and A. Rohatgi, "A Novel And Effective PECVD $\mathrm{SiO}_{2} / \mathrm{SiN}$ Antireflection Coating For Si Solar Cells," IEEE. Transactions on Electron Devices, vol. 40, (1993): 1161-1165.

4.28 E. Yablonovitch, D. L. Allara, C.C. Chang, T. Gmitter, and T. B. Bright, Phys. Rev. Lett. 57, (1986): 249.

4.29 A. Rohatgi, Z. Chen, W.A. Doolittle, J. Salami, and P. Sana, "Fundamental Research On Post Growth Enhancement Techniques In Crystalline Silicon Materials" Final Technical Report to National Renewable Energy Laboratory, Contract No. XX-0-19145-1, (March, 1992).

4.30 H.J. Hovel, Semetals and Semiconductors. (London: Academic Press, Inc., 1975).

4.31 P A. Basore, PC-1D Installation Manual and User's Guide, SAND91-0516, (Alburquerque: Sandia National Laboratories, 1991) dated May 1991. 

CHAPTER 5.

LOW-COST, HIGH-EFFICIENCY SILICON SOLAR CELLS BY

RAPID THERMAL PROCESSING

\subsection{Introduction}

Low cost and high-efficiency is the key to large scale acceptability of photovoltaic systems. PV modules today cost about $\$ 4 / \mathrm{Watt}$, which can produce electricity at a rate of about $25 \mathrm{c} / \mathrm{kWhr}$. A factor of two in cost reduction is needed to make PV attractive for peak-power load applications and about a factor of 3 or 4 reduction would make it extremely competitive with conventional energy sources for base load utility applications. No PV material or technology has yet been able to achieve the cost and efficiency goals simultaneously because the efficient cells are too expensive and the cheaper cells are not efficient enough. Rapid thermal processing (RTP) is becoming established as a simplified and cost-effective fabrication technique which significantly reduces the cell process time, thermal budget, and wafer cleaning steps, without a significant loss in cell efficiency. In this study, RTP involves a rapid, simultaneous front and back diffusion for the formation of an emitter and back-surface-field. To minimize process steps and time, low temperature plasma enhanced chemical vapor deposition (PECVD) of $\mathrm{SiN}_{\mathrm{SiO}} 2$ dielectrics was used for efficient front surface passivation and antireflection (AR) [5-1]. Currently, the RTP process at Georgia Tech utilizes photolithography for patterning contacts; however, research is underway for defining industrially viable, screen-printed contacts on RTP emitters.

\subsection{Comparison Between RTP and Conventional Furnace Processing (CFP)}

The fundamental difference between RTP and conventional furnace processing (CFP) is the spectrum of electromagnetic energy used to heat the substrate. The radiation spectrum of a furnace consists mostly of photons in the infrared region that excite the ground state of the substrate's molecules to higher vibrational states, and dissociation occurs when sufficient energy is 
concentrated in the bond to be broken. In contrast, RTP typically consists of tungsten-halogen lamps which radiate from the vacuum ultra violet to infrared regions. These higher energy photons emitted in an RTP system can induce transitions into quantized electronically excited states as well as higher vibrational modes. Since these dominating photophysical effects in RTP differ from thermal reactions of the furnace, RTP can provide lower temperature cell processing compared to furnace processing [5-2].

These physical differences allow various advantages in favor of RTP over CFP. Conventional cell processing generally involves separate long furnace diffusions and oxidations at high temperatures, which require extensive and careful wafer cleaning, prolonged cell processing, and use of more chemicals and gases. RTP generally involves short thermal cycles (on the order of seconds or minutes--instead of hours) which results in a reduced thermal budget (i.e. lower power consumption).

Perhaps the best advantage of RTP is the rapid, simultaneous diffusion of the emitter on the front and the BSF on the back. Figure 5-1 compares the single wafer process time for each step of the RTP and CFP performed at Georgia Tech. RTP can reduce the total cell fabrication time by about a factor of two. Note that nearly 6.5 hours ( $\mathrm{P}$ diffusion + emitter etch back + wafer cleaning $+\mathrm{Al}$ diffusion/front-surface oxidation) of CFP is replaced by a quick, $40 \mathrm{~min}$ spin-on plus RTP simultaneous diffusion. As a result of the reduced exposure to high temperatures, RTP also requires fewer cleaning steps and therefore lesser use of chemicals (as shown in the shorter initial cleaning time required for RTP).

As stated earlier, at Georgia Tech, RTP was used in conjunction with PECVD to provide front surface passivation and $\mathrm{AR}$ properties; whereas, $\mathrm{ZnS} / \mathrm{MgF}_{2}$ coatings were evaporated on top of the $10 \mathrm{~nm}$ oxide grown during the $\mathrm{Al}$ diffusion step in the case of CFP. Integrating PECVD with RTP reduced the deposition time of a double-layer antireflection (DLAR) coating from 2 hours, as in the case of $\mathrm{ZnS} / \mathrm{MgF}_{2}$ coatings in CFP, to about $15 \mathrm{~min}$ for PECVD. PECVD also serves as an ideal alternative to oxides for front surface passivation since the simulatneous diffusion in RTP cannot incorporate oxidation of the front surface without additional steps. 
It is important to note that out of the 8.75 hour RTP sequence that 5.75 hours are lost in the photolithographical techniques for contact formation (useful only in laboratory cells) which involve numerous steps including spin-on of photoresist, baking, exposing, developing, evaporation, metal lift-off, plating, and annealing. Substantial simplification can be achieved by screen printing the front and back contacts which takes only a few minutes. Figure 5-2 illustrates the potential of RTP with screen-printed contacts. By a reduction in cleaning time and metallization, cells can be fabricated in almost 1 hour. This process involves a simultaneous diffusion and contact firing/annealing in a single step. Many experiments will have to be performed in order to achieve such a "single-shot" process step, however, the diffusion and contact firing can be separated into two steps if unsuccessful. The key for this technology is to limit any diffusion of metal into silicon (which can short the cell) while the $\mathrm{P}$ dopants are diffusing to form the emitter. Use of appropriate high temperature $\mathrm{Ag}$ pastes doped with $\mathrm{P}$ dopants will help to limit the interface contact resistance. Integrating screen-printing with RTP and PECVD may achieve an industrially viable process for low-cost cell fabrication. The question, however, will be how much will be given up in terms of efficiency since screen-printing requires a very low emitter sheet resistance and the quality of the contacts are inferior compared to evaporated contacts. 


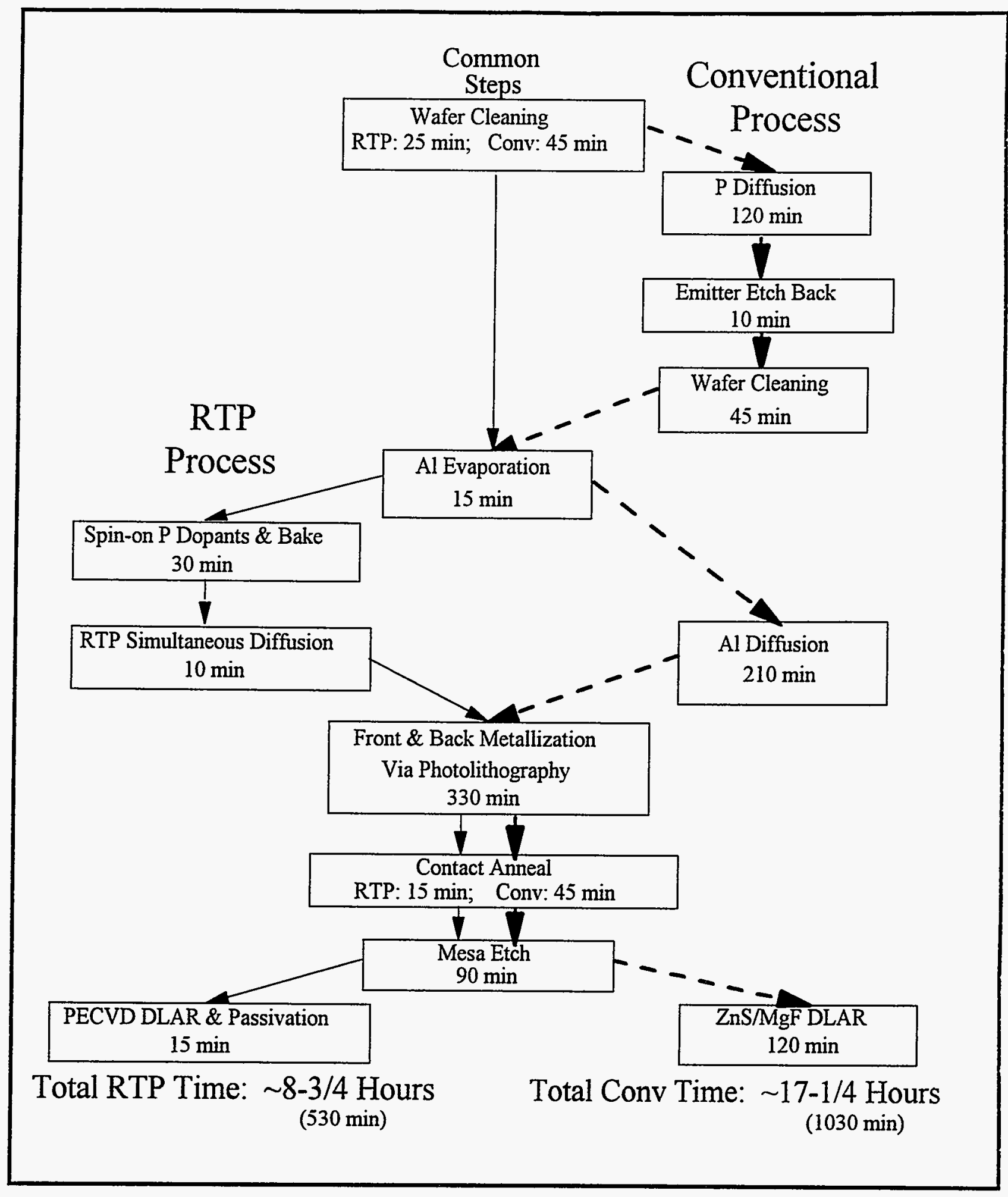

Figure 5-1. Single wafer fabrication time for RTP and conventional furnace processing. 


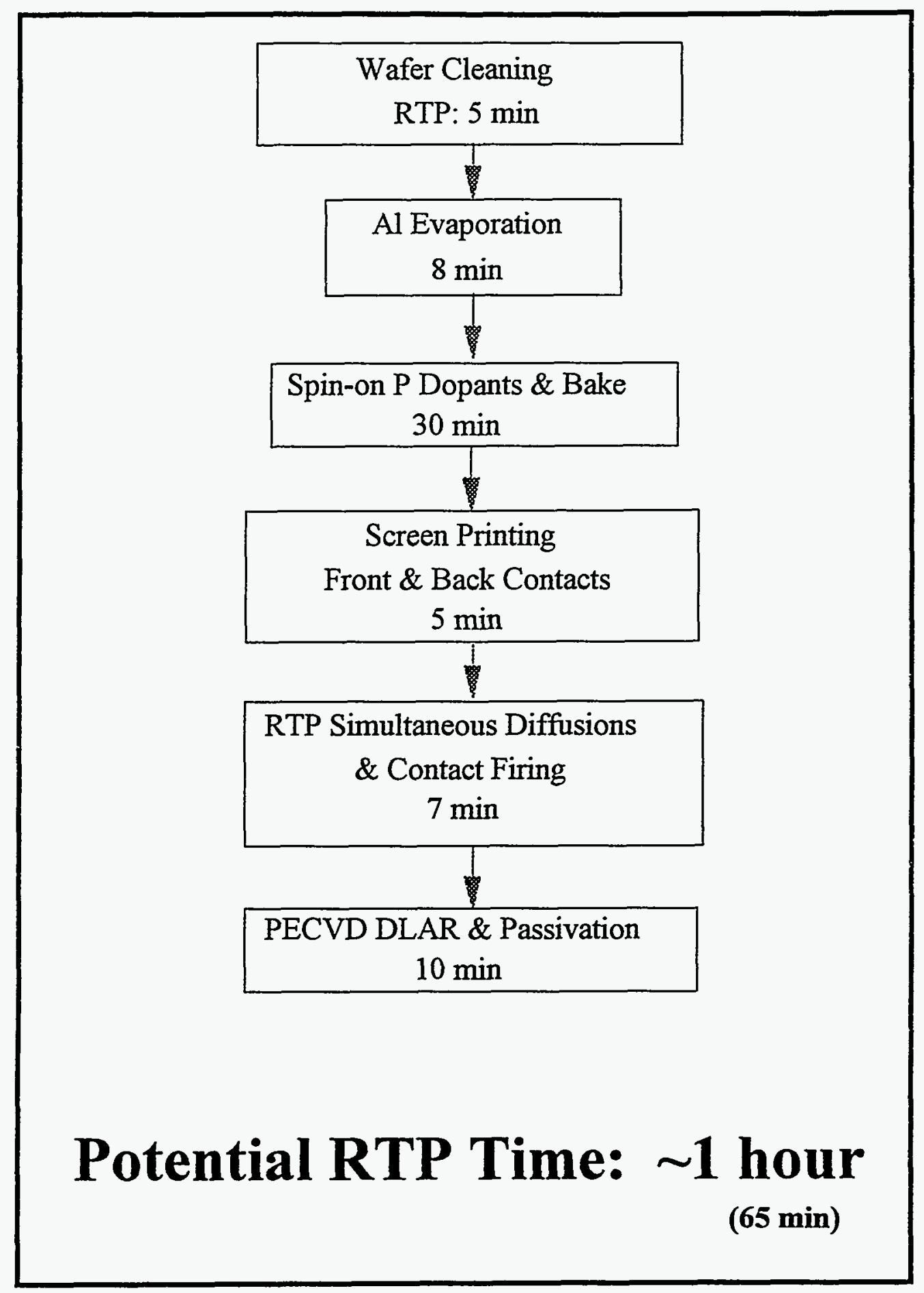

Figure 5-2. Potential single wafer fabrication time for RTP with screen printed contacts. 
RTP systems can also be utilized as a multiprocessing tool. Processes such as diffusion, oxidation, annealing of contacts and films (such as antireflection coatings), and surface cleaning via ozone or UV exposure can be integrated into a single RTP system as in-situ processes. Multiprocessing is feasible in RTP systems because of the water-chilled "cold walls" which prevent impurities on the wall from contaminating the substrate or creating problems such as cross-contamination or auto-doping. All of these advantages tranlate into reduced cell processing cost. The goal is to incorporate these advantages of RTP into an optimized process sequence that allows cost reduction without sacrificing cell efficiency greatly. RTP technology has the potential of reducing the total dollars/watt for electricity production thus making PV competitive to other forms of energy conversion and more industrially relevant.

\subsection{Progress of RTP/PECVD Silicon Solar Cells at Georgia Tech}

Simple $\mathrm{n}^{+}-\mathrm{p}-\mathrm{p}^{+}$solar cells were fabricated on $0.2 \Omega-\mathrm{cm}$, p-type, (100) float zone Si. Wafers were cleaned in 4:1 $\mathrm{H}_{2} \mathrm{SO}_{4}: \mathrm{H}_{2} \mathrm{O}_{2}$ for $5 \mathrm{~min}$ followed by $1 \mathrm{~min} 40: 1 \mathrm{HNO}_{3}: \mathrm{HF}$ treatment, $20 \mathrm{sec}$ dip in 10:1 H $\mathrm{H}_{2} \mathrm{O}: \mathrm{HF}, 8 \mathrm{~min}$ boil in 1:1:5 $\mathrm{HCl}: \mathrm{H}_{2} \mathrm{O}_{2}: \mathrm{H}_{2} \mathrm{O}$ and a final $20 \mathrm{sec}$ dip in 10:1 $\mathrm{H}_{2} \mathrm{O}: \mathrm{HF}$. After DI water rinse and $\mathrm{N}_{2}$ blow dry, about $150 \mathrm{~nm}$ thick phosphorosilica film was spun-on onto the front using a spin-on source with a phosphorous concentration of $1 \times 10^{21} \mathrm{P}$ atoms $/ \mathrm{cm}^{3}$. After a $120^{\circ} \mathrm{C} / 30 \mathrm{~min}$. bake, $1 \mu \mathrm{m}$ thick aluminum was evaporated onto the back of the wafer. A commercial RTP system with tungsten-halogen heating lamps below a graphite susceptor was used. Samples were placed on the susceptor, with the spin-on layer facing away from the lamps. (Note that this configuration does not directly illuminate the spin-on layer, however, there may be some reflected light from the top of the chamber heating the front. The system is currently being modified to allow direct optical heating of wafers.) After a number of experiments, an appropriate time and temperature profile was established for simultaneous $\mathrm{P}$ and Al diffusions with acceptable junctions depths, surface doping concentration, reverse saturation 
currents $\left(\mathrm{J}_{\mathrm{oe}}\right)$ and bulk lifetime for high efficiency cells. Figure 5-3 shows the programmed heating and cooling cycle which involves $20 \mathrm{sec}$. initial rapid heating at a rate of $43^{\circ} \mathrm{C} / \mathrm{sec}$ to $880^{\circ} \mathrm{C}$, followed by a $30 \mathrm{sec}$. hold at $880^{\circ} \mathrm{C}$, a $3 \mathrm{~min}$. slow cool at a rate of $0.33^{\circ} \mathrm{C} / \mathrm{sec}$ to $820^{\circ} \mathrm{C}$, and rapid cool of $\sim 4.4^{\circ} \mathrm{C} / \mathrm{sec}$ until natural (uncontrolled) cooling takes over. After RTP, the phosphosilicate glass was stripped off in a dilute HF solution and the front metal grid was defined by evaporating $60 \mathrm{~nm} \mathrm{Ti}$ and $5 \mu \mathrm{m} \mathrm{Ag}$ using lift-off photolithography. The back contact was formed by evaporation of $60 \mathrm{~nm} \mathrm{Ti}$ and $2 \mu \mathrm{m}$ of $\mathrm{Al}$ over the entire back followed by a $400^{\circ} \mathrm{C} / 30$ min contact-anneal in forming gas. Finally, a double layer antireflection coating, consisting of a 59 $\mathrm{nm} \mathrm{SiN}$ layer with refractive index of 2.27 and $95 \mathrm{~nm} \mathrm{SiO}_{2}$ with a refractive index of 1.46 , was deposited in a deposition time less than $9 \mathrm{~min}$ by $\mathrm{PECVD}$ at low temperatures $\left(<300^{\circ} \mathrm{C}\right)$ for emitter surface passivation.

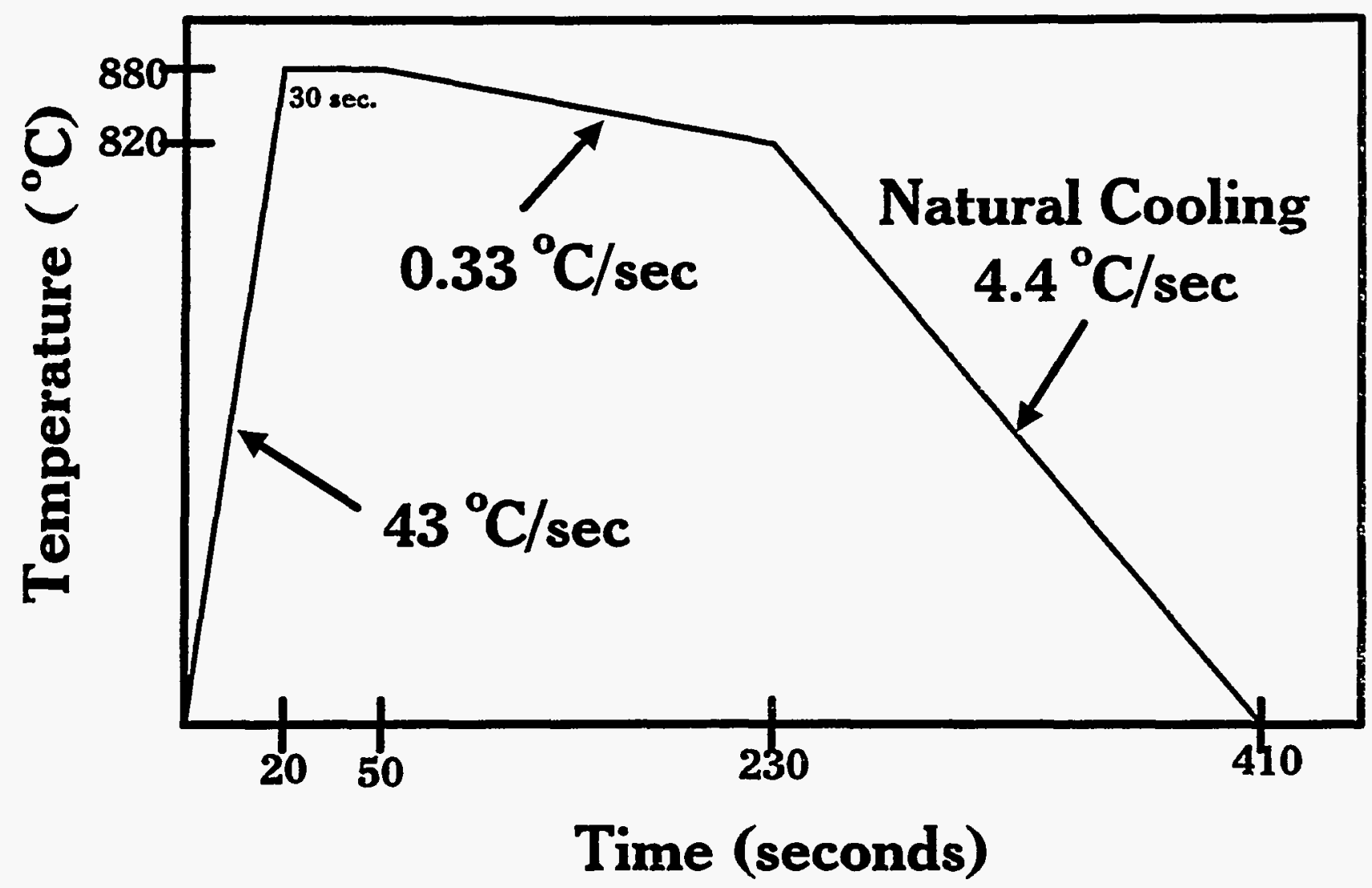

Figure 5-3. Programmed temperature cycle for RTP simultaneous diffusion and in-situ anneal. 
A number of experiments were performed to select the RTP temperature cycle in figure 5-3. For example, the peak temperature of $880^{\circ} \mathrm{C}$ and holding for $30 \mathrm{sec}$ determine the surface concentration, $\mathrm{J}_{\mathrm{O}}$, and sheet resistance; similarly, the slow cooling rate of $0.33^{\circ} \mathrm{C} / \mathrm{sec}$ for $3 \mathrm{~min}$ allows the formation of an $\mathrm{Al}$ back-surface-field, performs $\mathrm{Al}$ gettering, prevents lifetime degradation due to rapid quenching from high temperatures, and creates appropriate junction depths and diffusion profiles for high efficiency cells. PECVD SiN/SiO 2 coatings provided good surface passivation, very efficient double layer AR properties, and passivation of grown-in or process-induced bulk defects in silicon. Thus, the combination of appropriate RTP sequence and PECVD coatings allows control of key material and device parameters necessary to fabricate high efficiency cells. Additionally, it reduces the thermal budget, relaxes the wafer cleaning requirements, reduces the use of chemicals and gases, and increases the throughput.

Figure 5-4 shows the front and back diffusion profiles obtained by the $7 \mathrm{~min}$ time/temperature cycle in figure 5-3. Phosphorus emitter profiles, measured by spreading resistance, had a surface concentration about $2 \times 10^{20} \mathrm{~cm}^{-3}$ and a junction depth of $0.15 \mu \mathrm{m}$. This resulted in a sheet resistance of $80 \Omega / \square$. The aluminum back surface field profile, determined by $\mathrm{C}-\mathrm{V}$ measurements using an electrochemical etching profiler, had a surface concentration of $10^{18}$ $\mathrm{cm}^{-3}$ and a junction depth of $2 \mu \mathrm{m}$. These simultaneously diffused profiles are quite consistent with the requirements for high efficiency silicon cells and can be optimized further for even better results. Figure 5-5 shows the light I-V characteristics and the cell data, measured by Sandia National Laboratories (SNL). The record high $16.9 \%$ efficiency RTP cell had a $\mathrm{V}_{\text {oc }}$ of $623 \mathrm{mV}$, $\mathrm{J}_{\mathrm{Sc}}$ of $33.6 \mathrm{~mA}$, and a fill factor of 0.808 . Figure 5-6 shows the measured reflectance and the internal quantum efficiency (IQE) of this cell. The IQE analysis calculated an average weighted reflectance of $5.1 \%$ and a bulk diffusion length of $212 \mu \mathrm{m}$ corresponding to a bulk lifetime of about $22 \mu \mathrm{s}$ in the $0.2 \Omega-\mathrm{cm}$ base. 
Phosphorus Spin-on Emitter

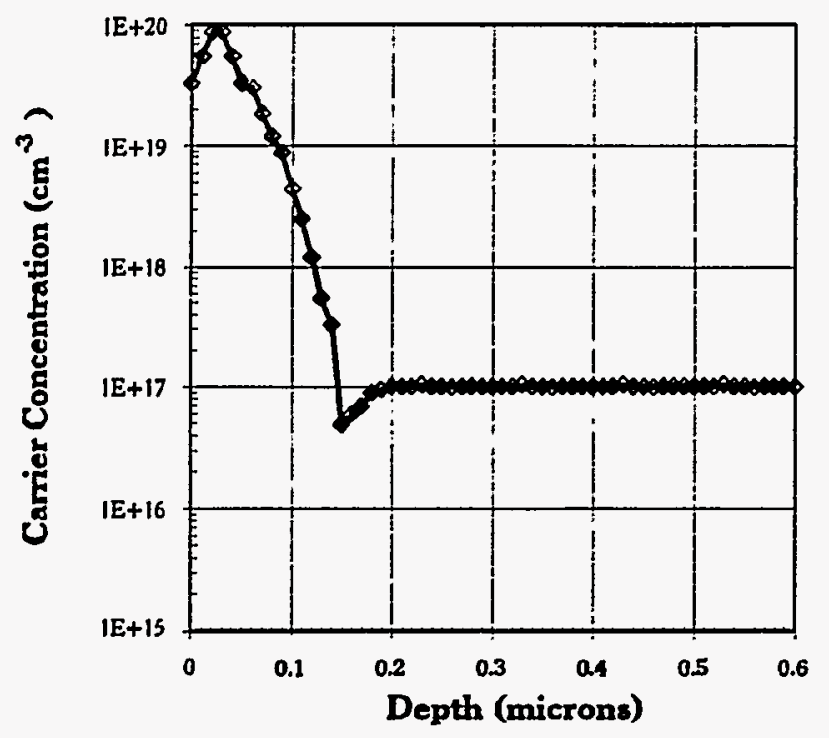

(a)

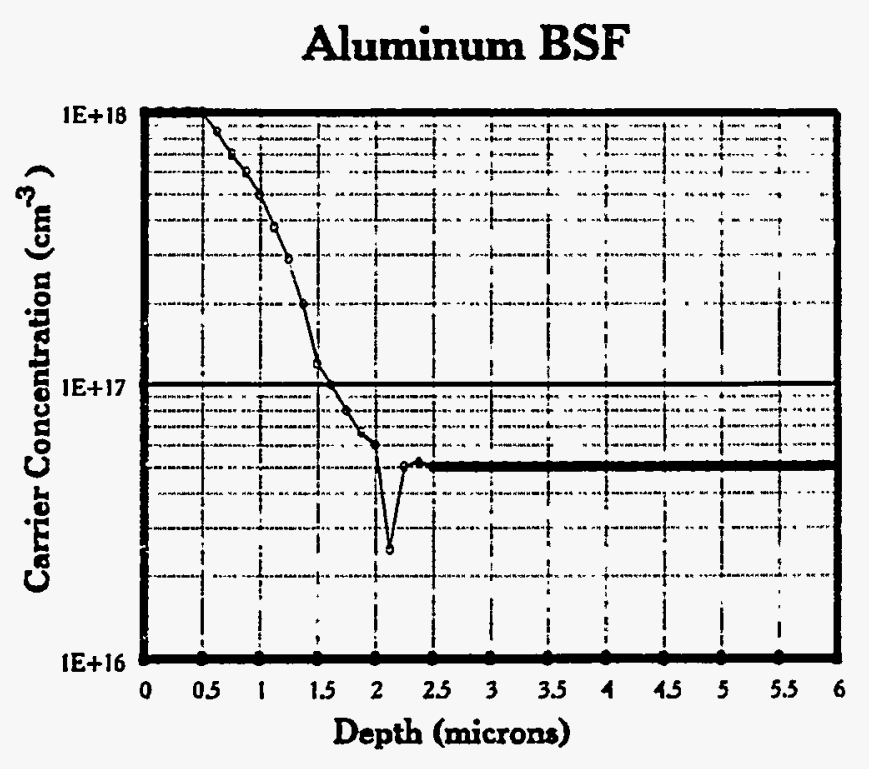

(b)

Figure 5-4. (a) Front emitter and (b) back BSF carrier concentration profiles resulting from the RTP temperature cycle in figure 5-3.

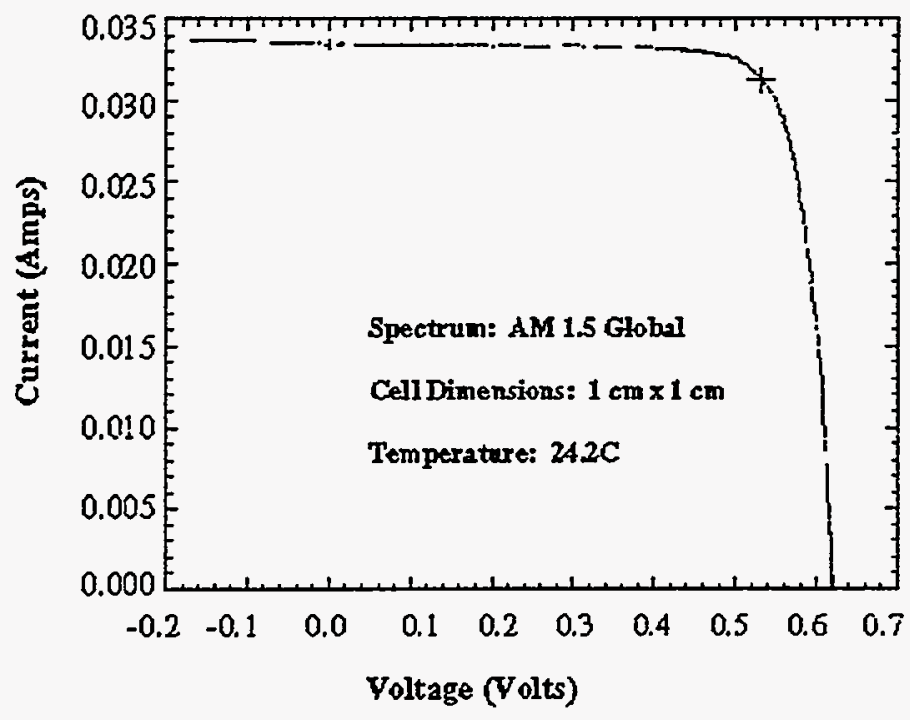

Figure 5-5. I-V curve for the $16.9 \%$ efficient RTP/PECVD solar cell on $0.2 \Omega-\mathrm{cm}$ FZ silicon. (Measured at Sandia National Laboratories.) 


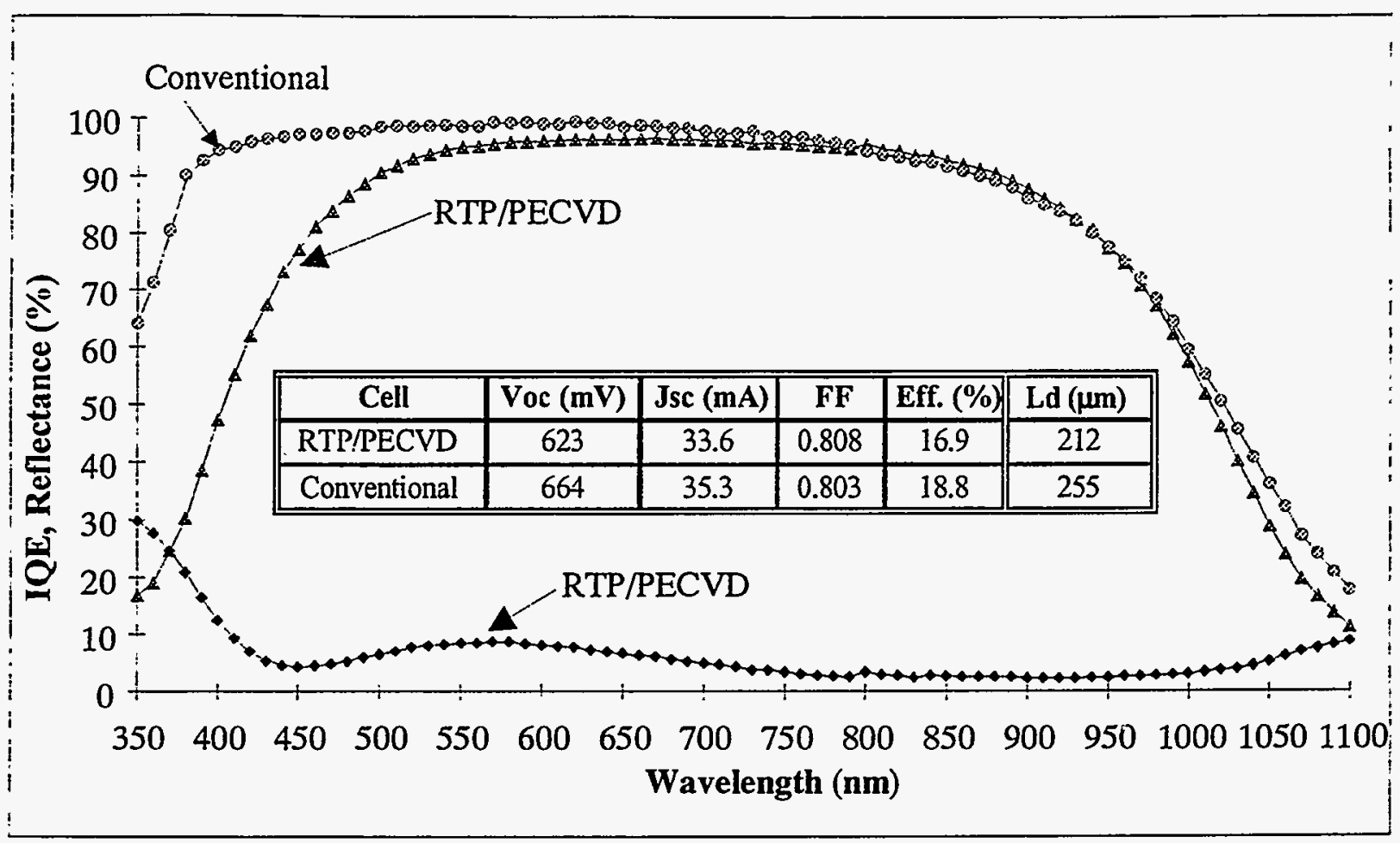

Figure 5-6. Comparison between the internal quantum efficiency of the $16.9 \%$ RTP/PECVD cell and the $18.8 \%$ conventional cell. Measured at Sandia National Laboratories.

Figure 5-6 also shows a comparison of IQE and cell data of a conventional furnace diffused and RTP diffused cell on $0.2 \Omega$-cm FZ Si. The conventional cell fabrication involved 930 ${ }^{\circ} \mathrm{C} / 25 \mathrm{~min}$ phosphorus diffusion on the front, followed by an etch back to obtain a comparable emitter sheet resistance of $80 \Omega / \square$, and $850^{\circ} \mathrm{C} / 45 \mathrm{~min} \mathrm{Al}$ diffusion on the back which includes a 10 min thermal oxide passivation on the front. The conventional cell gave an efficiency of $18.8 \%$ with a slightly better long wavelength response but considerably better short wavelength response indicating somewhat higher bulk lifetime $(255 \mu \mathrm{m})$ and much lower front surface recombination velocity (FSRV or Sf). Emitter doping profile measurements for the conventional cell showed a much lower surface concentration of $2 \times 10^{19} \mathrm{~cm}^{-3}$ and a junction depth of $0.6 \mu \mathrm{m}$. The order of magnitude higher surface concentration of the RTP emitter can increase Sf, Auger recombination, and bandgap narrowing to account for the poor short wavelength response. Absorption due to the SiN coating accounts for some of the reduced short wavelength response. Research is underway to 
increase the short and long wavelength response of the RTP/PECVD cells by optimizing the $\mathrm{J}_{0}$ and bulk lifetime values to bridge the gap between the conventional and RTP cells. The RTP cell efficiencies in excess of $17 \%$ achieved in this study demonstrate the potential for low cost high efficiency RTP cells.

More recently, an even more efficient RTP cell has been fabricated at Georgia Tech. Figure 5-7 is the I-V curve for the new record high $17.1 \%$ RTP/PECVD cell tested at SNL. This cell had a $\mathrm{V}_{\mathrm{oc}}$ of $637 \mathrm{mV}$, a $\mathrm{J}_{\mathrm{sc}}$ of $32.6 \mathrm{~mA}$, and a FF of 0.819 . Table 5-1 indicates that many RTP/PECVD cells above $16.5 \%$ efficiency have been fabricated on FZ silicon at Georgia Tech. Also record high efficiencies have been attained on lower-cost PV materials such as $16.4 \%$ on Siemens CZ, $14.9 \%$ on dendritic web, and $14.8 \%$ on multicrystalline silicon without any furnace processing. Figure 5-8 exhibits the good uniformity of these $1 \mathrm{~cm} \mathrm{x} 1 \mathrm{~cm}$ cells on typical samples.

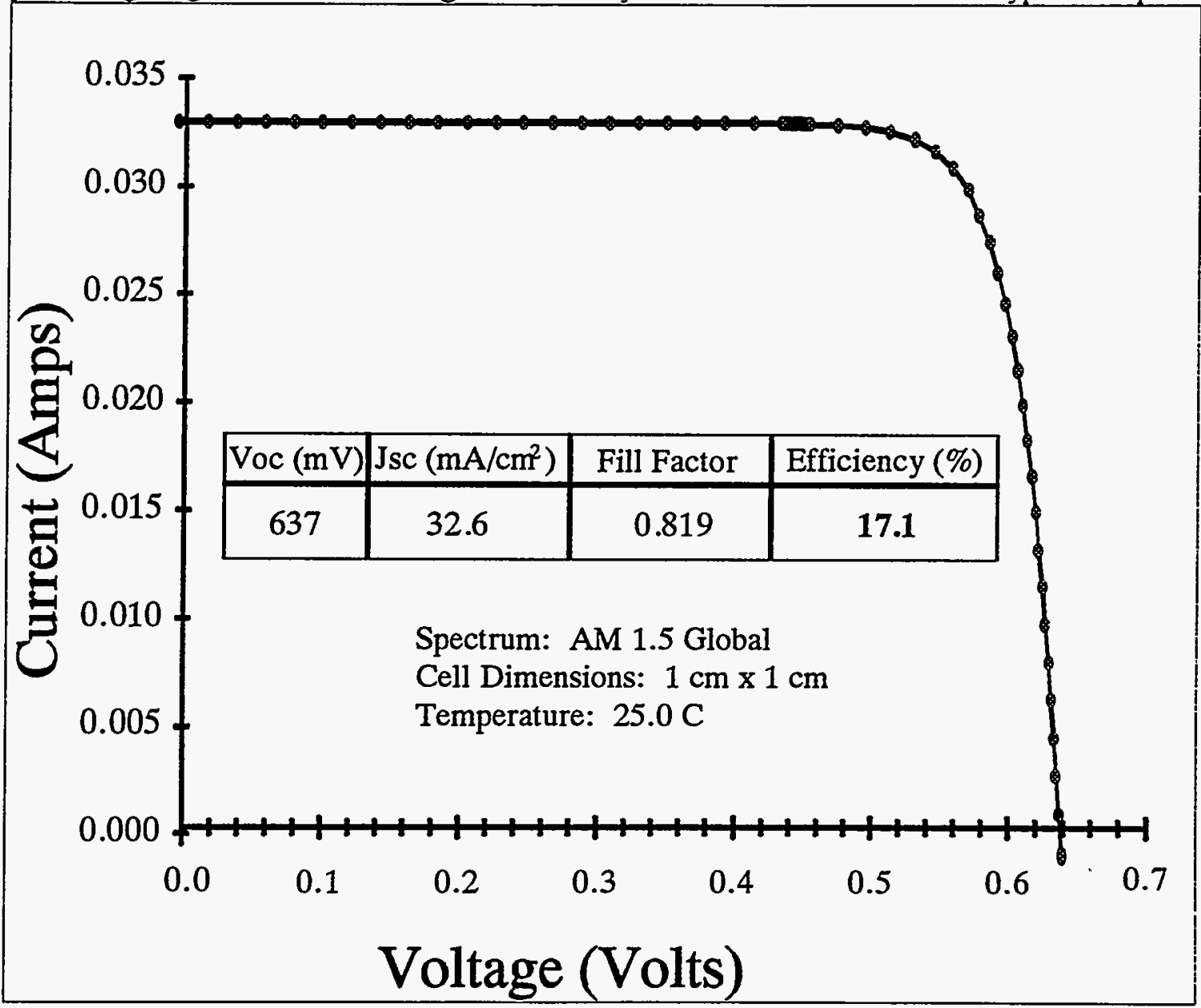

Figure 5-7. I-V curve for the record high $17.1 \%$ efficient RTP solar cell. Measured at SNL. 
Table 5-1. High Efficiency RTP/PECVD Silicon Solar Cells Fabricated at Georgia Tech

\begin{tabular}{|c|c|c|c|c|}
\hline 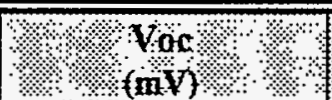 & 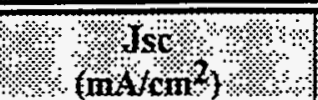 & $1 \%+\mathrm{FP}+4$ & \%. & \% Material \\
\hline 637 & 32.8 & 0.819 & 17.1 & $\mathrm{FZ}$ \\
\hline 627 & 34.9 & 0.779 & 17.0 & $\mathrm{FZ}$ \\
\hline 623 & 33.6 & 0.808 & 16.9 & $\overline{F Z}$ \\
\hline 622 & 33.5 & 0.809 & 16.8 & $\mathrm{FZ}$ \\
\hline 626 & 32.6 & 0.813 & 16.6 & $\overline{\mathrm{FZ}}$ \\
\hline 627 & 32.3 & 0.819 & 16.6 & $\mathrm{FZ}$ \\
\hline 609 & 35.2 & 0.763 & 16.4 & $\mathrm{Cz}$ \\
\hline 559 & 34.5 & 0.771 & 14.9 & Dend. Web \\
\hline 594 & 33.0 & 0.756 & 14.8 & $\mathrm{mc}-\mathrm{Si}$ \\
\hline
\end{tabular}

All cells measured at Sandia National Laboratories

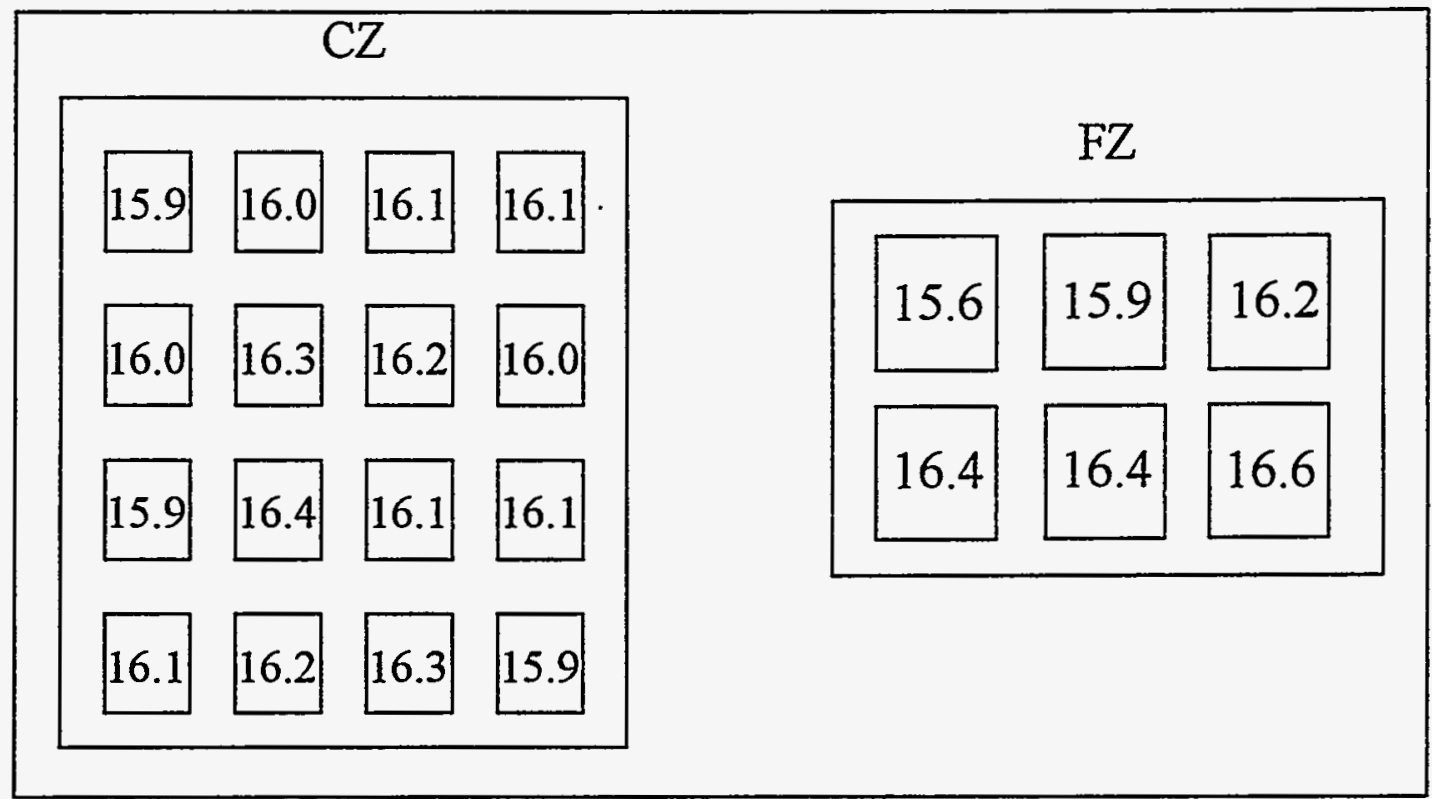

Figure 5-8. Uniformity of RTP/PECVD Solar Cells. 
Figure 5-9 depicts the progress on RTP cells. Many investigators have used RTP in the past. However, because of the improved understanding of the thermal cycle and proper choice of cooling rates to limit lifetime degradation and $\mathrm{J}_{\mathrm{O}}$ (due to appropriate diffusion profiles), Georgia Tech has maintained the highest efficiencies on all silicon materials. In order to push these efficiencies even higher, it is necessary to properly optimize the cooling rates of the in-situ RTP anneal for greatest cell performance. In the next section, the effect of these cooling rates and their material specific nature revealed and quantified.

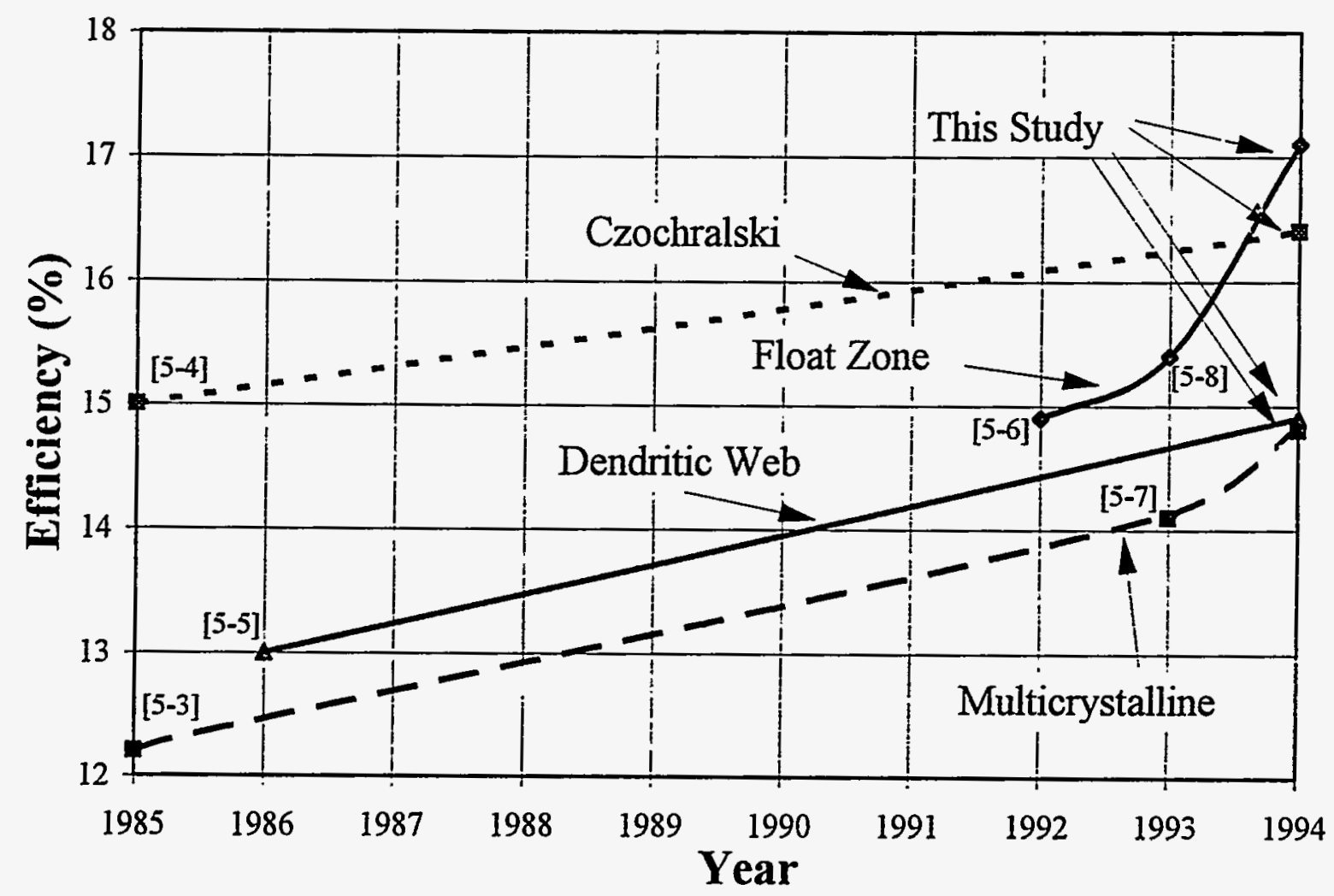

Figure 5-9. Progress of RTP-diffused silicon solar cells without any furnace treatment.

(The number in brackets represents the reference.) 


\subsection{RTP Cooling Rate Effect on Silicon Solar Cells}

\subsubsection{Quenching Problems During RTP}

Various investigators have attempted RTP techniques in the past for silicon solar cell fabrication with only moderate success [5-3 to 5-8]. This is because RTP is susceptible to generating electrically active quenched-in defects. The quenching induced lifetime degradation from a conventional process is well documented. Quenching can give rise to defects such as vacancies, interstitials, and point defect clusters. Dissolved impurities such as metallic contaminants are quenched into interstitial sites and can form deep levels that serve as effective recombination centers. Such defects become extremely detrimental when they are decorated with further impurities. During slow cooling these impurities may have sufficient time to migrate, precipitate, and become electrically inactive. In figure 5-10, Rohatgi et al. have shown that rapid cooling rates and high quench temperatures can significantly reduce the generation lifetime [5-9]. In this case, rapid cooling was capable of killing a material with $1 \mathrm{~ms}$ generation lifetime by an order of magnitude. Quenching from $900^{\circ} \mathrm{C}$ can severely degrade the lifetime-in this case by nearly two order of magnitude.

Researchers at Westinghouse noticed similar problems when they performed an RTP diffusion with a quench temp of $1100^{\circ} \mathrm{C}$ and a cooling rate of $60^{\circ} \mathrm{C} / \mathrm{sec}$ [5-5]. Such a process would achieve only $13 \%$ efficient RTP cells on dendritic web silicon. But, when they went back into a conventional furnace to perform a high-temp anneal, they were capable of reviving the bulk lifetime and achieving cells up to $15.2 \%$ efficiency. They found that the optimum temperatures for the post-RTP anneal was between $750^{\circ} \mathrm{C}-900^{\circ} \mathrm{C}$. This post-RTP anneal, however, greatly mitigates the attractiveness of RTP since it would mean taking the wafer out of the RTP system, performing extra cleaning steps, and then going back to a long high-temp furnace step. Therefore, we have focused on performing an in-situ anneal during the RTP diffusion step. But, in order to properly optimize the annealing conditions, a better understanding of RTP cooling rates and how 


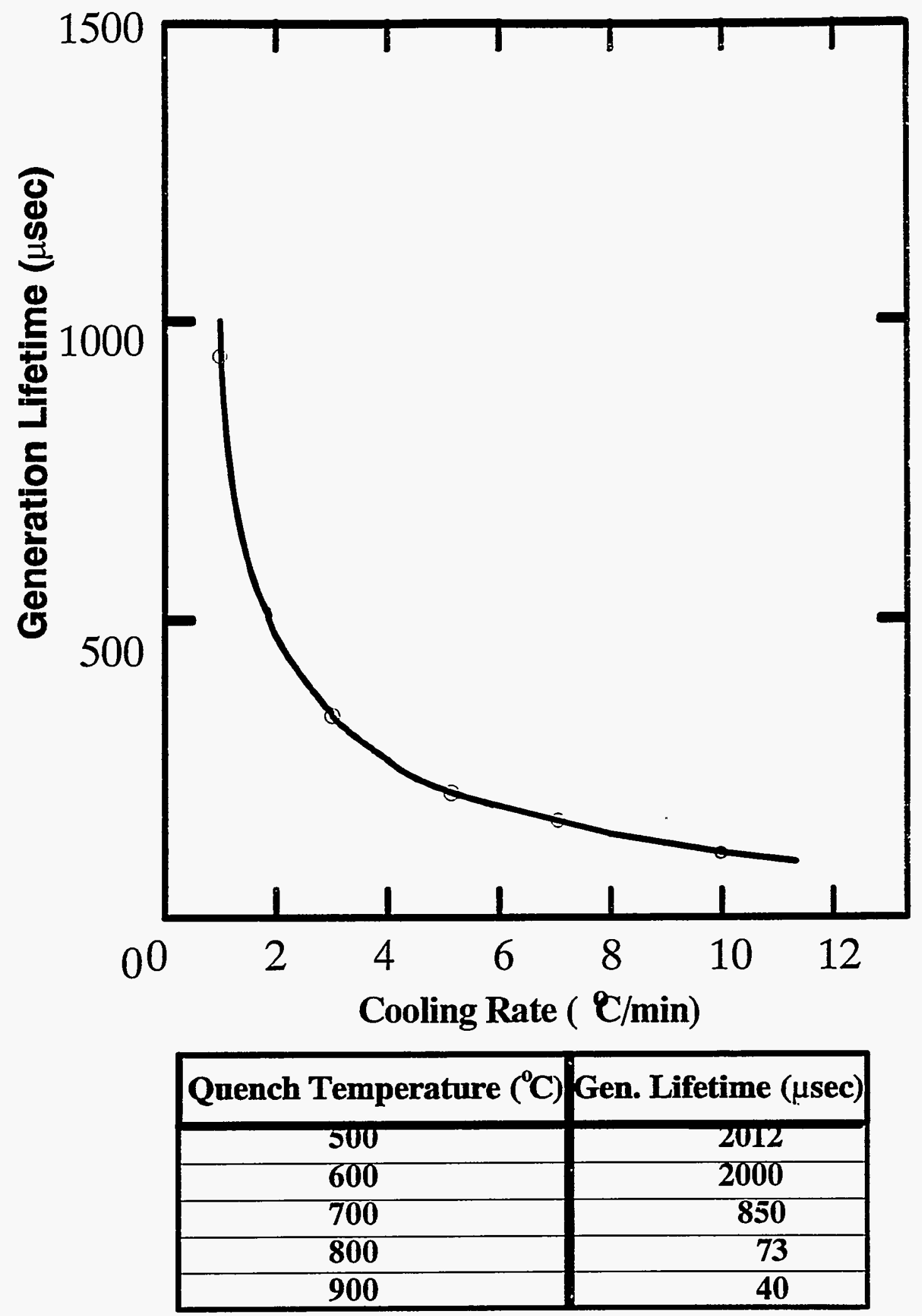

Figure 5-10. Effect of quenching during a conventional furnace process on FZ silicon. 
they can affect cell performance is required. It is also important to recognize that the cooling rate effects may be material specific.

\subsubsection{Optimization of the RTP Cooling Rate and In-situ Anneal}

As indicated earlier, many preliminary experiments were performed to select the RTP temperature cycle in figure 5-3. However, this cycle has not been fully optimized. Of key importance is the in-situ anneal (between the temperatures of $880^{\circ} \mathrm{C}$ and $820^{\circ} \mathrm{C}$ ) which may prevent lifetime degradation due to rapid quenching. Although a cooling rate of $0.33^{\circ} \mathrm{C} / \mathrm{sec}$ gave good preliminary results, the question of what is the optimum cooling rate has not been investigated-nor has the effect of cooling rate on different materials been assessed. To achieve higher bulk lifetimes $\left(\tau_{b}\right)$, we have begun in-depth characterization, modeling, and analysis to improve the understanding of RTP cooling rate effects on PV materials and devices. The lower quench temperature of $820^{\circ} \mathrm{C}$ was chosen because, on $\mathrm{FZ}$ silicon, no significant quenching problems were seen below $820^{\circ} \mathrm{C}$ for the $880^{\circ} \mathrm{C}$ peak temperature process.

Two major experiments involving four RTP cooling rates were performed. The cooling rate was varied only between the temperatures of $880^{\circ} \mathrm{C}$ and $820^{\circ} \mathrm{C}$. In all cases, the cooling rate was maintained at a controlled rate $5^{\circ} \mathrm{C} / \mathrm{sec}$ below $820^{\circ} \mathrm{C}$ until natural cooling takes over (at $\sim 520^{\circ} \mathrm{C}$ ). Figure 5-11 illustrates the four different cooling rates, namely:

$0.1^{\circ} \mathrm{C} / \mathrm{sec}$ which involves a $10 \mathrm{~min}$ in-situ anneal $0.33^{\circ} \mathrm{C} / \mathrm{sec}$ which involves a $3 \mathrm{~min}$ in-situ anneal

$1^{\circ} \mathrm{C} / \mathrm{sec}$ which involves a $1 \mathrm{~min}$ in-situ anneal $\sim 100^{\circ} \mathrm{C} / \mathrm{sec}$ which involves no annealing (Quenched) 


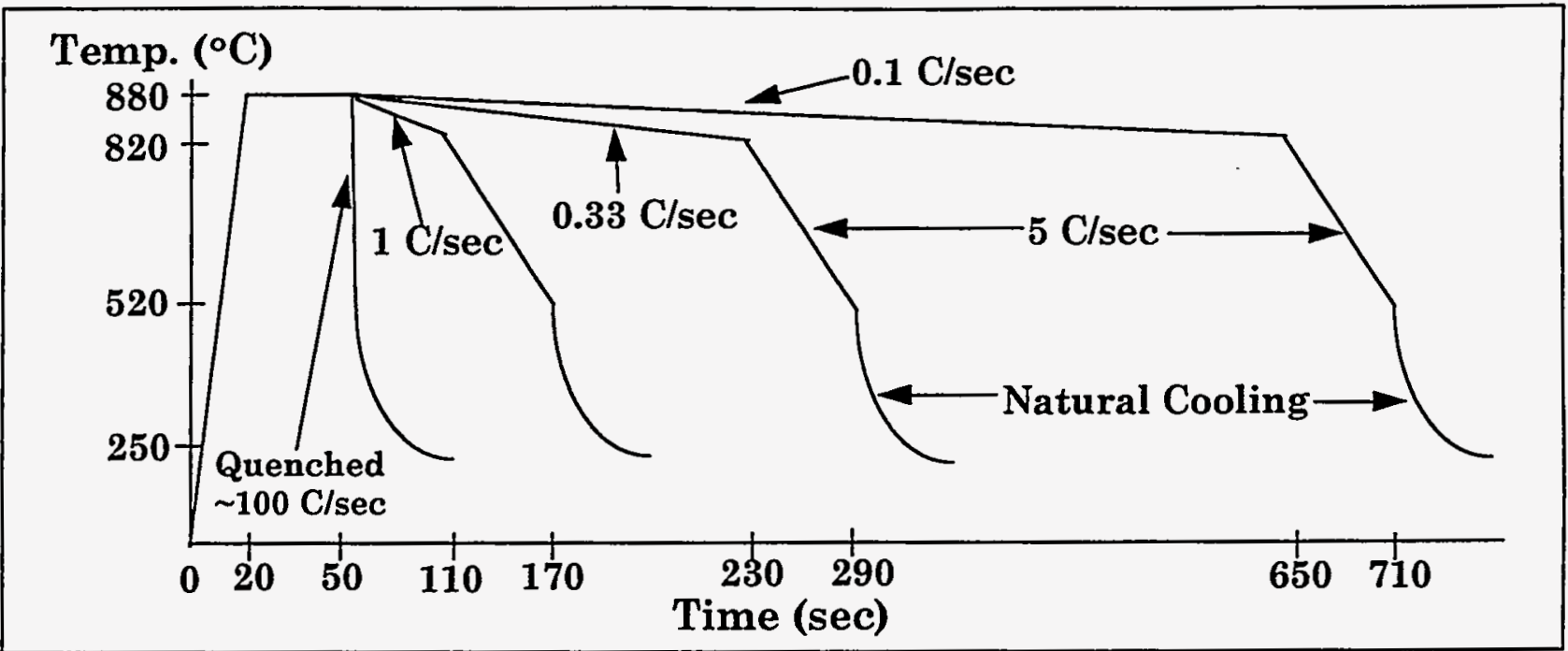

Figure 5-11. Temperature cycles of four different cooling rates between $880^{\circ} \mathrm{C}$ and $820^{\circ} \mathrm{C}$ for RTP cooling rate experiments.

The cooling rate of $0.33{ }^{\circ} \mathrm{C} / \mathrm{sec}$ corresponds to the baseline RTP process in which the $16.9 \%$ cell was fabricated. The 1st experiment involved PCD measurements of bulk lifetime on high resistivity FZ samples for the different cooling rates. To determine the effects of cooling rate on cell performance, the second experiment involved PV materials such as low-resistivity FZ and dendritic web. Research on $\mathrm{Cz}$ and multicrystalline are underway and will be presented in following reports.

The results from the 1st experiment on high resistivity FZ material is shown in figure 5-12. In order to replicate cell processing, these samples were prepared with the identical cleaning and emitter formation steps involved in cell processing. Emitters were fabricated to manifest any phosphorus gettering that may occur in the cells during the RTP diffusion. Following the RTP temperature cycles where only the cooling rate was varied (figure 5-11), the emitters were etched off and the bulk lifetimes were measured with the samples immersed in HF (to passivate the surfaces). 


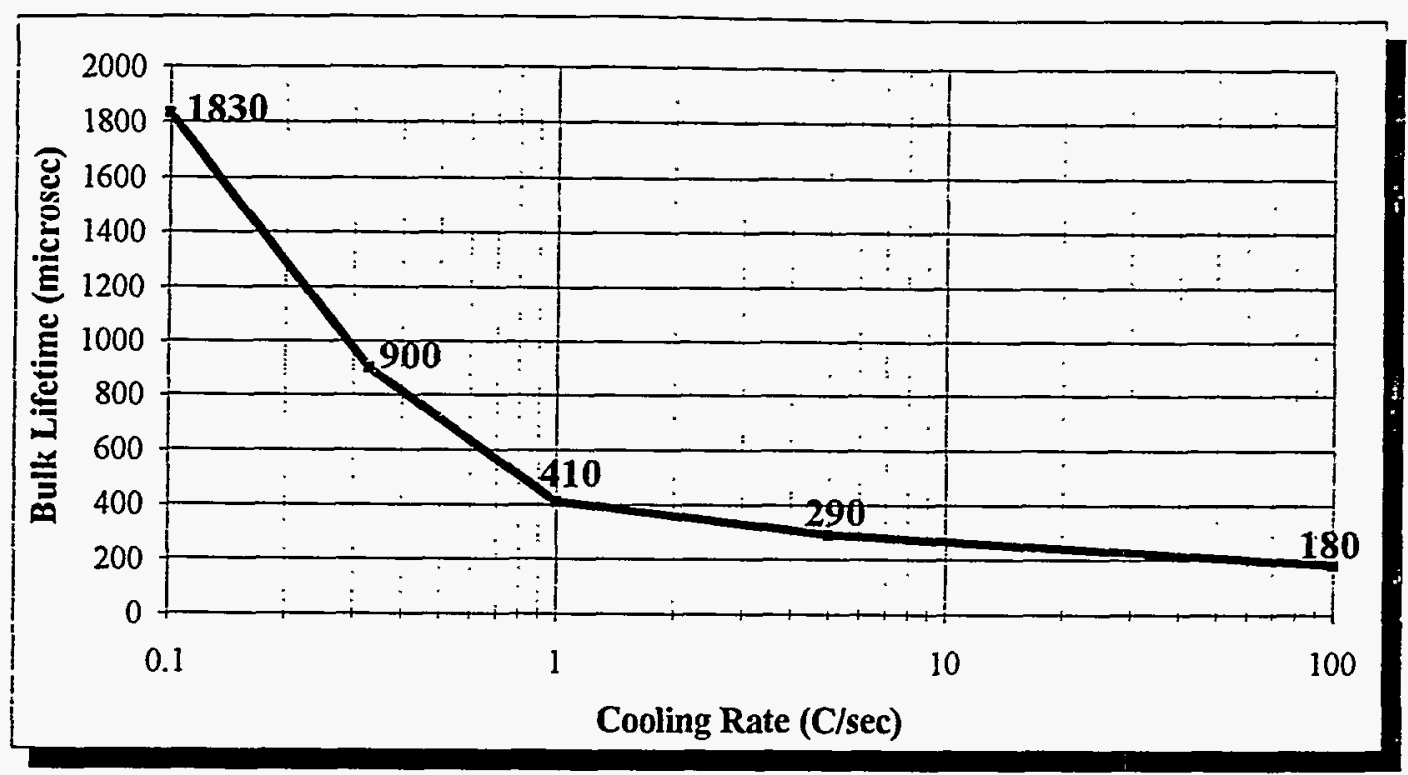

Figure 5-12. RTP cooling rate induced lifetime degradation of high resistivity FZ silicon.

For the first time, a similar trend in cooling rate induced lifetime degradation has been established for an RTP system. Figure 5-12 reveals that quenching from $880^{\circ} \mathrm{C}$ results in a poor $\tau_{\mathrm{b}}$ of only $180 \mathrm{~ms}$; however, by controlling the cooling rate to as slow as $0.1{ }^{\circ} \mathrm{C} / \mathrm{sec}$, very high lifetimes above $1.8 \mathrm{~ms}$ are achievable. Such high $t_{\mathrm{b}}$ values demonstrate that RTP systems are capable of achieving lifetimes compatible with high efficiency solar cells.

Next, the same cooling rates were applied to PV devices on materials such as dendritic web. Figure 5-13 shows that the web exhibits a strong dependence on the RTP cooling rate. Quenching of the web material resulted in only a $10.2 \%$ efficient RTP/PECVD cell; however, a dramatic improvement of $50 \%$ in efficiency occurs when web cells are slow-cooled at a rate of $0.33^{\circ} \mathrm{C} / \mathrm{sec}$. $14.9 \%$ is the record high efficiency for RTP web cells without any furnace anneal. Figure 5-13 also depicts that there is substantial improvement in the long wavelength internal quantum efficiency (IQE) response which can be attributed to bulk diffusion length enhancement with the slower cooling rates. Extended IQE analysis confirmed this fact by depicting a bulk 
diffusion length (in figure $5-14$ ) as high as $194 \mu \mathrm{m}$ which is over 4 times greater than that of the quenched case of only $45 \mu \mathrm{m}$.

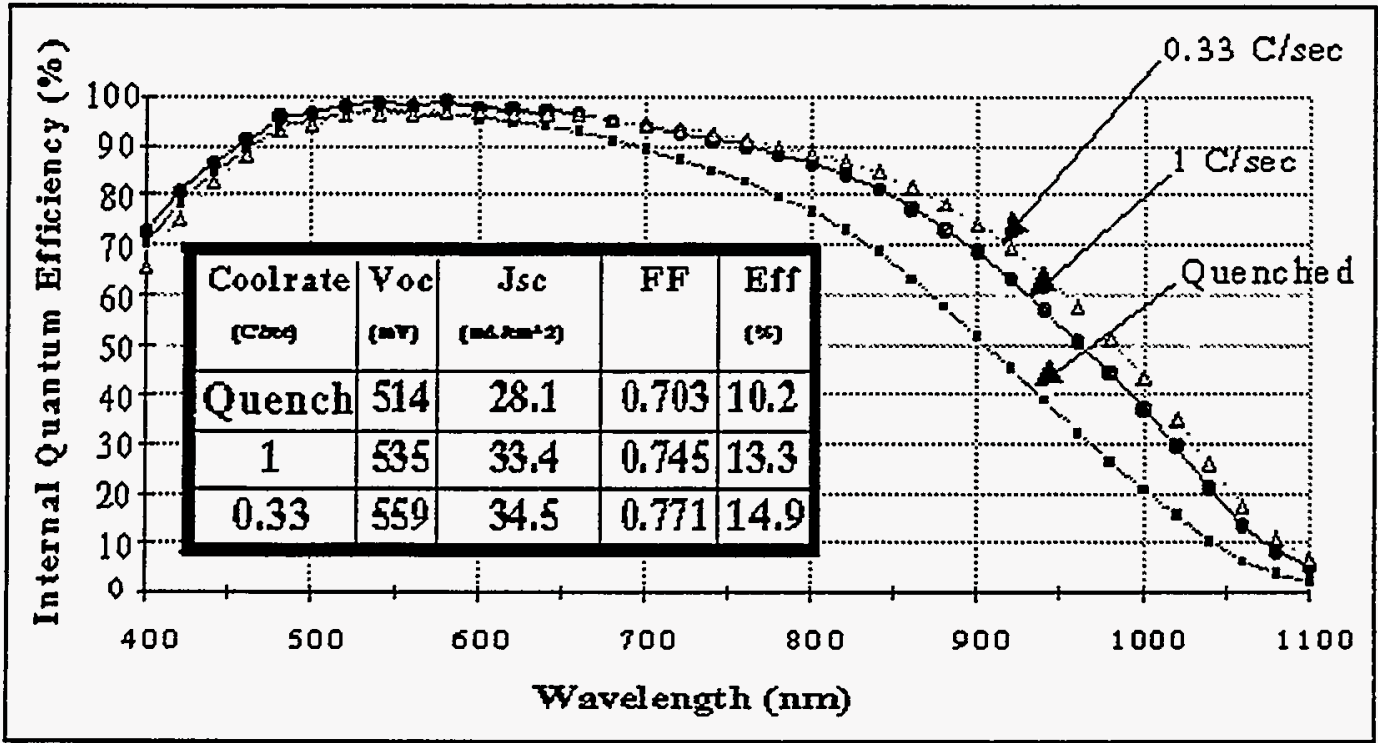

Figure 5-13. Effect of RTP cooling rate on $11 \Omega-\mathrm{cm}$ dendritic web silicon solar cells.

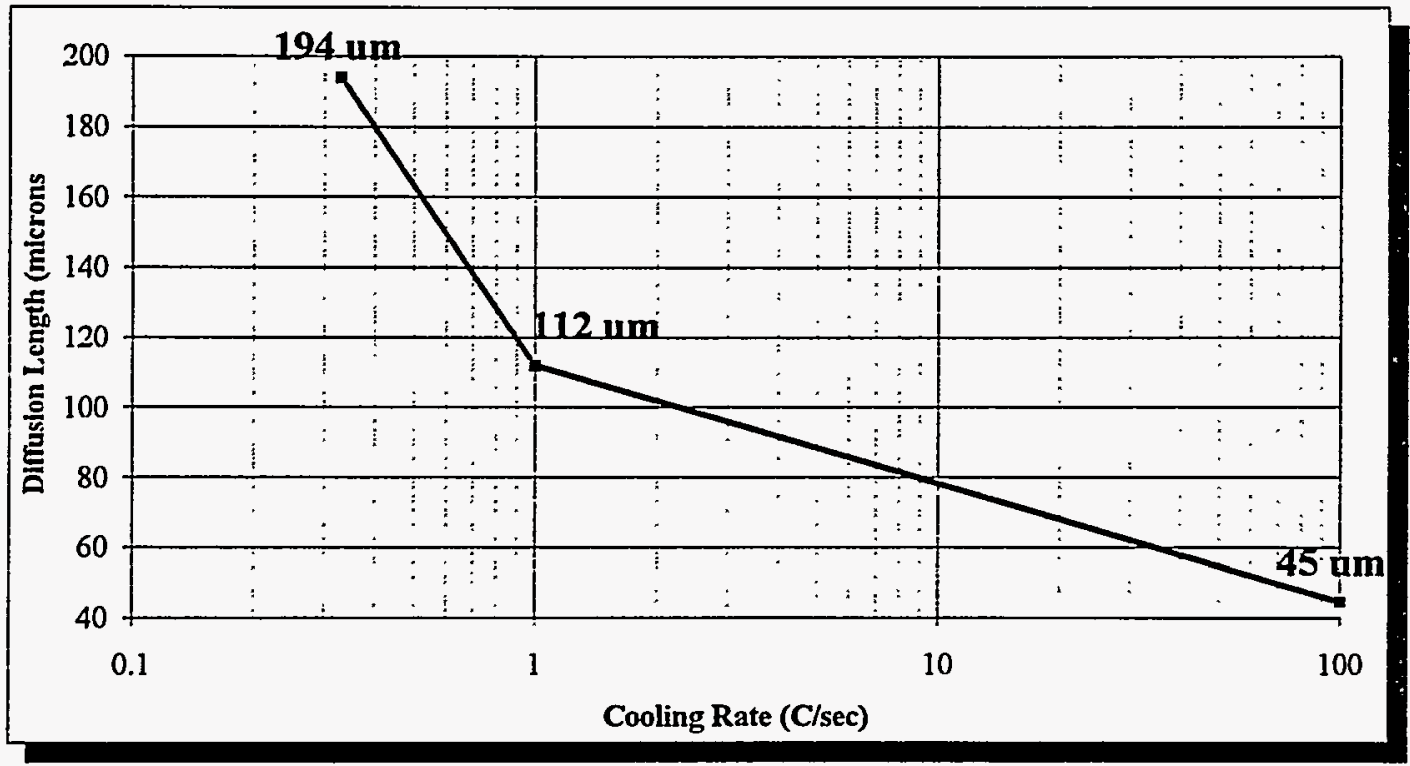

Figure 5-14. Diffusion length of the dendritic web cells as a function of RTP cooling rate. 
In figure 5-15, Dark I-V analysis revealed that the reverse saturation current, Jo, drops by a factor of 5 for the slow cooled case relative to the quenched one. Since the bulk diffusion length enhancement is accompanied by an improvement in $\mathrm{J}_{\mathrm{O}}$, this suggests that $\mathrm{J}_{\mathrm{ob}}$ is the dominating component of the total $\mathrm{J}_{\mathrm{o}}=\mathrm{J}_{\mathrm{oc}}+\mathrm{J}_{\mathrm{ob}}$, and that recombination in the base is the limiting mechanism for RTP cell efficiency on dendritic web silicon.

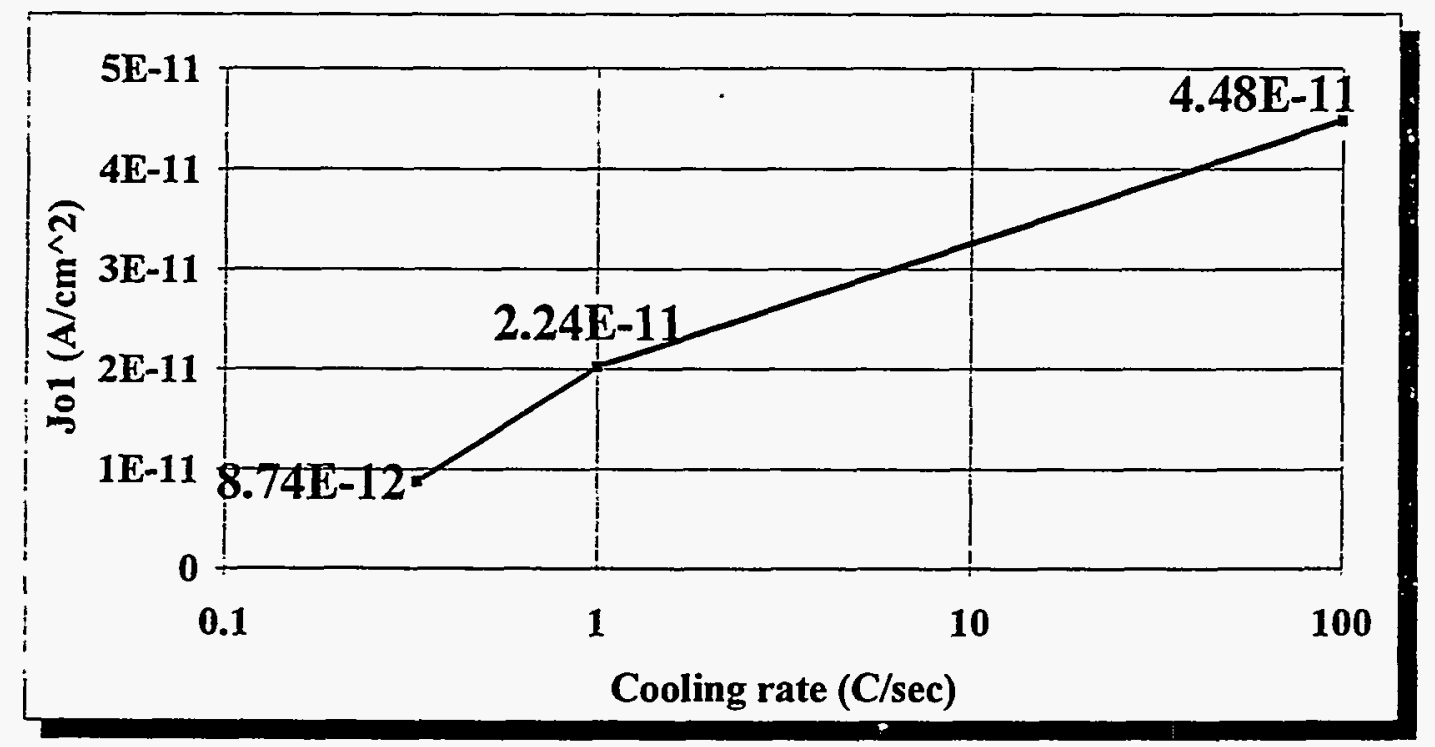

Figure 5-15. Total $J_{0}$ as a function of RTP cooling rate for the dendritic web cells. (Measured at approximately $300 \mathrm{~K}$.)

The performance of the FZ cells was nearly opposite (see figure 5-16). No significant trend in the long wavelength (i.e. $\tau_{\mathrm{b}}$ ) and efficiency was observed. In fact, the quenched cell in this case turned out to be the new record for RTP cells with $17.1 \%$ efficiency. As a result, the cooling rate effects on low-resistivity $\mathrm{FZ}$ is not completely understood, however, there was a clear trend in the short wavelength response. 


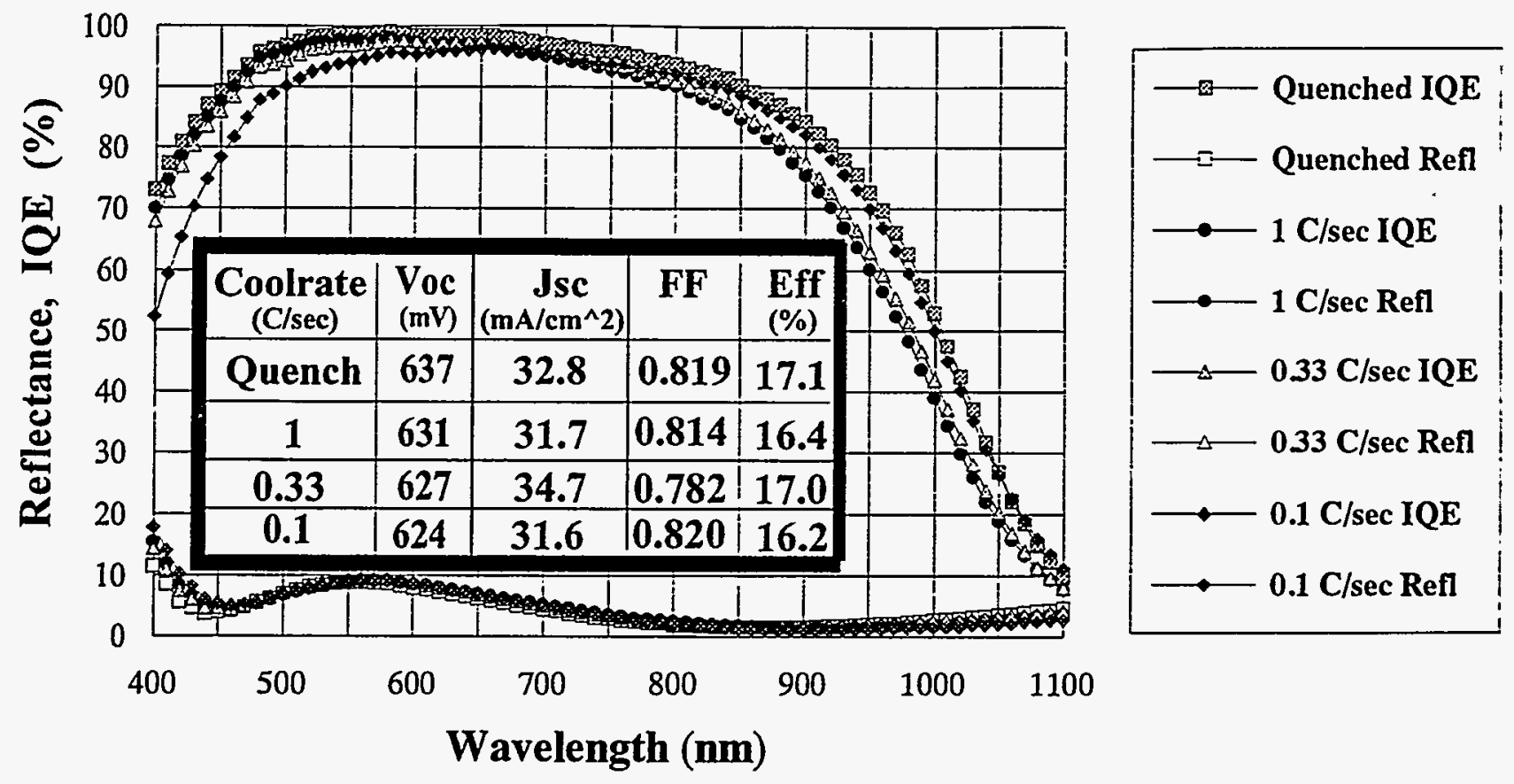

Figure 5-16. Effect of RTP cooling rate on $0.2 \Omega-\mathrm{cm}$ FZ silicon solar cells.

Note that the quenched cell had the superior short wavelength response which decreased with the decrease in cooling rate. This phenomenon can be explained on the basis of emitter profiles. Recall that the cells with slower cooling rates encountered much longer in-situ annealing times-10 $\mathrm{min}$ in the case of $0.1^{\circ} \mathrm{C} / \mathrm{sec}$. Since these anneals represent a substantial portion of the total thermal budget during RTP diffusion, these slow-cooled cells should have deeper emitters accounting for the observed lower short wavelength response due to greater heavy doping effects such as Auger recombination and band-gap narrowing. Unlike the web cells, it seems that these FZ cells are emitter influenced if not emitter dominated. The $V_{o c}$ trend which decreases with cooling rate seems to support this idea.

As expected, Dark I-V analysis (figure 5-17) of the FZ cells did indeed reveal a trend completely opposite to that of the web cells. The $\mathrm{J}_{\mathrm{O}}$ actually decreased by increasing the cooling rate. Quenching of $F Z$ cells reduced the value of $J_{0}$ by a factor of 1.5 relative to the slowest cooling rate of $0.1^{\circ} \mathrm{C} / \mathrm{sec}$. Since both the web and $\mathrm{FZ}$ cells had similar emitters, the $\mathrm{J}_{\mathrm{oe}}$ for the web cells should be at most in the $10^{-13} \mathrm{~A} / \mathrm{cm}^{2}$ range (similar to the $\mathrm{FZ}$ cells in figure 5-17). 
Figure $5-15$ shows that the total $\mathrm{J}_{\mathrm{o}}$ for the web cells is in the $10^{-11} \mathrm{~A} / \mathrm{cm}^{2}$ range. The remainder must therefore be $\mathrm{J}_{\mathrm{ob}}$, thus proving $\mathrm{J}_{\mathrm{ob}}$ dominance for the web cells. In $\mathrm{FZ}$, where recombination in the emitter $\left(\mathrm{J}_{\mathrm{Oe}}\right)$ accounts for most of the $\mathrm{J}_{\mathrm{O}}$, the slower cooling rates which involve longer insitu annealing times INCREASE $\mathrm{J}_{\mathrm{O}}$. In dendritic web, where bulk recombination $\left(\mathrm{J}_{\mathrm{ob}}\right)$ accounts for most of the total $\mathrm{J}_{\mathrm{O}}$, the slower cooling rates enhance the lifetime and DECREASE $\mathrm{J}_{\mathrm{O}}$.

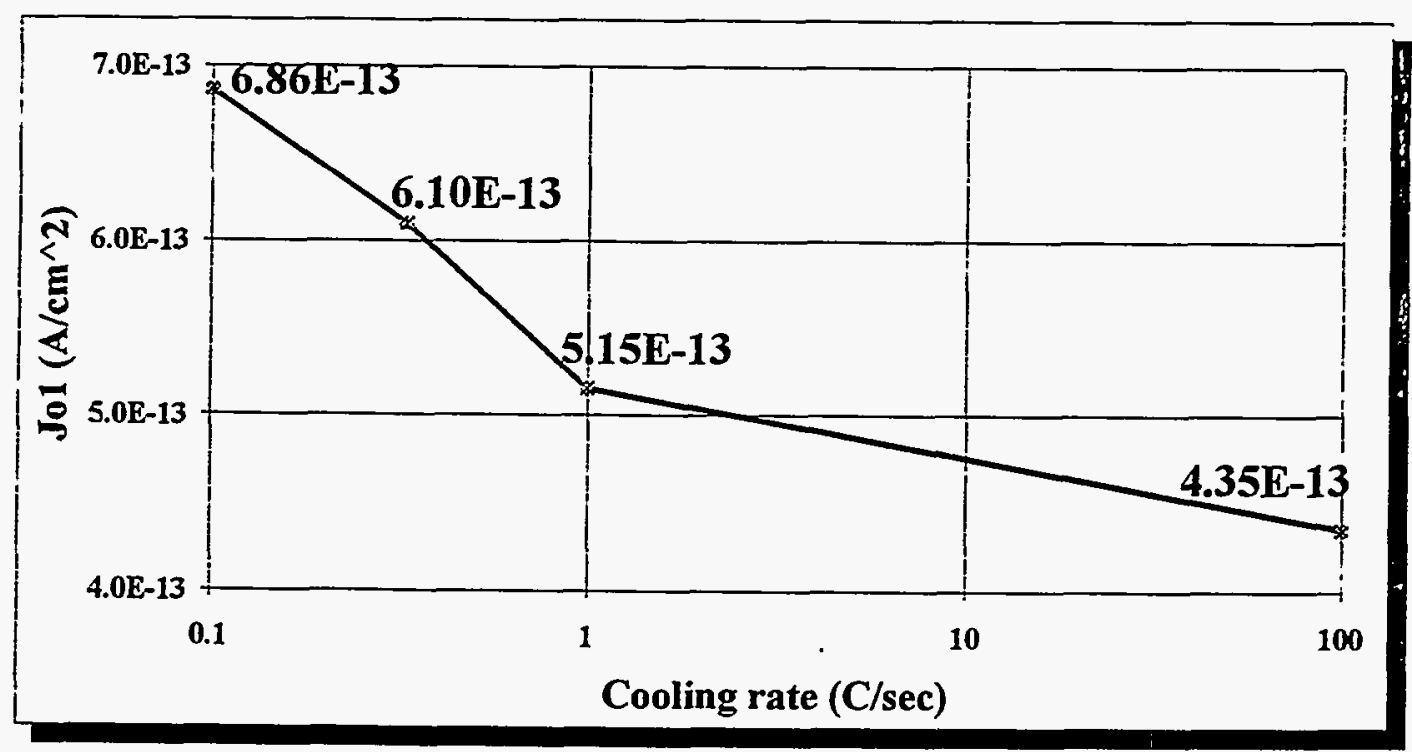

Figure 5-17. Total $\mathrm{J}_{\mathrm{O}}$ as a function of RTP cooling rate for the FZ cells. (Measured at approximately $300 \mathrm{~K}$.)

The observed difference in the performance between web and FZ cells imply that the RTP cooling rate effect is highly material and base-resistivity specific. For example, in contrast to DW, cells fabricated on FZ showed little or no improvement in $\tau_{\mathrm{b}}$. Unlike $F Z, D W$ contains point defects and dislocations; consequently, vacancies, silicon self-interstitials, and possibly impurity atoms such as oxygen and/or iron may be quenched into electrically active sites upon rapid cooldown. Also, the high base doping of $\sim 10^{17} \mathrm{~cm}^{-3}$ in the $0.2 \Omega-\mathrm{cm} \mathrm{FZ} \mathrm{base} \mathrm{masks} \mathrm{the} \mathrm{impact} \mathrm{of}$ 
quenching due to two reasons. First, quenching may not influence the lifetime of heavily doped materials as much because of the low starting lifetime associated with dopant-related complexes. Secondly, these low-resistivity cells generally are more emitter $\left(\mathrm{J}_{\mathrm{oe}}\right)$ controlled so that small changes in $\tau_{b}$, which affect $J_{o b}$, do not alter the total $J_{o}$. In fact, the longer annealing times associated with the slower cooling rates hurt the short wavelength response of $\mathrm{FZ}$ cells due to excessive heavy doping effects in the emitter. Preliminary results of slow-cooling on $0.8 \Omega-\mathrm{cm} \mathrm{Cz}$ and mc-Si exhibit the similar competition between $\tau_{\mathrm{b}}$ enhancement and the undesirable increase in $\mathrm{J}_{\mathrm{oe}}$. Proper optimization of RTP cooling rates thus requires tuning both the $\tau_{\mathrm{b}}$ and $\mathrm{J}_{\mathrm{o}}$ for maximum efficiency. The next logical step for controlling the $\mathrm{J}_{\mathrm{o}}$ is to etch-back the emitters to reduce the $\mathrm{J}_{\mathrm{oe}}$ component without sacrificing bulk lifetime.

\subsection{Characterization, Modeling, and Optimization of RTP Emitter Etch-Back}

There are two ways to reduce the value of $J_{0 e}$. First, doping concentrations can be decreased to reduce the recombination within the emitter. Second, techniques to improve the passivation conditions can be formulated to limit the front surface recombination. Etching-back the emitter is a convenient way to attenuate both the "dead layer" recombination within the emitter and the surface recombination due to a lower surface concentration. Although etching-back does not impair lifetime, it does increase the emitter sheet resistance and therefore the cell's series resistance. Figure 5-18 depicts the clear improvement in the short wavelength response resulting from emitter etch-back of two solar cells from $80 \Omega / \square$ (lower curve) to $150 \Omega / \square$ (two upper curves). 


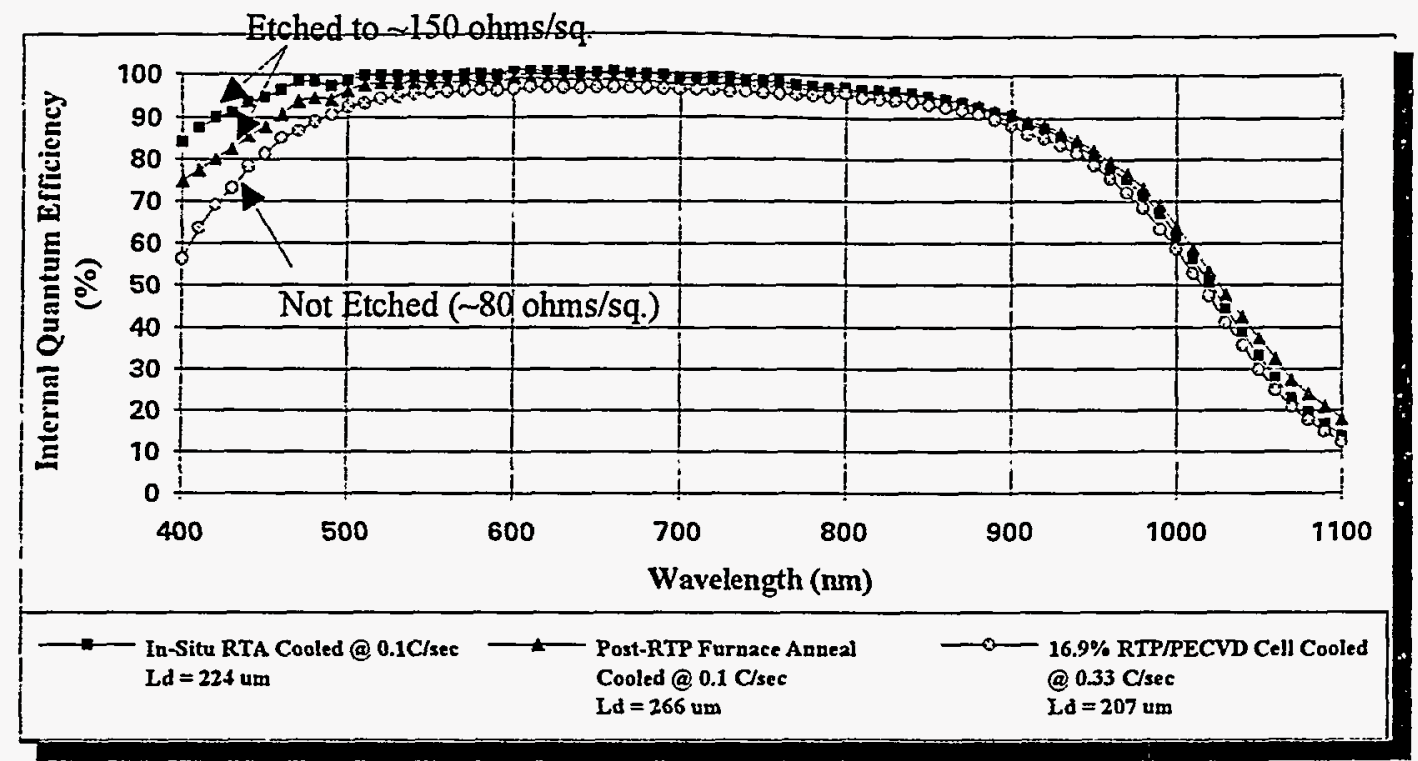

Note: The data has been corrected to account for SiN absorption

Figure 5-18. Improvement in short wavelength response due to emitter etch-back of slow-cooled cells.

In order to know how much etch-back is sufficient to optimize the RTP cell efficiency, extensive characterization and modeling is required. Proper optimization requires information about the etch-back induced change in emitter doping profiles and front surface recombination velocity (Sf).

To accomplish the first objective, spreading resistance profile measurements (figure 5-19) were obtained for four etched-back RTP emitters diffused according to the baseline RTP temperature cycle (involving a cooling rate of $0.33^{\circ} \mathrm{C} / \mathrm{sec}$ ). The amount of etch-back was monitored by the etch times of $0 \mathrm{sec}$ (i.e. no etch-back), $30 \mathrm{sec}, 50 \mathrm{sec}$, and $85 \mathrm{sec}$ in a solution of $1 \mathrm{HF}: 100 \mathrm{H}_{2} \mathrm{O}: 1000 \mathrm{HNO}_{3}$. Both the surface concentration and junction depth decreases with etch time, but the sheet resistance goes up. The 0 sec etch time represents the baseline RTP process with very high surface concentrations of about $3 \times 10^{20} \mathrm{~cm}^{-3}$-resulting in detrimental heavy doping effects. 


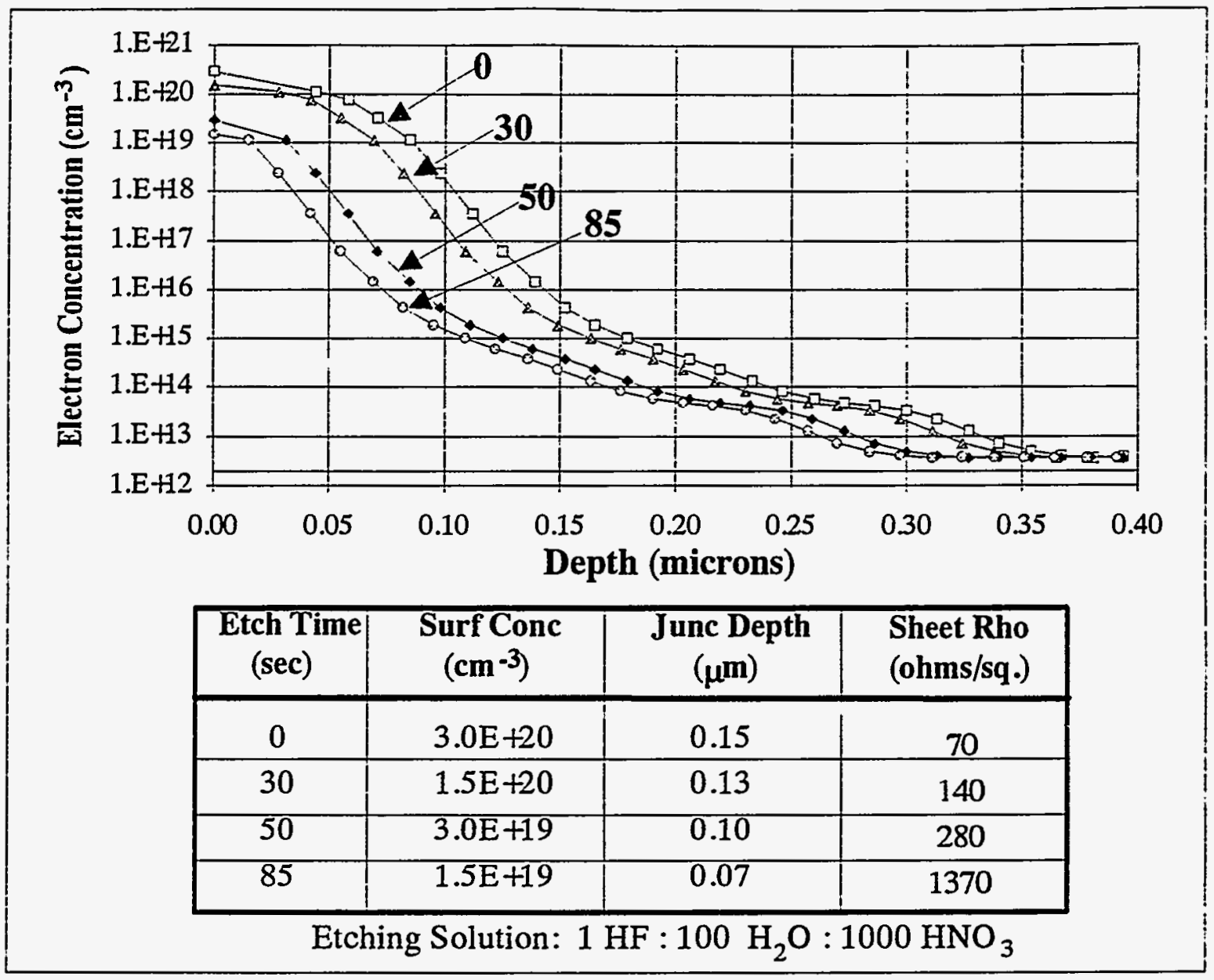

Figure 5-19. Spreading resistance measurements of etched-back RTP emitters (diffused with the temperature cycle in figure 5-3).

Next, in order to quantify the effects of enhanced surface passivation due to the etch-back, the four etched-back RTP emitters were passivated with the typical PECVD passivation/AR coatings used for solar cells and $J_{o e}$ measurements were performed by the PCD technique. Modeling in PC-1D allowed the computation of the Sf as a function of etch time for these RTP emitters.

The procedure for determining the Sf from measured values of $\mathrm{J}_{\mathrm{oe}}$ is shown in figure 5-20. Basically, PC-1D is used to compute the cumulative recombination rate in the emitter and the split in quasi-Fermi levels at the depletion region edge on the emitter side. By iteration, the value for the 
Sf can be calculated by using the formula which equates the dark forward biased current to the total current loss due to recombination in the emitter.

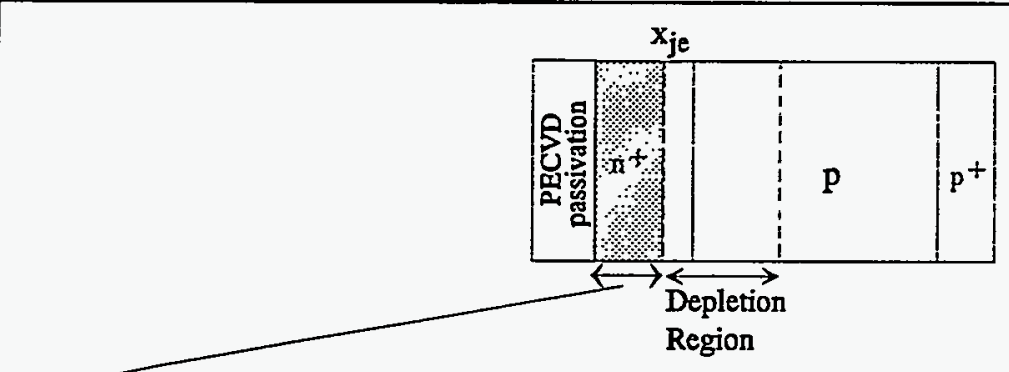

- Make an initial guess for the front surface recombination velocity, Sf.

Compute the total recombination rate in the emitter $=\mathbf{R c}\left(x_{j e}\right)$ which is the cumulative recombination rate from the front surface to the edge of the emitter.

- Compute the split in quasi-Fermi levels at $x_{j e}=V$

- Compute the following formula for Joe:

$$
\operatorname{Joe}(S f)=\frac{q^{*} \operatorname{Rc}(S f)}{\exp \left(\frac{q^{*} V}{k T}\right)-1}
$$

- Iterate Sf until the ratio equals the measured Joe.

Figure 5-20. Determination of front surface recombination velocity (Sf) from measured $\mathrm{J}_{\text {oe.* }}$

The results of the analysis is shown in figure 5-21 which displays the measured value of $\mathrm{J}_{\mathrm{Oe}}$ and the computed values of Sf. Etching-back for $85 \mathrm{sec}$ reduced the $\mathrm{J}_{\mathrm{oe}}$ by a factor of 9 -from $4.4 \times 10^{-13} \mathrm{~A} / \mathrm{cm}^{2}$ to $4.9 \times 10^{-14} \mathrm{~A} / \mathrm{cm}^{2}$. Without any etch-back, the $\mathrm{Sf}$ is very high $(64,000$ $\mathrm{cm} / \mathrm{sec})$; but $85 \mathrm{sec}$ emitter etch-back reduces $\mathrm{Sf}$ by an order of magnitude $(5700 \mathrm{~cm} / \mathrm{sec})$. Another important observation is that the $\mathrm{J}_{\mathrm{Oe}}$ of $4.4 \times 10^{-13} \mathrm{~A} / \mathrm{cm}^{2}$ is a significant portion of the total $\mathrm{J}_{\mathrm{O}}$ of the FZ cell shown as $6.1 \times 10^{-13} \mathrm{~A} / \mathrm{cm}^{2}$ in figure 5-17. This fact proves the strong influence of the emitter on the total $\mathrm{J}_{0}$ in $\mathrm{FZ}$ cells. 


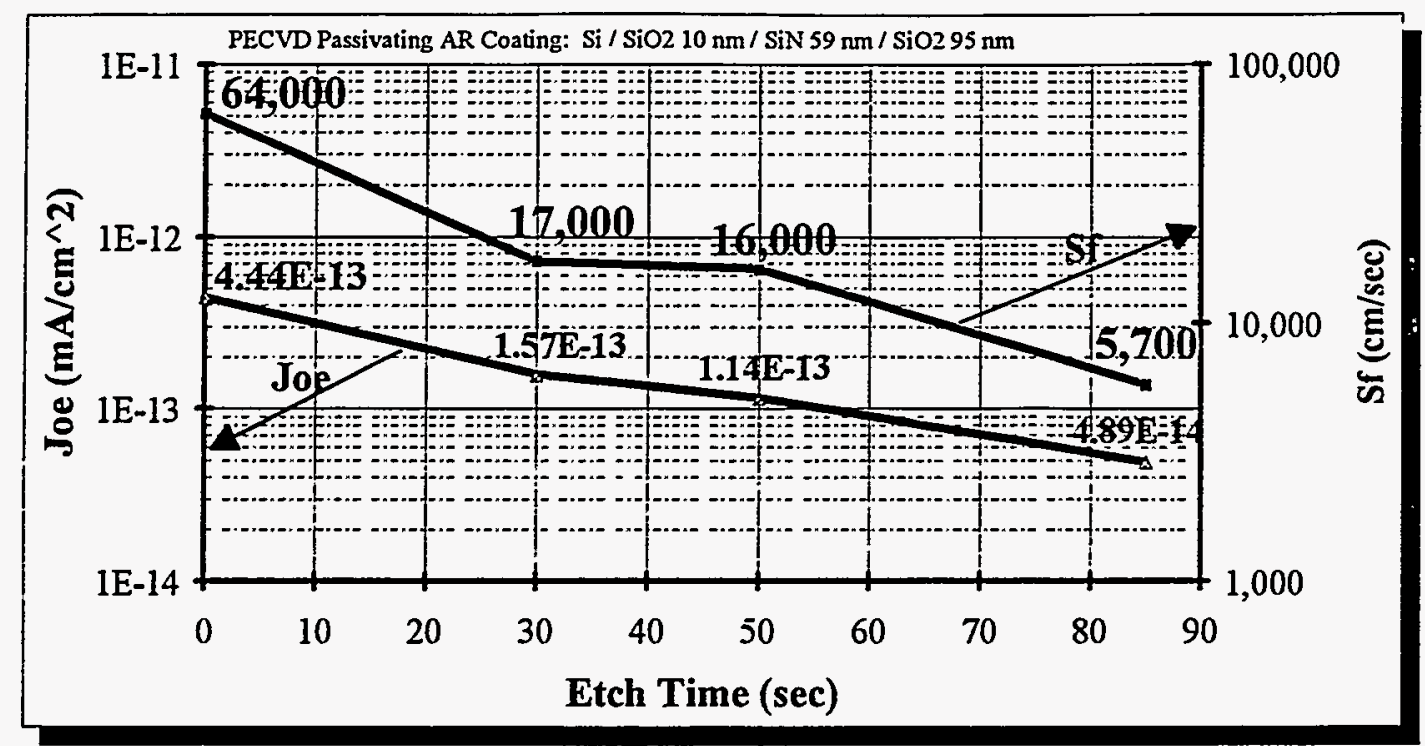

Figure 5-21. Measured $\mathrm{J}_{\mathrm{oe}}$ and calculated Sf for etched-back RTP emitters with PECVD passivation. ( $\mathrm{J}_{\mathrm{oe}}$ was measured at Sandia National Laboratories.)

After quantifying the etched emitter profiles and front surface recombination velocities, cell performance can be predicted by PC-1D simulations. Table 5-2 presents the results of the model calculations. Note that PC-1D predicts that the cells efficiency will continue to go up (from $17.61 \%$ to $18.19 \%$ ) with increasing amounts of etch time. However, it is important to note that increased amounts of etch-back increase the sheet resistance. In order to model this effect properly, it is necessary to correct the efficiencies computed by PC-1D to account for the increased series resistances due to various etch-backs. By running the GridModel program, to compute the series resistance for the four different emitters for a typical grid pattern used at Georgia Tech, the efficiencies were corrected. The "Eff w/ Grid" column indicates that there is a clear optimum that accounts for the competition between reduced emitter recombination and increased series resistance associated with emitter etch-back. According to this modeling, $30 \mathrm{sec}$ etch-back (of RTP emitters diffused with the cycle in figure 5-3) is the optimum time which can improve RTP cell efficiencies from $17.16 \%$ to $17.53 \%$. Optimizing the grid pattern for each particular emitter sheet resistance 
makes up some of the difference for the longer etch times, however, $30 \mathrm{sec}$ will still be the optimum time.

Table 5-2. Simulated Performance of RTP/PECVD Solar Cells with Etched-Back Emitters.

\begin{tabular}{|c|c|c|c|c|c|c|c|c|}
\hline & & & $4 \mathbf{P C}$ & Dowlostro & it exrid & & zhtho & Corrections \\
\hline Etch Tine & $(\mathrm{sur} / \mathrm{sec})$ & Sheetroho & trit & 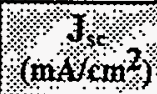 & $\begin{array}{l}\text { Enffrito } \\
\text { Grids }\end{array}$ & \% $\left(\Omega \mathrm{R}_{1}\right.$ & 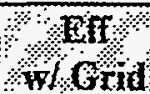 & $\begin{array}{l}\text { Eff ol } \\
\text { Optrimized Grid }\end{array}$ \\
\hline 0 & 64,250 & 70 & 632.7 & 34.07 & 17.61 & 0.185 & 17.16 & 17.17 \\
\hline 30 & 17,340 & 140 & 646.2 & 34.28 & 18.02 & 0.227 & 17.53 & 17.53 \\
\hline 50 & 16,100 & 280 & 647.7 & 34.31 & 18.07 & 0.308 & 17.49 & 17.51 \\
\hline 85 & 5,737 & 1370 & 653.5 & 34.33 & 18.19 & 0.935 & 16.98 & 17.41 \\
\hline
\end{tabular}

\subsection{Guidelines for Achieving Greater than 19\% Efficient Low-Cost RTP/PECVD Cells}

It has been established that a combination of in-depth characterization, modeling, and analysis is necessary to improve the efficiency of RTP cells intelligently. We are committed to pursuing this path. Through further PC-1D modeling, we have developed guidelines for achieving above $19 \%$ efficient RTP solar cells without any texturing or furnace processing. Figure 5-22 illustrates (in the first block) the existing $\sim 17 \%$ RTP solar cell (fabricated on $0.2 \Omega-\mathrm{cm}$ with a $\tau_{\mathrm{b}}$ of $\sim 22 \mu$ s) which was matched by PC-1D. A 30 sec emitter etch-back has already been shown to offer $\sim 0.4 \%$ improvement. Improving the lifetime to $55 \mu$ s will offer another quarter percent increase in efficiency. This can be done, not only by better optimization of cooling rates, but also by moving to a slightly higher resistivity of $0.5 \Omega-\mathrm{cm}$. Back surface passivation which can reduce the back surface recombination velocity from $10^{6} \mathrm{~cm} / \mathrm{sec}$ to $10^{3} \mathrm{~cm} / \mathrm{sec}$ can push the efficiency well beyond $18 \%$. This will require replacing the full metal back contact with either point or grid contacts. Further improvement in lifetime up to $220 \mu \mathrm{s}$ which is justifiable on a $2 \Omega$-cm substrate will give an extra $0.5 \%$ enhancement. Lifetimes of $220 \mu$ s should be reasonable-if not conservative-since lifetimes approaching $2 \mathrm{~ms}$ have been reported for $500 \Omega$-cm (figure 5-12). 


\subsection{Conclusion}

RTP silicon solar cell efficiencies above $17 \%$ have been realized for the first time by simultaneous front and back diffusion using tungsten-halogen lamps and no high-temperature furnace annealing. Low temperature $\mathrm{PECVD} \mathrm{SiN} / \mathrm{SiO}_{2}$ coating further speeds up the process and renders good surface passivation and excellent antireflection qualities. Incorporation of surface texturing, screen-printing, and the use of low-cost polycrystalline materials can make the RTP/PECVD technique even more attractive for low-cost high efficiency cells. The basic understanding of the effects of RTP cooling rate on different PV materials has been improved. Some control in bulk lifetime can be achieved by adjusting cooling rates while the control of $J_{o}$ can be performed by emitter etch-back. As a result of the current understanding, Georgia Tech has achieved record high $\mathrm{RTP}$ cell efficiencies of $17.1 \%$ on $\mathrm{FZ}, 16.4 \%$ on $\mathrm{Cz}, 14.9 \%$ on dendritic web, and $14.8 \%$ on multicrystalline silicon. All of these record efficiencies were attained without any high-temperature furnace processing. And finally, through in-depth modeling and analysis, guidelines for achieving between 19\% and 20\% efficient RTP/PECVD silicon solar cells (without any texturing) have been presented to provide the future direction of research. 


\subsection{REFERENCES}

1. Z. Chen, P. Sana, J. Salami, A. Rohatgi, IEEE Trans. on Electron Devices 40, 1161 1993.

2. R. Singh, "Rapid Isothermal Process Technology for Opto-Electronic Applications," SPIE, vol. 1418, Laser Diode Technology and Applications III, pp. 203-216, 1991.

3. A. Usami, M. Tsunekane, T. Wada, Y. Inoue, S. Shimada, N. Nakazawa, Y. Meada, in 18th E.C. PV Solar EnergyConf., 1985, pp. 1078-1083.

4. A. Usami, M. Ando, M. Tsunekane, K. Yamamoto, T. Wada, Y. Inoue, in 18th E.C. PV Solar Energy Conf., 1985, pp. 797-803.

5. R. Campbell, D Meier, J. Electrochem. Soc. 133, 1986, 2210.

6. B. Hartiti, A. Slaoui, J. C. Muller, P. Siffert, in 11th E.C. PV Solar Energy Conf., 1992, p. 420 .

7. B. Hartiti, A. Slaoui, J. C. Muller, P. Siffert, in Proc. 23rd IEEE PVSC (IEEE, Louisville, 1993), p.224.

8. R. Schindler, I. Reis, B. Wagner, A. Eyer, H. Lautenschlager, C. Schetter, W. Warta, in Proc. 23rd IEEE PVSC (IEEE, Louisville, 1993), pp.162-166.

9. A. Rohatgi, P. Rai-Choudhury, in Silicon Processing, ASTM STP 804, D. C. Gupta, Ed., American Society for Testing and Materials, 1983, p. 389. 

Distribution:

Alpha Solarco

Attn: Anco Blazev

6507 South Hardy Drive

Tempe, AZ 85283

Applied Solar Energy Corp. (2)

Attn: Frank Ho and Henry Yoo

15251 East Don Julian Road

City of Industry, CA 91746

Arizona State University (3)

College of Engineering

Attn: Robert Hammond, Charles Backus, and Dieter Schroder

Tempe, AZ 85287-5806

Bechtel National, Inc.

Attn: Walter J. Stolte

P. O. Box 3965

Mail Stop 50/15/D17

San Francisco, CA 94119-3965

Boeing Aerospace

Attn: Dr. John W. Yerkes

High Technology Center

P. O. Box 3999, MS 7J-71

Seattle, WA 98124-2499

City of Austin Electric Department

Attn: John E. Hoffner

P. O. Box 1088

Austin, TX 78767

Cummings Engineering

Attn: Richard Cummings

323 Andover Street

Wilmington, MA 01887

\section{ENDECON}

Attn: Chuck Whitaker

3401 Crow Canyon Road

Suite 253

San Ramon, CA 94583

G. P. S.

Attn: Howard Somberg

P. O. Box 398

Woodland Hills, CA 91365

Jet Propulsion Lab (2)

Attn: Russ Sugimura and Ron Ross

4800 Oak Grove Drive

Pasadena, CA 91109
American Optical Corporation

Attn: Clark Grendol

14 Mechanic Street

Southbridge, MA 01550

Arizona Public Service Company

Attn: Thomas Lepley

Mail Stop 9110

Post Office Box 53999

Phoenix, AZ 85072-3999

Ascension Technology, Inc.

Attn: Miles Russell

P. O. Box 314

Lincoln Center, MA 01773

Black and Veatch

Attn: Kevin Kerschen

P. O. Box 8405

Kansas City, MO 64114

California Energy Commission

Attn: Alexander Jenkins

1516 Ninth Street, MS 43

Sacramento, CA 95814

Cleveland State University

Attn: Jacques Moulot

Dept. of Electrical Engineering

Cleveland, OH 44115

Daystar

Attn: Vern Risser

4200 South Research Drive

Las Cruces, NM 88003

\section{ENTECH}

Attn: Mark O'Neill

P. O. Box 612246

DFW Airport, TX 75261

Georgia Institute of Technology (2)

School of Electrical Engineering

Attn: Prof. Ajeet Rohatgi \& Mr. Gerry

Crotty

Atlanta, GA 30331

Kopin

Attn: Ron Gale

695 Myles Standish Boulevard

Taunton, MA 02780
Amonix, Inc. (2)

Attn: Sewang Yoon, Vahan Garboushian

3425 Fujita Street

Torrance, CA 90505

Arizona Public Service Company

Star Facility

Attn: Peter Eckert

1500 East University

Tempe, AZ 85281

AstroPower

Attn: Allen Barnett

Solar Park

Newark, DE 19716-2000

Blue Mountain Energy

Attn: Kay Firor

59943 Comstock Road

Cove, OR 97824

Mr. Clement Chiang

GE Aerospace, MS NP-2K

100 Nassau Park Boulevard

West Windsor, NJ 08543-800

Crystal Systems

Attn: Fred Schmid

27 Congress Street

Salem, MA 01970

DSET

Attn: Gene A. Zerlant

P. O. Box 1850

Black Canyon Stage 1

Phoenix, AZ 85020

EPRI (3)

Attn: Frank Dostalek, John Bigger, and

Frank Goodman

P. O. Box 10412

Palo Alto, CA 94303

James Associates

Attn: Larry James

7329 Meadow Court

Boulder, CO 80301

Massachusetts Institute of Technology

Attn: Lionel C. Kimerling

77 Massachusetts Avenue

Room 13-5094

Cambridge, MA 02139 
Midway Laboratories

Attn: Paul Collard

77 West Wacker

Chicago, Il 60601

NREL (5)

Attn: Dick DeBlasio, Laxmi Mrig,

Bhushan Sopori, Ted Ciszek, John Benner

1617 Cole Boulevard

Golden, CO 80401

Photonic Power Systems, Inc.

Attn: Jan Werthan

550 Califomia Avenue

Palo Alto, CA 94306

Siemens Solar Industries (2)

Attn: Kim Mitchell, Richard R. King

P. O. Box 6032

Camarillo, CA 93011

Solar Kinetics, Inc.

Post Office Box 540636

Dallas, TX 75354-0636

Southern Electric International

Georgia Power Research Center

Attn: Edward King

62 Lake Mirror Road, Bldg. 3

Forest Park, GA 30050

Spire Corp.

Attn: Michael J. Nowlan

Patriots Park

Bedford, MA 01730

\section{SWTDI}

Attn: Steven Durand

Box 30001, Dept. 3SOL

Las Cruces, NM 88003-0001

\section{M Company}

Attn: Paul Jaster, 225-2N-06

3M Center

St. Paul, MN 55144

Australian National University

Attn: Dr. Andres Cuevas

Department of Engineering

Canberra, ACT 0200

AUSTRALIA
Mobil Solar Energy Corp.

Attn: Juris Kalejs

Four Suburban Park Drive

Billerica, MA 01821

NREL Library

1617 Cole Boulevard

Golden, CO 80401

Public Service Company of New Mexico

Attn: R. Frank Burcham

Alvarado Square, MS 0150

Albuquerque, NM 87158

Mr. Ronald Sinton

4820 La Fiesta Place

San Jose, CA 95129

Solarex Corporation (2)

Attn: John Wohlgemuth and Mohan

Narayanan

630 Solarex Court

Frederick, MD 20701

SPECO

Attn: Walt Hart

P. O. Box 91

Morrison, CO 80465

SunPower Corp.

Attn: Richard Swanson

435 Indio Way

Suite 100

Sunnyvale, CA 94086

Texas Instruments

Attn: Jules Levine

P. O. Box 655012

Dallas, TX 75265

U. S. Department of Energy

Attn: James Rannels, EE-131

Forrestal Building

1000 Independence Avenue, S. W.

Washington, DC 20585

University of New South Wales

Attn: Dr. Martin Green

School of Electrial Engineering

P. O. Box One

Kensington, NSW 2033

AUSTRALIA
NASA/Lewis Research Center (2)

Attn: Dennis Flood and Shiela Bailey,

MS 302-1

21000 Brookpark Road

Cleveland, OH 44135

Pacific Gas and Electric (4)

Attn: Steve Hester, Joe Iannucci, Howard

Wenger, Tammie Candelaria

3400 Crow Canyon Road

San Ramon, CA 94583

Purdue University (2)

Attn: Dick Schwartz, Jeff Gray

School of Electrical Engineering

West Lafayette, IN 47907

Solar Engineering Applications

Attn: Neil Kaminar

3500 Thomas Road, Suite E

Santa Clara, CA 95054

Southern California Edison

Attn: Nick Patapoff

6090 Irwindale Avenue

Irwindale, CA 91702

Spectrolab (2)

Attn: Dmitri Krut and James Albeck

12500 Gladstone Avenue

Sylmar, CA 91342

Suntracker

Attn: Glenn Eiden

302 U. S. 30 East

New Haven, IN 46774

Texas Southern University

Attn: V. S. Murty, Physies

3100 Cleburne Avenue

Houston, TX 77004

Wattsun

Attn: John Doherty

P. O. Box 751

Albuquerque, NM 87103

Commission of the European

Communities (2)

Joint Research Centre, ESTI

Attn: H. Ossenbrink and James Bishop, TP 450

21020 Ispra, VA ITALY 
Fraunhofer Institute for Solar Energie Systeme

Attn: Klaus Heidler

Oltmannsstrasse 22

D-7800 Freiburg

GERMANY

0753 P. Valencia, 6218

Library (5)

0752 P. A. Basore, 6219

0752 D. S. Ruby, 6219

0619 Tech Publications, 13416
Instituto de Energia Solar

0702 D. E. Arvizu, 6200

Ciudad Universitaria, $\mathbf{s} / \mathbf{n}$

Attn: Antonio Luque

ETSI Telecomunicacion (UPM)

28040 Madrid

SPAIN

0753 C. P. Cameron, 6218

0752 M. L. Tatro, 6219

0752 D. L. King, 6219

0752 A. B. Maish, 6219

0752 J. M. Gee, 6219

0752 W. K. Schubert, 6219

0899 Tech Library (5), 13414

0100 Document Processing, 7613-2

DOE/OSTI (10)
- 9018 Central Tech Files, 8523-2 



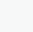


 